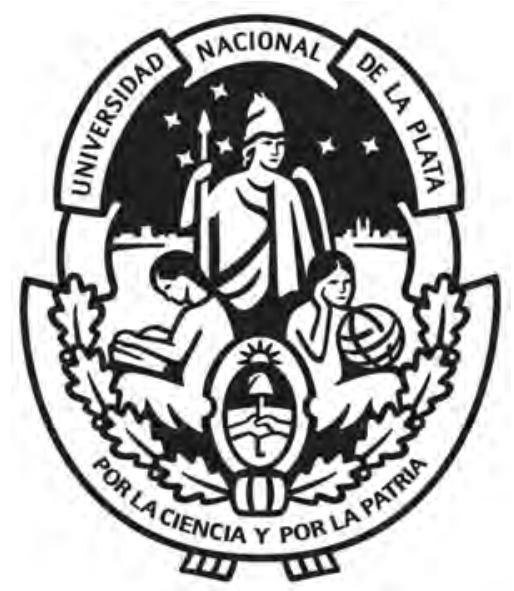

Universidad Nacional de La Plata

Facultad de Ciencias Astronómicas y Geofísicas

\title{
CARACTERIZACIÓN DEL MACIZO NORPATAGÓNICO POR MEDIO DEL ANÁLISIS INTEGRADO DE INFORMACIÓN GEOFÍSICA Y GEOLÓGICA.
}

Tesis presentada para obtener el grado de Doctora en Geofísica

Geof. María Laura Gómez Dacal

Directora: Dra. Claudia Tocho

Codirector: Dr. Eugenio Aragón

La Plata, Argentina

- JuliO DE 2017 - 
CARACTERIZACIÓN DEL MACIZO NORPATAGÓNICO POR MEDIO DEL ANÁLISIS INTEGRADO DE INFORMACIÓN GEOFÍSICA Y GEOLÓGICA.

TESIS PRESENTADA EN CUMPLIMIENTO DE LOS REQUISITOS PARA OBTENER EL GRADO DE DOCTORA EN GEOFÍSICA

en la

FACULTAD DE CIENCIAS ASTRONÓMICAS Y GEOFÍSICAS UNIVERSIDAD NACIONAL DE LA PLATA.

Por: María Laura Gómez Dacal

Directora: Dra. Claudia Tocho

Codirector: Dr. Eugenio Aragón

Jurado: Dra. Claudia Ravazzoli

Dra. Claudia Prezzi

Dr. Liliana Barrio-Alvers

Facultad de Ciencias Astronómicas y Geofísicas

Universidad Nacional de La Plata

Paseo del Bosque S/N

(1900) La Plata, Argentina

e-mail: gomezdacal@fcaglp.unlp.edu.ar

6 de julio de 2017 
A todos los que hacen felíz mi mundo. En especial a mi familia, mi mayor felicidad. 


\section{Agradecimientos}

Agradezco profundamente a mis directores, Claudia y Eugenio, por todo lo que hemos pasado juntos durante estos años, por su acompañamiento, paciencia y sabias palabras. Gracias Claudia por estar siempre, sin importar el día, ni el horario, por darme tanto en cada momento, en el ámbito académico y fuera de él. Gracias Eugenio por todas esas charlas y discusiones tan enriquecedoras.

A la Facultad de Ciencias Astronómicas y Geofísicas por darme el lugar y el soporte para realizar este trabajo, por tener siempre las puertas abiertas. Al CONICET por permitirme desarrollar esta tesis. A la educación pública de mi país.

A cada uno de los integrantes de la sección 6.1 del GFZ, Potsdam, Alemania por esas dos maravillosas experiencias, por todo lo aprendido y compartido y por hacerme sentir en casa estando tan lejos. Especialmente a Leni por darme la oportunidad de ser parte de su grupo y a Judith por contagiarme el entusiasmo por la geología, por todos los momentos compartidos y por el acompañamiento constante a pesar de la distancia.

A Transinsight GMBH que, a través de la Dra. Liliana Barrio-Alvers, ha proveido el soporte para la utilización del programa IGMAS+. A YPF S.A por los datos provistos.

A todos esos amigos que están siempre, los del barrio, los de mi segunda casa que es mi grupo scout, los de la facultad con los que compartí cada paso de este camino. También a aquellos que, lejos o cerca, siempre están en el corazón. Gracias cada uno de ellos por esas charlas, esos mates, esos momentos únicos, por todas las risas y también por aquellas lágrimas compartidas.

Quiero agradecer con todo mi corazón a mi familia, lo más importante y hermoso que tengo. A Juan, por ser mi sostén en todo momento, por estar siempre a mi lado, por ayudarme en todos los aspectos, por caminar juntos. A mis papás y hermanos, por su amor incondicional, por darme todo, por enseñarme y estar en cada paso de mi vida. A todos los integrantes de esta gran familia por ser, cada uno a su manera, tan especiales e importantes para mi. 


\section{Resumen}

El modelado geofísico directo de las propiedades de la litósfera es una poderosa herramienta para analizar el estado geodinámico actual de un área en particular. Los resultados de este modelado, junto con la información independiente disponible permiten establecer hipótesis que ayudan a la comprensión de procesos geodinámicos del pasado.

El objetivo principal de esta tesis es la caracterización de la altiplanicie del Macizo Norpatagónico (MNP) mediante la integración de información tanto geofísica como geológica empleando métodos geofísicos de modelado directo. De este modo, se pretende aportar al esclarecimiento de las causas de la elevación del área de estudio. La integración de información de diversas fuentes es especialmente importante en este caso ya que la zona no cuenta con gran cantidad de datos.

La altiplanicie del MNP es un área de $100000 \mathrm{~km}^{2}$ que cuenta con una altura aproximada de $1200 \mathrm{msnm}$, presentando poca variación de relieve en su interior, pero distinguiéndose de las cuencas que la circundan por una diferencia de altura de entre 500 y $700 \mathrm{~m}$. Esta altiplanicie se elevó, desde alturas por debajo del nivel del mar en el Paleoceno, hasta más de 1200 msnm en el Oligoceno. Este levantamiento tan significativo en menos de $25 \mathrm{Ma}$ se generó sin evidencias de deformación interna notable y en una época durante la cual la zona se encontraba bajo un régimen extensivo. Simultáneamente, en el margen activo (al oeste de Sudamérica) ocurría un reacomodamiento de placas que originó una anomalía térmica en el manto. Teniendo en cuenta estas evidencias, surge el interrogante de cuál fue el mecanismo que generó el levantamiento.

Todo modelado geofísico directo requiere de la parametrización de un modelo inicial en el cual es posible incorporar información independiente que ayudará a reducir la incerteza de los parámetros y, por lo tanto, la ambigüedad del método. En consecuencia, el primer paso consistió en el análisis crítico de información disponible en el área (desde la superficie hasta el manto), lo cual nos permitió elegir los mejores parámetros para la construcción del modelo 
inicial. El análisis permitió, además, la obtención de algunos resultados preliminares sobre las características de la altiplanicie del MNP. Utilizando datos de gravedad, se realizó una inversión con el fin de obtener la discontinuidad corteza-manto (Moho), ya que representa el mayor contraste de densidad de la litósfera. Este resultado fue comparado con otros modelos existentes para el área y, al haber muy pocos datos de profundidad de Moho en la zona, se observaron diferencias importantes. Sin embargo, la gran mayoría de los modelos indican la presencia de una corteza engrosada debajo de la altiplanicie del MNP. Por otro lado, mediante el análisis de datos petrológicos de xenolitos del área, se determinó la densidad del manto. Los resultados evidenciaron heterogeneidades en el manto dentro de la zona de trabajo. También se observó una correlación entre las densidades obtenidas para los xenolitos y la edad de la extrusión de la lava que los contiene. Estos estudios evidenciaron la necesidad de una caracterización más detallada de la profundidad del Moho y de la configuración de densidades en el manto para ser incluida en un modelo de densidades.

Una vez recopilada y analizada la información geofísica y geológica, se procedió al desarrollo de los modelos. Los primeros en ser realizados fueron los gravimétricos, que fueron confeccionados utilizando el software IGMAS+. En el modelado tridimensional a escala litosférica, se hizo especial hincapié en la distribución de densidades en el manto, convirtiendo velocidades de tomografías sismológicas en densidades utilizando diversos métodos. Luego se eligió la distribución más adecuada mediante el contraste con datos independientes obtenidos a partir de datos de xenolitos del manto. La distribución de densidades del manto elegida se tomó como parámetro fijo y así se obtuvieron las características de la corteza (densidad media y espesor) que mostraron el mejor ajuste con los datos de anomalías de Bouguer disponibles.

Seguidamente, se utilizó el modelo resultante (geometría y composición) como parámetro de entrada para calcular la distribución tridimensional de temperaturas. Este paso fue realizado mediante la utilización del programa GMS creado en el GFZ, Potsdam, Alemania que resuelve la ecuación tridimensional de conducción del calor utilizando elementos finitos. Luego, el modelo fue validado mediante la comparación con datos de temperatura de pozos.

Por último, utilizando tanto la estructura como las temperaturas resultantes de los modelos anteriores (gravimétrico y térmico), se modeló la reología del área, es decir, se predijo el comportamiento mecánico de las distintas partes de la litósfera y su resistencia. Este modelo también fue realizado utilizando software desarrollado en el GFZ.

A partir del modelado de las distintas propiedades físicas se pudieron obtener los siguientes resultados con respecto al estado actual del área de estudio: 
- En cuanto a las densidades, se puede observar un gran contraste, de $110 \mathrm{~kg} / \mathrm{m}^{3}$, entre dos áreas del modelo que coinciden con terrenos paleozoicos descriptos en trabajos previos. Con respecto al espesor cortical, éste es mayor en la altiplanicie que en sus alrededores, llegando a observarse una diferencia de hasta $7 \mathrm{~km}$. Este engrosamiento es coincidente con áreas de topografía elevada, con lo que podría estar indicando un balance isostático a escala cortical en la actualidad.

- El modelado térmico predice para la parte somera de la corteza, una temperatura hasta $20^{\circ} \mathrm{C}$ menor en el área de la altiplanicie en comparación con sus alrededores. En la parte más profunda de la corteza y en el manto litósferico esta característica se invierte, habiendo una temperatura aproximadamente $50^{\circ} \mathrm{C}$ mayor en la altiplanicie que en sus alrededores. Consecuentemente, en el área de la altiplanicie, la resistencia de la litósfera estaría concentrada a bajas profundidades. Este hecho podría relacionarse con las evidencias de deformación detectadas en zonas aledañas a la altiplanicie del MNP, pero ausentes en el interior de la misma. Las altas temperaturas y poca rigidez predicha por los modelos para mayores profundidades podría estar relacionada con los remanentes de la anomalía térmica ocurrida en la época del levantamiento, aunque también se discute la posibilidad de que una fuente de calor más reciente esté afectando la zona y sea la razón de dichas observaciones.

Estos resultados, en conjunto con el análisis de información existente sobre el área, han permitido establecer las siguientes hipótesis:

- En la actualidad, el posible equilibrio isostático inferido en el modelado de densidades puede estar contribuyendo a mantener la altura topográfica de la altiplanicie del MNP. A esta posibilidad se le suman las altas temperaturas predichas por el modelado y la tectónica activa en el margen occidental de Sudamérica, que también podrían estar contribuyendo a que el área de estudio se mantenga elevada.

- En el Paleógeno, cuando el área de la altiplanicie del MNP estaba sometida a un régimen extensional, el calentamiento del manto causado por la anomalía térmica pudo haber generado el decrecimiento de las densidades, que en conjunto con el gran espesor cortical del área habrían causado un desequilibrio isostático y su consecuente levantamiento.

Los resultados obtenidos en la presente tesis contribuyen al conocimiento de un área desafiante debido a la escasez de datos e información. 


\section{Índice general}

Agradecimientos $\quad$ iv

Resumen $\quad$ v

1. Introducción 1

1.1. Estructura de la tesis . . . . . . . . . . . . . . 5

2. Área de estudio y problema de investigación 9

2.1. Área de estudio . . . . . . . . . . . . . . . . . . 9

2.2. Problema de investigación . . . . . . . . . . . . . . . . . 11

3. Primeros trabajos mediante el análisis de datos disponibles 16

3.1. Análisis de modelos de profundidad de Moho . . . . . . . . . . . . . 16

3.1.1. Descripción de los modelos de Moho . . . . . . . . . . . . . . . 17

3.1.2. Comparación de modelos de Moho . . . . . . . . . . . . . . . . 23

3.2. Análisis de densidades con xenolitos . . . . . . . . . . . . . . . 29

4. Modelado gravimétrico tridimensional 35

4.1. Metodología . . . . . . . . . . . . . . . . . . 35

4.1.1. Fundamentos . . . . . . . . . . . . . . . . . . 35

4.1.2. Aplicación . . . . . . . . . . . . . . . . . . 36

4.2. Modelado preliminar: escala cortical _ . . . . . . . . . . . . . . 38

4.2.1. Modelo inicial . . . . . . . . . . . . . . . . . . . . . . . . 40

4.2.2. Resultados . . . . . . . . . . . . . . . . . . 42

4.3. Modelo litosférico . . . . . . . . . . . . . . . . . . . . . . . . . . 45

4.3.1. Modelo inicial . . . . . . . . . . . . . . . . . . . . . 45

4.3.2. Procedimiento y resultados . . . . . . . . . . . . . . . 57 
5.1. Metodología . . . . . . . . . . . . . . . . . . . 63

5.1.1. Fundamentos . . . . . . . . . . . . . . . . . 63

5.1.2. Aplicación . . . . . . . . . . . . . . . . . . . 69

5.2. Modelado preliminar: escala cortical . . . . . . . . . . . . . 71

5.3. Modelado litosférico . . . . . . . . . . . . . . . . . . . . 76

5.3.1. Definición de parámetros de entrada . . . . . . . . . . . . 76

5.3.2. Resultados .......................... 82

$\begin{array}{ll}\text { 6. Modelado reológico y espesor elástico } & 87\end{array}$

6.1. Modelado reológico . . . . . . . . . . . . . . . . . . 87

6.1.1. Metodología ....................... 88

6.1.2. Resultados . . . . . . . . . . . . . . . . . 98

6.2. Cálculo del espesor elástico efectivo . . . . . . . . . . . . . . . . 100

6.2.1. Aplicación . . . . . . . . . . . . . . . . . . . . . . . . . . . . 108

6.2.2. Resultados . . . . . . . . . . . . . . . . . 109

6.2.3. Comparación con el espesor elástico equivalente . . . . . . . . . . . 111

$\begin{array}{ll}\text { 7. Discusión } & 113\end{array}$

7.1. Análisis del modelo de densidades . . . . . . . . . . . . . . . . . . . . . . . 113

7.1.1. Robustez . . . . . . . . . . . . . . . . . . 113

7.1.2. Análisis e implicancias . . . . . . . . . . . . . . . . . . . . . . 114

7.2. Análisis de los modelos de temperatura, reología y espesor elástico . . . . . . 120

7.2.1. Robustez . . . . . . . . . . . . . . . . 120

7.2.2. Análisis e implicancias . . . . . . . . . . . . . . . . . 125

7.3. Hipótesis geodinámica . . . . . . . . . . . . . . . . . . . . 128

$\begin{array}{ll}\text { 8. Conclusiones } & 130\end{array}$

$\begin{array}{ll}\text { Bibliografía } & 133\end{array}$ 


\section{Índice de figuras}

1.1. Área de estudio . . . . . . . . . . . . . . . . . . . 2

1.2. Diagrama de flujo de trabajo de la tesis . . . . . . . . . . . . . . 4

2.1. Ilustración de las teorías de isostasia . . . . . . . . . . . . . . . . . 14

3.1. Modelo GEMMA . . . . . . . . . . . . . . . . . . . . . . . . . . . . . . 18

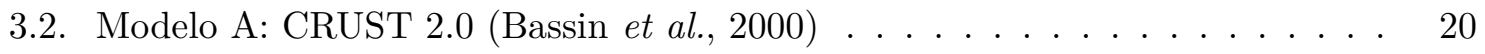

3.3. Modelo B (Feng et al., 2007) . . . . . . . . . . . . . . . . . 21

3.4. Modelo C (Assumpção et al., 2013) . . . . . . . . . . . . . . . . . . 21

3.5. Modelo D (Tassara y Echaurren, 2012). . . . . . . . . . . . . . . . 22

3.6. Modelo E confeccionado a partir de la inversión de datos de gravedad . . . . 23

3.7. Diferencia entre Modelo GEMMA y Modelo A . . . . . . . . . . . . . . . . . 24

3.8. Diferencia entre Modelo GEMMA y Modelo B . . . . . . . . . . . . . . 24

3.9. Diferencia entre Modelo GEMMA y Modelo C . . . . . . . . . . . . . . 25

3.10. Diferencia entre Modelo GEMMA y Modelo D . . . . . . . . . . . . . . 25

3.11. Diferencia entre Modelo GEMMA y Modelo E . . . . . . . . . . . . . . . . 26

3.12. Comparación de modelos de Moho en un perfil a $\operatorname{los} 41^{\circ} S \ldots \ldots$. . . . . 27

3.13. Ubicación de las localidades donde se encontraron xenolitos . . . . . . . . . . 30

3.14. Histogramas de densidades obtenidas a partir de xenolitos del manto . . . . . 34

4.1. Diagrama de flujo de los modelos gravimétricos . . . . . . . . . . . . . . . . 39

4.2. Modelo inicial de densidad a escala cortical. . . . . . . . . . . . . . . . . . . . 43

4.3. Anomalías observadas, calculadas y residuales del modelo preliminar a escala

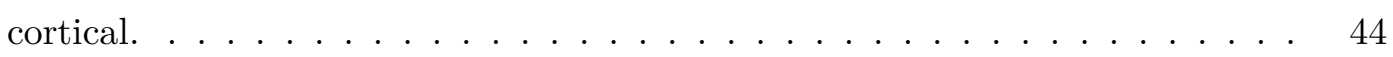

4.4. Perfiles del modelo final preliminar a escala cortical . . . . . . . . . . . . . 46

4.5. Modelo inicial de densidad a escala litosférica. . . . . . . . . . . . . . . . . 48 
4.6. Configuraciones de densidad para el manto obtenidas a partir de modelos de tomografía sismológica . . . . . . . . . . . . . . . . .

4.7. Histogramas de densidades obtenidas a partir de xenolitos a presión y temperatura del manto. Comparación con configuraciones provenientes de tomografías. 58

4.8. Anomalías residuales del modelo inicial . . . . . . . . . . . . . . . . . . . . 60

4.9. Moho y anomalías residuales del modelo final . . . . . . . . . . . . . 62

5.1. Flujo térmico a través de una placa . . . . . . . . . . . . . . . 65

5.2. Flujo térmico entrante y saliente en una placa fina con producción de calor

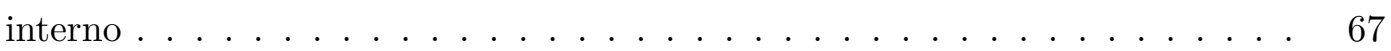

5.3. Flujo térmico en dos dimensiones en un elemento rectangular. . . . . . . . . 68

5.4. Diagrama de flujo del modelado térmico . . . . . . . . . . . . . . . 70

5.5. Ubicación de los pozos con datos de temperatura . . . . . . . . . . . . 73

5.6. Cortes en profundidad de los modelos preliminares de temperatura . . . . . 75

5.7. División de cuerpos de la corteza para el modelado térmico litosférico . . . . 78

5.8. Densidad media cortical calculada bajo la hipótesis de balance isostático . . . 80

5.9. Profundidad de la isoterma de $1300^{\circ} \mathrm{C} \ldots \ldots \ldots$. . . . . . . . . . 82

5.10. Cortes en profundidad del modelo litosférico de temperatura . . . . . . . . . 84

5.11. Flujo térmico superficial predicho por el modelo litosférico de temperatura. . $\quad 85$

6.1. Distintos tipos de reptación según la presión y la temperatura . . . . . . . . . 92

6.2. Ejemplo de Envolvente de resistencia a la deformación permanente . . . . . . 93

6.3. Diagrama de flujo del modelo reológico . . . . . . . . . . . . . . . . . . . 97

6.4. Resistencia integrada del modelo. . . . . . . . . . . . . . . . . . . . . . 99

6.5. YSEs predichas por el modelo en distintos puntos del area de estudio . . . . 101

6.6. Distribución de espesor elástico equivalente . . . . . . . . . . . . . . . . . 102

6.7. Distribución de espesor elástico cortical efectivo . . . . . . . . . . . . . . . . . 110

7.1. Comparación de presiones y temperaturas determinadas mediante xenolitos y tomografías . . . . . . . . . . . . . . . . . . 118

7.2. Cortes en profundidad del modelo de temperatura homogéneo . . . . . . . . . 122

7.3. Resistencia integrada para el modelo de corteza homogénea . . . . . . . . . . 124

7.4. Situación geodinámica actual propuesta . . . . . . . . . . . . . . 126 


\section{Índice de tablas}

3.1. Comparación de modelos de Moho. . . . . . . . . . . . . . . . . . . . . . 19

3.2. Desvíos estándar de las diferencias entre modelos regionales y locales y el modelo GEMMA . . . . . . . . . . . . . . . . . . . . . . . . 28

3.3. Descripción de los xenolitos del área de estudio . . . . . . . . . . . . . . . 31

4.1. Densidad de los cuerpos del modelo preliminar . . . . . . . . . . . . . . 44

4.2. Estadísticas de las diferentes configuraciones de densidad del manto. . . . . . 56

4.3. Estadísticas de las anomalías residuales del modelo final litosférico . . . . . . 61

5.1. Propiedades térmicas de los cuerpos del modelo preliminar . . . . . . . . . . 72

5.2. Validación de los modelos preliminares con temperaturas medidas en pozos $\quad$. 76

5.3. Comparación de los modelos preliminares con datos de flujo térmico superficial 77

5.4. Propiedades térmicas de los cuerpos del modelo litosférico . . . . . . . . . . 81

5.5. Validación del modelo térmico litosférico con temperaturas medidas en pozos 86

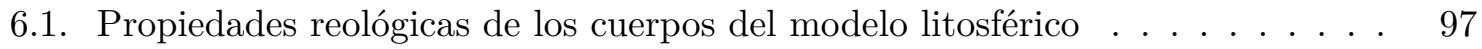

7.1. Estadísticas de los residuos de modelos con distinta configuración de densidad en el manto . . . . . . . . . . . . . . . . . . . . . . . . 115

7.2. Comparación del modelo térmico de corteza homogénea con temperaturas medidas en pozos . . . . . . . . . . . . . . . . . . . . . 123 


\section{Capítulo 1}

\section{Introducción}

La corteza continental del norte de la Patagonia (entre los 36 y $45^{\circ}$ de latitud sur) es heterogénea y alberga cuencas de diversos orígenes generadas entre el Jurásico y el Cenozoico que sufrieron algún grado de deformación terciaria y rodean a una altiplanicie que no presenta deformación notable de esa edad (Gómez Dacal et al. 2013, 2017; Figura 1.1). La misma es denominada altiplanicie del Macizo Norpatagónico (MNP) y es el objeto de estudio de esta tesis.

Esta altiplanicie, que es entre 500 y $700 \mathrm{~m}$ más elevada que sus alrededores (Figura 1.1), fue generada durante el Paleógeno (entre los $60 \mathrm{y}$ los $35 \mathrm{Ma}$ ) mediante un levantamiento repentino y sin la ocurrencia de deformación interna notable. En el momento del levantamiento el área estaba bajo un régimen de esfuerzos extensivo, mientras tenía lugar un proceso de reacomodamiento de placas tectónicas en el margen activo del oeste de Sudamérica (Aragón et al., 2011a). Teniendo en cuenta estas características particulares, es difícil comprender cuál fue el mecanismo que generó la presente topografía y distinguió el área de estudio de sus alrededores.

Para poder mejorar la comprensión de la evolución geodinámica pre-Oligocena es necesario investigar las características físicas del área de estudio, especialmente aquellas que la diferencian y destacan de las zonas aledañas y que pueden haber cumplido un rol en la elevación de esta área en particular y no de sus alrededores. En consecuencia, el objetivo de esta tesis es la caracterización de la altiplanicie del Macizo Norpatagónico y las zonas inmediatamente linderas mediante la integración de la información geofísica y geológica disponible y la utilización de diversos métodos geofísicos.

Se pueden utilizar varios métodos para interpretar aspectos de la Tierra a partir de datos geofísicos. La calidad de esa interpretación y su cercanía con la realidad depende de como esté 


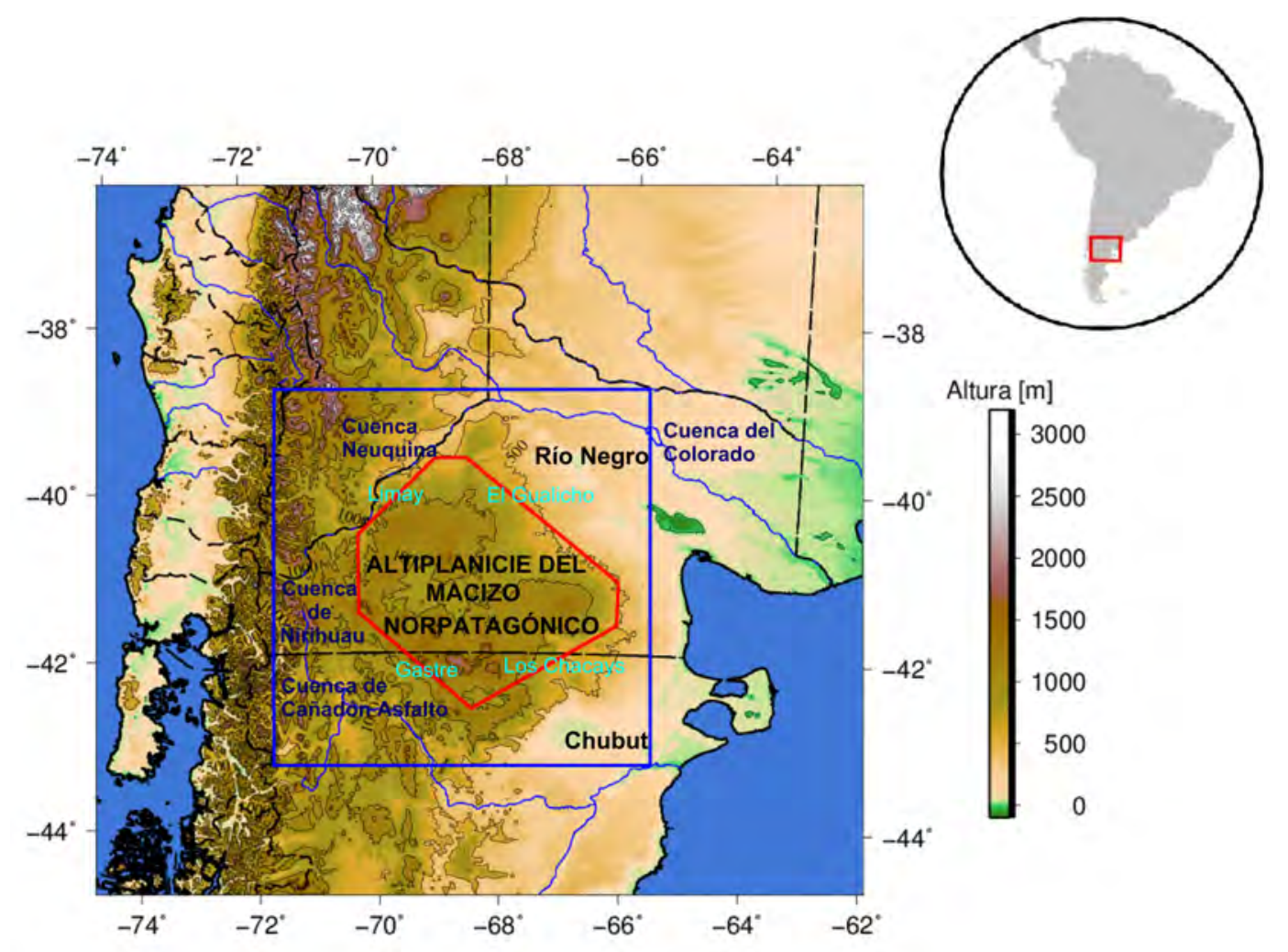

Figura 1.1. Área de estudio. Mapa topográfico. El poligono rojo delimita la altiplanicie del Macizo Norpatagónico. El área de estudio de los modelos litosféricos está marcada en azul. 
restringido el problema por otros criterios, como observaciones geofísicas y geológicas adicionales o asunciones basadas en modelos (Lillie, 1999). Tanto los métodos geofísicos directos como inversos se utilizan para interpretar observaciones intentando encontrar las causas que generaron dicha observación. Los métodos inversos utilizan formulaciones matemáticas para calcular modelos directamente desde las observaciones. En cambio, el método directo asume un modelo, al que llamamos inicial y luego calcula las observaciones que resultarían si así fuera la realidad (Lillie, 1999). Luego se modifica ese modelo hasta que el resultado calculado sea coincidente con el observado. En este caso, los datos de restricción pueden utilizarse para fijar el modelo inicial y así tener menos parámetros libres a la hora de ajustar el modelo a las observaciones. Esta última metodología (modelado directo) es la que se emplea en esta tesis.

Una técnica geofísica por si misma puede no decir mucho sobre un sector de la Tierra, pero si esta es combinada con otras observaciones puede ser muy útil para conocer el estado actual de una región y su evolución. Por esta razón el primer paso de la tesis fue analizar y evaluar la información disponible. Estas observaciones, a las que llamamos restricciones, pueden ser datos geológicos u otra información geofísica y en el caso de esta tesis se pueden dividir en los siguientes aspectos:

- Modelos globales: gravedad (Pavlis et al., 2012), espesor de sedimentos (Heine, 2007), tomografías sismológicas del manto (Amaru, 2007; Schaeffer y Lebedev, 2013), modelos de discontinuidad corteza-manto (Barzaghi et al., 2014; Laske et al., 2013).

- Modelos regionales: modelos de discontinuidad corteza-manto (Feng et al., 2007; Assumpção et al., 2013), modelos de densidad (Tassara y Echaurren, 2012).

- Datos puntuales: determinación de temperaturas (provistas por YPF S.A.), de profundidad de Moho con funciones receptoras y perfiles de refracción (Assumpcao, comunicación personal).

- Muestras de xenolitos y datos petrológicos de los mismos (más de 50 muestras de 5 localidades; Mundl et al. 2015; Ponce 2016) para obtener densidades.

- Datos bibliográficos del área en cuanto a densidades y discontinuidades principales.

- Otros datos e información geológica sobre el área.

A partir de esta información, se realizó un primer estudio de las características del área mediante trabajos preliminares (Figura 1.2). Se estudiaron, compararon y validaron distintos 


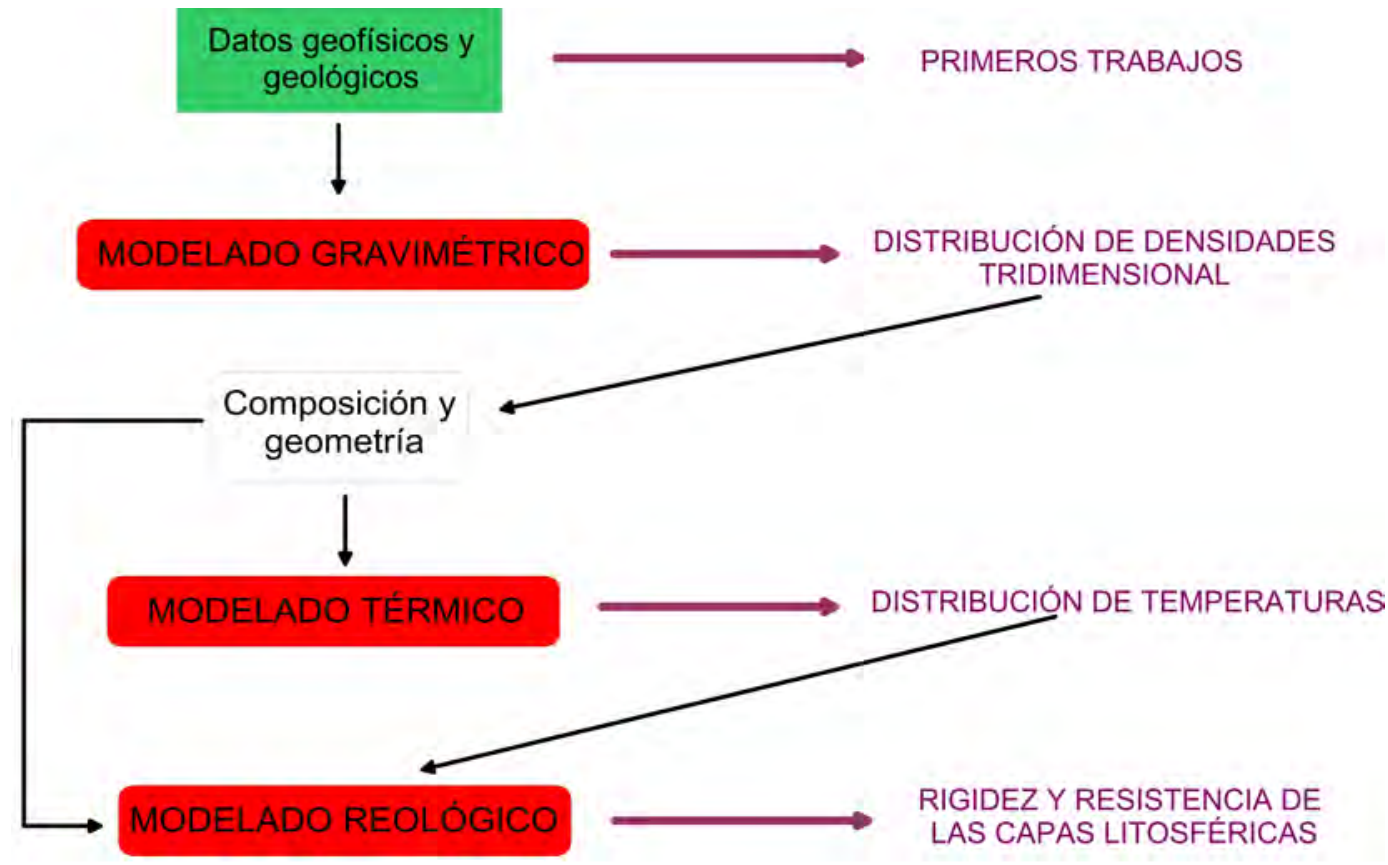

Figura 1.2. Diagrama de flujo de trabajo de la tesis, conteniendo los datos de entrada de cada modelo y sus salidas.

modelos de profundidad de la discontinuidad corteza-manto, se realizó una inversión de datos de gravedad para obtener dicha discontinuidad y compararla, a su vez, con los modelos previos. Por otro lado se analizaron las densidades del manto a partir de xenolitos, mediante estudios de laboratorio y cálculos sobre datos petrológicos.

Reuniendo la información recopilada y analizada se generaron modelos iniciales (estructurales y composicionales) que luego fueron utilizados como entrada para obtener los finales. El diagrama de flujo del trabajo de tesis se detalla en la figura 1.2, aclarando los datos de entrada y sus salidas en cada caso. Se realizaron los siguientes modelos:

- Modelado gravimétrico tridimensional a escala cortical (en forma preliminar) y a escala litosférica. Se realizó con el objetivo de encontrar la distribución de densidades y sus discontinuidades principales en la corteza. Se obtuvo la forma de la discontinuidad corteza-manto (siendo ésta el principal contraste de densidad en la litósfera) y se caracterizó la densidad media de la corteza. Fue realizado mediante el software IGMAS+ (Götze y Schmidt, 2010), una herramienta de modelado gravimétrico y magnético tridimensional interactivo.

- Modelado térmico tridimensional a escala cortical (en forma preliminar) y a escala litosférica. El objetivo fue encontrar la distribución de temperaturas en la litósfera, 
utilizando los resultados de estructura y composición extraídos del modelo de densidades (Figura 1.2). Fue realizado mediante un software denominado GMS (GeoModellingSystem; Bayer et al. 1997) que es un paquete de programas realizado en el GFZ (GeoForschungsZentrum), Potsdam, Alemania.

- Modelado reológico a escala litosférica para encontrar el comportamiento mecánico y la rigidez de las distintas capas que integran la litósfera. Realizado mediante una herramienta diseñada por Cacace y Scheck-Wenderoth (2016), utilizando la salida de los modelos de densidad y de temperatura (Figura 1.2).

A partir de los resultados obtenidos mediante el modelado y reuniéndolos con información de trabajos previos se propone una hipótesis de historia geodinámica para el área de estudio, teniendo en cuenta las limitaciones que pueden encontrarse por la falta de mediciones y estudios en el área y las restricciones del método.

\subsection{Estructura de la tesis}

La tesis está estructurada de la siguiente manera:

- En el capítulo 2 se presenta una descripción del área de investigación en cuanto a su ubicación, composición e historia, presentando así una recopilación de los trabajos previos realizados en la zona. Luego se introduce detalladamente el problema objeto de esta investigación y las condiciones en las que se generó y así se evidencia la necesidad de la caracterización del área mediante métodos geofísicos.

- En el capítulo 3 se explican los primeros trabajos realizados en la tesis a partir del análisis de los datos disponibles en el área con el fin de confeccionar el modelo inicial que luego sirvió como entrada para los distintos modelos. En este sentido, primero se explica el estudio llevado a cabo sobre la discontinuidad corteza-manto como principal contraste de densidad en la litósfera. Allí se habla sobre la inversión de datos de gravedad para obtener la mencionada discontinuidad y su comparación con distintos modelos publicados previamente que van desde escala regional hasta global. Luego se hace un análisis de la densidad en el manto a partir de datos petrológicos de xenolitos del área.

- El capítulo 4 trata sobre el modelado gravimétrico empezando con los fundamentos de esta metodología. Luego se explica la integración del modelo inicial y los resultados en 
dos etapas: un modelo tridimensional preliminar a escala cortical y otro modelo también tridimensional pero a escala litosférica.

- El capítulo 5 está dedicado al modelado térmico tridimensional. Este también comienza con los fundamentos de esta metodología y luego se habla sobre el modelado realizado en la tesis en dos etapas: un modelo preliminar a escala cortical y otro modelo a escala litosférica.

- El capítulo 6 comienza con una explicación de los fundamentos de la reología de los materiales de la litósfera y el mecanismo de modelización de los mismos a partir de un modelo base composicional y térmico. Luego se detalla el modelado reológico realizado y sus resultados. A partir de estos se calcula el espesor elástico equivalente, el cual es comparado con el efectivo extraído directamente de la relación entre la topografía y la discontinuidad corteza-manto.

- En el capítulo 7 se realiza la discusión de todos los resultados de los distintos modelos en conjunto, para poder llegar a una hipótesis sobre la historia geodinámica del área de estudio en el momento del levantamiento (Paleógeno) y su estado actual.

- El capítulo 8 presenta las conclusiones generales de la tesis.

Como resultado de esta tesis surgieron los siguientes trabajos en revistas científicas:

- Mira A., Gómez Dacal M. L., Tocho C., Vives L. 2013. 3D Gravity modelling of Corrientes Province (NE Argentina). Tectonophysics. 608, 212-221. http://dx.doi.org/10.1016/ j.tecto.2013.09.034

- Gómez Dacal M. L., Tocho C., Aragón E, 2014. Adaptación de un modelo gravimétrico tridimensional al área del Macizo Norpatagónico. Geoacta. 38 (2), 153-167.

- Gómez Dacal M. L., Tocho C., Aragón E, 2016. Mohorovicic discontinuity depth analysis beneath North Patagonian Massif. International Association of Geodesy Symposia Series, Volumen 143, 211-218. Springer. doi 10.1007/1345.2015.89.

- Gómez Dacal M. L., Tocho C., Aragón E., Sippel, J., Scheck-Wenderoth M., Ponce A., 2017. Lithospheric 3D gravity modelling using upper-mantle density constraints: Towards a characterization of the crustal configuration in the North Patagonian Massif area, Argentina. Tectonophysics. 700-701, 150-161. http://dx.doi.org/10.1016/ j.tecto.2017.02.011. 
Y los siguientes trabajos en actas de congresos:

- Gómez Dacal M. L., Tocho C., Aragón E. Caracterización de las propiedades físicas de la litósfera en el área del Macizo Norpatagónico: densidad, temperatura y reología. Resúmenes de la XXVIII Reunión Científica de la Asociación Argentina de Geofísicos y Geodestas, La Plata, 17- 21 de abril de 2017. Presentación oral.

- Gómez Dacal M. L., Tocho C., Aragón E. Caracterización del manto superior en la región norpatagónica mediante el análisis de tomografías sísmicas. XVI Reunión de Tectónica y V Taller de campo en Tectónica. Acta de resúmenes, 173-174. ISBN 978987-3667-17-6. Universidad Nacional de Río Negro. General Roca, Río Negro, Argentina. 19 al 23 de Octubre de 2015. Presentación oral.

- Aragón E., D’Eramo F., Pinotti L., Aguilera Y., Cavarozzi C., Demartis M., Gómez Dacal M. L., Castro A., Rabbia O., Hernando I., Fuentes T. El rift invertido Paleógeno de los Patagonides, Patagonia septentrional: Evolución y cambios de estilo extensional. XIV Congreso Geológico Chileno. La Serena, Chile. 4 a 8 de Octubre de 2015.

- Gómez Dacal M. L., Tocho C., Aragón E. Modelado gravimétrico preliminar de la altiplanicie del Macizo Norpatagónico. Segundas Jornadas de Geociencias para la Ingeniería. Buenos Aires, Argentina. 2 y 3 de Septiembre de 2015. Presentación oral.

- Gómez Dacal M. L., Sippel J., Scheck-Wenderoth M., Tocho C., Aragón E. Gravity and Thermal modeling of the North Patagonian Massif. XXVII Reunión científica de la Asociación Argentina de Geofísicos y Geodestas. San Juan, Argentina. 10 al 14 de Noviembre de 2014. Presentación oral.

- Gómez Dacal M. L., Tocho C., Aragón E. Espesor cortical en el área del Macizo Norpatagónico. XIX Congreso Geológico Argentino 2014. Córdoba, Argentina. 2 - 6 Junio 2014. Presentación en formato poster.

- Gómez Dacal M. L., Tocho C., Aragón E. Mohorovicic discontinuity depth analysis beneath North Patagonian Massif. IAG Scientific Assembly 2013. Postdam, Alemania, 1 - 6 de septiembre de 2013. Presentación en formato poster.

- Aragón, E., Aguilera Y.E., Gómez Dacal, M.L., Mendoza, P.L.O., Tavarone, M.F., Cavarozzi, C.E., Ribot, A., Perdomo, R., Tocho, C. La altiplanicie del Macizo Norpatagonico, su rol como divisoria de aguas, estado isostático y movimientos relativos. Simposio 
multidisciplinario: El estadío isotópico 3 en la Argentina y el Sur de América del Sur: 60000 a 25000 años atrás. La Plata, Argentina 27 a 29 de Junio de 2013. CONICET CADIC FCNyM. Presentación oral.

- Gómez Dacal M. L., Tocho C., Aragón E. Análisis de la profundidad de la discontinuidad de Mohorovicic debajo del Macizo Norpatagónico. Resúmenes de la XXVI Reunión Científica de la Asociación Argentina de Geofísicos y Geodesias, San Miguel de Tucumán, 7- 9 de noviembre de 2012. p 99 - 100. Con referato. Presentación oral 


\section{Capítulo 2}

\section{Área de estudio y problema de}

\section{investigación}

\section{1. Área de estudio}

El área de estudio específica de esta tesis, la altiplanicie del MNP, está delimitada por cuatro lineamientos morfo-estructurales denominados Limay, Gastre, Los Chacays y El Gualicho (Figura 1.1), que permiten movimientos relativos haciendo que la altiplanicie actué tectónicamente como un bloque independiente (Aragón et al., 2011b,a; Gómez Dacal et al., 2017). Tiene un área de alrededor de $100000 \mathrm{~km}^{2}$ que ocupa gran parte de la provincia de Río Negro y una porción de la de Chubut. Está ubicada $400 \mathrm{~km}$ al este de la trinchera del sistema de subducción placa Sudamericana - placa de Nazca (Figura 1.1). La altiplanicie limita con la cuenca Neuquina hacia el noroeste, la cuenca del Colorado hacia el noreste, la cuenca del Ñirihuau en el oeste y sudoeste, y con la cuenca de Cañadón Asfalto en el Sur y con los ríos Chubut, Limay y Negro (Figura 1.1). El área de estudio, al ser una altiplanicie, posee una gran elevación, de aproximadamente 1200 metros sobre el nivel del mar, pero tiene también relieve plano en su interior y se encuentra entre 500 y $700 \mathrm{~m}$ más elevada que las cuencas circundantes, como se puede observar en el mapa topográfico de la figura 1.1 (Gómez Dacal, 2012).

La altiplanicie del MNP está compuesta por complejos metamórficos (gneises, micacitas y metamorfitas) del Paleozoico temprano y tardío (Pankhurst et al., 2006) sobre los que se apoyan en discordancia angular en el sector oriental, depósitos marinos de ambiente de plataforma clástica silúricos o devónicos inferiores (Caminos, 1999). Este conjunto está intruído por rocas plutónicas del Devónico, Carbonífero, Pérmico y Triásico (Pankhurst et al., 2006), 


\section{2. Área de estudio y problema de investigación}

alternadas con grandes complejos riolíticos volcánicos jurásicos y triásicos (Rapela et al., 2005) y cubiertos por sedimentitas finas triásicas y jurásicas. Estas unidades geológicas estuvieron sujetas a una fuerte erosión, desarrollada desde el Jurásico tardío hasta el Cretácico temprano, que generó una superficie de planación (topografía plana, Aragón et al. 2015) que fue cubierta por capas finas de sedimentitas marinos del límite Cretácico-Terciario inferior y continentales del Terciario. Gran parte del sector sudeste de la altiplanicie está cubierta por extensas coladas basálticas que cubren unos $15.000 \mathrm{~km}^{2}$, de edad Oligocena, que fueron derramadas desde la parte más alta de la altiplanicie hacia los alrededores más bajos (Aragón et al., 2011a; Gómez Dacal, 2012; Gómez Dacal et al., 2017). Los depósitos terciarios se interdigitan con el volcanismo basáltico pero no alcanzan gran desarrollo (Caminos, 1999). Según Heine (2007) no habría espesores sedimentarios mayores a los $200 m$ en la zona de la altiplanicie.

La corteza del sector sur de Sudamérica, de la cual forma parte la altiplanicie del MNP, tiene una historia compleja. Antes de la formación de los Andes, dos ciclos previos (uno desde el Cámbrico hasta el Devónico y el otro entre el Carbonífero y el Triásico) modelaron las características del continente y formaron el basamento (Ramos, 1986). Según Ramos (1988), el basamento cortical cristalino de esta zona está compuesto por bloques cratónicos que fueron amalgamados al sudoeste de Gondwana entre el Precámbrico tardío y el Paleozoico. Estos bloques, que hoy en día forman el núcleo del sur del continente, son llamados terrenos. Los límites entre estos terrenos se denominan suturas y son discontinuidades corticales mayores (Ramos, 1994), o bien, discontinuidades fundamentales en estratigrafía que no pueden ser explicadas fácilmente por cambios de facies o inconformidades (Ramos, 1986). Chernicoff y Zappettini (2004) delimitaron las suturas mediante la utilización de datos aero-magnéticos en la zona centro sur de Argentina (entre los 36 y $40^{\circ}$ de latitud sur). Según este trabajo, la altiplanicie se encuentra enteramente incluida en la Patagonia, sin embargo, está en el límite norte, es decir, se encuentra limitando con el terreno de Chilenia. Estos terrenos se supone que viajaron largos trayectos antes de amalgamarse por lo que podrían tener muy diferentes orígenes y composición. Se cree que Chilenia colisionó con Gondwana durante el Devónico (Ramos, 1988) siendo la última de una secuencia de colisiones de terrenos que hoy componen la parte central de Argentina. Para el terreno Patagonia hay varias teorías muy diferentes entre sí que en la actualidad se dividen entre las que postulan que es autóctona a Gondwana, las que dicen que es un terreno alóctono y aquellas que hablan de un origen para-autóctono (Lince Klinger, 2010; Gregori et al., 2008; Pankhurst et al., 2006; Dalla Salda et al., 1990; 
Ramos, 1988; Von Gosen, 2003; González et al., 2010, 2011b,a).

Las teorías que hablan de la autoctonía de Patagonia, tales como las de Gregori et al. (2008); Pankhurst et al. (2006); Dalla Salda et al. (1990) entre otras, se basan en la posible continuidad del basamento de las Sierras Pampeanas en el MNP. Algunos de ellos hablan de movimientos de varios cientos de kilómetros de la Patagonia respecto a la plataforma sudamericana en la época del desmembramiento de Gondwana (Lince Klinger, 2010). Entre las hipótesis que proponen una Patagonia alóctona, Ramos (1988) propuso que podría haber colisionado con Gondwana en el Carbonífero tardío generando una subducción con inclinación al sudoeste por debajo del MNP (Vaughan y Pankhurst, 2008). Esto se basa en la deformación en la Sierra de la Ventana y el magmatismo al norte de la Patagonia en esa época, lo que fue interpretado por el mencionado autor como el resultado de la colisión entre los terrenos. Esta hipótesis también es apoyada por Von Gosen (2003) en sus estudios sobre estructuras en el área del MNP (Lince Klinger, 2010). Por otro lado, estudios recientes refieren el carácter alóctono de la Patagonia de una manera distinta (para-autóctono); ellos muestran que el terreno de la Patagonia es una parte del orógeno Antártico Ross que fue transportado a lo largo del margen sudoeste de Gondwana (González et al., 2010, 2011b,a) y por lo tanto no habría colisión continente-continente con superposición de cortezas (duplicación del espesor cortical) para este límite entre terrenos.

\subsection{Problema de investigación}

La elevación actual de la altiplanicie del MNP fue causada por un levantamiento repentino de más de $1200 m$ en aproximadamente 25 millones de años (Aragón et al., 2011a). La primera restricción temporal para este levantamiento está dada por los sedimentos marinos del Paleoceno (60 Ma) que cubrieron no sólo la altiplanicie sino también el trasarco circundante. Estos sedimentos se encuentran actualmente sin deformar y a una altura de $1100 \mathrm{msnm}$ en la altiplanicie y, a su vez, en las cuencas circundantes, entre 500 y $700 \mathrm{~m}$ por debajo de la cima de la altiplanicie, con evidencias de distintos grados de deformación a causa de la inversión tectónica del Mioceno. La segunda restricción está dada por los basaltos del Plateau de Somún Curá. Estos basaltos son del Oligoceno (35 $M a$ ) y se derramaron como cascadas desde la cima de la altiplanicie hacia el trasarco circundante. Con lo cual se puede decir que el levantamiento ocurrió en algún momento entre el Paleoceno y el Oligoceno (Aragón et al., 2011a). Es importante destacar, que mediante estas restricciones podemos decir que el 


\section{2. Área de estudio y problema de investigación}

levantamiento de la altiplanicie tuvo lugar antes de la inversión tectónica que creó los Andes en el Mioceno. Es decir, si bien son estructuras vecinas, las fuerzas que generaron la cadena montañosa no tuvieron que ver con la formación de la altiplanicie, aunque si pueden tener un efecto en la altura que observamos en la actualidad (Aragón et al., 2015).

El levantamiento de la altiplanicie del MNP ocurrió sin dejar evidencias de deformación notable. Los sedimentos marinos descriptos anteriormente son también una evidencia de esto, ya que se encuentran sin deformación en la altiplanicie (Aragón et al., 2011a, 2015).

La zona en la cual se emplaza la altiplanicie estuvo sometida, durante el momento del levantamiento (Paleógeno), a un régimen extensivo regional desarrollado cuando el rift activo Farallón-Alluk alcanzó y colisionó con la placa Sudamericana. El cambio drástico en las velocidades de convergencia entre las placas generó el detenimiento de la subducción y el margen se convirtió, temporalmente, en transcurrente. Es decir, hubo un período de ausencia de subducción que terminó cuando la placa de Farallón se rompió para generar las de Cocos y Nazca en el Mioceno y comenzó el régimen de subducción ortogonal (Aragón et al., 2011b). Aragón et al. (2011a) indican que la actividad sísmica en la placa que subduce en la actualidad y los modelos de velocidad de onda $\mathrm{P}$ en el manto superior sugieren la presencia de la mencionada ausencia de subducción durante la mayor parte del Paleógeno en el norte de la Patagonia.

Este reacomodamiento de placas podría haber generado una anomalía térmica en el manto, que es documentada por varios autores tales como Aragón et al. (2011a, 2015); Kay et al. (1993, 2007); Muñoz et al. (2000); De Ignacio et al. (2001). Estos estudios no coinciden en el origen de la inestabilidad, pero si en su existencia y en su relación con la reorganización de placas de esa época. Algunos se la atribuyen a una ventana astenosférica y posterior ascenso del manto generado por la subducción de la dorsal entre las placas de Farallón y Alluk (Aragón et al., 2011a), Muñoz et al. (2000) también hablan de ascenso del manto pero a causa de slab roll back de la placa que subducía, Kay et al. $(1993,2007)$ hablan de un hot spot transitorio y De Ignacio et al. (2001) proponen la existencia de un ascenso del manto somero generado por un flujo astenosférico debido a la geometría de la placa ( corner flow).

Los lineamientos que permitieron el movimiento epirogénico (y que separan un área morfoestructural de comportamiento tectónico distinto que las áreas circundantes), son fallas mayores de sistemas pre-existentes que, en el régimen extensional del Paleógeno, fueron reactivadas de manera normal.

Es decir que el levantamiento rápido de la altiplanicie del MNP, fue sin deformación, coincidente espacio-temporalmente con un régimen extensional y con una anomalía térmica 
en el manto. Estas condiciones generan la pregunta de cómo y por qué fue que se originó la altiplanicie.

La topografía elevada, normalmente, es producida por uno de los siguientes procesos:

- El más común está relacionado con una corteza engrosada como producto de una orogenia, es decir, interacción entre placas tectónicas que deriva en fuerzas horizontales que crean cordones montañosos.

- El otro, se relaciona con la dinámica del manto y con fuerzas de flotación que pueden elevar la litosfera. Estos procesos pueden estar asociados con plumas del manto u otra discontinuidad de temperatura de la astenósfera que pueden generar tumescencia de la litósfera. La tumescencia es una elevación regional de gran ancho y una altura de hasta $3 \mathrm{~km}$ (Turcotte y Schubert, 1982)

Según la información del área de estudio (amplia superficie plana, con alta topografía que no evidencia deformación interna cenozoica y que fue levantada en una época de régimen extensivo), no hay indicadores que nos hagan suponer que haya sido levantada por procesos tectónicos, ya que estos implican deformación, zonas de mucha variación de relieve y son creadas bajo regímenes compresivos. En cambio, sí hay evidencias de dinámica del manto debajo de la altiplanicie, ya que varios autores (Aragón et al., 2011a, 2015; Kay et al., 1993, 2007; Muñoz et al., 2000; De Ignacio et al., 2001) hablan de una anomalía de temperatura en la época del levantamiento.

Cualquiera de los procesos mencionados puede generar un desequilibrio que luego será compensado, según estudia la isostasia. Isostasia es un término utilizado para describir una condición de equilibrio hacia la cual las capas superficiales de la Tierra tienden en ausencia de fuerzas perturbadoras. Esto requiere una capa superficial rígida y más liviana que "flote"sobre un sustrato más denso (Watts, 2001). Existen multitud de procesos que perturban este estado de equilibrio, tales como, erosión, sedimentación, vulcanismo, glaciaciones, etc. Como consecuencia de estos desequilibrios, aparecen fuerzas verticales que tienden a restaurar el equilibrio, las cuales trabajan para balancear las cargas, de modo que a una cierta profundidad de compensación sean lateralmente iguales.

Los primeros modelos de isostasia que fueron desarrollados (y que fueron utilizados como mejor aproximación de la realidad hasta principios del siglo XX) consideran las características geológicas compensadas localmente, es decir, el balance se genera en puntos ubicados debajo de las cargas intervinientes (masas topográficas) y no en sus alrededores. En estos 

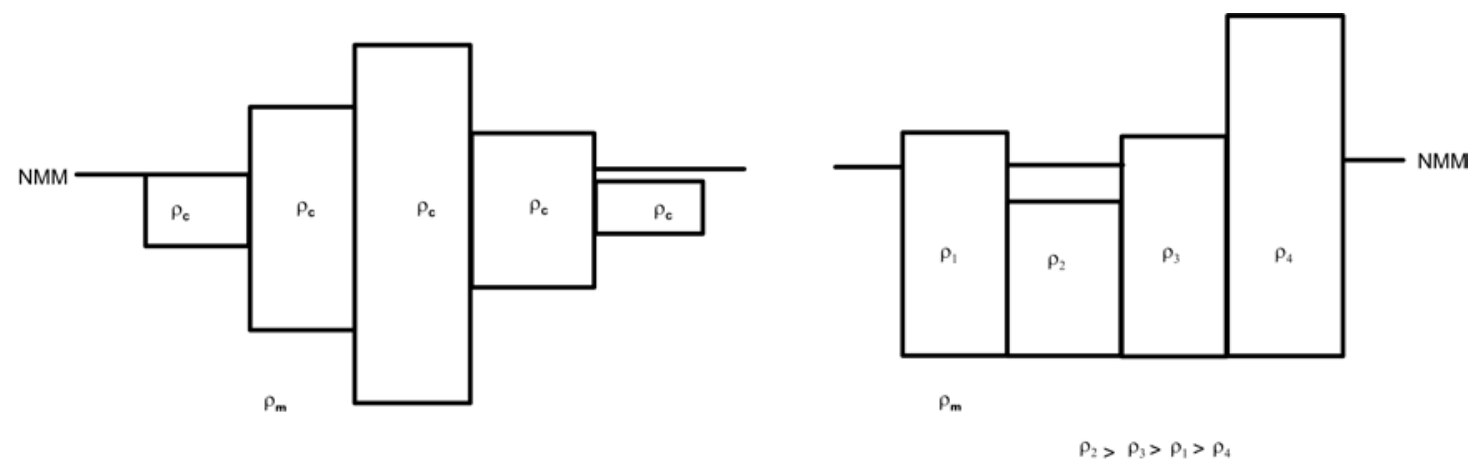

Figura 2.1. Ilustración de las teorías de isostasia. A la izquierda la teoría de Airy y a la derecha la de Pratt.

modelos se llega a la compensación localmente, mediante la igualación de la presión debajo de columnas verticales que soportan una carga topográfica. Existen dos teorías principales de compensación local, con concepciones distintas y denominadas modelo de Airy-Heiskanen y de Pratt-Hayford (Airy, 1855; Pratt, 1859). El primero postula que la igualdad de peso sobre una determinada profundidad de compensación, en todos los puntos de un área, se logra mediante la variación de la profundidad de la discontinuidad entre la capa superior rígida y la inferior más densa, ambas homogéneas (Figura 2.1). Es decir, propone que la capa superior flota en el sustrato denso tal como lo hacen los icebergs en el agua con lo cual, el espesor de la raíz varía en proporción con la elevación de la topografía (Figura 2.1). Según esta teoría, la deficiencia de masa de la raíz iguala el exceso de carga en la superficie. La teoría de Pratt-Hayford, en cambio, sugiere que la igualdad de presiones en la profundidad de compensación se da mediante la variación de la densidad lateral de la capa superficial rígida (Figura 2.1). En este caso, la expansión diferencial del material en columnas verticales da cuenta de la topografía, entonces cuanto más alta sea la columna por encima del nivel de base, menos densa será (Lowrie 2007; Figura 2.1).

Más adelante, se comenzaron a considerar modelos en los cuales la compensación de la carga topográfica en un punto involucra regiones que no se ubican directamente por debajo de la misma, si no que se extienden lateralmente. Estos modelos, que llamamos de compensación isostática regional o flexural son los más aceptados en la actualidad (modelo de Vening Meinesz 1931) y en ellos se incorpora el concepto de resistencia o rigidez.

Como se mencionó previamente, la isostasia restablece el equilibrio, con lo cual actúa si existe (o existió) algún proceso perturbando el mismo, como los que se mencionaron para la generación de topografía. Es decir, las fuerzas de flotación que aparecen en un área 
desbalanceada isostáticamente también pueden aportar a la creación de topografía.

En este contexto, la problemática a resolver para el área de estudio es el por qué de la generación de la altiplanicie que hoy en día es posible observar. En esta tesis se intenta encontrar una posible explicación para la formación de dicha estructura mediante la caracterización del área y sus alrededores utilizando el modelado geofísico directo y datos geofísicos y geológicos disponibles en el área. 


\section{Capítulo 3}

\section{Primeros trabajos mediante el análisis de datos disponibles}

En este capítulo se describen dos trabajos realizados a partir del análisis de la información disponible en el área. El análisis se realizó con la intención de conocer los datos con los que se contaba para el armado del modelo inicial necesario para la generación de los modelos subsiguientes y, a su vez, hacer un primer reconocimiento de las características del área. Se analiza la discontinuidad corteza-manto y las densidades del manto.

\subsection{Análisis de modelos de profundidad de Moho.}

Este capítulo dio lugar al trabajo publicado por Gómez Dacal et al. (2016), en el cual fueron usados la totalidad de los desarrollos, tablas y figuras.

La discontinuidad de Mohorovičić (Moho) es el límite entre la corteza y el manto. Es definida por los sismólogos como la profundidad a la cual la velocidad de la onda $\mathrm{P}$ excede los $7.6 \mathrm{~km} / \mathrm{s}$ y por lo tanto, depende de la densidad y de las propiedades elásticas de las rocas de la corteza y del manto (Lowrie, 2007). El Moho juega un rol fundamental en la dinámica terrestre. En particular ayuda a entender el estado de compensación isostática de un área y en consecuencia sus movimientos epirogénicos. También constituye una discontinuidad fundamental de los modelos gravimétricos.

Los modelos de Moho están basados principalmente en datos sísmicos o gravimétricos del área que pretenden modelar, y por lo tanto, requieren grandes cantidades de este tipo de información para ser generados. Los datos sísmicos permiten la creación de modelos regionalmente más precisos de la superficie del Moho, sin embargo, el MNP es un área que no 
cuenta con datos sísmicos, por lo cual es difícil la creación de un modelo regional preciso. Por esta razón, es necesario recurrir a modelos globales o regionales a gran escala para estudiar esta discontinuidad en nuestra área de estudio. Existen varios modelos globales de Moho que pueden ser utilizados y por consiguiente en esta tesis se describieron, compararon y graficaron varios de ellos y se testeó el desempeño de uno en particular: el modelo GEMMA (GOCE Exploitation for Moho Modeling and Applications; Barzaghi et al. 2014) en el área del MNP.

\subsubsection{Descripción de los modelos de Moho}

El modelo GEMMA fue generado por el proyecto que lleva el mismo nombre, de la Agencia Espacial Europea y el Politécnico de Milán, y es un modelo de alta resolución de la superficie del Moho basado en la inversión de datos gravimétricos, homogéneos y bien distribuidos medidos mediante la misión GOCE (Steady-State Ocean Circulation Explorer), lo que asegura cobertura global (Barzaghi et al., 2014). Los autores redujeron los datos mediante la sustracción de la contribución del potencial normal, luego la corrigieron por el efecto de la topografía y batimetría e hicieron un análisis de esféricos armónicos del campo residual para obtener los coeficientes del campo de gravedad residual. Luego de esto, relacionaron los coeficientes con el producto entre la profundidad del Moho y el contraste de densidad (entre la corteza y el manto) mediante una relación lineal. Tomaron el contraste de densidad como una constante igual a $630 \mathrm{~kg} / \mathrm{m}^{3}$ (corteza homogénea de densidad $2670 \mathrm{~kg} / \mathrm{m}^{3}$ y manto también homogéneo de $3270 \mathrm{~kg} / \mathrm{m}^{3}$ ) y obtuvieron así la profundidad del Moho (Sampietro y Reguzzoni, 2011). La figura 3.1 muestra un mapa del modelo, de 30 minutos de resolución, en el área del MNP (Riccardo Barzaghi, comunicación personal). Puede observarse en ella que la profundidad del Moho varía entre 34 y $36 \mathrm{~km}$ en la mencionada área y se torna más somera hacia los bordes norte, este y sur, mientras que en el borde oeste se ve lo opuesto.

La estimación del Moho del modelo GEMMA (Barzaghi et al., 2014) fue comparada, para el área del MNP, con una serie de modelos a distintas escalas (desde globales hasta locales) y de diferentes orígenes (basados en diferentes datos y compilados con distintos métodos) como se muestra en la tabla 3.1. Se compararon cinco modelos: dos de ellos fueron realizados utilizando información sísmica (Feng et al., 2007; Bassin et al., 2000); otros dos mediante una combinación de técnicas sísmicas y gravimétricas (Assumpção et al., 2013; Tassara y Echaurren, 2012) y el último es producto de una inversión de datos de gravedad para el área de estudio realizada durante el desarrollo de la tesis (Tabla 3.1). El objetivo de la comparación es tanto validar el modelo GEMMA en un área de estudio con muy pocos datos sísmicos, 


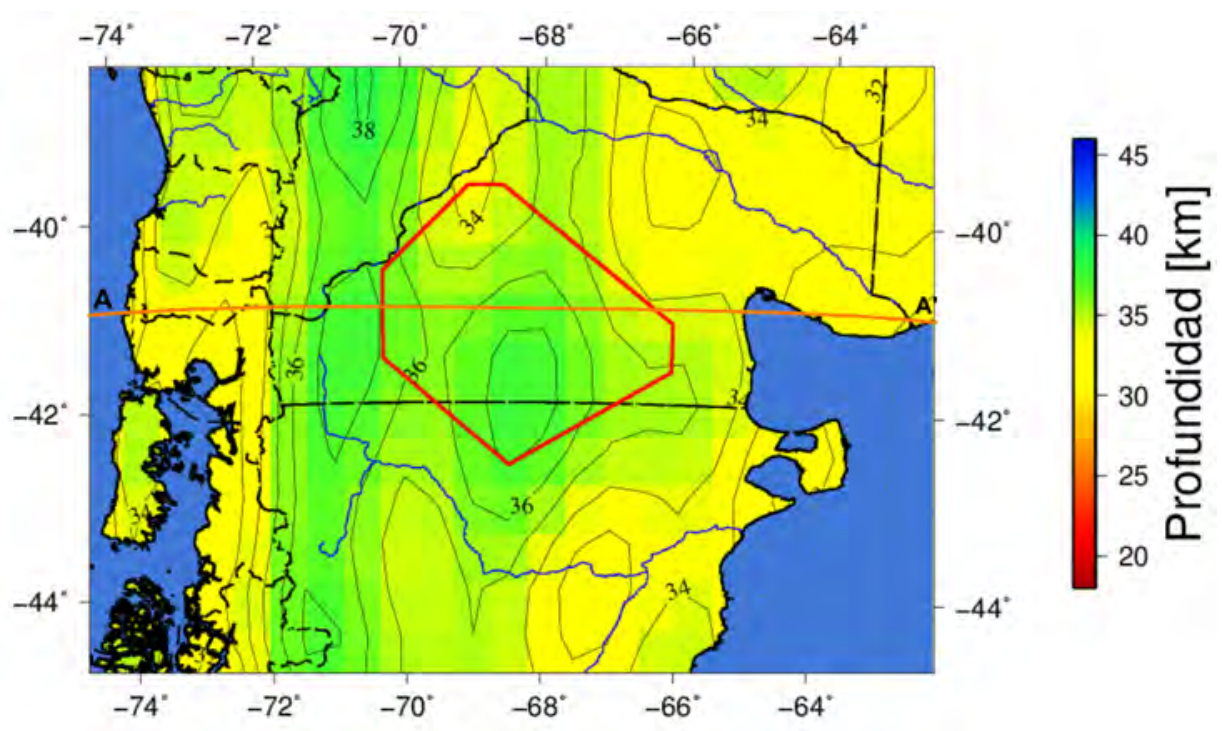

Figura 3.1. Modelo GEMMA (Barzaghi et al., 2014). Se indica en naranja el perfil A-A' de la figura 3.12

como obtener información del Moho para la mencionada área. Se esperaría que el modelo GEMMA ajuste razonablemente con estos modelos que son la única información disponible acerca de la discontinuidad en la zona.

Como se puede observar en las figuras, los modelos de Moho en el área de estudio tienen las siguientes características:

- El modelo A (CRUST 2.0, Bassin et al. 2000; Figura 3.2) muestra una profundidad de Moho de entre 36 y $40 \mathrm{~km}$ para el área de la altiplanicie que está rodeada por áreas de corteza más finas al sur y este y por áreas de corteza gruesa en los otros dos límites. Hay que destacar que este modelo tiene poca resolución y que existen pocos datos en los que se basa en el área de estudio, por lo tanto, resulta de una interpolación de los datos disponibles en las áreas circundantes. Este modelo fue elegido para la comparación porque es uno de los modelos más conocidos y diseminados dentro de la comunidad geocientífica a pesar de su poca resolución y además fue utilizado como la profundidad media del Moho durante la confección del modelo GEMMA (Reguzzoni et al., 2013).

- La profundidad del Moho del Modelo B (Feng et al., 2007) en la zona de la altiplanicie del MNP oscila entre 36 y $45 \mathrm{~km}$ y está rodeada por cortezas más finas hacia el norte, este y noroeste, en el oeste la corteza es más gruesa y al sur hay un área de no cobertura del modelo. Lo descripto puede ser observado en la Figura 3.3. No hay estimaciones puntuales de profundidad de Moho dentro de la altiplanicie que sirvan para restringir 
Tabla 3.1. Modelos de Moho (profundidad medida desde el nivel medio del mar) comparados en la tesis.

\begin{tabular}{|c|c|c|c|c|}
\hline Modelo & Cobertura & Descripción & Figura & Referencia \\
\hline $\begin{array}{l}\text { Modelo A } \\
\text { CRUST } \\
2.0\end{array}$ & Global. & $\begin{array}{l}\text { Datos sísmicos: reflexión, refracción y estudios de fun- } \\
\text { ciones receptoras; Resolución: } 2^{\circ} x 2^{\circ} \text {; Disponible online; } \\
\text { Valores dentro de la altiplanicie: entre } 36 \text { y } 40 \mathrm{~km}\end{array}$ & $\begin{array}{l}\text { Figura } \\
3.2\end{array}$ & $\begin{array}{l}\text { Bassin et } \\
\text { al. (2000) } \\
\text { http://igpp- } \\
\text { web. ucsd.- } \\
\text { edu/ gabi/ } \\
\text { crust2.html }\end{array}$ \\
\hline Modelo B & $\begin{array}{l}\text { Modelo re- } \\
\text { gional: Su- } \\
\text { damérica. }\end{array}$ & $\begin{array}{l}\text { Datos sísmicos: inversión conjunta de formas de onda } \mathrm{S} \\
\text { y Rayleigh regionales y velocidades de grupo del modo } \\
\text { fundamental de la onda Rayleigh. Integra un perfil de } \\
\text { refracción a los } 39^{\circ} \text { de latitud sur; Valores dentro de la } \\
\text { altiplanicie: entre } 36 \text { y } 45 \mathrm{~km}\end{array}$ & $\begin{array}{l}\text { Figura } \\
3.3\end{array}$ & $\begin{array}{l}\text { Feng et al. } \\
(2007)\end{array}$ \\
\hline Modelo C & $\begin{array}{l}\text { Modelo re- } \\
\text { gional: } \mathrm{Su}- \\
\text { damérica. }\end{array}$ & $\begin{array}{l}\text { Datos sísmicos: estimaciones puntuales de experimentos } \\
\text { de sísmica de refracción, funciones receptoras, dispersión } \\
\text { de ondas superficiales (integra el mismo perfil de refrac- } \\
\text { ción del Modelo B y una estimación puntual más) y es- } \\
\text { timaciones basadas en gravedad obtenidas de Tassara y } \\
\text { Echaurren (2012) para cubrir las zonas de falta de in- } \\
\text { formación sísmica; interpolada con tomografía de onda } \\
\text { superficial; Valores dentro de la altiplanicie: entre } 32 \text { y } \\
38 \mathrm{~km}\end{array}$ & $\begin{array}{l}\text { Figura } \\
3.4\end{array}$ & $\begin{array}{l}\text { Assumpção } \\
\text { et } \quad a l \text {. } \\
(2013)\end{array}$ \\
\hline Modelo D & $\begin{array}{l}\text { Modelo } \\
\text { regional: } \\
\text { Andes cen- } \\
\text { trales y del } \\
\text { Sur. }\end{array}$ & $\begin{array}{l}\text { Modelo tridimensional de densidad restringido por datos } \\
\text { independientes (principalmente sísmicos; también integra } \\
\text { el perfil del modelo B): Superficie de Moho extraída de } \\
\text { la adaptación al área de estudio del mencionado mode- } \\
\text { lo (descripta en Gómez Dacal et al. 2013) utilizando el } \\
\text { software IGM AS+ (Götze, 1978, 1984; Götze y Lahme- } \\
\text { yer, 1988; Schmidt y Götze, 1998); Valores dentro de la } \\
\text { altiplanicie: entre } 35 \text { y } 37 \mathrm{~km}\end{array}$ & $\begin{array}{l}\text { Figura } \\
3.5\end{array}$ & $\begin{array}{l}\text { Tassara y } \\
\text { Echaurren } \\
(2012)\end{array}$ \\
\hline Modelo E & $\begin{array}{l}\text { Modelo lo- } \\
\text { cal: área del } \\
\text { MNP. }\end{array}$ & $\begin{array}{l}\text { Inversión de datos de gravedad (software Lithoflex; Brai- } \\
\text { tenberg et al. 2007): anomalías de Bouguer extraídas del } \\
\text { modelo geopotencial EGM2008 (Pavlis et al., 2012); Va- } \\
\text { lores dentro de la altiplanicie: entre } 39 \text { y } 46 \mathrm{~km}\end{array}$ & $\begin{array}{l}\text { Figura } \\
3.6\end{array}$ & \\
\hline
\end{tabular}




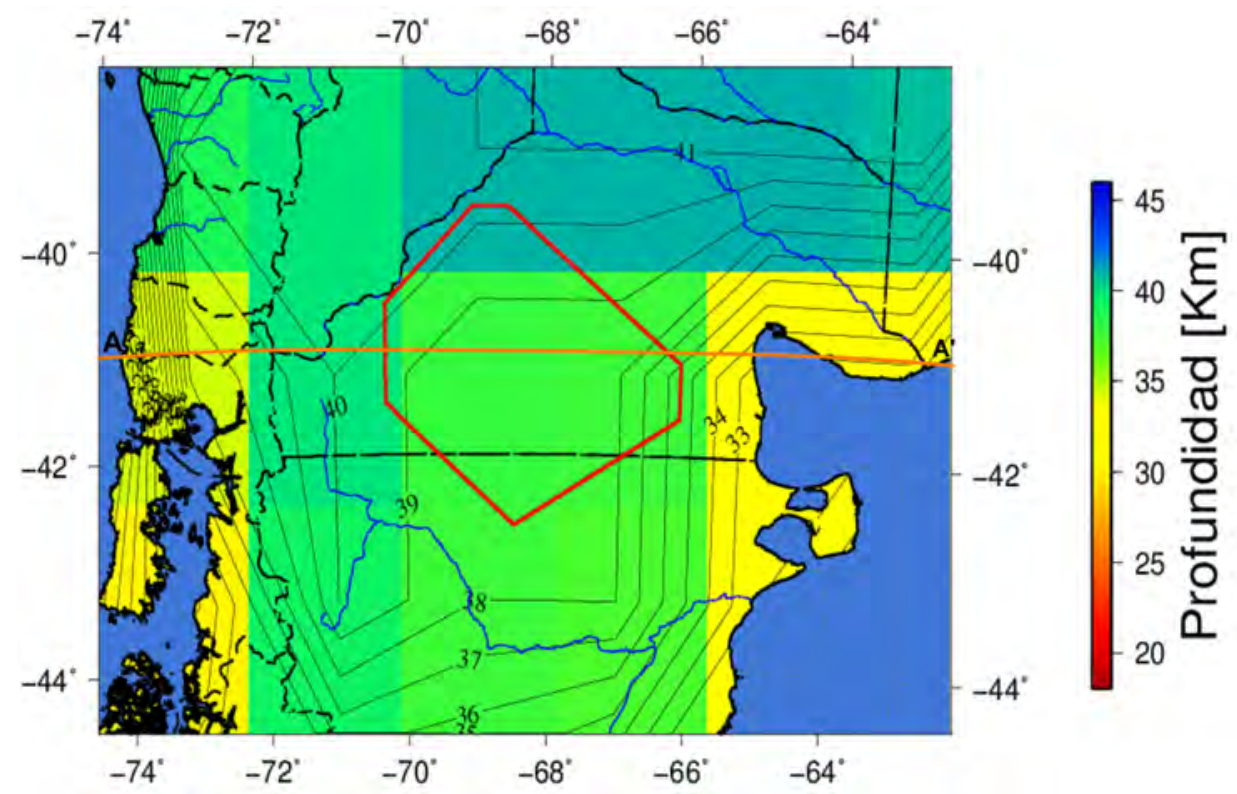

Figura 3.2. Modelo A: CRUST 2.0 (Bassin et al., 2000). Se indica en naranja el perfil A-A' de la figura 3.12

el modelo, pero si hay un perfil de refracción con datos de la superficie al norte de la misma (Figura 3.3). La resolución del este modelo es de 2 minutos.

- Según el Modelo C (Assumpção et al. 2013; Figura 3.4), la profundidad del Moho debajo de la altiplanicie está entre 32 y $38 \mathrm{~km}$ y al igual que en el caso del modelo anteriormente descripto, el área está rodeada por corteza más fina hacia el norte, este y noroeste. En el oeste la corteza es más gruesa y al sur hay un área de no cobertura del modelo (Figura 3.4). Es importante destacar que no hay estimaciones puntuales de Moho dentro de la altiplanicie habiendo una sólo cerca de la misma y el mismo perfil de refracción mencionado para el Modelo B al norte (Figura 3.4). Por esta razón, el modelo está basado principalmente en datos de gravedad (del trabajo de Tassara y Echaurren (2012)) para el área de la altiplanicie y podría estar pobremente definido. A pesar de esto, el Modelo $\mathrm{C}$ es el que tiene la mayor base de datos de todos los modelos analizados.

- En la figura 3.5 se puede ver que la profundidad del Moho del Modelo D (Tassara y Echaurren, 2012) para la altiplanicie oscila entre 35 y $37 \mathrm{~km}$ y está rodeada por áreas de corteza más fina al norte, este y sur y por un área de corteza más gruesa al oeste. El Modelo D resulta de la adaptación de un modelo tridimensional de densidades (Tassara y Echaurren, 2012) al área de estudio (Gómez Dacal, 2012). El modelado fue realizado 


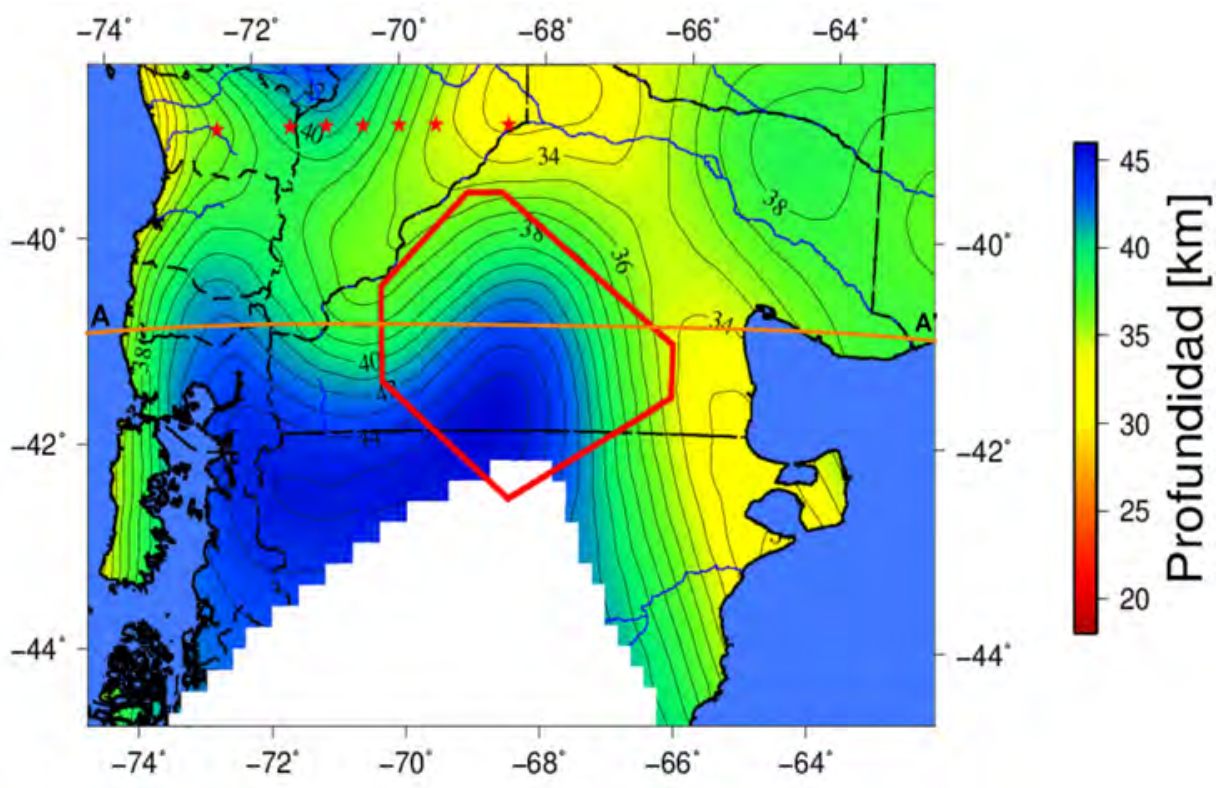

Figura 3.3. Modelo B (Feng et al., 2007). El área blanca indica falta de cobertura del modelo y las estrellas rojas los datos de restricción. Se indica en naranja el perfil A-A' de la figura 3.12

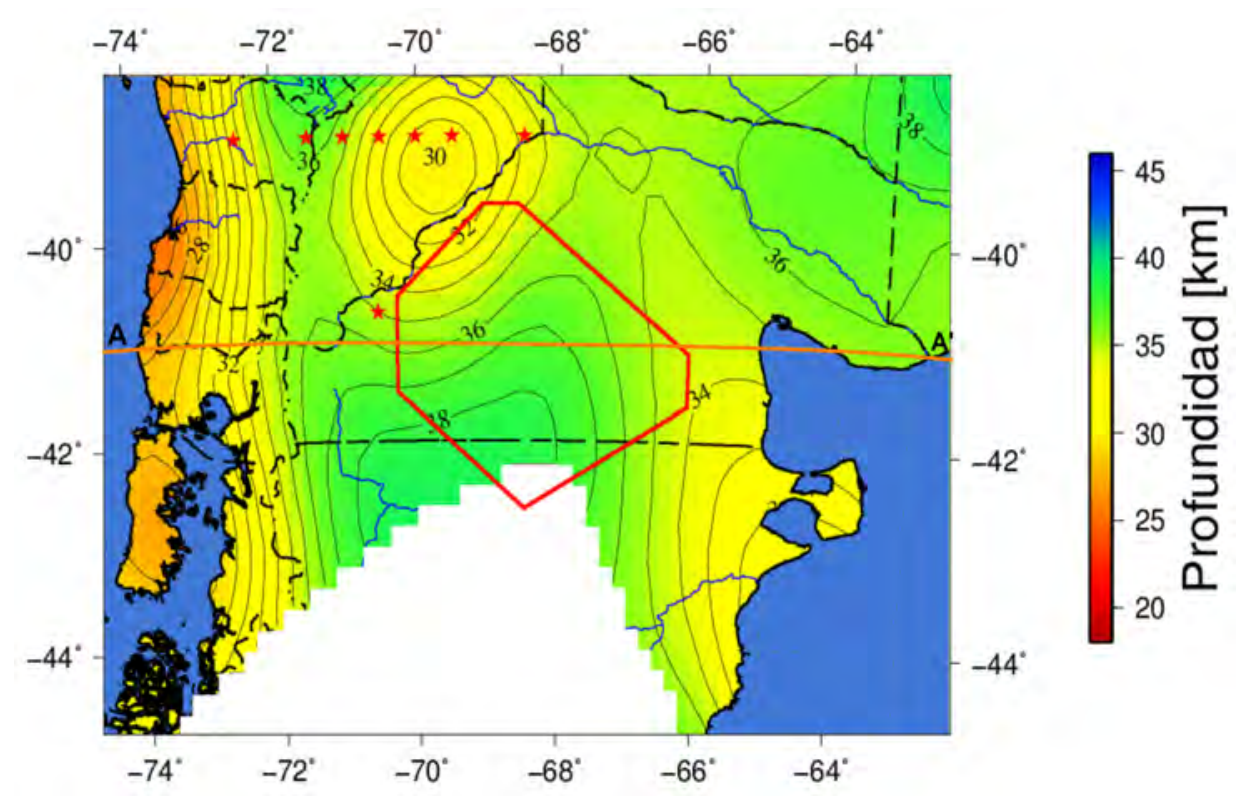

Figura 3.4. Modelo C (Assumpção et al., 2013). El área blanca indica que no hay cobertura del modelo y las estrellas rojas la ubicación de los datos de restricción. Se indica en naranja el perfil A-A' de la figura 3.12 


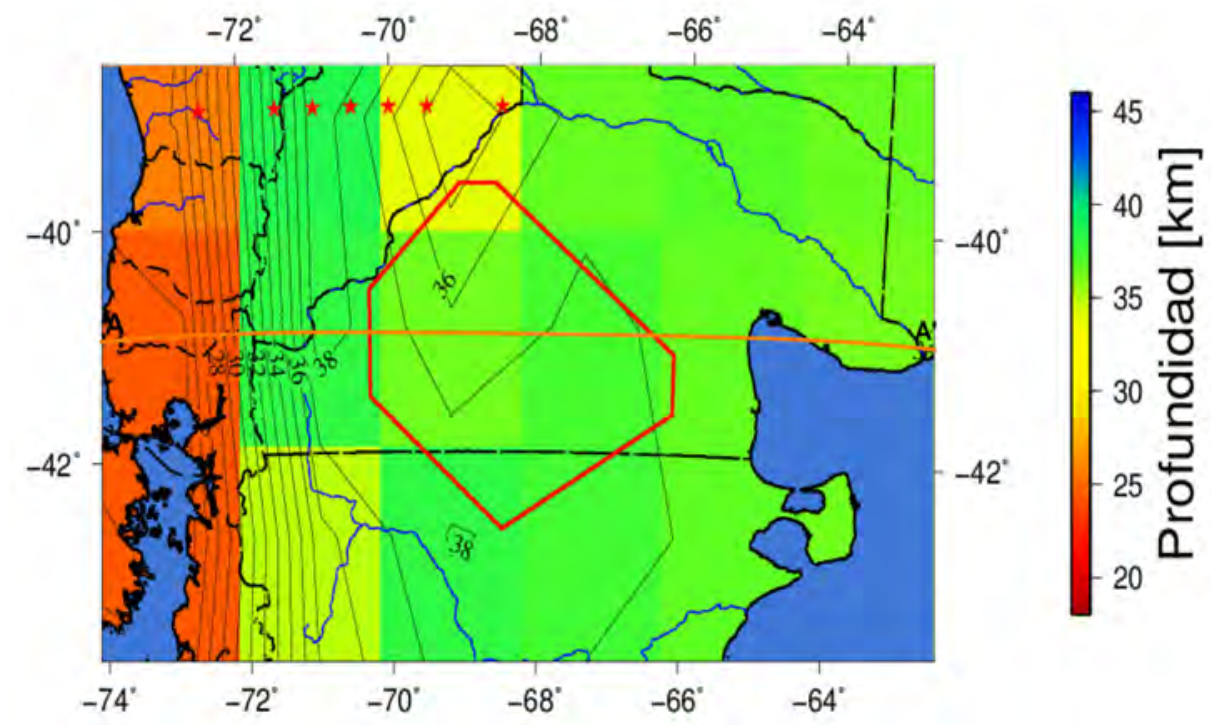

Figura 3.5. Modelo D (Tassara y Echaurren, 2012). Las estrellas rojas indican datos de restricción. Se indica en naranja el perfil A-A' de la figura 3.12

utilizando el software IGMAS+ (Interactive Gravity and Magnetic Application System) del cual se hablará más adelante, y las anomalías de Bouguer del modelo geopotencial EGM2008, a través de la triangulación de secciones separadas $0.5^{\circ}$ y una resolución longitudinal de $25 \mathrm{~km}$. Tassara y Echaurren (2012) restringieron el Moho fue restringido usando determinaciones de funciones receptoras y perfiles de refracción, pero hay áreas sin restricciones. Para estas regiones, el Moho fue modelado ajustando la longitud de onda intermedia de la anomalía de Bouguer y bajo la asunción de que la topografía orogénica está principalmente compensada por raíces corticales (Tassara y Echaurren, 2012). En la altiplanicie, el modelo no tiene datos independientes que restrinjan la superficie (Figura 3.5) y, por lo tanto, podría estar pobremente definida.

- Según el Modelo E (Figura 3.6), la profundidad del Moho debajo de la altiplanicie del MNP oscila entre 39 y $46 \mathrm{~km}$ y está rodeada por corteza más fina al norte, este y sur y por corteza más gruesa al oeste. Este modelo fue realizado utilizando el software Lithoflex (Braitenberg et al., 2007), las anomalías de Bouguer del modelo EGM2008 (Pavlis et al., 2012) y un corte en la longitud de onda a los $200 \mathrm{~km}$. Los datos de gravedad seleccionados son consistentes con aquellos usados por los modelos B y C, y el corte en longitud de onda fue elegido con el fin de no proyectar masas superficiales al nivel del Moho y para ser consistente con los otros modelos que muestran largas longitudes de onda. Los parámetros físicos utilizados fueron: $36 \mathrm{~km}$ para la profundidad 


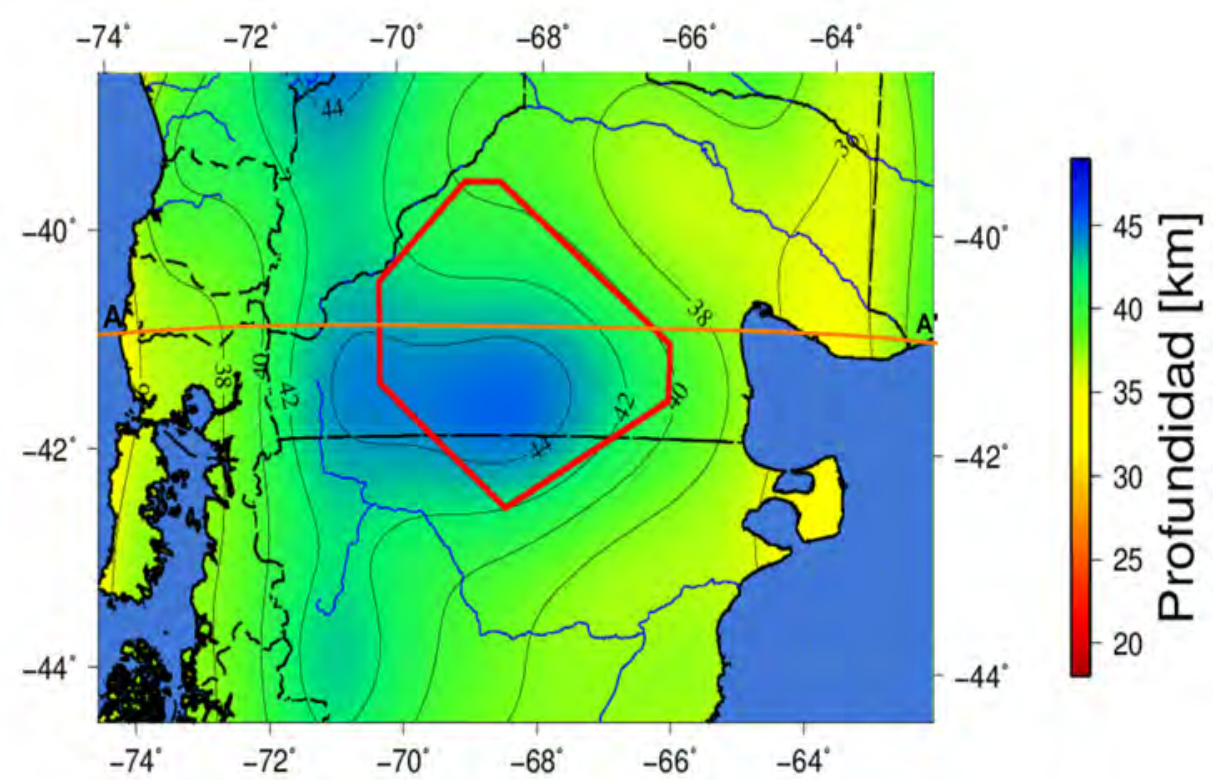

Figura 3.6. Modelo E confeccionado a partir de la inversión de datos de gravedad. Se indica en naranja el perfil A-A' de la figura 3.12

de referencia y $340 \mathrm{~kg} / \mathrm{m}^{3}$ para el contraste de densidad. La elección de la profundidad de referencia fue basada en la coincidencia de varios modelos de Moho fuera del área de la altiplanicie. La densidad de contraste fue calculada con valores de densidad extraídos de xenolitos de la corteza inferior y manto superior (los cuales se introducirán en la sección siguiente) y para la corteza superior valores encontrados en la literatura de trabajos en la zona (Castro et al., 2011; Lince Klinger, 2010; Kostadinoff y Schillizi, 1996; Kostadinoff y Gelós, 1994). Los valores de profundidades del Modelo E han sido obtenidos sin tener en cuenta la topografía ni ninguna hipótesis isostática. El desvío estándar de las diferencias entre el modelo GEMMA y el E es de \pm 2.57 km (tabla 3.2).

\subsubsection{Comparación de modelos de Moho}

Con el fin de evaluar el modelo GEMMA (Barzaghi et al., 2014) en el área de estudio, se realizaron las comparaciones con los otros modelos descriptos en la sección anterior:

- Las diferencias, en valor absoluto, entre el modelo GEMMA y los otros modelos se muestran en las figuras $3.7,3.8,3.9,3.10$ y 3.11 .

- Se eligió un perfil que cruza el área de estudio (ubicación graficada en las figuras 3.2, 3.3, 3.4, 3.5 y 3.6) para comparar los diferentes modelos de Moho. El perfil, realizado a una latitud de $41^{\circ} S$ porque atraviesa la altiplanicie del MNP por su zona media, 


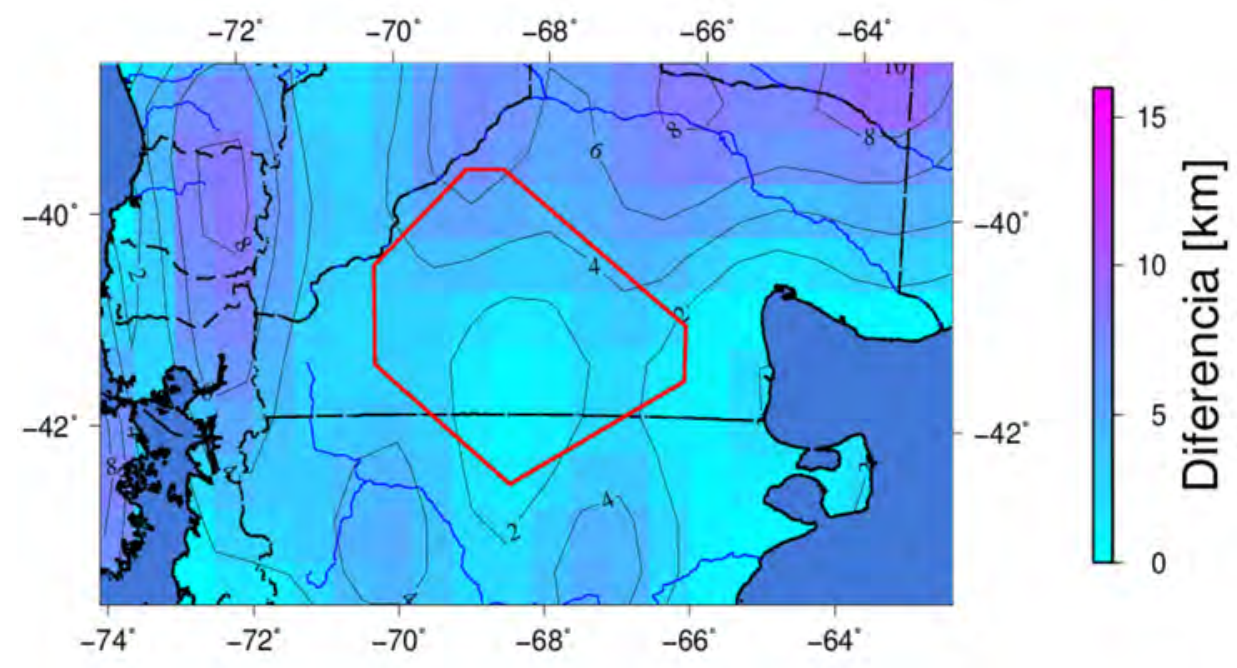

Figura 3.7. Diferencia entre Modelo GEMMA y Modelo A

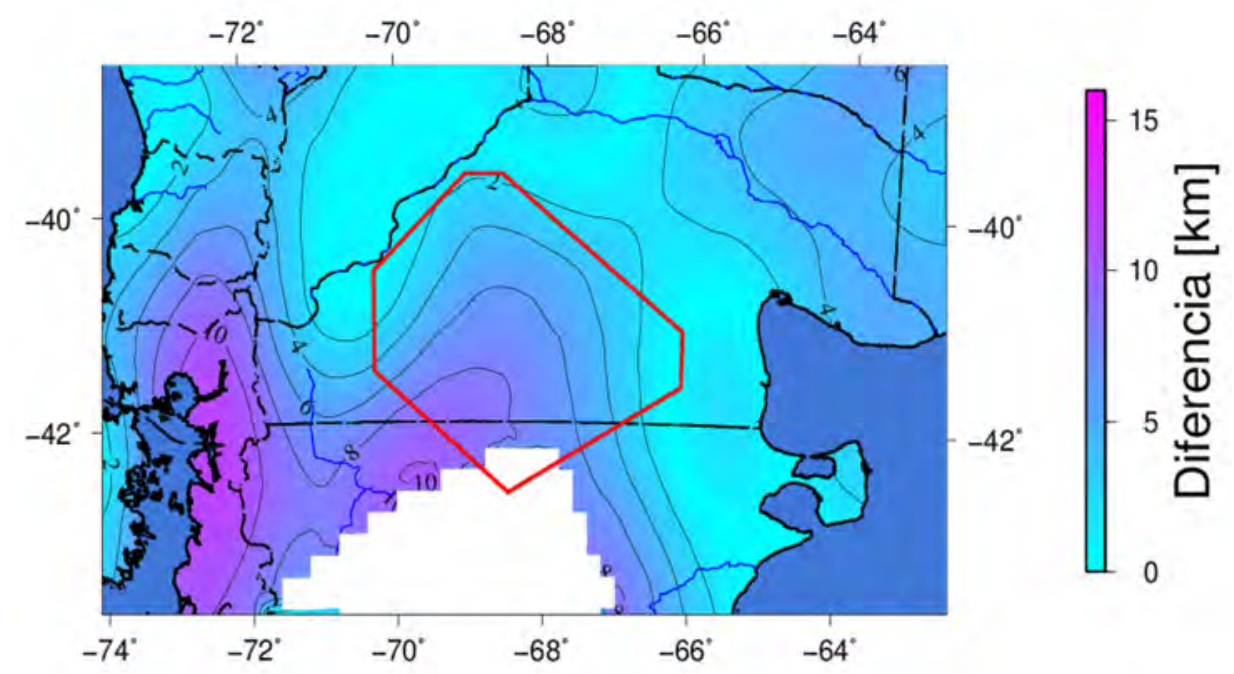

Figura 3.8. Diferencia entre Modelo GEMMA y Modelo B 


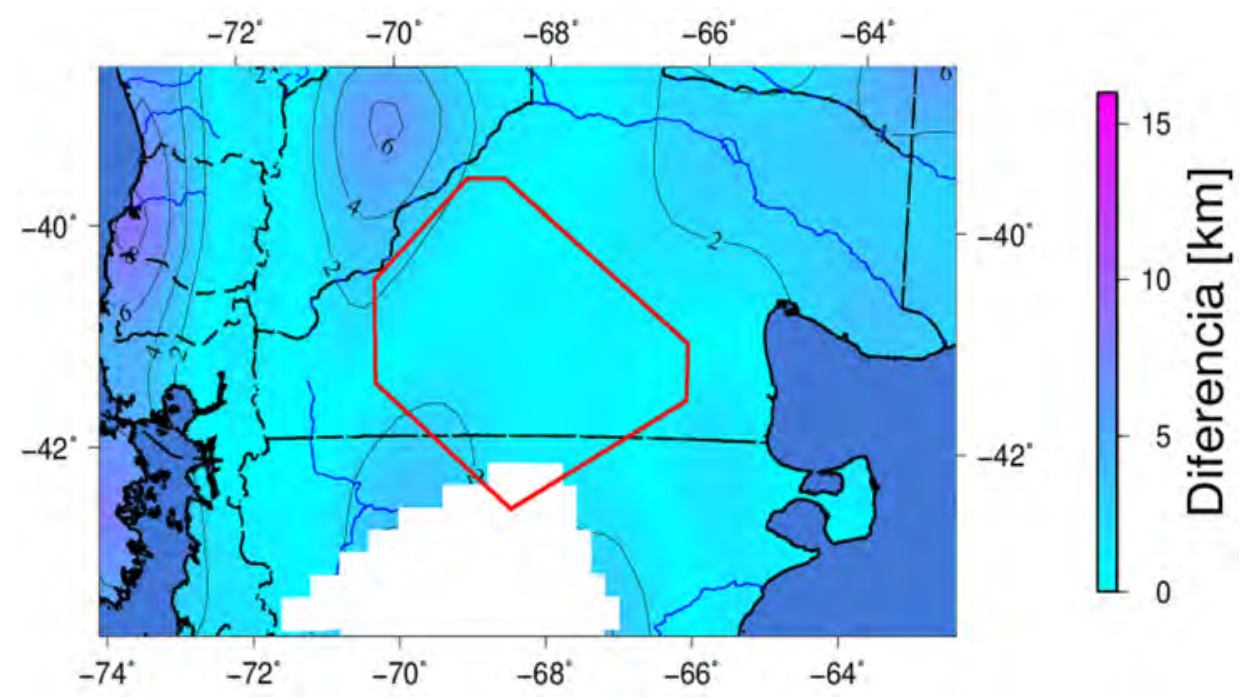

Figura 3.9. Diferencia entre Modelo GEMMA y Modelo C

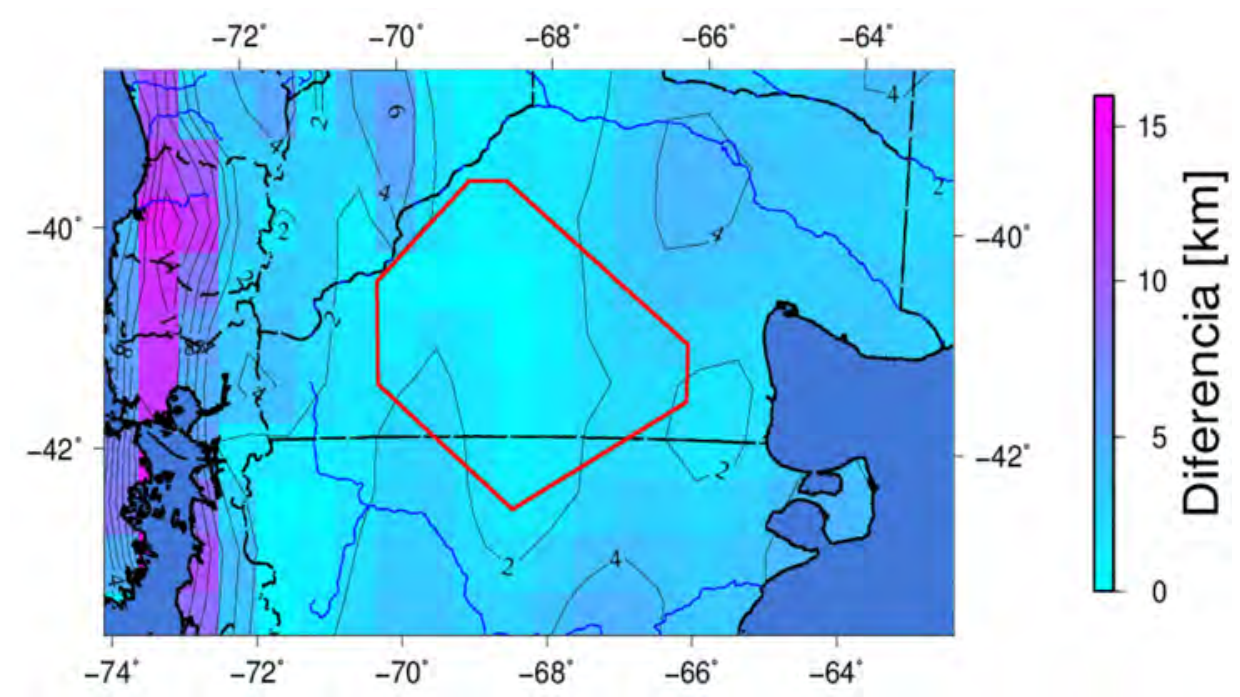

Figura 3.10. Diferencia entre Modelo GEMMA y Modelo D 


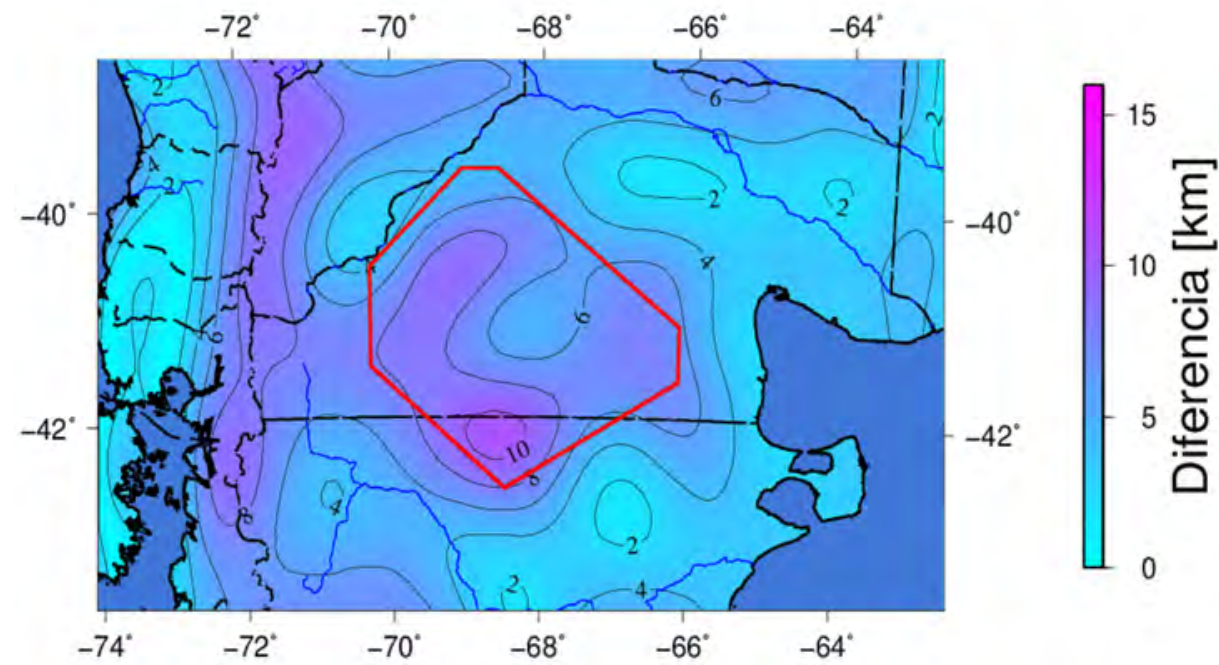

Figura 3.11. Diferencia entre Modelo GEMMA y Modelo E

puede observarse en la figura 3.12. Cruzando el MNP de oeste a este (de A hasta A'), la profundidad de Moho varía más de $20 \mathrm{~km}$ para los distintos modelos, desde una profundidad relativamente somera (cerca de los $25 \mathrm{~km}$ ), profundizándose hasta llegar a los $40 \mathrm{~km}$ entre las latitudes $72^{\circ}$ y $66^{\circ}$ oeste y decreciendo nuevamente hasta alrededor de los $35 \mathrm{~km}$ de profundidad en el este.

En general, se pueden observar las siguientes características en las comparaciones:

- El Modelo A difiere significativamente del GEMMA con un desvío estándar de $4.53 \mathrm{~km}$ (Figura 3.7, tabla 3.2). Sin embargo, más importante es la diferencia entre el modelo mencionado (Modelo A) y todos los otros modelos. La diferencia puede ser observada en la figura 3.12. Esto indica que el modelo no es confiable en esta área. Las diferencias entre el Modelo A y los otros modelos de Moho pueden ser causadas por la poca resolución del Modelo A y los pocos datos en los que está basado para interpolar el Moho en el área de estudio.

- La figura 3.8 muestra que el Modelo B difiere del modelo GEMMA esencialmente en la altiplanicie del MNP y en su límite oeste pero es similar en las demás áreas circundantes. La figura 3.12 muestra que el Modelo B es considerablemente más profundo (en casi todos los puntos del perfil) que los otros modelos, excepto que el Modelo E. Los modelos A y $\mathrm{B}$ son los únicos realizados completamente con datos sísmicos, sin embargo no es razonable considerar el Modelo A debido a su baja resolución. Estos modelos demuestran 


\section{Comparación entre modelos de Moho a $41^{\circ} \mathrm{S}$}

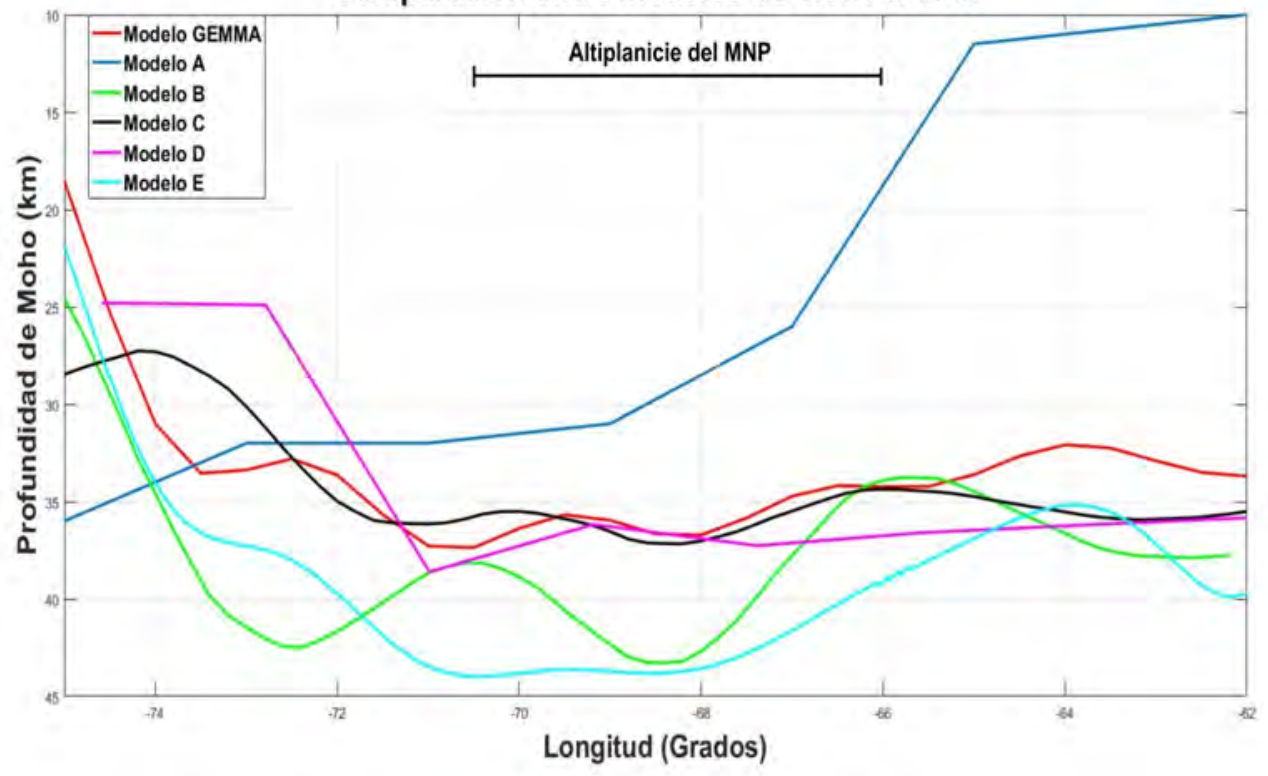

Figura 3.12. Comparación de modelos de Moho en un perfil que cruza la altiplanicie a los $41^{\circ} \mathrm{S}$ de latitud

la falta de datos de origen sismológico en el área y su influencia en los modelos puramente realizados con datos provenientes de estas técnicas.

- La figura 3.9 muestra una situación opuesta a la mencionada en el punto anterior. El Modelo C pareciera ser más similar al GEMMA en el área de la altiplanicie y distinto en los alrededores. El Modelo $\mathrm{C}$ es el que presenta la mejor coincidencia con el modelo GEMMA de los modelos analizados (Figura 3.12). Esta información es relevante considerando que este modelo es el que incluye la base de datos más grande entre los modelos elegidos. Sin embargo, no tiene ninguna estimación de profundidad de Moho dentro de la altiplanicie. La similitud entre el modelo C y el GEMMA en el área de estudio puede estar causada por el hecho de tener más puntos de determinación sísmica de la profundidad del Moho y por haber sido interpolados con tomografía de onda superficial y complementado con el modelo cortical, basado en gravedad, de Tassara y Echaurren (2012). Las diferencias entre GEMMA y los modelos B y C muestran un desvío estándar similar de 3.07 y 3.08 km, respectivamente (Tabla 3.2).

- El Modelo D tiene valores similares a aquellos del Modelo GEMMA en el área de la altiplanicie del MNP (Figura 3.10). Esto también puede ser observado en la Figura 3.12. Sin embargo, la diferencia entre este modelo y el GEMMA muestra el más grande 
Tabla 3.2. Desvíos estándar de las diferencias entre modelos regionales y locales y el modelo GEMMA

\begin{tabular}{|l|l|}
\hline $\begin{array}{l}\text { Comparación en- } \\
\text { tre modelos }\end{array}$ & $\begin{array}{l}\text { Desvío estándar } \\
{[\mathrm{km}]}\end{array}$ \\
\hline Modelo A - GEMMA & 4.53 \\
\hline Modelo B - GEMMA & 3.07 \\
\hline Modelo C - GEMMA & 3.08 \\
\hline Modelo D - GEMMA & 6.94 \\
\hline Modelo E - GEMMA & 2.56 \\
\hline
\end{tabular}

desvío estándar de $\pm 6.94 \mathrm{~km}$ como puede observarse en la tabla 3.2 .

- El Modelo E presenta grandes diferencias con el GEMMA, especialmente en la altiplanicie del NPM como se muestra en la figura 3.11. Esta diferencia podría estar causada por la selección de los parámetros de inversión. Los valores del Modelo E son más similares a los del Modelo B (Figura 3.12).

La mayoría de los modelos muestran una profundidad de Moho entre 36 y $38 \mathrm{~km}$ (Modelos GEMMA, A, C y D) evidenciando una buena correlación con el Modelo GEMMA para el área de estudio. El Modelo A tiene poca resolución y se basa en pocos datos en el área de interés, por lo tanto no resulta confiable para dicha área. La influencia de la gravedad puede ser observada en la concordancia entre los modelos C, D y GEMMA. Los modelos B y E muestran una profundidad de Moho que alcanza los $46 \mathrm{~km}$. Esto podría estar causado por las distintas fuentes de datos utilizados (sólo sísmicos) en el Modelo B y por el contraste de densidades más realista de $340 \mathrm{~kg} / \mathrm{m}^{3}$ y la profundidad de referencia de $36 \mathrm{~km}$ seleccionada para la inversión en el Modelo E. El Modelo C, que fue desarrollado utilizando la base de datos más amplia hasta el momento, muestra la mejor correlación con el Modelo GEMMA de todos los modelos analizados. Todos los modelos tienen discrepancias hacia el oeste donde el límite del continente y la subducción tienen lugar.

Se puede decir que el modelo derivado de datos de GOCE (Modelo GEMMA) es una contribución importante por su buen acuerdo con algunos de los modelos regionales en el área del MNP. Además, considerando su coincidencia con los modelos más actualizados para Sudamérica (Modelos C y D), al menos en el área de estudio, y su buena resolución, su 
homogeneidad y buena distribución, se justifica su utilización en otras áreas con pocos datos. Sin embargo, debería ser mejorado mediante la incorporación de modelos de densidad más realistas para la zona y de datos sísmicos.

Los modelos corticales son útiles para los estudios de isostasia, topografía dinámica y la comprensión de procesos geodinámicos a distintas escalas espacio-temporales. Ya que el estudio de comparación se realizó en una zona sin evidencias de deformación cenozoica, no se esperaba encontrar variaciones importantes en la forma o profundidad del Moho en términos de isostasia. Sin embargo, la mayoría de los modelos de Moho muestran una corteza engrosada debajo de la altiplanicie, lo que indica que podríamos encontrarnos con un escenario geodinámico más complejo del esperado. Este estudio sugiere que la superficie del Moho debe ser estudiada con más detalle, lo que se describirá en los próximos capítulos. También indica que este estudio puede ser beneficioso para comprender mejor la historia del levantamiento de la altiplanicie en el Paleógeno.

\subsection{Análisis de densidades con xenolitos}

En el área de estudio y sus alrededores inmediatos hay cinco localidades con basaltos que extrajeron $^{1}$ xenolitos ultramáficos del manto superior (Figura 3.13). Para obtener densidades del manto se estudiaron datos de análisis modal (abundancia relativa de los minerales que constituyen el xenolito) y composición química de cada una de las fases minerales, de más de 50 xenolitos publicados por Ponce (2016) y Mundl et al. (2015). Los xenolitos descriptos por Ponce et al. (2015) y Ponce (2016) se encuentran en basaltos del Eoceno (54 Ma) en el área de Paso de los Indios (localidad V, Figura 3.13) y los xenolitos investigados por Mundl et al. (2015) en basaltos alcalinos miocenos (23 Ma) a pleistocenos (1.3 $\mathrm{Ma}$ ), en cuatro localidades dentro de la altiplanicie del MNP (Cerro Chenque, Puesto Díaz, Comallo y Prahuaniyeu; localidades I, II, III y IV respectivamente en la figura 3.13). Ponce (2016) realizó un análisis modal de los xenolitos utilizando el método de conteo de puntos en imágenes escaneadas de secciones delgadas. También determinó la composición química de los elementos mayoritarios: olivina, clinopiroxeno, ortopiroxeno y espinela utilizando microsonda electrónica. Mundl et al. (2015) también realizaron análisis modal de los xenolitos pero usando balance de masas de roca completa y composición mineral para algunas muestras y conteo de puntos para otras. También realizaron análisis de elementos mayoritarios utilizando

\footnotetext{
${ }^{1}$ Extracción: el basalto arranca la roca aledaña y la arrastra hacia la superficie
} 


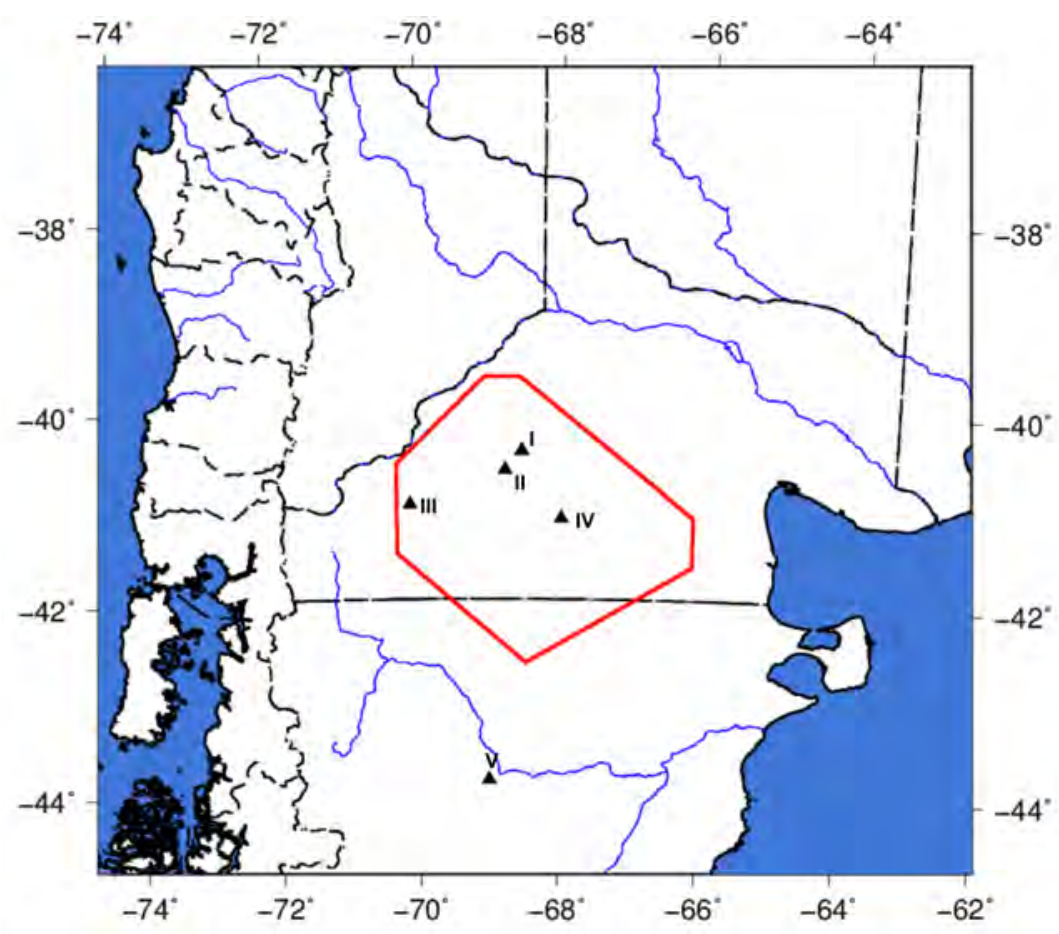

Figura 3.13. Ubicación de las localidades donde se encontraron xenolitos (indicadas con triángulos negros). I: Cerro Chenque, II: Puesto Diaz, III: Comallo, IV: Pahuaniyeu, V: Paso de Indios.

microsonda electrónica (Mundl et al., 2015). Los xenolitos de la localidad V son peridotitas con espinela, piroxenitas, hazburguitas y lherzolitas (Ponce et al., 2015). En las localidades I, II y III, los xenolitos son en su mayoria hazburguitas con espinela y las muestras de la localidad IV son espinelas y peridotitas con granate (Mundl et al., 2015). En la tabla 3.3 se muestra un resumen de la información acerca de los xenolitos.

El objetivo de determinar la densidad de esta numerosa serie de datos es obtener una visión estadística del rango de densidades y su distribución para las distintas localidades. De este modo se observaron las variaciones en composición en el manto y se determinó cuán homogéneo es el mismo en área de estudio .

La densidad de las muestras ha sido determinada utilizando los datos del análisis modal (abundancia relativa entre los minerales presentes) y de composición mineral de elementos mayoritarios y considerando que cada muestra está compuesta por cuatro minerales: olivina, clinopiroxeno, ortopiroxeno y espinela, ya que estos son los minerales principales de cada muestra (se despreciaron los porcentajes pequeños de elementos minoritarios). Estos minerales han sido analizados con microsonda electrónica y se especifican los porcentajes de minerales con composición extrema para cada uno en cada muestra: Forsterita (Fo) y Fayalita (Fa) 
Tabla 3.3. Descripción de los xenolitos del área de estudio

\begin{tabular}{|c|c|c|c|c|c|}
\hline Localidad & Nombre & Edad & Composición & Método & Referencia \\
\hline $\mathbf{I}$ & $\begin{array}{l}\text { Cerro } \\
\text { Chenque }\end{array}$ & $\begin{array}{l}\text { Mioceno }(23 \\
\text { Ma) }\end{array}$ & $\begin{array}{l}\text { Hazburguita } \\
\text { con espinela }\end{array}$ & $\begin{array}{l}\text { Análisis modal por } \\
\text { conteo de puntos }+ \\
\text { Elementos mayori- } \\
\text { tarios por micro- } \\
\text { sonda electrónica }\end{array}$ & $\begin{array}{l}\text { Mundl et } \\
\text { al. (2015) }\end{array}$ \\
\hline II & $\begin{array}{l}\text { Puesto } \\
\text { Diaz }\end{array}$ & $\begin{array}{l}\text { Mioceno }(23 \\
\text { Ma) }\end{array}$ & $\begin{array}{l}\text { Hazburguita } \\
\text { con espinela }\end{array}$ & $\begin{array}{l}\text { Análisis modal por } \\
\text { conteo de puntos }+ \\
\text { Elementos mayori- } \\
\text { tarios por micro- } \\
\text { sonda electrónica }\end{array}$ & $\begin{array}{l}\text { Mundl et } \\
\text { al. (2015) }\end{array}$ \\
\hline III & Comallo & $\begin{array}{l}\text { Pleistoceno } \\
(1.3 \mathrm{Ma})\end{array}$ & $\begin{array}{l}\text { Hazburguita } \\
\text { con espinela }\end{array}$ & $\begin{array}{l}\text { Análisis modal por } \\
\text { conteo de puntos }+ \\
\text { Elementos mayori- } \\
\text { tarios por micro- } \\
\text { sonda electrónica }\end{array}$ & $\begin{array}{l}\text { Mundl et } \\
\text { al. (2015) }\end{array}$ \\
\hline IV & Prahuaniyeu & $\begin{array}{l}\text { Mioceno }(23 \\
\text { Ma), según } \\
\text { Mundl et al. } \\
(2015) ; \quad 3.5 \\
\text { Ma según } \\
\text { Bertotto, } \\
\text { comunicación } \\
\text { personal }\end{array}$ & $\begin{array}{l}\text { Peridotitas con } \\
\text { granate o espi- } \\
\text { nela }\end{array}$ & $\begin{array}{l}\text { Análisis modal por } \\
\text { conteo de puntos }+ \\
\text { Elementos mayori- } \\
\text { tarios por micro- } \\
\text { sonda electrónica }\end{array}$ & $\begin{array}{l}\text { Mundl et } \\
\text { al. (2015) }\end{array}$ \\
\hline V & $\begin{array}{l}\text { Paso de los } \\
\text { Indios }\end{array}$ & $\begin{array}{l}\text { Eoceno } \\
\mathrm{Ma})\end{array}$ & $\begin{array}{l}\text { Peridotitas, } \\
\text { piroxenitas, } \\
\text { hazburguitas y } \\
\text { lherzolitas }\end{array}$ & $\begin{array}{l}\text { Análisis modal por } \\
\text { balance de masas } \\
\text { y conteo de puntos } \\
+ \text { Elementos ma- } \\
\text { yoritarios por mi- } \\
\text { crosonda electróni- } \\
\text { ca }\end{array}$ & $\begin{array}{l}\text { Ponce et } \\
\text { al. (2015); } \\
\text { Ponce } \\
(2016)\end{array}$ \\
\hline
\end{tabular}


en las olivinas, Enstatita (En), Wollastonita (Wo) y Ferrosilita (Fs) en los clinopiroxenos y ortopiroxenos y los elementos mayoritarios en las espinelas. Utilizando los valores de densidad típicos de los minerales extremos $\left(\rho_{i}\right)$, se obtuvo la densidad de la olivina, clinopiroxeno y ortopiroxeno de cada muestra $\left(\rho_{m}\right)$ :

$$
\rho_{m}=\sum \rho_{i} f_{i}
$$

en donde $f_{i}$ es la fracción volumétrica de cada mineral extremo (Fo, Fa, En, Wo, Fs) y, por lo tanto, $\sum f_{i}=1$.

Para calcular la densidad de la espinela se siguió un procedimiento diferente ya que las fracciones volumétricas de minerales extremos no estaban disponibles. Se obtuvo la fórmula estructural utilizando los datos de microsonda electrónica y con ella, se derivaron los porcentajes de magnetita, hercinita y cromita de cada muestra ( $f_{i}$ de los minerales extremos de la espinela). Luego, se utilizó la ecuación 3.1 con valores adecuados de densidad para los minerales extremos. Luego de haber obtenido las densidades de los cuatro minerales principales para cada muestra, se obtuvo la densidad de toda la roca mediante un promedio pesado de las densidades de sus minerales utilizando el análisis modal (abundancia relativa entre los minerales).

La figura 3.14 muestra histogramas con las densidades de los xenolitos del manto obtenidas para las cuatro localidades dentro de la altiplanicie del MNP (Figura 3.14(a)) y para la localidad V al sur de la altiplanicie (Figura 3.14(b)). También podemos observar en la figura 3.14(c) un histograma con todas las densidades obtenidas dentro de la altiplanicie. Para representar la densidad "promedio" en cada lugar, hemos elegido la moda ya que tiene en cuenta la forma de la distribución del histograma y por lo tanto, es la más representativa. Si nos concentramos en los histogramas de las figuras 3.14(b) y 3.14(c) (representativos de densidades del manto fuera y dentro del MNP respectivamente), podemos observar que ambos tienen asimetría y bimodalidad pero con distintas características. En los xenolitos de fuera de la altiplanicie (figura 3.14(b)) no hay brecha entre las dos modas de densidad, en cambio en los xenolitos de dentro de la altiplanicie del MNP hay una brecha importante de $100 \mathrm{~kg} / \mathrm{m}^{3}$ entre las dos modas de densidad. Además, el primero (Figura 3.14(b)) tiene más dispersión de valores de densidad que el segundo (Figura 3.14(c)) y las distribuciones alrededor de las modas mayores tienen un sesgo opuesto en ambos casos (Figuras 3.14(b) y 3.14(c)). El histograma de la figura 3.14(b) está sesgado a la derecha, incrementando sus frecuencias desde 3360 hacia $3340 \mathrm{~kg} / \mathrm{m}^{3}$ donde se encuentra la moda mayor; en cambio el histograma de la figura 3.14(c) 
está sesgado a izquierda, incrementando sus frecuencias desde 3330 hacia $3350 \mathrm{~kg} / \mathrm{m}^{3}$ donde ocurre la mayor moda. Los histogramas de las localidades que se encuentran al norte de la altiplanicie (localidades I y II; Figuras 3.13) preservan las características del histograma que contiene todas las muestras de la altiplanicie (Figuras 3.14(a) y 3.14(c)). En contraste, los histogramas de las localidades III y IV (Figura 3.14(c)) tienen diferentes características: son unimodales (no tienen la moda de alta densidad) y con sesgo opuesto. Prahuaniyeu es la localidad con moda de densidad más baja.

La figura 3.14 indica que existiría heterogeneidad en el manto en el área de estudio. Mediante el análisis realizado se pueden observar diferencias en el manto entre distintos sectores del área de estudio, especialmente entre los comportamientos de los histogramas de densidades dentro y fuera de la altiplanicie (Figura 3.14). Estas diferencias se ven en la brecha entre las modas y en el sesgo de la moda principal pero no en los valores de la densidad. Dentro de la altiplanicie se puede observar una diferencia entre las localidades ubicadas más al norte (I y II; Figura 3.13) con respecto a las restantes (III y IV; Figura 3.13), las primeras tienen algunas muestras con densidades altas, mientras que las últimas conservan sólo la moda de bajas densidades. Los xenolitos de las localidades que tienen una moda de alta densidad, con una gran brecha con la otra moda, son antiguos de aproximadamente $23 \mathrm{Ma}$, en cambio la localidad III, que sólo presenta densidades bajas, tiene xenolitos más jóvenes (con edades en el orden de 4 a $1 \mathrm{Ma}$ ) . Los xenolitos de la localidad IV, según Mundl et al. (2015) son tan antiguos como los primeros mencionados (localidades I y II), sin embargo, hay dataciones más recientes en la misma localidad que hablan de edades mucho más recientes (aproximadamente 3.5 Ma; Bertotto, W., comunicación personal). Según estas dataciones, en las localidades con emplazamientos de xenolitos más recientes, las densidades tienen sólo la moda de densidades bajas.

No es posible utilizar las densidades descriptas en este capítulo como representativas del manto en un modelo de densidad, ya que son densidades calculadas para condiciones ambiente y no para las presiones y temperaturas que mediríamos en el manto. El cálculo de las densidades del manto en estas condiciones se explica en el capítulo 4 con el fin de formar parte del modelado gravimétrico. Sin embargo, los resultados encontrados en este capítulo son importantes ya que indican que sería significativo incorporar al modelo una variación espacial de la densidad en el manto, ya que esta podría tener influencia en el resultado final del mismo. Esto es tenido en cuenta en la confección del modelo gravimétrico tridimensional litosférico explicado en el capítulo 4. 

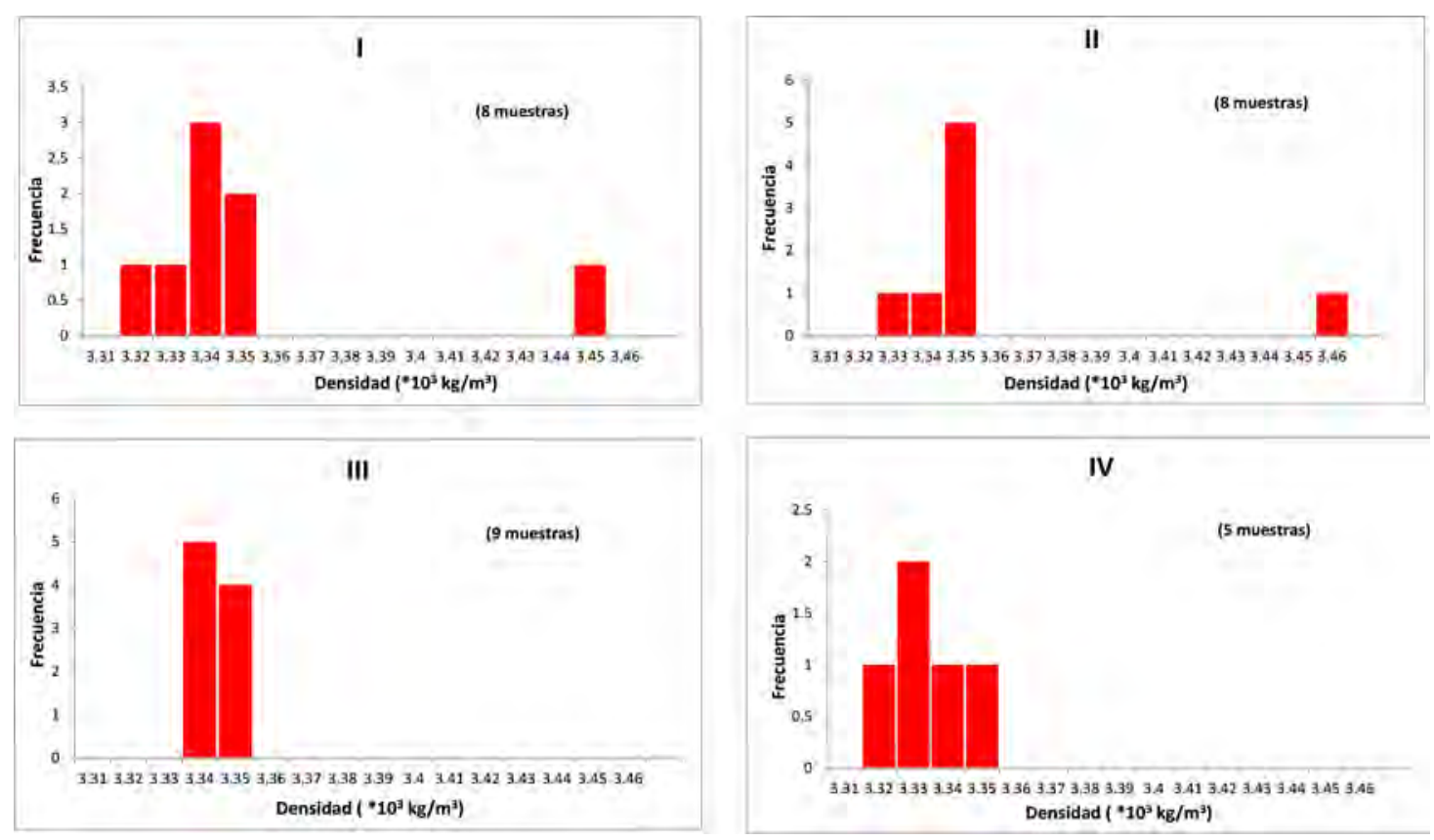

(a)

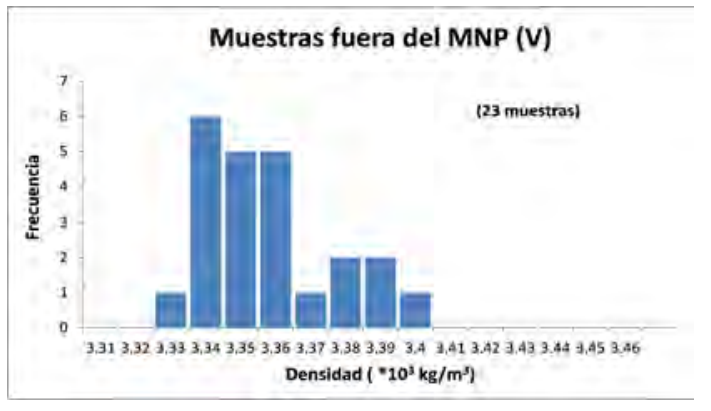

(b)

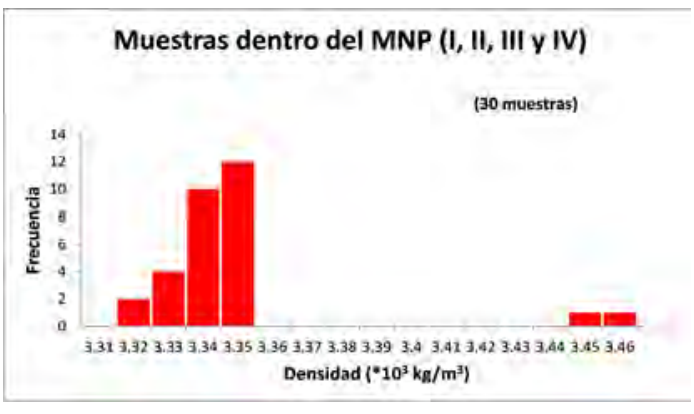

(c)

Figura 3.14. Histogramas de densidades obtenidas a partir de datos de análisis modal de xenolitos del manto (Ponce, 2016; Mundl et al., 2015). a) Densidades de xenolitos de la altiplanicie del MNP discriminadas por localidad (Localidades I, II, III y IV; Figura 3.13 Mundl et al. 2015). b) Densidades de xenolitos de Paso de los Indios (localidad V; Figura 3.13; Ponce 2016). c) Densidades de xenolitos de la altiplanicie del MNP (Mundl et al., 2015). 


\section{Capítulo 4}

\section{Modelado gravimétrico}

\section{tridimensional}

\subsection{Metodología}

\subsubsection{Fundamentos}

Los métodos gravimétricos involucran mediciones de la variación del campo de gravedad terrestre. Mediante estas mediciones se desea encontrar zonas de mayor o menor densidad con el objetivo de obtener nueva información sobre el área estudiada, a partir de las variaciones encontradas en el campo medido. Sin embargo, no es posible determinar una única fuente para la gravedad observada, lo cual constituye un problema denominado ambigüedad del método gravimétrico. Este método es de fuente natural, ya que las variaciones en la densidad de las rocas del subsuelo son las que generan los cambios en el campo de gravedad (Telford et al., 1990).

A las lecturas de gravedad hay que hacerles correcciones para reducirlas a los valores que se habrían obtenido en una superficie equipotencial, como por ejemplo, en el geoide (Telford et al., 1990) y a partir de esos valores corregidos, se calculan las anomalías de gravedad. En este trabajo se utilizan anomalías de Bouguer que son las que usualmente se emplean en los trabajos de modelado gravimétrico en zonas continentales. Una anomalía surge a causa de una distribución inhomogénea de la densidad, es decir, su presencia indica que hay un cuerpo o estructura con densidad anómala. La apariencia de una anomalía de gravedad se ve afectada por las dimensiones, contraste de densidad y profundidad del cuerpo anómalo (Lowrie, 2007). Como los mapas de anomalías de Bouguer muestran sólo diferencias laterales 
en la aceleración de la gravedad, entonces sólo los cambios de densidad laterales producen cambios en las anomalías.

Después de corregir las observaciones de gravedad debemos interpretar los datos obtenidos. El problema de la interpretación consiste en encontrar la distribución de masas responsable de la generación de esa anomalía. Muchas veces esto es realizado mediante modelado iterativo, es decir, se modela una distribución de masas y se calculan las anomalías que genera, luego se determinan las diferencias con las anomalías observadas y el modelo se cambia en consecuencia. Este proceso se repite hasta que las anomalías observadas y calculadas estén lo suficientemente cercanas. En general, se suele limitar el número de iteraciones incluyendo datos independientes a modo de restricción o como parte de un modelo inicial. Esto además ayuda a disminuir las ambigüedades del método (Telford et al., 1990).

En esta tesis se realizan modelos gravimétricos tridimensionales del área de estudio (el Macizo Norpatagónico y sus alrededores). Para la realización de este tipo de modelos es necesario, como primer paso, la definición de un modelo inicial que contenga las principales unidades geológicas y su distribución de densidades y en el cual se incluya toda la información independiente disponible para el área. Luego, se calcula la respuesta gravimétrica que este modelo genera y se compara con la gravedad medida. A continuación, se modifican los parámetros libres del modelo inicial (es decir, los que no han sido fijados por información independiente) hasta que la gravedad generada por el modelo ajuste la gravedad medida. El modelo resultante, que ajusta a la vez a la gravedad y a toda la información de restricción, es considerado un modelo representativo de la realidad.

\subsubsection{Aplicación}

Para realizar el modelado de gravedad se utilizó el programa IGMAS+ (Interactive Geophysical Modelling ASsistant; Götze y Schmidt (2010)) que es un programa de modelado gravimétrico y magnético tridimensional interactivo. Las interfaces entre los distintos cuerpos del modelo son definidas a través de un número de perfiles verticales, a los que denominaremos perfiles de trabajo. Luego, el programa realiza una triangulación entre los distintos perfiles generando así poliedros que constituyen los cuerpos tridimensionales del modelo y los que representan las distintas litologías de la zona. A cada uno de estos cuerpos se le asigna una densidad constante la cual puede ser modificada introduciendo su variación en el espacio mediante una herramienta del programa denominada voxelización (Alvers et al., 2014; Gómez Dacal et al., 2017; Mira et al., 2013). 
El programa calcula el efecto de gravedad generado por el modelo introducido mediante un algoritmo desarrollado por Götze (1978, 1984); Götze y Lahmeyer (1988) y Schmidt y Götze (1998). El mencionado algoritmo se basa en el concepto de que todos los cuerpos tridimensionales con densidad constante pueden ser aproximados por poliedros con cualquier precisión deseada.

La componente vertical de la atracción gravitacional (que es la componente de interés por ser la medida por los gravímetros) de un cuerpo, en un punto $P$ del espacio puede ser calculada a partir de su potencial $U$, también en el punto $P$, cuya expresión es:

$$
U(P)=G \iiint_{v o l} \frac{1}{R} d m
$$

siendo $R$ la distancia del punto $P$ al elemento de masa $d m=\rho d x d y d z, \rho$ la densidad del elemento de masa y $G$ la constante de gravitación universal (Barrio, 1993). Teniendo esta expresión, derivamos el potencial en la dirección $z$ (suponiendo $z$ como la dirección de la vertical) para obtener la mencionada atracción gravitatoria en esa dirección:

$$
g_{z}(P)=\frac{\partial U(P)}{\partial z}=G \rho \iiint_{v o l} \frac{\partial}{\partial z} \frac{1}{R} d v .
$$

Podemos convertir la integral de volumen de la ecuación 4.2 en una de superficie utilizando el teorema de Gauss:

$$
g_{z}(P)=G \rho \iint_{S} \cos (n, z) \frac{1}{R} d S,
$$

en la cual la superficie S, donde se calcula la integral es la superficie del poliedro y el término $\cos (n, z)$ representa la dirección del elemento de superficie $d S$ respecto del sistema de coordenadas cartesianas (Barrio, 1993). Como para cada superficie del poliedro $S_{j}(\mathrm{j}=1,2, \ldots \mathrm{m}$, con m número de superficies) se da que $\cos \left(n_{j}, z\right)$ es constante, entonces se puede expresar la componente vertical de la gravedad como la suma de los efectos gravitacionales de las distintas superficies que lo componen:

$$
g_{z}(P)=G \rho \sum_{j=1}^{m}\left[\cos \left(n_{j}, z\right) \iint_{S_{j}} \frac{1}{R} d S_{j}\right] .
$$

Mediante la aplicación del álgebra se resuelve esta ecuación (4.4) y así se expresa la atracción gravitacional ejercida por un poliedro sobre un punto P, en función de las distancias geométricas de las distintas partes del cuerpo al punto de observación, vectores normales a las superficies que componen el cuerpo y la densidad del mismo. La expresión final es simple 
a la hora de su programación (Barrio, 1993). Con el fin de obtener anomalías de gravedad, IGMAS+ compara la gravedad generada por el modelo con un modelo de referencia que debe ser definido por el usuario (Gómez Dacal, 2012).

El usuario debe definir un modelo inicial con un número de cuerpos y sus densidades, luego el programa calcula las anomalías de gravedad generadas por este modelo y permite la comparación con las anomalías medidas en el área. IGMAS+ admite la variación de la geometría y las densidades del modelo interactivamente, con el fin de ajustar la gravedad calculada a la medida. Este ajuste es posible mediante la modificación de las discontinuidades entre los cuerpos en las secciones de trabajo y las densidades definidas previamente.

Para evitar el efecto de borde, el área del modelo 3D se extiende una gran distancia más allá de los límites reales del modelo. Además, para disminuir la ambigüedad del método, el programa admite la inclusión de datos independientes para restringir el modelo y así hacerlo más similar a la realidad (Gómez Dacal et al., 2017).

En esta tesis se realizaron dos modelos tridimensionales de densidad. El primero es un modelo preliminar a escala cortical y el segundo es a escala litosférica integrando todos los datos disponibles en el área. En la figura 4.1 se detalla el flujo de trabajo seguido en la confección de los modelos gravimétricos.

\subsection{Modelado preliminar: escala cortical}

Como primer paso se realizó un modelo a escala cortical. Este tiene $50 \mathrm{~km}$ de profundidad y está compuesto por 10 secciones orientadas en dirección norte-sur para poder apreciar el contraste entre la altiplanicie del MNP y la cuenca Neuquina. El área modelada tiene una extensión de $600 \mathrm{~km}$ en longitud y $820 \mathrm{~km}$ en latitud e incluye la altiplanicie y sus alrededores. Las secciones de trabajo están separadas $60 \mathrm{~km}$ entre sí y el modelo fue extendido $1000 \mathrm{~km}$ a cada lado para evitar efectos de borde.

Se utilizaron anomalías de Bouguer del modelo geopotencial EGM2008 (Earth Gravitational Model, Pavlis et al. 2012, Barthelmes 2009). El EGM2008 fue creado por la U.S. National Geospatial-Intelligence Agency (NGA) y está completo hasta el armónico esférico de grado y orden 2159. Sus coeficientes están disponibles públicamente en forma completa. El modelo geopotencial tiene una resolución de $5^{\prime} x 5^{\prime}$, por lo tanto sus anomalías son suficientes para estudios a escala regional como los realizados en esta tesis. La Figura 4.2(b) deja ver que hay anomalías de Bouguer negativas dentro de la altiplanicie del MNP. Todas ellas tienen 


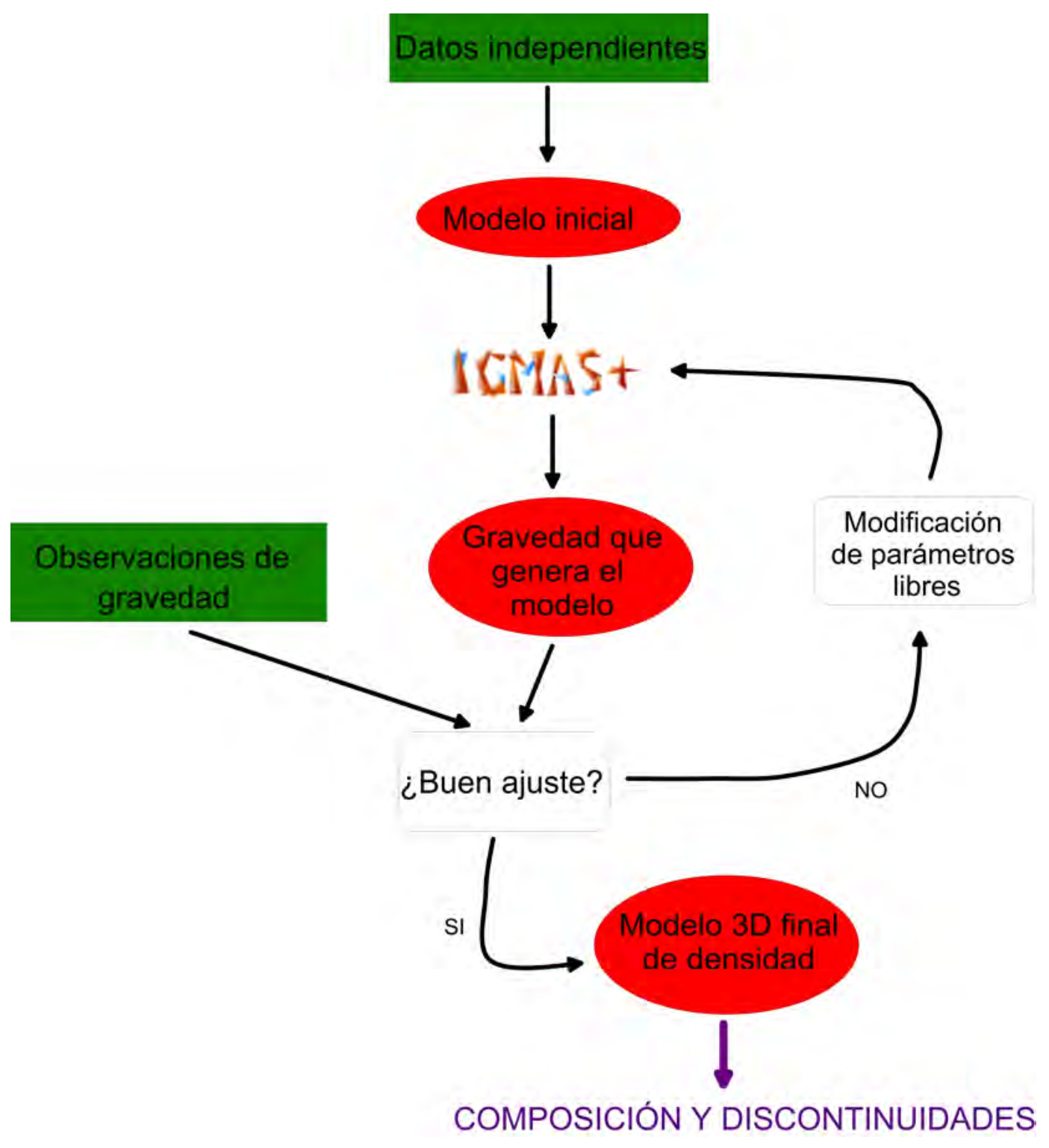

Figura 4.1. Diagrama de flujo de los modelos gravimétricos 
valores menores a los $-60 m G a l$ llegando a un mínimo de $-100 m$ Gal en el sector sudoeste de la altiplanicie. Estos valores son similares a los encontrados en los Andes, donde hay raíces corticales (Lowrie, 2007). En las cuencas que rodean al MNP se observan valores más altos aumentando hacia el este desde los Andes hasta las topografías más bajas (Figura 4.2(b)). Se ve claramente una correlación entre las anomalías de Bouguer (Figura 4.2(b)) y la topografía en el área (Figura 1.1): donde hay topografía alta también podemos observar anomalías negativas, observándose este fenómeno tanto en los Andes como en la altiplanicie del MNP. Lo contrario (es decir, anomalías de Bouguer positivas en áreas de relieve bajo) puede ser observado al este de la región modelada donde se ubica el margen pasivo del Atlántico y también al norte y sur de la altiplanicie (Figuras 1.1 y $4.2(\mathrm{~b})$ )

\subsubsection{Modelo inicial}

El modelo inicial está compuesto por cuatro cuerpos: sedimentos, corteza superior, corteza inferior y manto litosférico (Figura 4.2(a)), separados por discontinuidades llamadas Fondosed, ICD (de Intra Crustal Discontinuity) y Moho. Para restringir la profundidad de dichas discontinuidades, se utilizaron distintas fuentes de información.

Fondo-sed se obtuvo mediante la digitalización de la sección Mobil isopaches del Atlas ICONS (Heine, 2007), que es una compilación de datos de espesor sedimentario para cuencas sedimentarias intra-continentales de todo el mundo. El espesor sedimentario en la altiplanicie es, según el modelo, casi en su totalidad menor a $200 \mathrm{~m}$, como puede observarse en la figura 4.2(c). También se ve, en la misma figura, que la cuenca Neuquina es la única zona con un volumen significativo de sedimentos.

Para definir el ICD se utilizó el modelo CRUST 1.0 (Laske et al., 2013), que es una actualización del modelo CRUST 2.0 (Bassin et al., 2000) pero para una resolución de $1^{\text {o }}$ $x 1^{\mathrm{o}}$, es decir, es un modelo realizado a escala global que integra datos principalmente de origen sísmico. En la figura 4.2(d) se puede ver que no hay mucho cambio de profundidad en la discontinuidad ICD en la altiplanicie y sus alrededores (entre 10 y $16 \mathrm{~km}$ ). En la zona de la altiplanicie la profundidad de la discontinuidad es entre 12 y $13 \mathrm{~km}$.

Teniendo en cuenta las diferencias encontradas entre los distintos modelos de Moho en el área de estudio y la necesidad de estudiar esta superficie en mayor profundidad (tal cómo se sugiere en el capítulo 3), se decidió calcular la geometría del Moho (Figura 4.2(e)) suponiendo balance isostático y validarla mediante datos independientes. Esto se realizó con el fin de verificar, mediante el modelado de gravedad, si la hipótesis asumida era correcta o no, es 
decir, analizar si el área de estudio se encuentra en balance isostático. Para esto se asumió que el área está balanceada isostáticamente siguiendo la hipótesis de Airy (explicada en el capítulo 2). Siguiendo esta hipótesis, es necesario establecer un modelo de referencia e igualar el peso del mencionado modelo en la profundidad de compensación con el que genera cada punto del área de estudio a la misma profundidad. Por último, respetando las densidades impuestas en el modelo de referencia, se calcula en cada punto la incógnita, es decir, la profundidad del Moho.

Para seleccionar las densidades de los sedimentos y de la corteza superior, se utilizó material bibliográfico de estudios específicos en el área (Castro et al., 2011; Lince Klinger, 2010; Kostadinoff y Schillizi, 1996; Kostadinoff y Gelós, 1994; Sigismondi, 2012) y para la corteza inferior y el manto litosférico se utilizaron muestras de mano de xenolitos hallados al sur de la altiplanicie (Localidad V; Figura 3.13). Las densidades de las muestras fueron medidas en el laboratorio utilizando un picnómetro y se eligió el valor de aquella que tenía menor efecto de transformación simplectitica. Finalmente, el modelo de referencia del cálculo isostático quedó compuesto por una densidad del manto de $3300 \mathrm{~kg} / \mathrm{m}^{3}$ y de la corteza de $2900 \mathrm{~kg} / \mathrm{m}^{3}$. La profundidad de Moho utilizada fue de $35 \mathrm{~km}$, calculado como el promedio de los modelos de Moho comparados en el capítulo 3 para zonas fuera de la altiplanicie del MNP, donde presentaban coincidencias entre sí.

El software utilizado para hacer los cálculos fue el GMS (Bayer et al., 1997) que es un paquete de programas desarrollado en el GFZ para realizar modelos estructurales, isostáticos y térmicos. Se calcularon las cargas sobre la profundidad de compensación, lo que permitió realizar una determinación del Moho multi-1D.

Por último, se comparó el modelo obtenido (Figura 4.2(e)) con datos independientes con el fin de validar la superficie obtenida. Los datos utilizados para restringir la superficie del Moho y validarla fueron extraídos de la base de datos compilada por Assumpção et al. (2013) (Assumpcao, comunicación personal). Estos datos fueron obtenidos mediante experimentos sísmicos tales como funciones receptoras y perfiles sísmicos de refracción. En la figura 4.2(e) se pueden ver los puntos donde hay datos de profundidad de Moho. Existe una buena correlación entre el Moho isostático y los datos independientes, siendo en todos los casos la diferencia menor a $5 \mathrm{~km}$, teniendo una media de $1.7 \mathrm{~km}$ y un desvío estándar de $4.6 \mathrm{~km}$. La profundidad de Moho obtenida (Figura 4.2(e)) se correlaciona con la morfología y las estructuras observadas en la superficie (Andes, cuenca Neuquina, altiplanicie del MNP). Debajo de los Andes, se observa una raíz correspondiente a una cadena montañosa con una profundidad 
máxima de $43 \mathrm{~km}$, en la cuenca Neuquina es más delgada llegando a su límite inferior en el área de estudio $(25 \mathrm{~km})$ y en la altiplanicie es más gruesa que en sus alrededores con una profundidad de entre 33 y $38 \mathrm{~km}$.

\subsubsection{Resultados}

En el modelo inicial hay muchos parámetros libres. La densidad de los sedimentos y de la corteza superior puede ser variada entre los límites encontrados en la literatura, mientras que la ICD y el Moho también son parámetros que admiten ser modificados. Siendo difícil imponer un criterio para la modificación de todos ellos ante la falta de datos de restricción, se decidió no modificar la discontinuidad ICD que propone el modelo CRUST 1.0 (Laske et al., 2013), ni el Moho encontrado mediante la hipótesis de balance isostático. De este modo, sólo se modificaron las densidades de los sedimentos y de la corteza superior, siempre dentro de los límites fijados por los valores publicados en la literatura.

Se encontraron valores de densidades (que pueden observarse en la tabla 4.1), dentro de extremos descriptos en trabajos previos, que hacen que la anomalía generada por el modelo (Figura 4.3 (b)) ajuste con la anomalía observada (Figura 4.3 (a)) en las largas longitudes de onda. Este buen ajuste puede observarse en los valores y el patrón similar que muestran las figuras 4.3 (a) y 4.3 (b), así como también en las altas frecuencias de la anomalía residual (diferencia entre las anomalías de gravedad observadas y las calculadas para el modelo; figura 4.3 (c)). Estas características pueden ser apreciadas también en los diferentes perfiles del modelo que se muestran en la figura 4.4. El primer perfil (Figura 4.4(a)) cruza la altiplanicie del MNP por el centro y la cuenca Neuquina a través de la zona de mayor espesor sedimentario. Allí se observa claramente como la respuesta gravimétrica del modelo es coincidente a gran escala con la gravedad observada. La misma apreciación puede hacerse al observar el perfil de la figura 4.4(b), que cruza ambas estructuras en el este. En ambos perfiles la anomalía residual es cercana a cero y tiene altas frecuencias. La anomalía residual tiene una media muy cercana a cero $\left(-1.05 \cdot 10^{-9} \mathrm{mGal}\right)$ y un desvío estándar de $18.05 \mathrm{mGal}$. Los mayores desvíos entre anomalías observadas y calculadas se dan en el límite oeste del área de estudio, donde se encuentran los Andes.

Los perfiles elegidos (Figuras 4.4(a) y 4.4(b)) muestran los espesores y geometrías de los cuerpos del modelo. A lo largo del perfil que se muestra en la figura 4.4(a) se puede ver el mayor espesor sedimentario del modelo que se alcanza debajo de la cuenca Neuquina. En este mismo lugar el Moho es más somero que debajo de la altiplanicie. La discontinuidad 


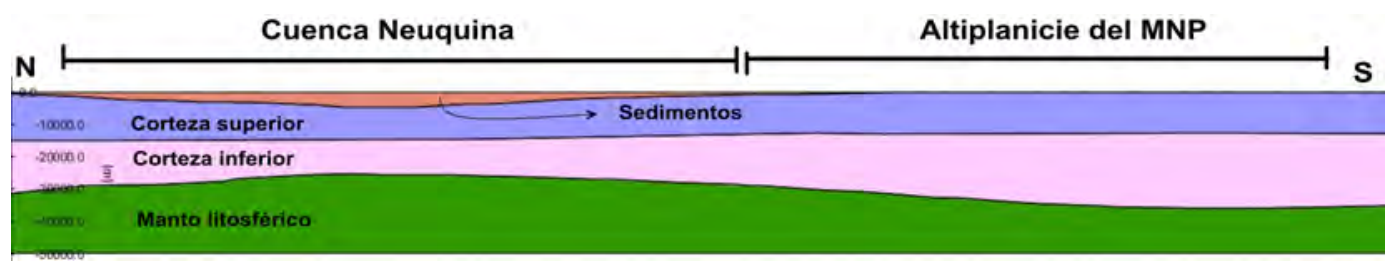

(a)

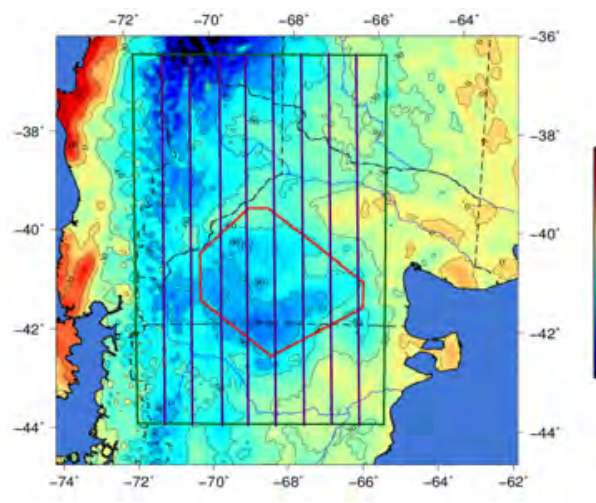

(b)

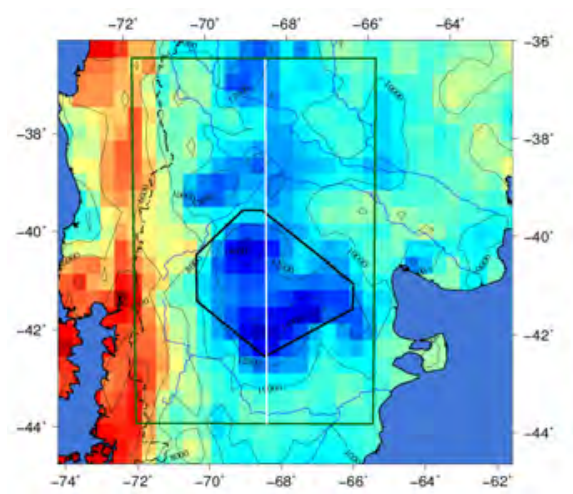

(d)

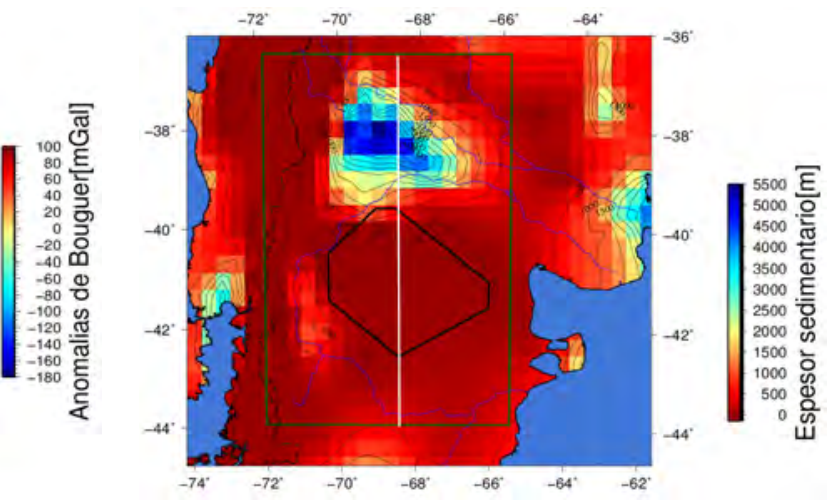

(c)

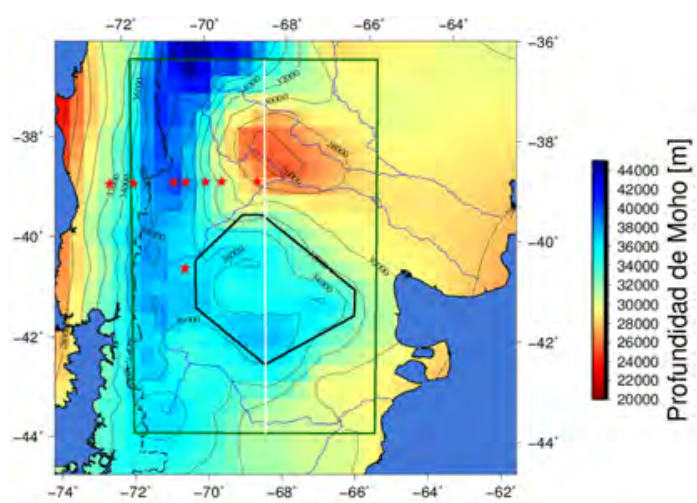

(e)

Figura 4.2. Modelo inicial de densidad a escala cortical. El área modelada está indicada en verde en las figuras 4.2(a), 4.2(c), 4.2(d) y 4.2(e). a) Perfil vertical del modelo inicial. La ubicación del perfil se indica en línea blanca continua en las figuras 4.2(c), 4.2(d) y 4.2(e). b) Anomalías de Bouguer observadas (modelo EGM2008; Pavlis et al. 2012). En violeta se indica la ubicación de las secciones de trabajo del modelo. c) Espesor sedimentario en el área de estudio (Heine, 2007). d) Discontinuidad intracortical (ICD; CRUST1.0, Laske et al. 2013) e) Profundidad de Moho del modelo inicial. La ubicación de los datos de Moho provenientes de la sismología está indicada con estrellas rojas. 
Tabla 4.1. Densidades de los cuerpos del modelo preliminar a escala cortical. Los valores están expresados en $\mathrm{kg} / \mathrm{m}^{3}$.

\begin{tabular}{|l|l|}
\hline Cuerpo & Densidad \\
\hline Sedimentos & 2500 \\
\hline $\begin{array}{l}\text { Corteza Supe- } \\
\text { rior }\end{array}$ & 2700 \\
\hline $\begin{array}{l}\text { Corteza infe- } \\
\text { rior }\end{array}$ & 2990 \\
\hline Manto & 3310 \\
\hline
\end{tabular}

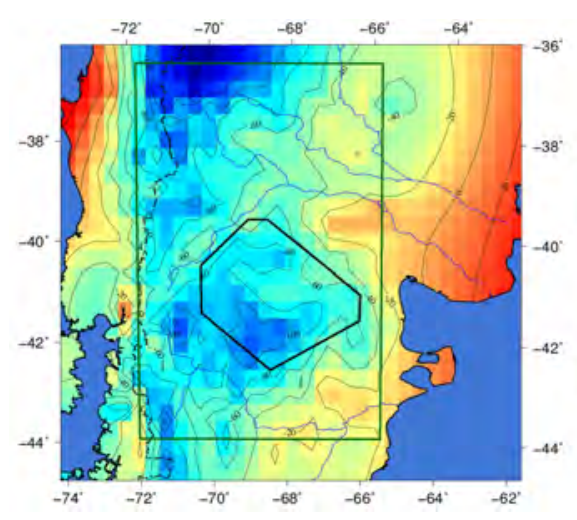

(a)

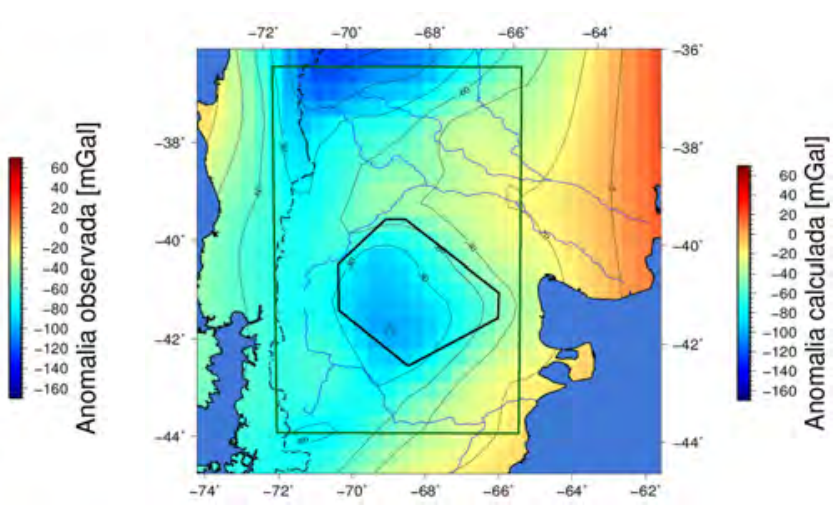

(b)

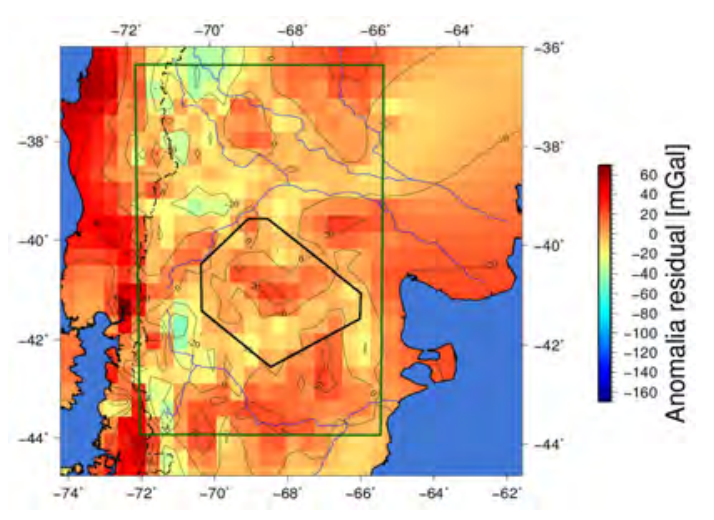

(c)

Figura 4.3. Anomalías del modelo preliminar a escala cortical. a) Anomalías observadas. b) Anomalías calculadas. c) Anomalías residuales. 
ICD no varía mucho en profundidad a lo largo del perfil. En el segundo perfil (Figura 4.4(b)) se pueden observar características similares en cuanto al ICD y al Moho se refiere, pero se observa menor espesor sedimentario en la cuenca Neuquina.

Se realizó una prueba, imponiendo una corteza homogénea con una densidad promedio entre la densidad de la corteza superior e inferior del modelo. Sin embargo, esta generó residuos mayores y por lo tanto, el modelo de corteza dividida funciona mejor en este caso.

Teniendo en cuenta que no hubo que modificar el Moho obtenido bajo la hipótesis de balance isostático, el modelo generado sugiere que el área de la altiplanicie del MNP está balanceada isostáticamente a escala cortical. Sin embargo, este modelo no está bien condicionado ya que contiene varios parámetros que no han sido restringidos. Por este motivo se decidió realizar un modelo a escala litosférica e integrando mayor cantidad de datos, con el fin de poder confirmar la sugerencia del presente modelo.

\subsection{Modelo litosférico}

Este capítulo dio lugar al trabajo Gómez Dacal et al. (2017) de nuestra autoría, en el cual fueron usados la totalidad de los desarrollos, tablas y figuras.

\subsubsection{Modelo inicial}

El modelo inicial se extiende hasta los $300 \mathrm{~km}$ de profundidad y tiene una extensión areal de $500 \mathrm{~km} x 500 \mathrm{~km}$ incluyendo el MNP y las áreas circundantes (Figura 1.1). Se eligió esta zona con el fin de poder comparar las características resultantes dentro y fuera del MNP. El modelo fue construido mediante 11 perfiles de trabajo separados una distancia de $50 \mathrm{~km}$ entre sí y orientados en dirección este-oeste. Para evitar los efectos de borde en el cálculo de la respuesta de gravedad, el modelo ha sido extendido $1000 \mathrm{~km}$ en cada una de sus direcciones.

La figura 4.5(a) muestra un perfil del modelo inicial, incluyendo todos los datos considerados. En ella se puede observar que dicho modelo consiste en 4 cuerpos: sedimentos, dos dominios corticales distintos y manto. También se pueden ver las densidades de cada cuerpo, la gravedad medida y los datos de restricción, tanto de la geometría de las discontinuidades como de las densidades.

Para este modelo también se utilizaron las anomalías de Bouguer del modelo geopotencial EGM2008 (Pavlis et al., 2012). La Figura 4.5(b) muestra estas anomalías en la nueva área de estudio, las cuales conservan las características descriptas para la figura 4.2(b): anomalías de 


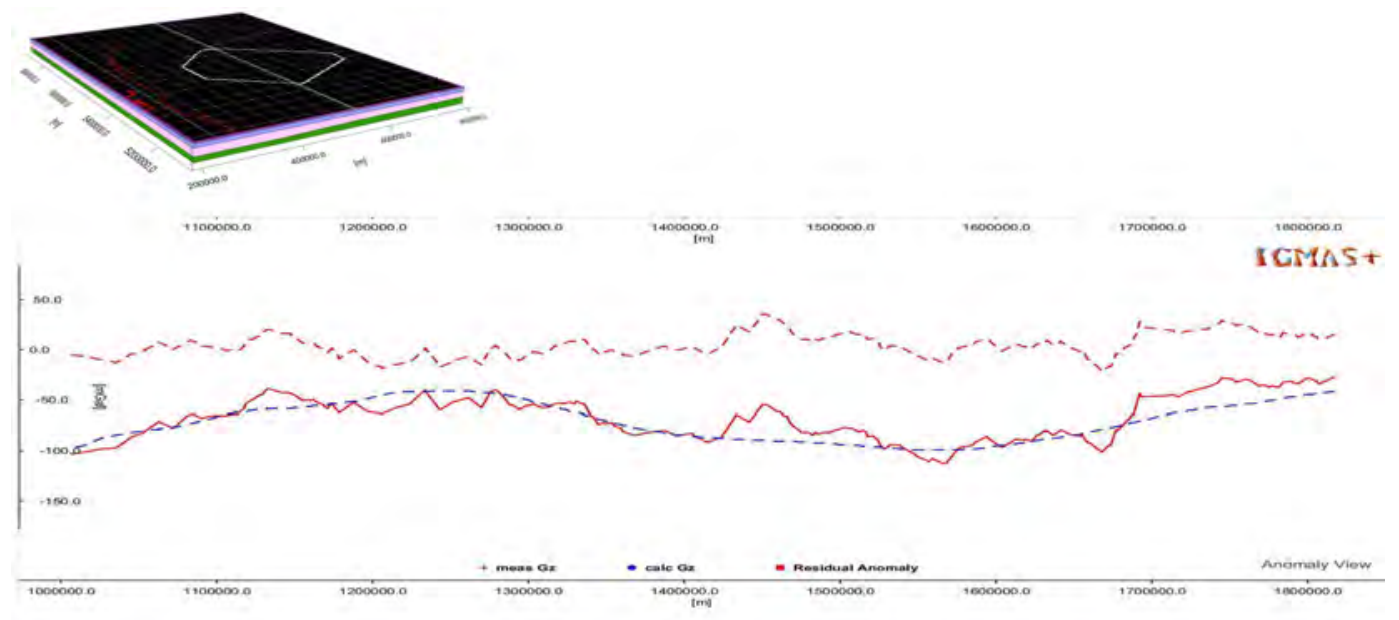

(a)

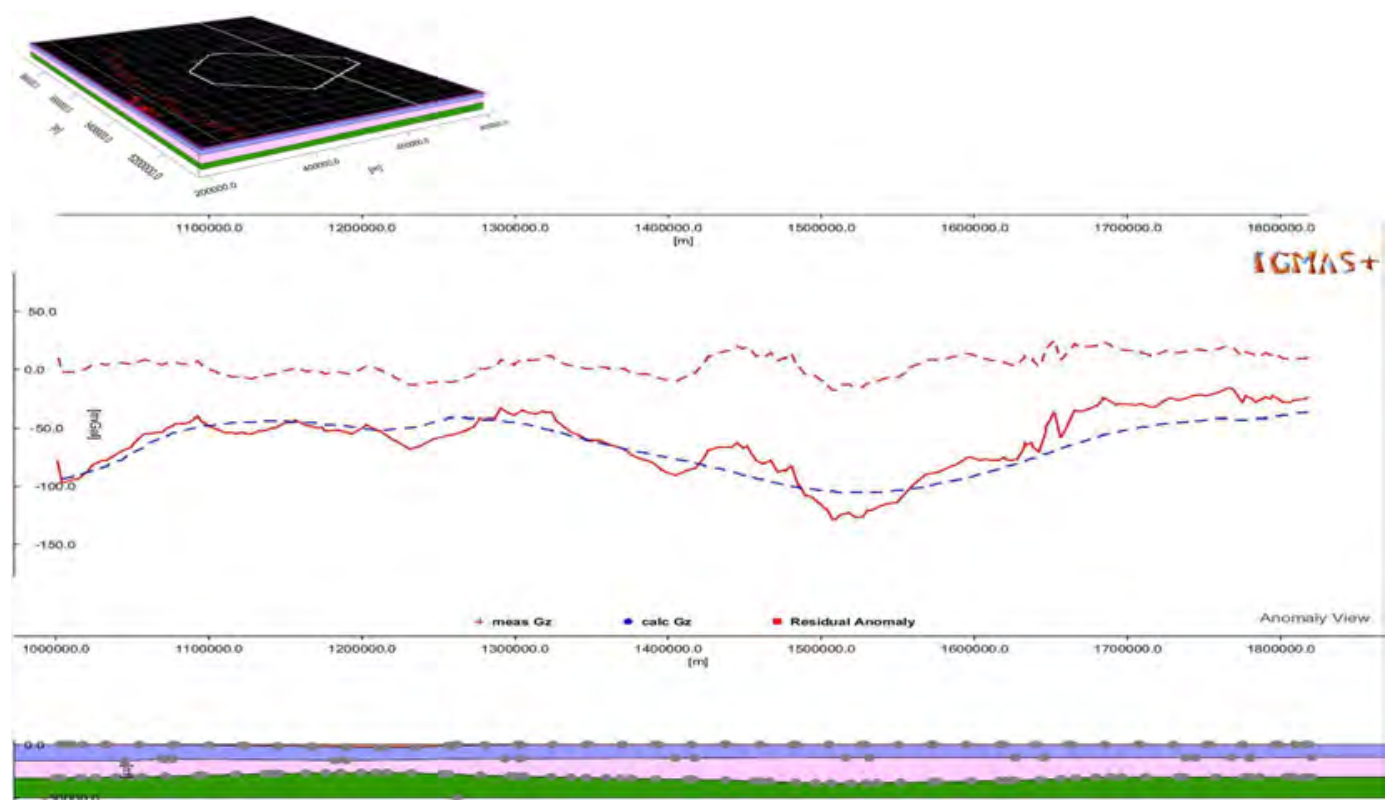

(b)

Figura 4.4. Perfiles del modelo final preliminar a escala cortical. a) Perfil atravesando la altiplanicie del MNP por su zona central y la cuenca Neuquina por su zona de mayor espesor sedimentario b) Perfil atravesando la altiplanicie del MNP y la cuenca Neuquina en su límite este. La línea roja continua es la anomalía observada, la azul a trazos es la modelada y la roja a trazos es la residual. En el modelo el cuerpo naranja es el espesor sedimentario, el lila la corteza superior, el rosa la corteza inferior y el verde el manto litosférico. 
Bouguer negativas dentro de la altiplanicie del MNP (menores a los -60 mGal con un mínimo de $-100 \mathrm{mGal}$ ) rodeadas por valores mayores en las cuencas circundantes que aumentan hacia el este (Figura 4.5(b)). También en esta figura (4.5(b)) se puede observar la correlación con la topografía en el área (Figura 1.1).

En los siguientes apartados se detalla la elección de las densidades y discontinuidades de los cuerpos del modelo, junto a los procedimientos realizados en cada caso y su justificación.

\section{Restricciones en la configuración de densidades de los sedimentos}

La discontinuidad entre los sedimentos y la corteza (Figura 4.5(c)) fue definida utilizando la digitalización del Atlas ICONS (Heine, 2007). Al igual que en la figura 4.2(c) el único sector, dentro del área modelada, con espesores sedimentarios mayores a los $200 \mathrm{~m}$ es la porción de la cuenca Neuquina que entra dentro del modelo (sector sur de la cuenca; Figura $4.5(\mathrm{c}))$.

Se utilizó una densidad constante para los sedimentos $\left(2400 \mathrm{~kg} / \mathrm{m}^{3}\right)$ ya que, al ser espesores no muy grandes, se espera que los efectos de porosidad (compactación) sean menores. El hecho de incluir más detalles requeriría la disponibilidad de más datos y no implicaría un cambio significativo del modelo a escala litosférica. El valor de la densidad de los sedimentos fue calculado de manera distinta que en el caso cortical, teniendo en cuenta las diferentes litologías que se reconocen en la cuenca Neuquina según el trabajo de Canale et al. (2015), ya que esta cuenca contiene el mayor volumen de sedimentos de la zona modelada.

\section{Restricciones en la configuración de densidades de la corteza}

En este caso, la forma inicial del Moho fue extraída de uno de los modelos analizados en el capítulo 3 ya que este fue el parámetro libre a modificar durante el modelado. El modelo elegido es a escala regional para el área de Sudamérica (Assumpção, comunicación personal) y fue desarrollado principalmente con datos sísmicos, como por ejemplo perfiles de refracción, análisis de funciones receptoras o dispersión de ondas superficiales (Assumpção et al., 2013). El modelo rellena las zonas donde no hay datos sísmicos disponibles con estimaciones basadas en gravedad provenientes del modelo de Tassara y Echaurren (2012) y tiene una resolución de $0.5^{\circ}$ (Figura $4.5(\mathrm{~d})$ ).

Cómo se mencionó en el capítulo 3, este modelo predice una profundidad del Moho debajo de la altiplanicie del MNP de entre 32 y $38 \mathrm{~km}$ y está rodeada por cortezas más finas hacia el norte, este y noreste y por una corteza más gruesa hacia el oeste. Como el modelo tiene un 


\section{Modelado gravimétrico tridimensional}

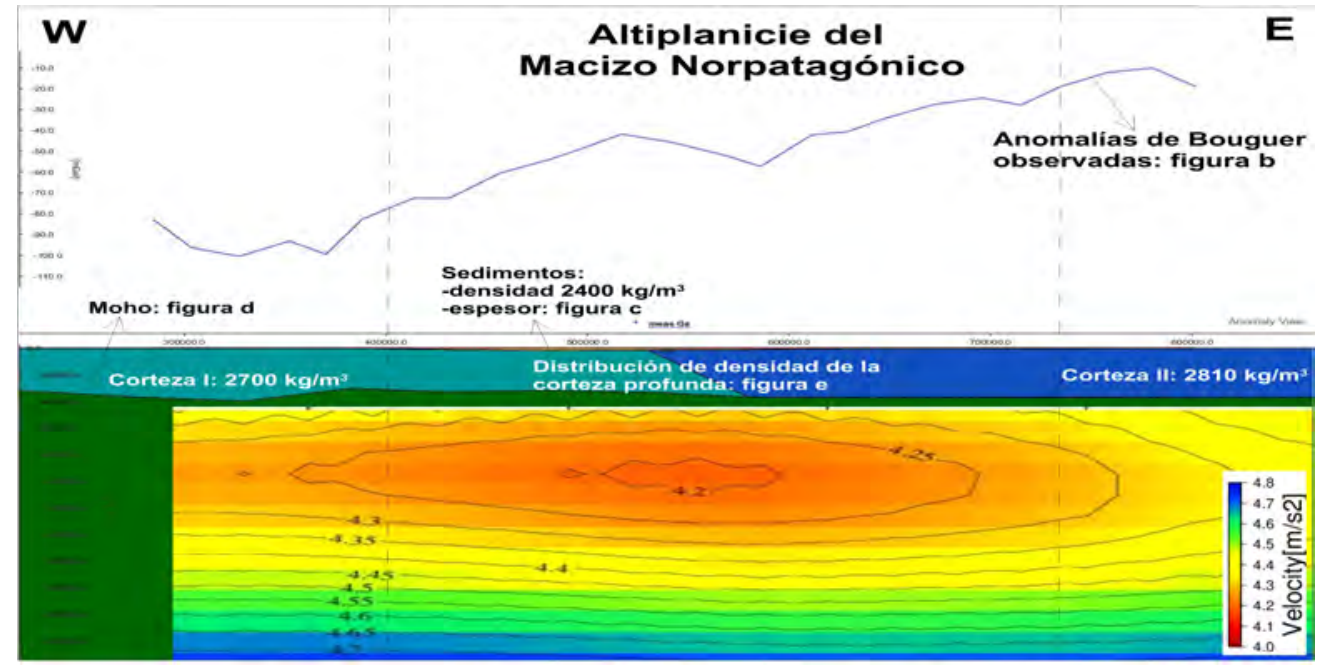

(a)

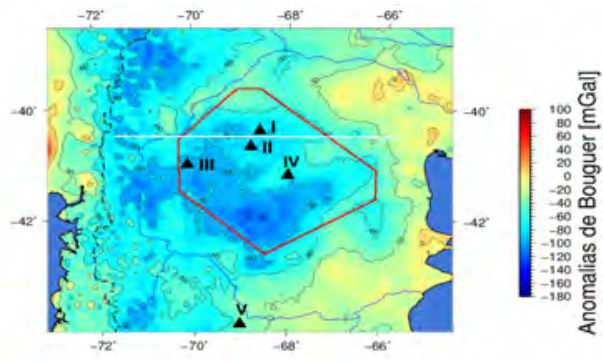

(b)

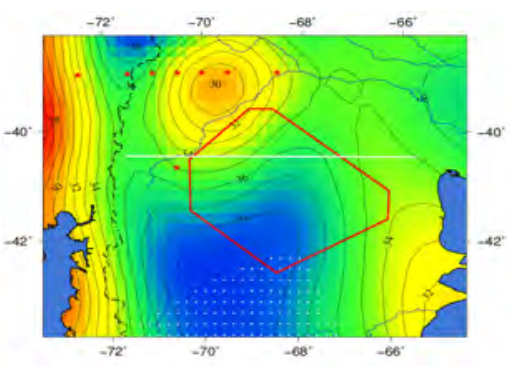

(d)

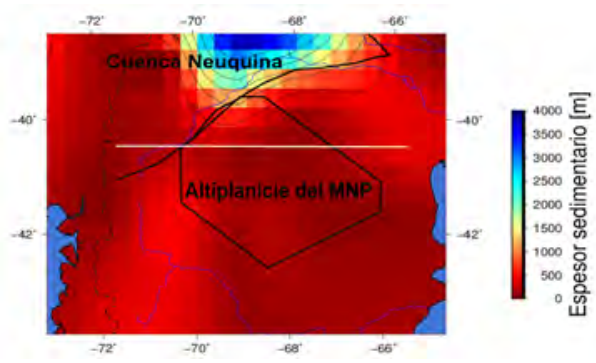

(c)

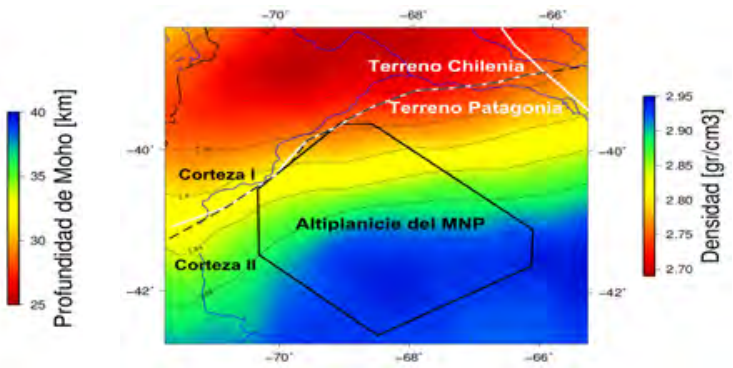

(e)

Figura 4.5. Modelo inicial de densidad a escala litosférica. a) Perfil vertical del modelo inicial y los datos de entrada. La distribución de velocidades es del modelo SL2013Sv (Schaeffer y Lebedev, 2013). La ubicación del perfil se indica en línea blanca contínua en las figuras 4.5(b), 4.5(c) y 4.5(d) b) Anomalías de Bouguer observadas (modelo EGM2008; Pavlis et al. 2012). Los triángulos negros indican las localidades donde hay datos de xenolitos (Ponce 2016 y Mundl et al. 2015). I: Cerro Chenque, II: Puesto Diaz, III: Comallo, IV: Pahuaniyeu, V: Paso de Indios. c) Espesor sedimentario en el área de estudio (Heine, 2007). d) Profundidad de Moho del modelo inicial (Assumpção et al., 2013). El área cubierta con puntos blancos no tiene resolución en el modelo y fue interpolada para ser utilizada en el modelo inicial. La ubicación de los datos de Moho provenientes de la sismología está indicada con estrellas rojas. e) Configuración de densidades a los $25 \mathrm{~km}$ de profundidad, convertida desde el modelo SL2013Sv (Schaeffer y Lebedev, 2013). La discontinuidad entre terrenos (Chernicoff y Zappettini, 2004) se muestra con una línea blanca continua. La discontinuidad entre los dos cuerpos modelados para la corteza se muestra con una línea negra a trazos. 
área sin información hacia el sur del MNP, se interpoló entre valores existentes para obtener la superficie de Moho inicial para el modelo.

A pesar de que el modelo de Assumpção et al. (2013) está basado en una gran base de datos, hay sólo unas pocas estimaciones de profundidad de Moho en el área del MNP (Figura 4.5(d), Assumpção, comunicación personal). Estos datos fueron utilizados como puntos de control para la forma final del Moho en este estudio.

Algunos de los datos que restringen las densidades provienen de las rocas corticales aflorantes que han sido descriptas en estudios geológicos. Tal cómo se explicó en el capítulo 2, estos estudios indican que la corteza cristalina sub-sedimentaria del MNP contiene complejos metamórficos del Paleozoico inferior, intruidos por rocas plutónicas (ordovícicas, devónicas, carboníferas, pérmicas y triásicas; Pankhurst et al. 2006), alternadas con complejos volcánicos riolíticos (Rapela et al., 2005). Esta corteza cristalina está cubierta por una capa fina de sedimentos triásicos y jurásicos. Estas unidades geológicas fueron cubiertas por una capa fina de de sedimentos del Cretácico superior (marinos) y del Terciario (continentales). La mayoría del sector sudeste del MNP está cubierto por basaltos del Oligoceno (Aragón et al., 2011a). Al norte de la altiplanicie del MNP, el basamento está compuesto principalmente por granitos, granodioritas, riolitas y sucesiones volcaniclásticas de composición andesítica a riolítica (Gregori et al. 2008 y Kostadinoff et al. 2005). A pesar de la posible conexión entre rocas del MNP y del basamento del norte, sugerida por Gregori et al. (2008) y Kostadinoff et al. (2005) mediante la que concluyen que estas zonas deberían tener un origen común, ellos también mencionan que habría mayor abundancia de rocas metamórficas en el área del MNP. Teniendo en cuenta esta última afirmación, la corteza somera podría ser ligeramente más densa en el MNP que al norte del mismo.

El modelo de velocidades de onda S, SL2013Sv de Schaeffer y Lebedev (2013), provee información importante para la configuración de densidades de la corteza profunda, ya que posee información a una profundidad de $25 \mathrm{~km}$. La distribución de velocidades fue convertida a densidades en dos pasos: primero se convirtieron las velocidades de onda $\mathrm{S}\left(V_{s}\right)$ a velocidades de onda $\mathrm{P}\left(V_{p}\right)$ utilizando:

$$
V_{p}=1.75 * V_{s}
$$

El factor utilizado es un valor que se encuentra entre los rangos descriptos en varios trabajos para distintas áreas del mundo, como por ejemplo Alvarado et al. (2007); Julià y Mejía (2004); Nakajima et al. (2001), entre otros. Nakajima et al. (2001) encuentran este 
factor como un valor medio para la corteza inferior en el noreste de Japón, mientras que en el trabajo de Alvarado et al. (2007) el valor aparece como el valor medio para la parte norte del terreno de Chilenia. Este valor constante permite obtener velocidades de ondas $\mathrm{P}$ que son similares a las esperadas para los $25 \mathrm{~km}$ de profundidad según el modelo ak135 (Kennett et al., 1995).

El segundo paso fue convertir las velocidades de onda $\mathrm{P}$ obtenidas en densidades (Figura 4.5(e)). Esto fue realizado utilizando una modificación de la ley de Birch (Birch, 1961) que tiene la siguiente forma:

$$
\rho=a V_{p}+b
$$

siendo $\rho$ la densidad, $V_{p}$ la velocidad de onda $\mathrm{P}$ y $a$ y $b$ constantes que dependen de la litología. En este estudio se utilizó un valor diferente para la constante "b"para lograr que el resultado ajuste con las densidades obtenidas mediante xenolitos de la corteza inferior. Estos xenolitos, encontrados únicamente en la localidad de Paso de los Indios (localidad V, Figura 4.5(b)) corresponden a granulitas en basaltos del Paleógeno y fueron descriptas en el trabajo de Castro et al. (2011). Las densidades de estos xenolitos fueron calculadas usando análisis de elementos mayoritarios en roca total (Castro et al., 2011) y la norma CIPW (Johannsen, 1931) para reconstruir los minerales que pudieron haber compuesto la roca original y sus proporciones (sin las alteraciones causadas por la temperatura, presión y otros efectos). Usando estas restricciones en la densidad, la ley de Birch modificada que fue aplicada fue:

$$
\rho=0.3788 V_{p}+0.33
$$

La distribución de densidad para los $25 \mathrm{~km}$ de profundidad es mostrada en la Figura 4.5(e), donde se puede observar una clara tendencia en los valores de densidad desde valores menores en el noroeste hasta valores altos en el sudeste.

El área del modelo está ocupada principalmente por dos de los terrenos paleozoicos propuestos por Ramos (1988), la parte más austral de Chilenia y el extremo norte de Patagonia (Figura 4.5(e)). Las suturas (límites de los terrenos) que se encuentran en el área de estudio, según el trabajo de Chernicoff y Zappettini (2004) basado en datos aeromagnéticos, son mostradas en la Figura 4.5(e). El límite entre Chilenia y Patagonia, derivado de observaciones superficiales geológicas y geofísicas coincide en gran medida con el patrón cambiante de densidades a los $25 \mathrm{~km}$ de profundidad (Figura 4.5(e)). De acuerdo a este patrón Chilenia 
debería tener densidades corticales más bajas que Patagonia a esta profundidad. Las curvas de nivel de densidad no son totalmente coincidentes con la sutura observada en superficie entre los terrenos del área (Figura 4.5(e)), sin embargo la configuración de densidades a los $25 \mathrm{~km}$ de profundidad está expresando el límite de ambos terrenos a esa profundidad y no en superficie. Siguiendo la expresión superficial de los límites entre terrenos, como muestra la Figura 4.5(e), se ha dividido la corteza en dos cuerpos diferentes Chilenia con una densidad de $2700 \mathrm{~kg} / \mathrm{m}^{3}$ y Patagonia con $2810 \mathrm{~kg} / \mathrm{m}^{3}$ (Figura 4.5(a)). La densidad final elegida para cada cuerpo es representativa de valores en rocas someras y profundas y es un resultado de la combinación de los datos expuestos previamente.

\section{Restricciones sismológicas en la configuración de densidades del manto}

Con el fin de obtener la distribución de densidades en el manto superior, se exploraron dos modelos de tomografías, uno de velocidades de onda S (Schaeffer y Lebedev 2013, Figura 4.5(a)) y otro de velocidades de onda P (Amaru, 2007).

El modelo de onda S es llamado SL2013sv (Schaeffer y Lebedev, 2013) y es un modelo global de tomografías para el manto superior. Fue desarrollado usando formas de onda S y superficiales e invertido utilizando un algoritmo denominado AMI (Automated Multimode Inversion; Schaeffer y Lebedev 2013). El modelo de referencia que utilizaron es tridimensional y está basado en el modelo Crust 2.0 (Bassin et al., 2000) y en el modelo global de velocidades ak135 (Kennett et al., 1995). La ventaja del SL2013sv es que tiene cobertura en cada punto del modelo (Schaeffer y Lebedev, 2013). La versión utilizada tiene una resolución lateral de $0.5^{\circ}$ y vertical de $25 \mathrm{~km}$.

El segundo modelo, UU-P07 (Amaru, 2007), también es un modelo global de tomografías, pero en este caso contiene velocidades de onda P para la corteza y el manto. Su modelo de referencia es el modelo global de velocidades ak135 (Kennett et al., 1995). Está basado en una gran cantidad de datos que consisten en una selección de tiempos de viaje de catálogos, boletines, registros de redes sísmicas y experimentos temporales (Amaru, 2007). Este modelo no asegura cobertura en todos las celdas de su grilla como lo hacía el modelo anterior.

Ambos modelos de tomografías presentan un patrón similar de velocidades, observándose una anomalía de bajas velocidades debajo de la altiplanicie del MNP, entre los 50 y los $200 \mathrm{~km}$ de profundidad (Figura 4.5(a)). Esta anomalía continúa hacia el sur de la altiplanicie pero no lo hace así hacia el norte, donde se pueden observar mayores velocidades. El objetivo más importante que se persiguió al convertir velocidades en densidades fue el de encontrar la 
influencia de las anomalías del manto en el campo de gravedad, el cual es un requerimiento importante a la hora de modelar densidades corticales usando gravedad como lo demuestran algunos trabajos, como por ejemplo el de Klitzke et al. (2016).

Para el modelo de tomografía de ondas S -SL2013Sv-, se probaron y compararon dos conversiones de velocidad a densidad diferentes. La primera utiliza el cociente de heterogeneidad sísmico $R_{\left(\frac{\rho}{S}\right)}$, que es un factor de conversión dependiente de la profundidad y el segundo está basado en la aproximación de Goes et al. (2000) implementada en un código desarrollado por An y Shi (2007).

El cociente de heterogeneidad que relaciona la densidad con la velocidad de onda $\mathrm{S}$ $\left(R_{\left(\frac{\rho}{S}\right)}\right)$ es la división entre las perturbaciones de densidad lateral relativas al promedio esférico $(\delta \ln (\rho))$ y las perturbaciones de velocidad de corte relativas $\left(\delta \ln \left(V_{S}\right)\right)$ :

$$
R_{\left(\frac{\rho}{S}\right)}=\frac{\delta \ln (\rho)}{\delta \ln \left(V_{S}\right)} .
$$

Examinando la bibliografía (Cammarano et al. 2003; Ishii y Tromp 2001; Karato y Karki 2001; Resovsky y Trampert 2003) se pueden encontrar distintos valores para este parámetro dependiendo de la profundidad. Sin embargo, la mayoría de ellos varían entre 0.15 y 0.25 para el manto superior. Las únicas excepciones a este rango se pueden encontrar en áreas relacionadas a la subducción de placas donde, en algunos casos, se documentan valores muy bajos o incluso negativos (Cammarano et al., 2003). $R_{\left(\frac{\rho}{S}\right)}$ es principalmente derivado de la mineralogía y está basado en la asunción de que las variaciones laterales de densidad están causadas únicamente por variaciones de temperatura (Ishii y Tromp, 2001). A pesar de haber otras fuentes de heterogeneidad, principalmente causadas por variaciones composicionales, su efecto en la velocidad sísmica se cree que es pequeño (menos del $1 \%$ según estudios realizados con xenolitos del manto) comparados con los efectos generados por las variaciones térmicas en el manto superior (entre los 50 y 300 km; Goes et al. 2000; Cammarano et al. 2003).

En este estudio, se convirtieron las velocidades de onda $\mathrm{S}$ utilizando el perfil vertical de $\left.R_{(} \frac{\rho}{S}\right)$ publicado por Simmons et al. (2009), quienes han determinado un valor óptimo de $R_{\left(\frac{\rho}{S}\right)}$ para cada profundidad mediante la comparación de distintos perfiles de $R_{\left(\frac{\rho}{S}\right)}$ (derivados de la mineralogía y que consideran sólo variaciones de temperatura) con restricciones geodinámicas. También se utilizó un factor de corrección, propuesto por los mismos autores (Simmons et al., 2009), para el efecto de la temperatura en la atenuación sísmica en el manto superior.

La segunda conversión aplicada a los datos de velocidad de onda $\mathrm{S}$ fue realizada utilizando un programa denominado "velt" que fue desarrollado por An y Shi (2007). Velt está basado 
en la aproximación de Goes et al. (2000) quien asume que el manto superior puede ser modelado por cinco minerales básicos, cada uno con sus módulos elásticos característicos. Ellos proponen que estos módulos $\left(M_{i}\right)$ son funciones de la temperatura del lugar analizado $(T)$ y de su presión $(P)$ como así también del contenido de hierro $\left(X_{F e}\right)$ :

$$
M_{i}\left(P, T, X_{F e}\right)=M_{i}\left(P_{0}, T_{0}, X_{F e}\right)+\left(T-T_{0}\right) \frac{\delta M_{i}}{\delta T}+\left(P-P_{0}\right) \frac{\delta M_{i}}{\delta P}+X_{F e} \frac{\delta M_{i}}{\delta X_{F e}},
$$

donde $M_{i}$ puede ser cualquiera de los módulos elásticos: compresibilidad $(\kappa)$ o rigidez $(\mu)$. Velt determina tanto el módulo elástico en condiciones ambiente $\left(P_{0}, T_{0}, X_{F e}\right)$ como sus derivadas a partir de experimentos de laboratorio (An y Shi, 2007). Luego, el módulo elástico para el material del manto puede ser obtenido como el promedio de Voigt-Reuss-Hill (VRH) de los materiales que lo componen:

$$
\begin{gathered}
\langle M\rangle=\frac{1}{2}\left(M^{\text {Voigt }}+M^{\text {Reuss }}\right), \\
M^{\text {Voigt }}=\sum M_{i} \lambda_{i}, \\
M^{\text {Reuss }}=\left(\sum \frac{\lambda_{i}}{M_{i}}\right)^{-1},
\end{gathered}
$$

donde $\lambda_{i}$ es la porción volumétrica del mineral $i$. Según An y Shi (2007), velt considera una composición mantélica para áreas no cratónicas compuesta por $68 \%$ de olivina, $18 \%$ de ortopiroxeno, $11 \%$ de clinopiroxeno, $3 \%$ de granate, $0 \%$ de espinelas y un contenido de hierro de 0.1 (es decir, el contenido de Fe es el $10 \%$ del contenido de Fe $+\mathrm{Mg}$ ).

Una vez que los módulos elásticos fueron obtenidos, el programa calcula las velocidades de ondas S o P a partir de las siguientes relaciones:

$$
\begin{gathered}
V_{S}(P, T)=\sqrt{\frac{\langle\mu\rangle}{\langle\rho\rangle},} \\
V_{P}(P, T)=\sqrt{\frac{\langle\kappa\rangle+4 / 3\langle\mu\rangle}{\langle\rho\rangle}},
\end{gathered}
$$

y determina el valor de densidad iterativamente por aproximación a la $V_{s}$ o $V_{p}$ observadas. Por último, también corrige el resultado obtenido por el efecto de la anelasticidad utilizando una corrección dependiente de la frecuencia (Goes et al., 2000). 
Esta metodología fue también utilizada para convertir las velocidades de onda $\mathrm{P}$ del modelo UU-P07 (Amaru, 2007) en densidades.

En resumen, se obtuvieron tres configuraciones de densidad para el área: para el modelo de velocidades de onda S, SL2013sv, la configuración A, utilizando el parámetro $\left.R_{(} \frac{\rho}{S}\right)$ y la configuración B utilizando el programa velt. Por otra parte, la configuración C consiste en densidades derivadas del modelo de velocidad de onda P, UU-P07 y utilizando el programa velt. El patrón de densidades es similar en las tres configuraciones de densidad, mostrando una anomalía de baja densidad debajo de la altiplanicie del MNP. Sin embargo, se puede observar una diferencia importante en el valor de las densidades de cada configuración. La figura 4.6 muestra diferentes perspectivas de las tres configuraciones de densidad con el fin de ilustrar el patrón general de densidades y, a su vez, hacer visible la diferencia en valor. La figura 4.6(a) muestra un perfil oeste-este de la configuración A que atraviesa la altiplanicie del $\operatorname{MNP}\left(-41^{\circ} S\right)$. En esa figura se puede observar la anomalía mencionada debajo del área de la altiplanicie, así como también la diferencia con los alrededores que es mayor con respecto al este que con el oeste. La figura 4.6(b) muestra un perfil sur-norte $\left(-68^{\circ} \mathrm{W}\right)$ de la configuración C, donde también puede observarse la anomalía de baja densidad. En este caso, la diferencia de densidad entre el área de la altiplanicie y los alrededores puede observarse sólo hacia el norte, ya que la anomalía sigue hacia el sur hasta el final del área de estudio. La figura 4.6(c) muestra un mapa de la distribución $\mathrm{B}$ a una profundidad de $60 \mathrm{~km}$ en la que también es posible distinguir la anomalía debajo de la altiplanicie.

Para analizar las diferencias entre las distintas configuraciones de densidad, en la tabla 4.2 se detallan sus estadísticas. La mayor diferencia se observa entre las distribuciones A y B, siendo de $106 \frac{\mathrm{kg}}{\mathrm{m}^{3}}$ en promedio y $1 \frac{\mathrm{kg}}{\mathrm{m}^{3}}$ en desvío estándar. Los valores de la configuración C están generalmente entre los de las configuraciones A y B.

\section{Restricciones petrológicas en la configuración de densidades del manto}

Hacker y Abers (2004) desarrollaron un programa para calcular las propiedades físicas de las rocas a determinadas presiones y temperaturas. Una de las propiedades que el programa calcula es la densidad, que es influenciada por las proporciones volumétricas o modales de los minerales de cada roca. El primer paso del cálculo de densidad de una roca es obtener la densidad de cada mineral que la compone a esas condiciones particulares de presión y temperatura. Teniendo en cuenta el valor de densidad para temperatura y presión ambiente $\left(\rho_{0}\right)$, primero se calcula la variación con la temperatura y luego con la presión (Hacker y 


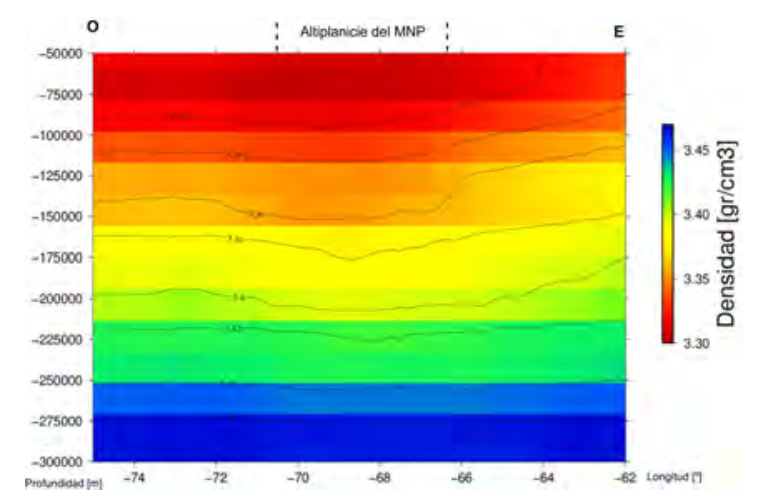

(a) Perfil E-O de la configuración A

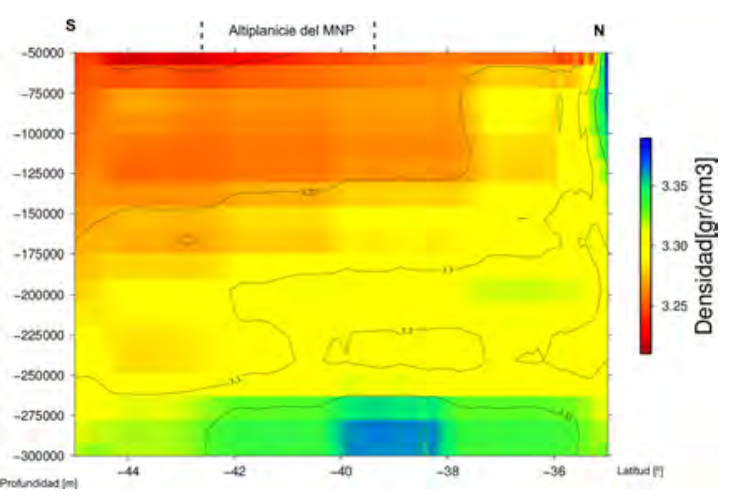

(b) Perfil S-N de la configuración C

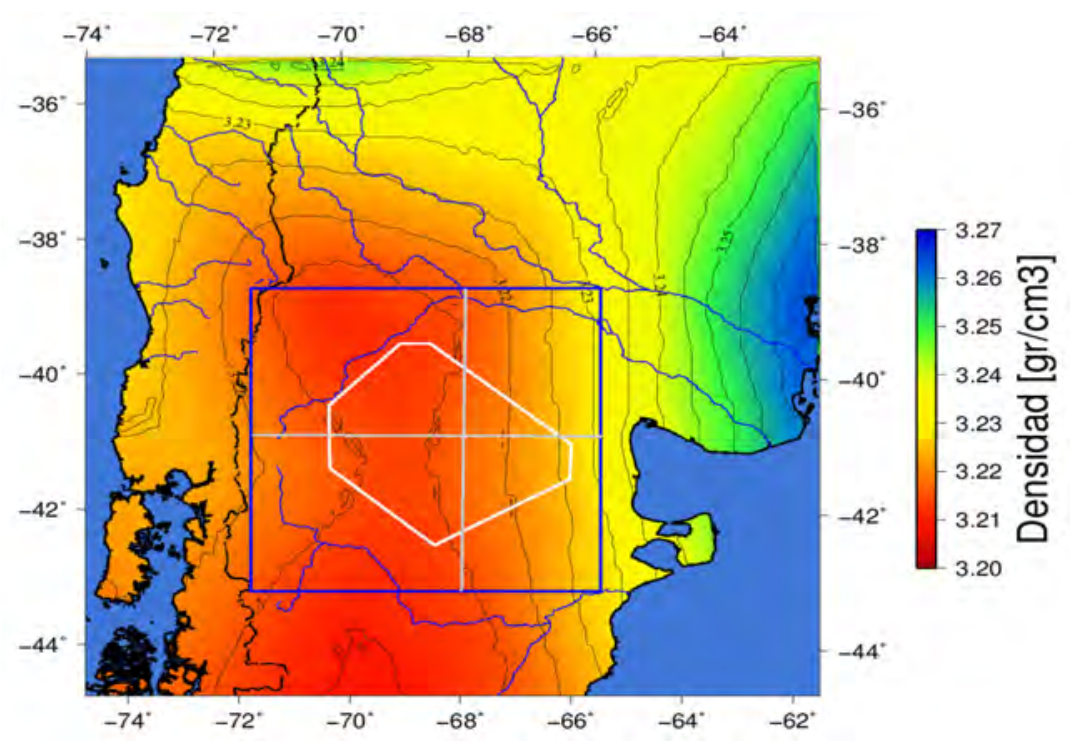

(c) Mapa a $60 \mathrm{~km}$ de profundidad de la configuración B

Figura 4.6. Configuraciones de densidad para el manto obtenidas a partir de modelos de tomografía sismológica a) Perfil oeste-este de la configuración A obtenida a partir del modelo SL2013Sv (Schaeffer y Lebedev, 2013) utilizando $R_{\left(\frac{\rho}{S}\right)}$. b) Perfil sur-norte de la configuración C obtenida a partir del modelo UU-P07 (Amaru, 2007) utilizando el programa velt (An y Shi, 2007). c) Corte a los $60 \mathrm{~km}$ de profundidad de la configuración B a partir del modelo SL2013Sv (Schaeffer y Lebedev, 2013) utilizando el programa velt (An y Shi, 2007). La ubicación de los perfiles de las figuras 4.6(a) y 4.6(b) se muestran en líneas grises continuas. 
Tabla 4.2. Estadísticas de las diferentes configuraciones de densidad del manto. Los valores están expresados en $\mathrm{kg} / \mathrm{m}^{3}$.

\begin{tabular}{|l|l|l|l|}
\hline Configuración & A & B & C \\
\hline Promedio & 3384 & 3278 & 3288 \\
\hline $\begin{array}{l}\text { Desvío es- } \\
\text { tandar }\end{array}$ & 52.5 & 51.4 & 22.8 \\
\hline Mínimo & 3304 & 3201 & 3240 \\
\hline Máximo & 3470 & 3379 & 3361 \\
\hline
\end{tabular}

Abers, 2004). La densidad $(\rho(T))$ a una temperatura dada $T$ es:

$$
\rho(T)=\rho_{0} e^{-\phi},
$$

donde,

$$
\phi=\ln \left(\frac{V(T)}{v_{0}}\right)
$$

siendo $v_{0}$ el volumen molar a temperatura y presión ambiente y $V(T)$ el volumen molar a la temperatura dada $T$. $\phi$ se extrae de la variación de la expansividad con la temperatura que depende de una constante para cada mineral (Hacker y Abers, 2004). La variación de la densidad con la presión viene dada por:

$$
\rho(P)=\rho_{0}(1+2 f)^{2 / 3}
$$

donde $f$ es la tensión finita euleriana, calculada a partir de la presión y las propiedades del mineral (Hacker y Abers, 2004). Entonces, la densidad a una temperatura y presión dadas es calculada como sigue:

$$
\rho(T, P)=\left(\frac{\rho(P)}{\rho_{0}}\right) \rho(T) .
$$

Una vez que fue calculada la densidad para cada mineral, se obtiene la densidad de la roca a través del uso de las proporciones volumétricas de los minerales $\left(v_{i}\right)$ que son especificadas en los análisis modales y aplicando:

$$
\rho_{\text {muestra }}(T, P)=\sum_{i=1}^{n} \rho_{i} v_{i} .
$$


Para determinar las densidades de las muestras de xenolitos en el área de estudio (descriptas en el capítulo 3), se utilizaron las composiciones derivadas de los análisis modales de Ponce (2016) y Mundl et al. (2015) y las temperaturas y presiones de equilibrio. Ponce (2016) determinó esas condiciones de equilibrio usando un análisis de elementos mayoritarios de núcleos de clinopiroxeno y ortopiroxeno, el geotermómetro de dos piroxenos de Brey y Köhler (1990) y el geobarómetro de clinopiroxeno de Mercier (1980). Los valores medios de los valores obtenidos fueron $1.8 \mathrm{GPa}$ para la presión y $972{ }^{\circ} \mathrm{C}$ para la temperatura. Mundl et al. (2015) también calcularon la temperatura de equilibrio usando el termómetro de dos piroxenos de Brey y Köhler (1990) pero sólo midieron la presión en una muestra. Por esta razón, y utilizando los datos mineralógicos disponibles en Mundl et al. (2015), se calculó la presión de equilibrio para los xenolitos dentro de la altiplanicie del MNP utilizando el geobarómetro de clinopiroxeno de Mercier (1980). Luego se seleccionó la media de temperatura y presión de equilibrio para cada localidad (Figura 4.7) para el cálculo de densidades.

Las densidades de xenolitos calculadas en las localidades dentro de la altiplanicie (localidades I, II, III y IV) están ilustradas en los histogramas de la figura 4.7(a) y las de la localidad V (al Sur de la altiplanicie del MNP) se muestran en el histograma de la figura 4.7(b). En la figura 4.7 (c) se muestran todas las muestras de las localidades dentro de la altiplanicie. Las densidades ilustradas en la figura 4.7 y calculadas considerando datos de xenolitos fueron comparadas con las obtenidas mediante las conversiones a partir de datos provenientes de la sismología (figura 4.7). Esto fue realizado obteniendo de las distintas configuraciones (A, B y C), las densidades en la ubicación de las distintas localidades y a las condiciones de presión correspondientes para cada caso (considerando la profundidad a la que la presión litostática según el modelo ak135 sea igual a la de equilibrio de la localidad; Kennett et al. 1995). La configuración de densidades que ajusta mejor con las densidades obtenidas a partir de xenolitos es la C (configuración obtenida a partir del modelo de velocidades de onda P). Por esta razón, se eligió la configuración $\mathrm{C}$ para integrar las densidades del manto en el modelo inicial.

\subsubsection{Procedimiento y resultados}

\section{Modelo inicial de densidades}

En resumen, el modelo inicial de densidades (ilustrado en la figura 4.5) quedó compuesto por:

- espesor sedimentario proveniente del Atlas ICONS (Heine 2007; Figura 4.5(c)) 


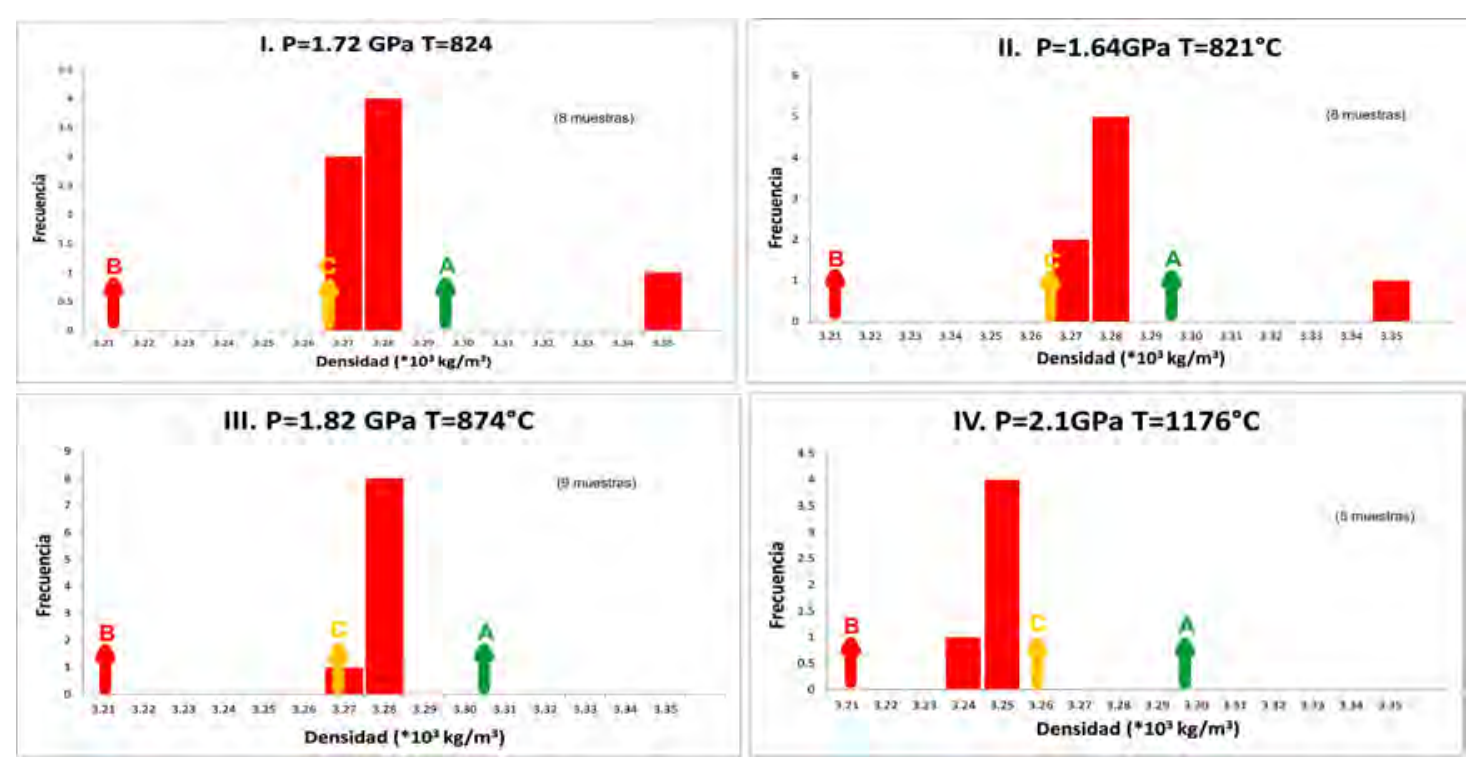

(a)

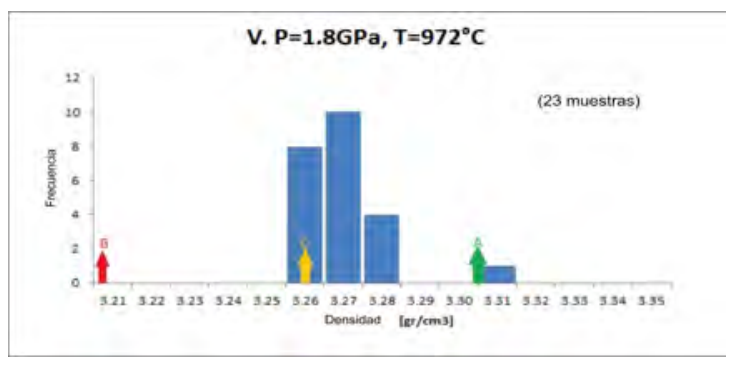

(b)

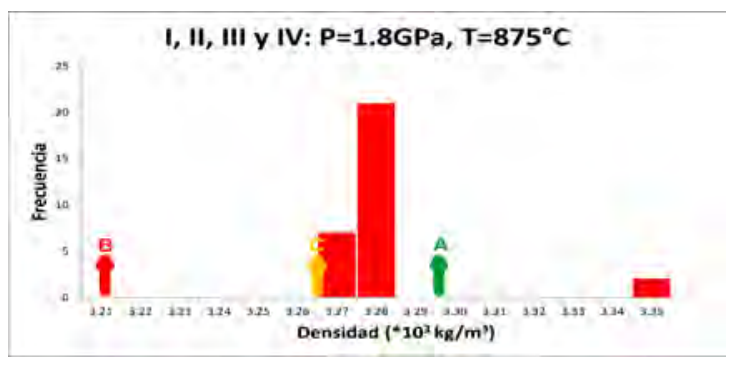

(c)

Figura 4.7. Histogramas de las densidades obtenidas a partir de datos de xenolitos (Ponce 2016 y Mundl et al. 2015) a presión y temperatura del manto y su comparación con las configuraciones de densidad resultantes de modelos de tomografía sismológicas. Las flechas muestran las densidades provenientes de las distintas configuraciones de densidades (A, B y C) en las localidades donde se tienen datos de xenolitos y a una profundidad equivalente a la presión de equilibrio para cada caso (considerando presión litostática según el modelo ak135; Kennett et al. 1995) a) Histogramas con valores de densidad para los xenolitos dentro de la altiplanicie del MNP, especificadas por localidad. b) Histogramas con valores de densidad para los xenolitos de Paso de los Indios (localidad V, al sur de la altiplanicie). c) Histogramas con valores de densidad para los xenolitos dentro de la altiplanicie (localidades I, II, III, IV and $\mathrm{V})$. 
- la densidad de los sedimentos fue asumida constante y su valor se corresponde con las litologías documentadas para la cuenca Neuquina (Figura 4.5(a))

- la profundidad del Moho fue extraída de Assumpção et al. (2013) (Figura 4.5(d))

- se dividió la corteza en dos dominios coincidentes con terrenos paleozoicos y con la variación de las velocidades de onda S de Schaeffer y Lebedev (2013) a los $25 \mathrm{~km}$ de profundidad

- la densidad de los dos dominios corticales se calculó mediante una combinación de geología de superficie y de la configuración de densidades a los $25 \mathrm{~km}$ obtenida de la conversión de las velocidades de onda S de Schaeffer y Lebedev (2013) (Figuras 4.5(a) y $4.5(\mathrm{e}))$

- la configuración de densidades para el manto fue calculada a partir de las velocidades de onda P del modelo UU-P07 (Amaru 2007; configuración C).

Este modelo inicial de densidades genera una anomalía residual (anomalía medida menos calculada) que es ilustrada en la figura 4.8. Como se puede observar, las anomalías calculadas ajustan bien con las medidas en los puntos en los que el Moho inicial tiene datos, siendo la anomalía residual menor a $30 \mathrm{mGal}$ de valor absoluto en dichos puntos. En el área de la altiplanicie se pueden observar anomalías residuales negativas de gran valor absoluto llegando a los -100 mGal (Figura 4.8) que indican el exceso de masa en el modelo. También se pueden observar otras áreas de alto valor absoluto de anomalía residual que están localizadas cerca de las discontinuidades entre los terrenos paleozoicos.

\section{Modelo de densidades final}

El proceso de modelado se llevó a cabo mediante la modificación del parámetro libre, la geometría del Moho, hacia profundidades mayores en el área de la altiplanicie del MNP para ajustar a las anomalías observadas. Esta discontinuidad no fue modificada en los puntos donde el Moho de Assumpção et al. (2013) está restringido con datos provenientes de la sismología (Figura 4.5(d)). El Moho resultante puede ser observado en la figura 4.9(a) y las anomalías residuales del modelo final en la figura 4.9(b). Estas últimas fueron calculadas realizando la diferencia entre la anomalía de Bouguer del modelo geopotencial EGM2008 (Pavlis et al., 2012) y la calculada mediante el programa IGMAS+ (Götze y Schmidt, 2010). Según el modelo mejorado que ajusta a la gravedad, la corteza es más gruesa en el área de 


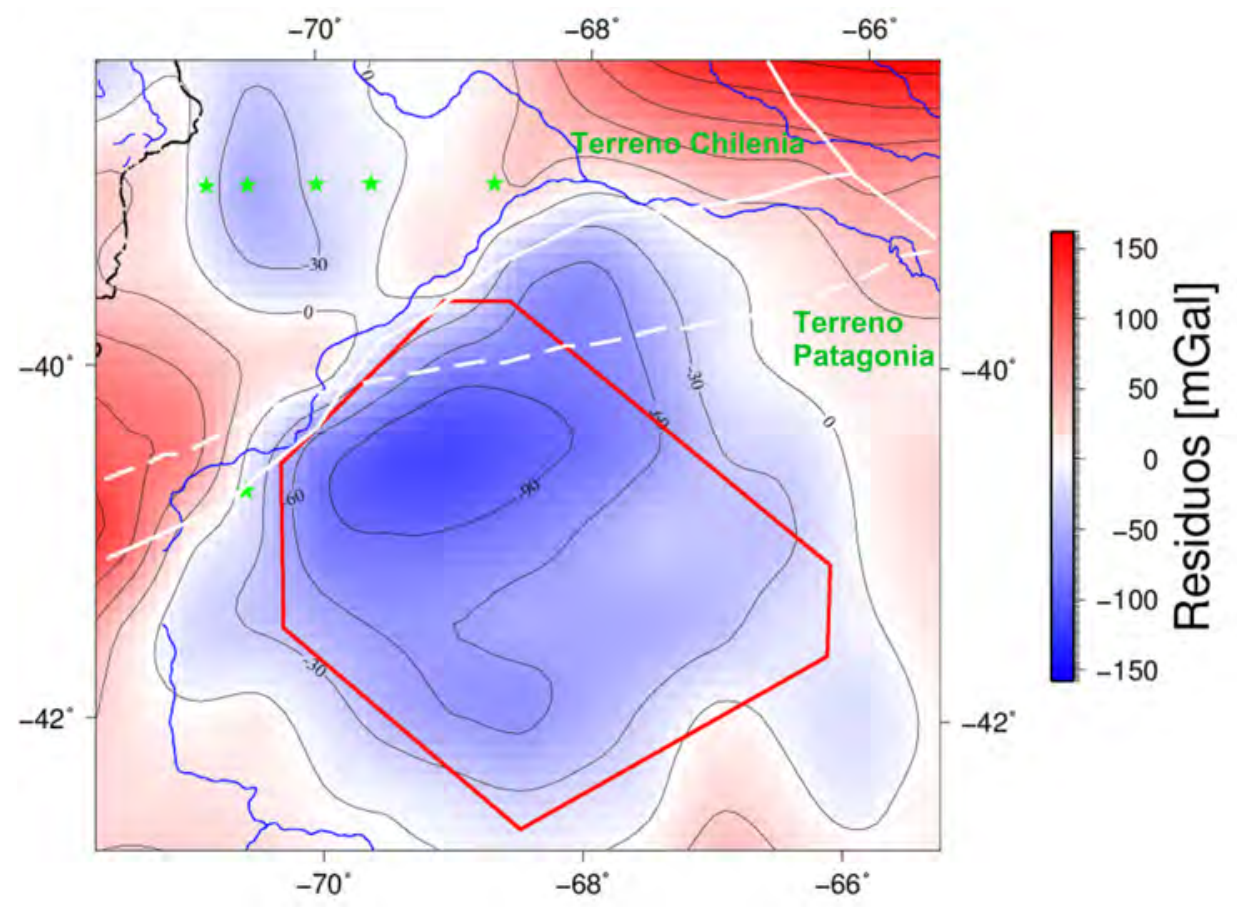

Figura 4.8. Anomalías residuales del modelo inicial calculadas realizando la diferencia entre la anomalía de Bouguer del modelo geopotencial EGM2008 (Pavlis et al., 2012) y la calculada mediante el programa IGMAS+ (Götze y Schmidt, 2010). La ubicación de los puntos donde hay datos independientes de profundidad de Moho están marcados con estrellas verdes. La sutura entre terrenos (Chernicoff y Zappettini, 2004) se señala con una línea blanca continua y el mismo límite proveniente de la velocidad de onda S con una línea blanca a trazos. 
Tabla 4.3. Estadísticas de las anomalías residuales del modelo final litosférico. Los valores están expresados en $m G a l$

\begin{tabular}{|l|l|l|l|l|l|}
\hline \multicolumn{3}{|c|}{ Área de estudio completa } & \multicolumn{2}{l|}{$\begin{array}{l}\text { Puntos donde hay datos de } \\
\text { profundidad de Moho sis- } \\
\text { mológico }\end{array}$} \\
\hline Promedio & $\begin{array}{l}\text { Desvío } \\
\text { estándar }\end{array}$ & $\begin{array}{l}\text { Valor } \\
\text { máximo }\end{array}$ & $\begin{array}{l}\text { Valor } \\
\text { mínimo }\end{array}$ & Promedio & Máximo \\
\hline$-7.76 \cdot 10^{-8}$ & 27.05 & 57.81 & -59.83 & 14.95 & 25.68 \\
\hline
\end{tabular}

la altiplanicie del MNP que en sus alrededores (Figura 4.9(a)). La profundidad del Moho varía entre 40 y $50 \mathrm{~km}$ en la altiplanicie, haciéndose más profunda desde los bordes hasta un punto cerca del centro y tiene forma elongada en dirección noreste a sudoeste (Figura 4.9(a)). La mayor diferencia entre la profundidad del Moho en la altiplanicie y en sus alrededores se puede observar en el borde norte, donde se ubica la cuenca Neuquina y con ella la zona de menores profundidades de la mencionada discontinuidad. En cambio, la menor diferencia en la profundidad del Moho se observa en el borde oeste, donde las fuerzas de compresión originadas en el margen de subducción causaron el engrosamiento de la corteza. En la esquina noroeste del área modelada, se puede observar el extremo sur de la raíz cortical de los Andes en su zona de máximas alturas (Figura 4.9(a)). También se puede observar que la profundidad de Moho encontrada en el área de la altiplanicie es similar a la de la zona andina mencionada previamente, así como también a la encontrada en otras raíces corticales.

El mapa de anomalías residuales de la figura 4.9(b) muestra un patrón similar en la parte norte (terreno de Chilenia) a los residuos del modelo inicial, pero con valores más bajos. En la parte sur del modelo (terreno de Patagonia), la anomalía de larga longitud de onda observada en la figura 4.8 fue eliminada mediante el proceso de modelado y en su lugar en la figura 4.9(b) se pueden observar pequeñas anomalías residuales. En la tabla 4.3 se resumen las estadísticas de estos residuos. En la localidad que tiene xenolitos extraídos recientemente (localidad III; Figura 4.9(b)) se puede ver un residuo negativo indicando un exceso de masa en el modelo. Sin embargo, las localidades que tienen extracción de xenolitos más antigua se encuentran afuera de los residuos negativos.

Los resultados, robustez e implicancias de este modelado serán discutidos en el capítulo 7. 


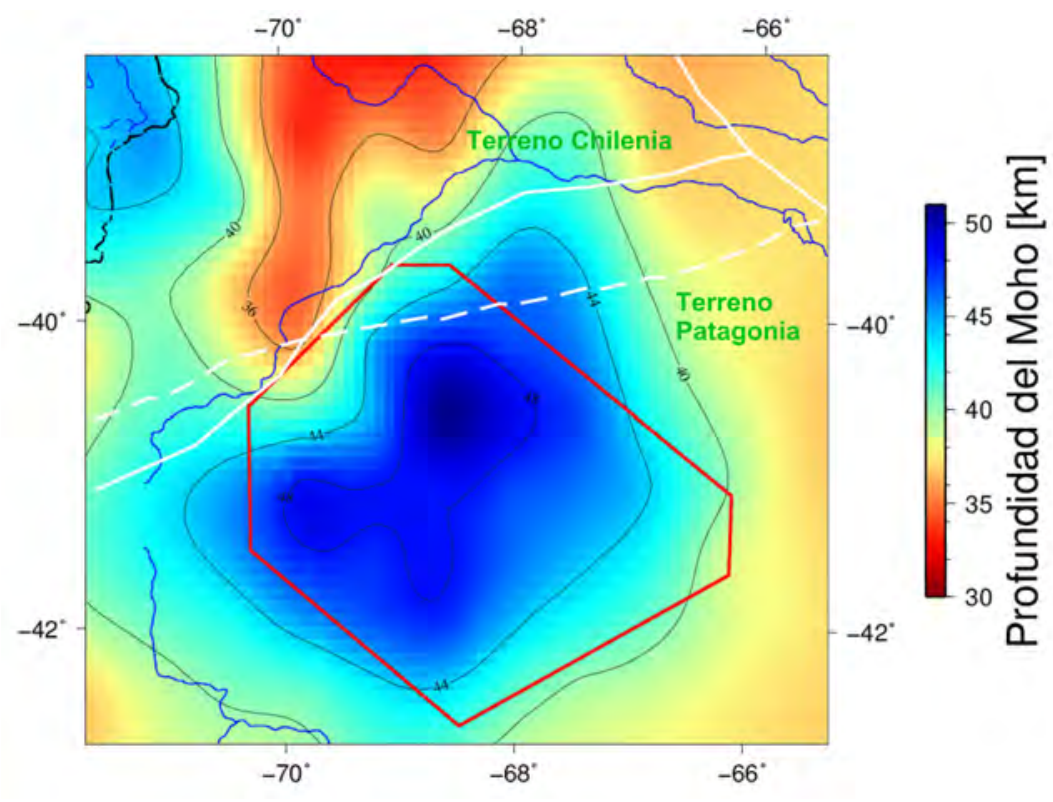

(a)

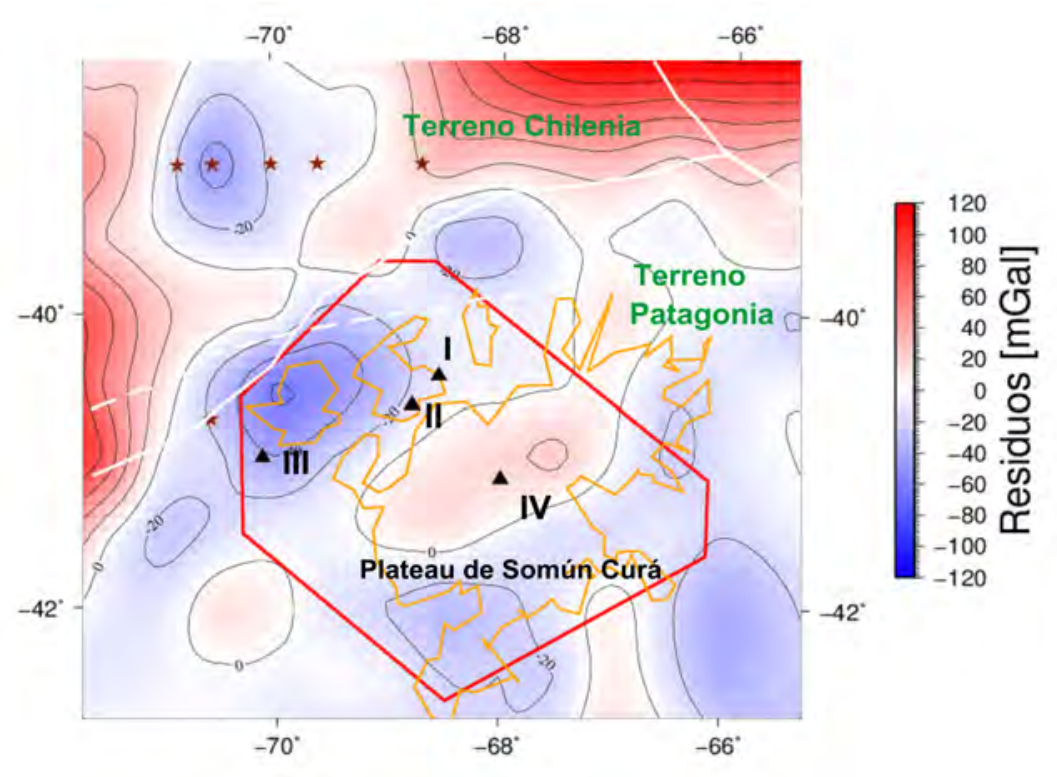

(b)

Figura 4.9. Moho y anomalías residuales del modelo final. La sutura entre terrenos (Chernicoff y Zappettini, 2004) se señala con una línea blanca continua y el mismo límite proveniente de la velocidad de onda S con una línea blanca a trazos. a) Profundidad de Moho predicha por el modelo. b) Anomalías residuales del modelo final. La ubicación de los puntos donde hay datos independientes de profundidad de Moho están marcados con estrellas rojas. Los basaltos aflorantes en el área están delimitados en naranja. La ubicación de las muestras de xenolitos es señalada con triángulos negros. 


\section{Capítulo 5}

\section{Modelado térmico tridimensional}

En este capítulo se describen los conceptos teóricos y procedimientos para obtener una distribución de temperaturas tridimensional tanto de la corteza como de la litósfera, mediante el modelado térmico. También se muestran y analizan los resultados obtenidos para el área de estudio de la tesis.

\subsection{Metodología}

\subsubsection{Fundamentos}

Para entender el comportamiento de las distintas regiones de la Tierra es necesario conocer su estructura termal, ya que la generación y transferencia de calor controla procesos geodinámicos tales como volcanes, terremotos, construcción de montañas, metamorfismo, etcétera (Fowler, 1990). El comportamiento mecánico, y por lo tanto la reología de las rocas, también está directamente relacionado con la temperatura y su variación con la profundidad (Turcotte y Schubert, 1982).

A la superficie de la Tierra llega el calor del Sol y también el de su interior, sin embargo, la fuente que influye en los procesos geodinámicos es la interna (Fowler, 1990). Esta proviene fundamentalmente del enfriamiento de la Tierra desde los primeros tiempos, cuando la temperatura era mucho mayor que la actual, y sobre todo de la producción de calor mediante el decaimiento de isótopos radiactivos (Lowrie, 2007).

Existen tres mecanismos de transferencia del calor: conducción, convección y radiación. La conducción transfiere el calor a través de la interacción molecular o atómica dentro del material, es un proceso difusivo en el cual las moléculas transmiten su energía cinética a otras colisionando entre sí. Para que exista transmisión mediante este mecanismo, debe haber en 
el medio en cuestión variación espacial de temperatura. El transporte por convección está asociado con la capacidad de las moléculas de moverse dentro del medio, por lo cual, es un medio de transporte importante en fluidos. La radiación es una transferencia directa de calor mediante ondas electromagnéticas (Fowler, 1990; Turcotte y Schubert, 1982).

En el interior de la Tierra, tanto la conducción como la convección son mecanismos importantes de transporte de calor. La distribución de temperatura en la corteza continental y litósfera está gobernada principalmente por el transporte de calor por conducción hacia la superficie del calor generado por el decaimiento de isótopos radiactivos en las rocas y del calor que fluye hacia arriba desde el manto subcontinental. La pérdida de calor interno en la corteza y litósfera oceánica también está controlada por la conducción aunque, en este caso, la convección es también importante, en particular cerca de las dorsales donde el agua circula a través de las rocas basálticas. La convección juega un papel importante en el transporte de calor en la Tierra ya que, a pesar de que no puede darse en sólidos, en el tiempo geológico el manto se comporta como un fluido de muy elevada viscosidad, lo cual permite una convección lenta. Por esta razón el mecanismo más importante de transporte de calor en el manto es la convección. En el núcleo interno sólido se supone que el mecanismo predominante es la conducción y en el externo la convección (Fowler, 1990; Turcotte y Schubert, 1982).

A pesar de la importancia del conocimiento de las temperaturas, no es posible medir temperaturas directamente en el interior profundo de la Tierra. Sólo es posible medir directamente temperaturas, gradientes de temperatura y flujos térmicos en la superficie o cerca de ella, como por ejemplo en pozos o minas. La estructura termal en las profundidades de la Tierra puede deducirse mediante la construcción de modelos, a través de la extrapolación, el conocimiento de la zona mediante información sísmica y los materiales que la forman junto con su comportamiento a altas temperaturas y presiones o conociendo la distribución de la producción del calor en el interior terrestre (Fowler, 1990). En este trabajo de tesis, se realizaron modelos utilizando cómo información de entrada el resultado de los modelos gravimétricos explicados en el capítulo anterior (Figura 1.2).

Los procesos de interés para el problema de investigación de la tesis se dan a escala litosférica y en zona continental, por lo cual, el mecanismo de transmisión de calor significativo es la conducción y será el que se expondrá a continuación.

La relación básica para el transporte de calor por conducción es la ley de Fourier, que dice que el flujo de calor o flujo térmico $(q)$, es decir el flujo de calor por unidad de área y por unidad de tiempo, en un punto de un medio es directamente proporcional al gradiente de 


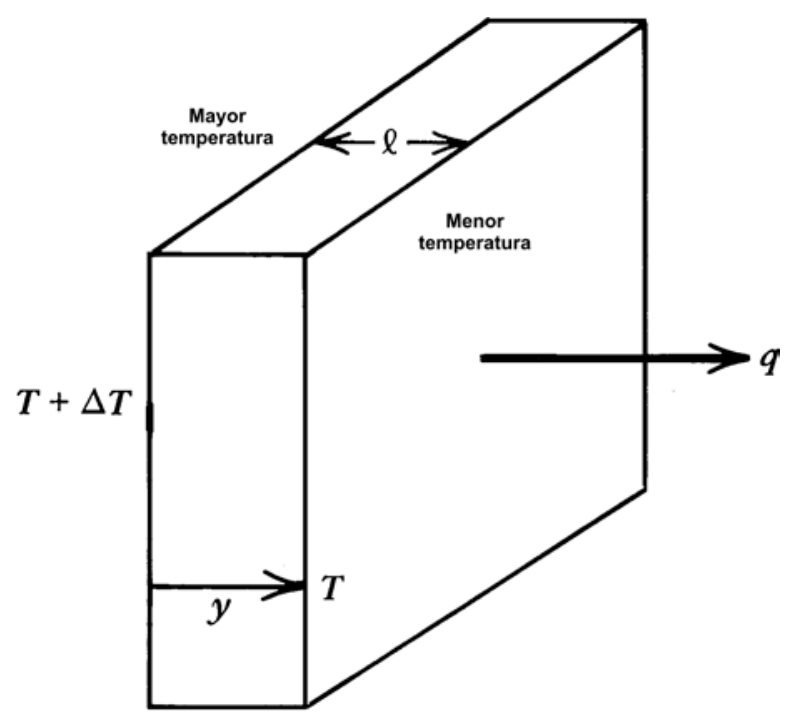

Figura 5.1. Flujo térmico a través de una placa. Imágen modificada de Turcotte y Schubert (1982)

temperatura en el punto. Por lo anteriormente mencionado, la ley de Fourier en una dimensión se puede expresar de la forma:

$$
q=-\kappa \frac{d T}{d y}
$$

en donde $\kappa$ (la constante de proporcionalidad) es el coeficiente de conductividad térmica e $y$ la dirección de la variación de la temperatura (Figura 5.1; Turcotte y Schubert 1982). La conductividad térmica es una propiedad física del material y es una medida de su capacidad de conducir el calor. El signo menos en la ecuación 5.1 indica que el flujo de calor va siempre en la dirección de decrecimiento de la temperatura (Figura 5.1). En general, el flujo térmico es medido en mili watts por metro cuadrado $\left(\mathrm{mW} / \mathrm{m}^{2}\right)$ y la conductividad térmica en watts por metro y por grado Kelvin $\left(W /\left(m^{\circ} K\right)\right)$. Se suele tomar el flujo superficial hacia arriba como creciente, aún en los casos en los cuales la profundidad se mide positiva hacia abajo y por lo tanto, el flujo queda negativo (Turcotte y Schubert, 1982).

El flujo térmico promedio en la superficie de la Tierra varía entre 40 y $90 \mathrm{~mW} / \mathrm{m}^{2}$, ya que el gradiente de temperatura cercano a la superficie generalmente está entre 20 a $30^{\circ} \mathrm{K} / \mathrm{km}$ y las conductividades térmicas de las rocas de la superficie rondan los 2 a $3 \mathrm{~W} /\left(\mathrm{m}^{\circ} \mathrm{K}\right)$. El valor de flujo térmico promedio es menor en los continentes que en los océanos y la media mundial es $70 \mathrm{~mW} / \mathrm{m}^{2}$. Hay muchas variaciones alrededor de esa media, por ejemplo en las áreas continentales, en zonas de volcanes activos o tectónica extensional. Sin embargo, suelen ser áreas pequeñas que no contribuyen mucho a la media. El mayor aporte a la variación 
del flujo térmico en zonas continentales está relacionado con las concentraciones de isótopos radiactivos. En las áreas oceánicas la característica más marcada es la disminución del flujo con la edad de la litósfera mientras esta se aparta de las dorsales centro oceánicas (Turcotte y Schubert, 1982).

Cómo fue mencionado, el calor que se conduce desde el interior caliente de la Tierra hacia la superficie, se genera por el decaimiento de elementos radiactivos y por el enfriamiento de la tierra durante el tiempo geológico. En áreas continentales, una parte sustancial del calor perdido se origina por la alta concentración de isótopos radiactivos de uranio, torio y potasio presentes en la corteza. Si llamamos $H$ a la tasa de producción de calor radiogénico por unidad de masa, entonces la cantidad de calor generada por una placa infinitesimal de espesor $d y$, por unidad de tiempo y de área en la placa será:

$$
\rho H d y
$$

siendo $\rho$ la densidad de la placa (Figura 5.2). La producción de calor $H$ varía según el material, ya que cada uno tiene distintas concentraciones de los isótopos radiactivos productores de calor. En la corteza y en el manto, esta propiedad es atribuida a los isotopos de uranio 235 y 238 , al de torio 232 y al de potasio 40, pero como estos no son estables en el tiempo y decaen en otros estables, entonces la producción de calor decrece con el tiempo. En la actualidad el uranio natural está compuesto por $99.27 \%$ del isótopo 238 y, por lo tanto, la concentración de este isótopo, junto con el de torio 232 y el de potasio 40, en las rocas terrestres es la responsable de la producción de calor radiactiva y en consecuencia del valor de $H$ para cada composición. Esta puede expresarse de la siguiente manera:

$$
H=C_{U}\left(H_{U}+\frac{C_{T h}}{C_{U}} H_{T h}+\frac{C_{K}}{C_{U}} H_{K}\right),
$$

siendo $C_{K}, C_{U}$ y $C_{T h}$ las concentraciones de isótopos radiactivos (potasio, uranio y torio, respectivamente) y $H_{K}, H_{U}$ y $H_{T h}$ la producción de calor radiogénico de cada elemento (Turcotte y Schubert, 1982). Las concentraciones de los isótopos varían considerablemente de una roca a otra y pueden obtenerse a partir del análisis composicional de muestras.

Ahora podemos unir la pérdida de calor por conducción con su generación por decaimiento de isótopos radiactivos en una ecuación: la ley de conducción de calor.

Si en la placa infinitesimal de espesor dy el flujo de calor saliente $q(y+\delta y)$ cruza la cara de la placa ubicada en $y+\delta y$ y el entrante $q(y)$ entra a través de la cara ubicada en $y$, entonces el flujo neto saliente de la placa por unidad de tiempo y de área será $q(y+\delta y)-q(y)$ (Figura 


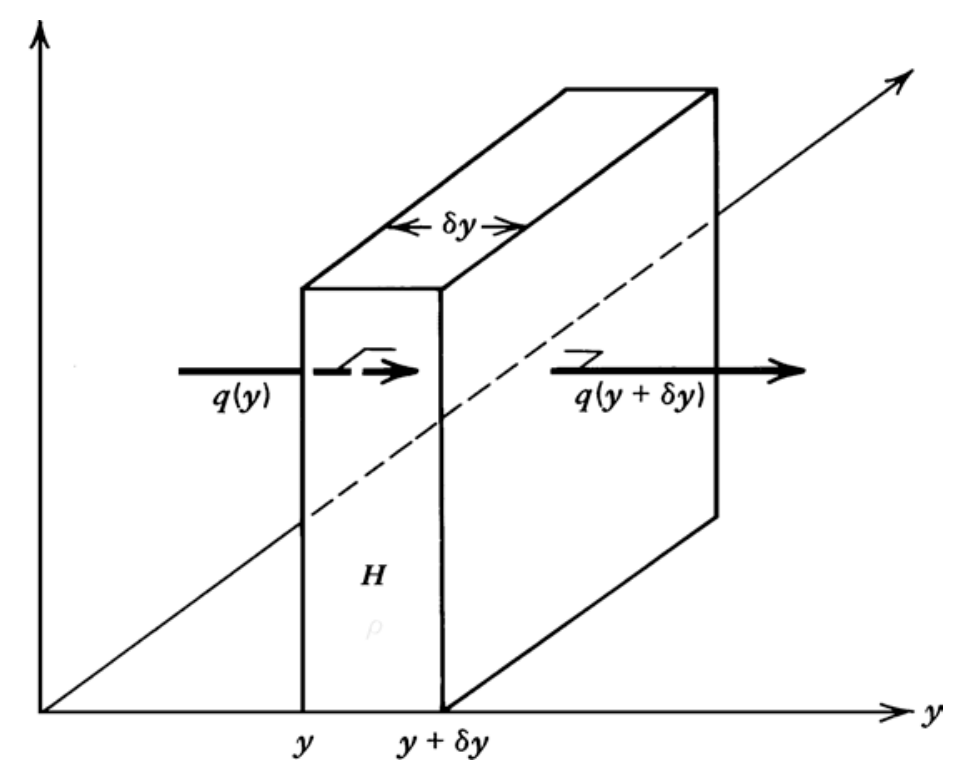

Figura 5.2. Flujo térmico entrante y saliente en una placa fina con producción de calor interno. Imágen modificada de Turcotte y Schubert (1982)

5.2; Turcotte y Schubert 1982). Como $\delta y$ es infinitesimal, podremos expandir en series de Taylor como:

$$
q(y+\delta y)=q(y)+\delta y d q / d y
$$

Usando la expresión para $q$ según la ley de Fourier y asumiendo una conductividad termal constante obtenemos:

$$
q(y+\delta y)-q(y)=\delta y d q / d y=\delta y d(-\kappa(d T / d y) / d y)=\delta y\left(-\kappa\left(d^{2} T / d y^{2}\right)\right) .
$$

Esta ecuación representa el flujo neto de la placa de espesor $\delta y$ por unidad de tiempo y de área y sólo es distinto de cero si hay curvatura en el perfil de temperaturas. Considerando que estamos en el caso estacionario, si el flujo neto es distinto de cero, entonces el calor debe ser proveído por un generador interno de la placa. Si consideramos la producción de calor radiogénico según la ecuación 5.2 e igualamos, obtendremos

$$
0=\kappa\left(d^{2} T / d y^{2}\right)+\rho H
$$

Esta ecuación puede ser resuelta para determinar la distribución de temperatura en función de la posición en una región, teniendo información acerca de temperaturas o flujos térmicos en los bordes de la región (condiciones de borde) y de las fuentes de producción de calor en el interior de la misma. Es una ecuación de conservación de energía que también 


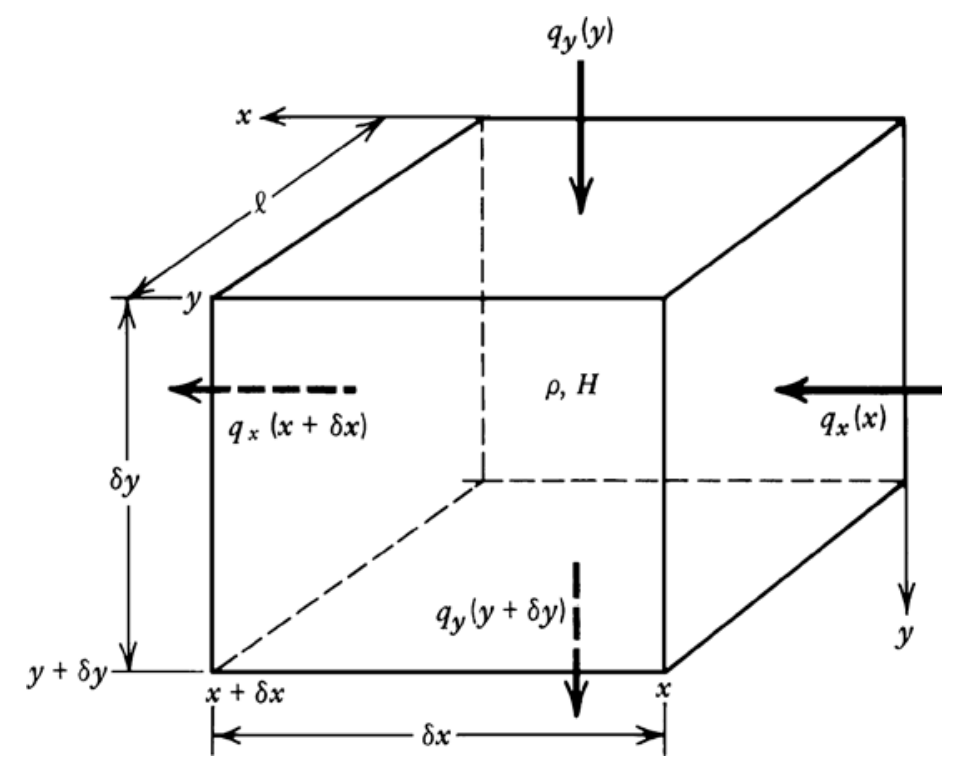

Figura 5.3. Flujo térmico en dos dimensiones en un elemento rectangular. Imágen modificada de Turcotte y Schubert (1982)

podría usarse para determinar variaciones temporales en la distribución de la temperatura si se considerara el caso no estacionario.

La ecuación 5.6 fue determinada en el caso en el cual el calor es transferido en una dimensión solamente, a continuación la extenderemos a dos y tres dimensiones.

Si ahora el calor puede conducirse en la coordenada $x$ y en la $y$, entonces podemos considerar un elemento con dimensiones $\delta x, \delta y, l$ (en la tercera dimensión no hay flujo de calor). El flujo en la dirección $x$ es $q_{x}$ y en $y$ es $q_{y}$ (Figura 5.3). La velocidad con la cual el calor fluye en el elemento en la dirección de $y$ es $q_{y}(y) \delta x l$ (flujo por área). Similarmente, el flujo de calor dentro del elemento en la dirección de $x$ es $q_{x}(x) \delta y l$. Y los flujos salientes son $q_{y}(y+\delta y) \delta x l$ y $q_{x}(x+\delta x) \delta y l$. Con lo cual el flujo de calor neto saliente del elemento es:

$\left(q_{x}(x+\delta x)-q_{x}(x)\right) \delta y l+\left(q_{y}(y+\delta y)-q_{y}(y)\right) \delta x l=\frac{\partial q_{x}}{\partial x} \delta x \delta y l+\frac{\partial q_{y}}{\partial y} \delta x \delta y l=\left(\frac{\partial q_{x}}{\partial x}+\frac{\partial q_{y}}{\partial y}\right) \delta x \delta y l$,

donde se realizó un desarrollo en series de Taylor para reemplazar en la diferencia entre flujos. La tasa de producción de calor radiogénico del elemento es $\rho H(\delta x \delta y l)$ e igualando se llega a:

$$
\frac{\partial q_{x}}{\partial x}+\frac{\partial q_{y}}{\partial y}=\rho H
$$

Lo mismo se puede hacer para el caso en que el calor fluya en las tres dimensiones y, en 
ese caso, la ecuación quedaría:

$$
\frac{\partial q_{x}}{\partial x}+\frac{\partial q_{y}}{\partial y}+\frac{\partial q_{z}}{\partial z}=\rho H
$$

o bien

$$
\bar{\nabla} \cdot \bar{q}=\rho H
$$

Es posible utilizar la ley de Fourier para relacionar el flujo de calor en cada dirección con el gradiente de temperatura. Si se asume que la conductividad termal de la roca es isotrópica, es decir, que la roca conduce calor de igual manera en todas las direcciones, entonces podemos escribir la ley de Fourier como:

$$
\begin{aligned}
& q_{x}=-\kappa \frac{\partial T}{\partial x}, \\
& q_{y}=-\kappa \frac{\partial T}{\partial y}, \\
& q_{z}=-\kappa \frac{\partial T}{\partial z},
\end{aligned}
$$

o bien,

$$
\bar{q}=-\kappa \nabla T
$$

Reemplazando las ecuaciones 5.11, 5.12 y 5.13 en la ley de conducción del calor (ecuación 5.10) obtenemos:

$$
\nabla \cdot(-\kappa \bar{\nabla} T)=\rho H
$$

o bien,

$$
-\kappa\left(\frac{\partial^{2} T}{\partial x^{2}}+\frac{\partial^{2} T}{\partial y^{2}}+\frac{\partial^{2} T}{\partial z^{2}}\right)=\rho H
$$

\subsubsection{Aplicación}

En la figura 5.4 se puede observar un detalle del flujo de trabajo realizado durante el modelado térmico.

Se asume que el volumen de roca investigado está en equilibrio térmico, es decir, en estado estacionario, con lo cual es posible utilizar la ecuación 5.15 para encontrar la distribución de temperaturas en el área de estudio. Al ser una ecuación diferencial, para encontrar una 


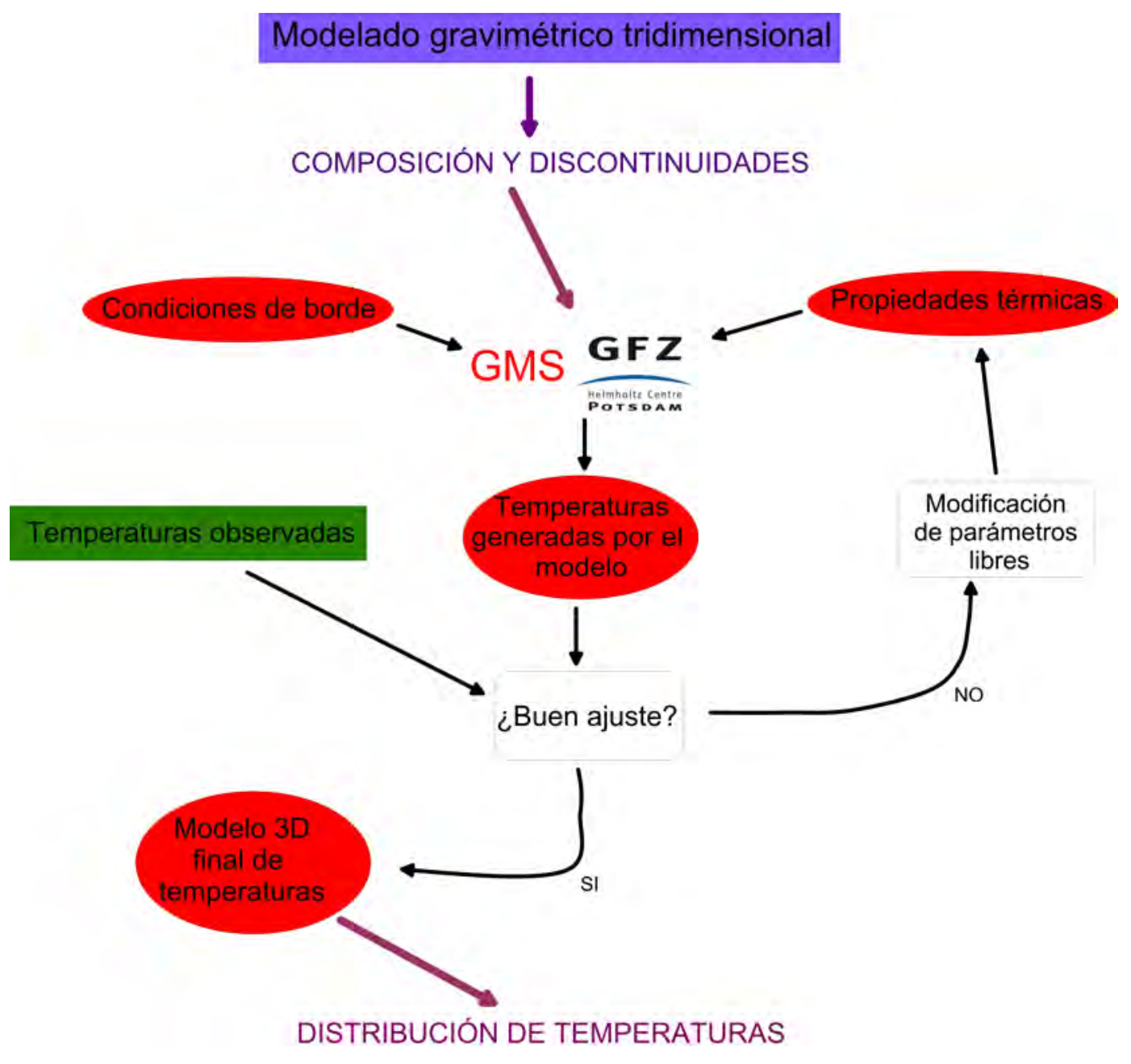

Figura 5.4. Diagrama de flujo del modelado térmico. 
solución única es necesario imponer condiciones de borde, en este caso en cada uno de los bordes del área a modelar (superior, inferior y laterales).

La ecuación tridimensional de conducción del calor se resolvió numéricamente utilizando elementos finitos en 3D mediante el software GeoModelling System (GMS) desarrollado en el GFZ, Potsdam, Alemania (Bayer et al., 1997) (Figura 5.4).

La ecuación 5.15 muestra que las temperaturas resultantes dependerán de la conductividad térmica $(\kappa)$ y de la producción de calor radiogénico de cada material $(S=\rho H)$. Para definir estas propiedades térmicas en todo el volumen a investigar es necesaria una parametrización, es decir, un modelo en el cual se definan los distintos cuerpos y su composición para poder asignarles propiedades coherentes. En el caso de esta tesis, se realizaron modelos térmicos utilizando como entrada la composición y geometría resultantes de los modelos gravimétricos explicados en el capítulo 4. Es decir, se utilizaron los resultados del modelado gravimétrico tridimensional para restringir las variaciones composicionales, las cuales a su vez, pueden ser interpretadas como variaciones de los parámetros térmicos (producción de calor radiogénico y conductividad térmica). Adicionalmente, se eligieron condiciones de contorno acordes, teniendo en cuenta la información disponible (Figura 5.4). El programa GMS permite al usuario la imposición de condiciones de borde superior e inferior tanto de Dirichlet (valor de la temperatura conocido en alguna de las dos superficies) cómo de Neumann (valor del flujo térmico conocido en alguna de las superficies). Los bordes laterales del modelo están cerrados al flujo térmico por defecto.

Los factores principales que controlan la temperatura que resulta de un modelo térmico son: las condiciones de contorno (geometría y valor); el espesor y composición de la corteza (ya que determina la cantidad de producción de calor radiogénico y tiene un gran contraste con el valor del mismo parámetro en el manto) y el espesor sedimentario que genera una aislación térmica debido a su bajo valor de conductividad térmica.

\subsection{Modelado preliminar: escala cortical}

El modelo de temperaturas preliminar se realizó a escala cortical, utilizando como base el modelo estructural resultante del modelado de gravedad tridimensional preliminar explicado en el capítulo anterior. La única diferencia en la estructura del modelo es que el límite inferior en este caso es el Moho y no una profundidad fija como en el caso del modelo gravimétrico.

Las propiedades térmicas utilizadas fueron obtenidas de la bibliografía. La producción 
Tabla 5.1. Propiedades térmicas de los cuerpos del modelo preliminar. Referencias en el texto

\begin{tabular}{|l|l|l|}
\hline Cuerpo & $\kappa\left[W /\left(m^{\circ} K\right)\right]$ & $S\left[\mu W / m^{3}\right]$ \\
\hline Sedimentos & 2.3 & 1.2 \\
\hline $\begin{array}{l}\text { Corteza su- } \\
\text { perior }\end{array}$ & 2.65 & 2 \\
\hline $\begin{array}{l}\text { Corteza in- } \\
\text { ferior }\end{array}$ & 3 & 0.75 \\
\hline Manto & 3.95 & 0.04 \\
\hline
\end{tabular}

de calor radiogénico $(S)$ fue obtenida de valores medios descriptos en Vila et al. (2010); la conductividad térmica $(\kappa)$ para los sedimentos de Sigismondi (2012), en donde se hace un análisis especial de este parámetro para la cuenca Neuquina que es la zona que tiene la gran mayoría de los sedimentos del área de estudio; y esta misma propiedad $(\kappa)$ para la corteza superior e inferior fue derivada de valores medios encontrados en Cermak y Rybach (1982) y Midttomme y Roaldstet (1999).

Las condiciones de contorno del modelado preliminar fueron de Dirichlet en el tope: la temperatura media anual en superficie calculada en la localidad de Maquinchao (ubicada en el centro de la altiplanicie del MNP), que según Del Barrio y Martin (2013), es de $9.5^{\circ} \mathrm{C}$ y de Neumann para la base: el flujo térmico en el Moho. Para esta última condición de contorno se buscaron los valores típicos según Turcotte y Schubert (1982) y se probaron dos valores distintos, que generaron dos modelos: $30 \mathrm{~mW} / \mathrm{m}^{2}$ (Modelo A) y $40 \mathrm{~mW} / \mathrm{m}^{2}$ (Modelo B).

Las propiedades térmicas de los distintos cuerpos del modelo fueron modificadas dentro de los límites dados por la literatura (Vila et al., 2010; Sigismondi, 2012; Midttomme y Roaldstet, 1999; Cermak y Rybach, 1982) de manera de ajustar los datos independientes de temperatura. Se obtuvieron dos sets de mediciones de temperatura, uno al norte y otro al sur de la altiplanicie del MNP con tres datos de temperaturas de fondo de pozo en cada caso (YPF S.A.; figura 5.5). Las propiedades térmicas finales se muestran en la tabla 5.1.

Las configuraciones de temperaturas que resultan de ambos modelados pueden observarse en los cortes en profundidad de la figura 5.6. En los primeros kilómetros en profundidad de ambos modelos (figuras 5.6(a) y 5.6(b)) se pueden observar temperaturas levemente más altas en la cuenca Neuquina que en el MNP (alrededor de $15{ }^{\circ} \mathrm{C}$ de diferencia en promedio). Este 


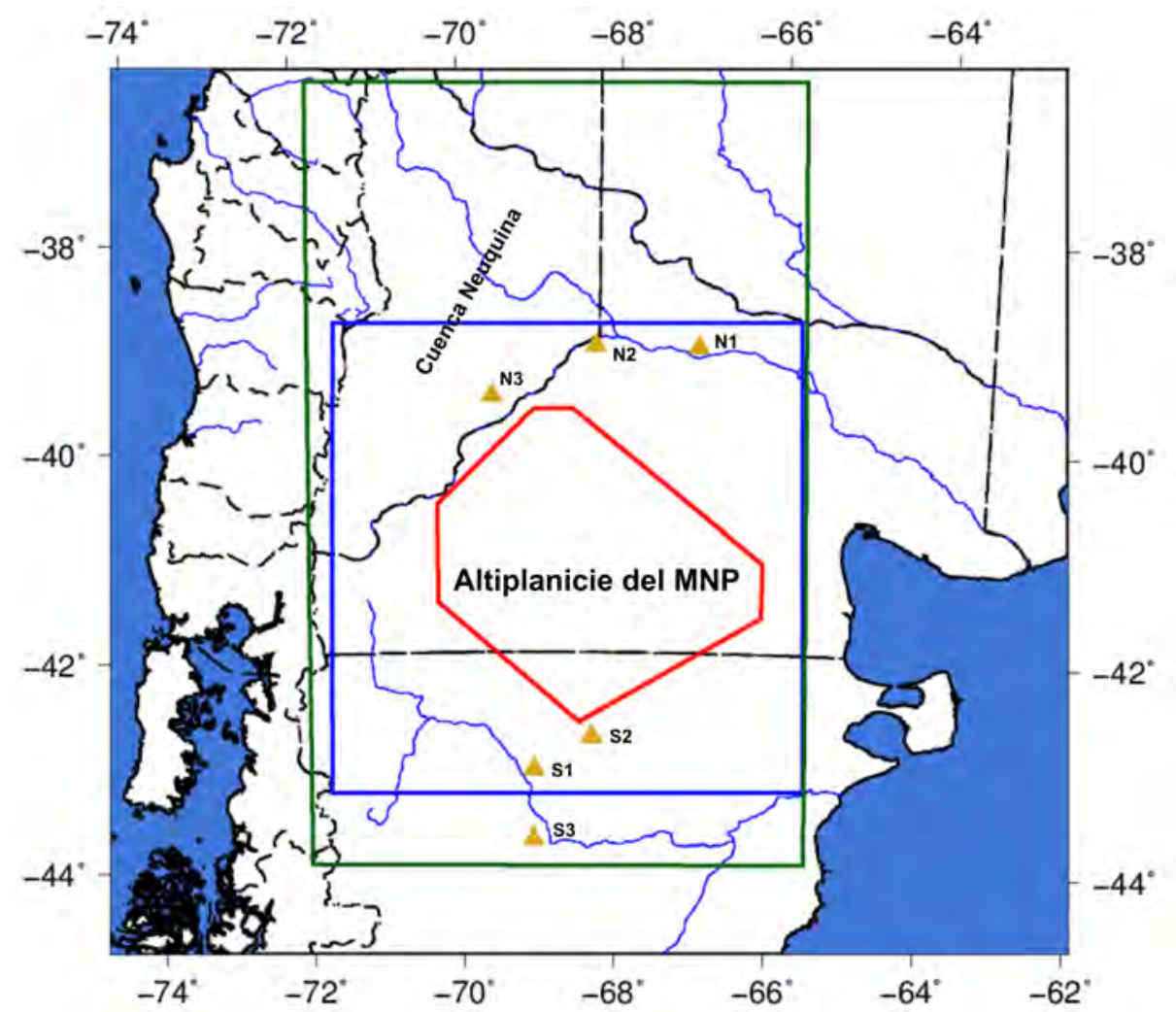

Figura 5.5. Ubicación de los pozos con datos de temperatura (denotados con triángulos amarillos) en relación con las áreas modeladas ( en verde la del modelo preliminar y en azul la del litosférico). 
efecto puede provenir del aislamiento térmico generado por los sedimentos debido a sus bajas conductividades térmicas. En cambio, en los cortes a una profundidad mayor $(15 \mathrm{~km})$ puede observarse que ocurre lo inverso, la altiplanicie del MNP presenta temperaturas más elevadas que la cuenca Neuquina $\left(30^{\circ} \mathrm{C}\right.$ de diferencia promedio). Este efecto puede estar influenciado por la profundidad del Moho en el modelo estructural, ya que en la altiplanicie hay mayor espesor de corteza cristalina y, por lo tanto, mayor generación de calor por decaimiento de isótopos radiactivos. En ambos modelos y a ambas profundidades se puede ver que, hacia el este, tanto del MNP como de la cuenca Neuquina, las temperaturas son menores. Lo contrario puede observarse debajo de la parte más alta de los Andes en la zona de estudio (mayores temperaturas con respecto al MNP y a la cuenca Neuquina).

Como se mencionó previamente, se realizó la validación de los modelos con datos de temperatura medidos en pozos del área de estudio (Figura 5.5). La tabla 5.2 muestra las diferencias entre los modelos preliminares realizados y los datos medidos.

Las diferencias entre los datos y el modelo A son la mayoría positivas indicando que el modelo necesita más temperatura para representar la realidad. En cambio con respecto al modelo B, la mayoría de las diferencias son negativas. Por lo tanto, el flujo térmico medio en el Moho debería estar entre 30 y $40 \mathrm{~mW} / \mathrm{m}^{2}$. Además hay variabilidad en las diferencias con respecto a ambos modelos, con lo cual o bien el flujo térmico podría variar en el Moho o la configuración del modelo podría no estar representando la realidad.

Por otro lado, se realizó la comparación del flujo térmico de los modelos con datos de flujo térmico publicados. Una de las fuentes de información es Hamza y Muñoz (1996) cuyos datos fueron obtenidos a partir de estudios geoquímicos en áreas de aguas termales. Todo el conjunto de datos, en este caso, está ubicado en el área de los Andes y reflejan variaciones locales en el flujo térmico superficial relacionadas con el vulcanismo. El otro set de datos es el de Davies (2013), este mapa está basado en mediciones de flujo térmico alrededor del mundo y está disponible en una grilla de $2^{\circ} x 2^{\circ}$. En áreas de buena cobertura el mapa se basa en las mencionadas mediciones, en áreas de corteza oceánica se estima usando un modelo de conducción basado en la edad de la placa oceánica y en áreas con pocos datos, la estimación se basa en la suposición de que hay relación entre el flujo térmico y la geología del lugar. En la comparación entre los datos y los modelos (tabla 5.3), se puede observar que, en general, los modelos térmicos no son coincidentes con los datos de Hamza y Muñoz (1996) pero sí con el mapa de Davies (2013). Esta diferencia puede deberse a la diferencia en los datos, ya que Davies (2013) realiza una aproximación regional del flujo en un área mientras que Hamza y 


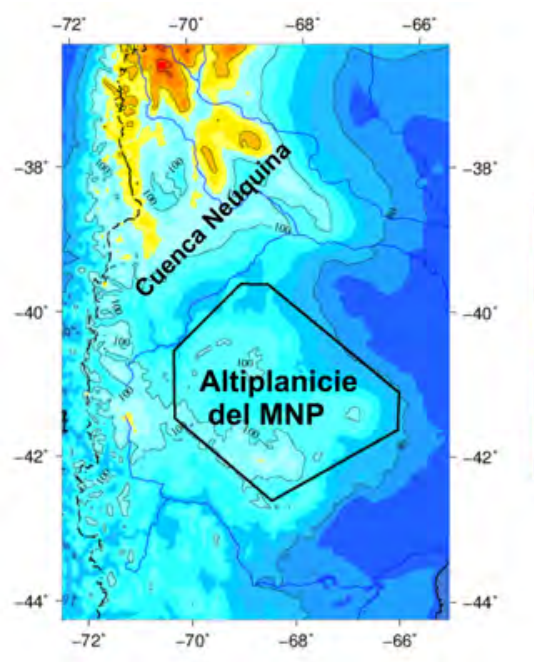

(a)

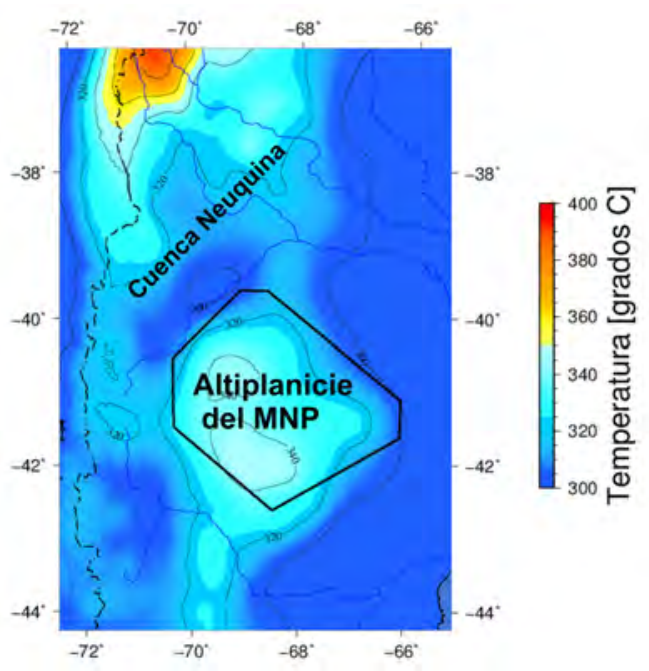

(c)

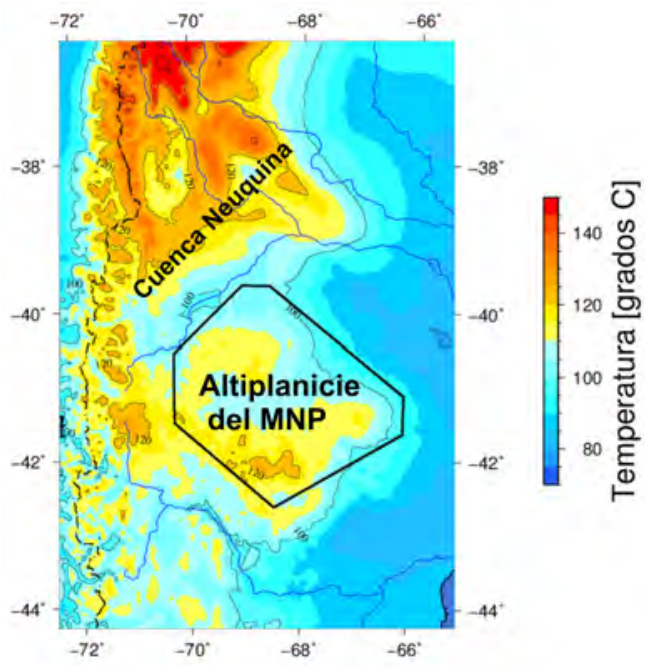

(b)

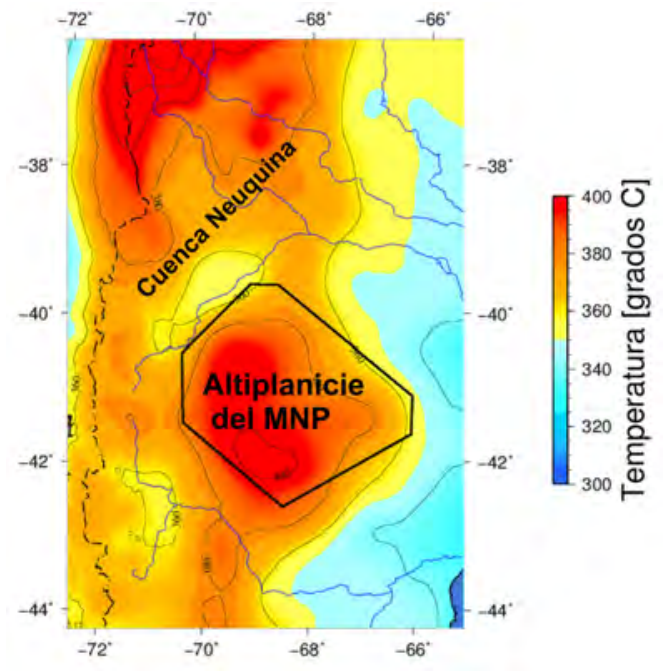

(d)

Figura 5.6. Cortes a distintas profundidades de los dos modelos preliminares de temperatura. A la izquierda se pueden observar los cortes del modelo A (30 $\mathrm{mW} / \mathrm{m}^{2}$ en el Moho). A la derecha, del modelo B (40 mW/ $\mathrm{m}^{2}$ en el Moho). a) Corte a $3 \mathrm{~km}$ de profundidad del modelo A. b) Corte a $3 \mathrm{~km}$ de profundidad del modelo B. c) Corte a $15 \mathrm{~km}$ de profundidad del modelo A. d) Corte a $15 \mathrm{~km}$ de profundidad del modelo B. 
Tabla 5.2. Validación de los modelos preliminares con datos de pozos. Cuadro de doble entrada que contiene las diferencias entre los datos de temperatura medidos (entrada vertical) y los modelos realizados (entrada horizontal). La ubicación de los pozos puede observarse en la figura 5.5. Los valores están expresados en ${ }^{\circ} \mathrm{C}$.

\begin{tabular}{|l|l|l|}
\hline---- & Modelo A & Modelo B \\
\hline N1 & 4.47 & -1.51 \\
\hline N2 & 2.09 & -4.54 \\
\hline N3 & -10.66 & -18.37 \\
\hline S1 & 11.92 & 1.73 \\
\hline S2 & 3.6 & -7.77 \\
\hline S3 & 7.87 & -2.34 \\
\hline
\end{tabular}

Muñoz (1996) presentan datos provenientes de variaciones locales del flujo térmico. Debido a las características del modelo estructural (y de las propiedades térmicas asociadas) los modelos son a gran escala, es decir, las temperaturas sólo representan la tendencia general, sin considerar variaciones locales. Por esto último es lógico que haya mejor ajuste con los datos del mapa de Davies (2013).

A causa de las incertidumbres del modelo preliminar, sobre todo en cuanto a las precisiones del modelo estructural de entrada y las variaciones en el flujo en el Moho (que sugieren los modelos), se decidió hacer un modelo litosférico de temperaturas explicado en la sección siguiente.

\subsection{Modelado litosférico}

\subsubsection{Definición de parámetros de entrada}

Modelo estructural. Para el caso del modelado térmico tridimensional a escala litosférica, se decidió utilizar como base la geometría y composición resultante del modelado gravimétrico tridimensional litosférico explicado en el capítulo anterior.

Observando los residuos que genera el modelo de densidades se puede concluir que existen variaciones de densidad de menor longitud de onda que la modelada entre terrenos paleozoicos (Figura 4.9(b)). Por esta razón, se decidió modificar el modelo agregando cuerpos corticales que sigan las variaciones de los residuos de gravedad como se observa en la figura 5.7(a). Se dividieron los dos cuerpos principales (Chilenia y Patagonia) en tres cuerpos corticales cada 
Tabla 5.3. Comparación de los modelos preliminares con datos de flujo térmico superficial. Los datos estadísticos de las diferencias están expresados en $m W / m^{2}$.

\begin{tabular}{|c|c|c|}
\hline Diferencias & Promedio & $\begin{array}{l}\text { Desvío es- } \\
\text { tándar }\end{array}$ \\
\hline $\begin{array}{ll}\text { Hamza } & \text { y Mu- } \\
\text { ñoz } & (1996)- \\
\text { Modelo A }\end{array}$ & 106.6 & 60.8 \\
\hline $\begin{array}{ll}\text { Hamza } & \text { y } \mathrm{Mu}- \\
\text { noz } & (1996)- \\
\text { Modelo B }\end{array}$ & 96.3 & 61.1 \\
\hline $\begin{array}{l}\text { Davies (2013)- } \\
\text { Modelo A }\end{array}$ & 2.8 & 4.9 \\
\hline $\begin{array}{l}\text { Davies (2013)- } \\
\text { Modelo B }\end{array}$ & 12.8 & 5 \\
\hline
\end{tabular}

uno siguiendo la isolinea de $0 \mathrm{mGal}$ de residuo de gravedad. En aquellos en los cuales los residuos son positivos, se aumentó la densidad con respecto al cuerpo original y en los que los residuos son negativos se redujo. La cantidad incrementada o reducida fue modificada iterativamente hasta llegar a un buen ajuste entre las anomalías observadas y modeladas. Así, el modelo refinado cuenta con 6 cuerpos corticales como se puede observar en la figura 5.7(a). La división de cuerpos, en general, no coincide con los afloramientos de roca en la zona ya que estos últimos no indican cual es la composición en profundidad en esa zona. La otra información existente sobre la composición de la corteza en el área de estudio es a los $25 \mathrm{~km}$ de profundidad (profundidad más superficial del modelo de tomografías sismológicas SL2013sv (Schaeffer y Lebedev 2013; Figura 4.5(e)). Como se puede observar en la figura 5.7(b), la división de cuerpos sigue mayormente la distribución de densidades que se observa a los $25 \mathrm{~km}$ de profundidad.

Con el objetivo de obtener una distribución de densidades para comparar con la división de cuerpos previamente explicada y así probar su validez, se realizó un modelado isostático según la hipótesis de Pratt, es decir, un cálculo de la densidad media cortical suponiendo balance isostático a escala litosférica. Se estableció una profundidad de compensación igual a $300 \mathrm{~km}$ y se planteó igualdad de presiones entre cada punto del modelo de densidades 


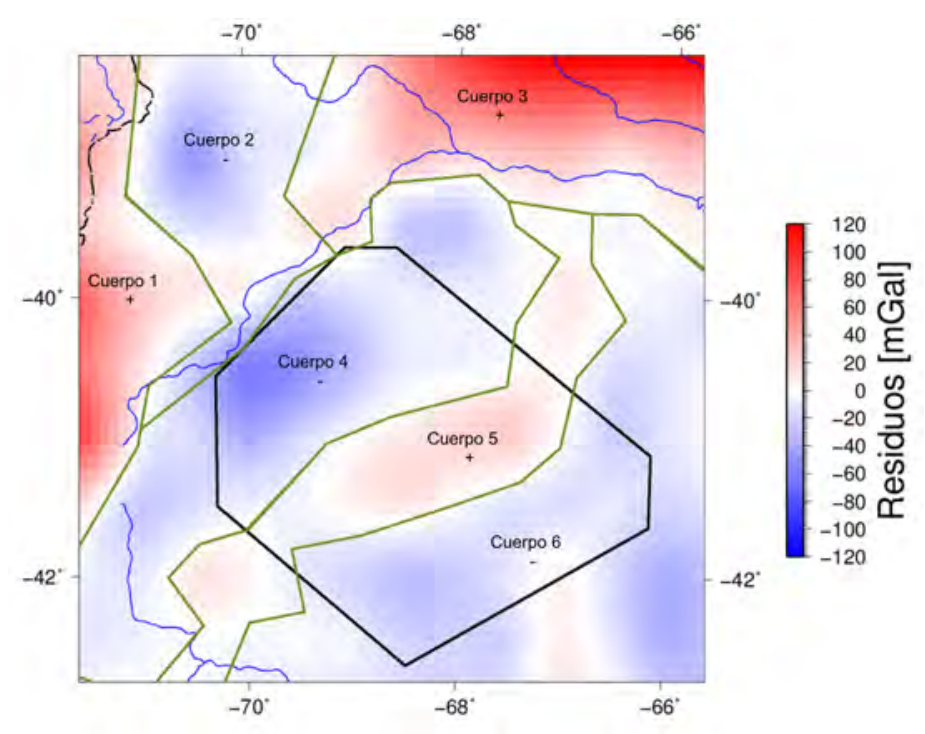

(a)

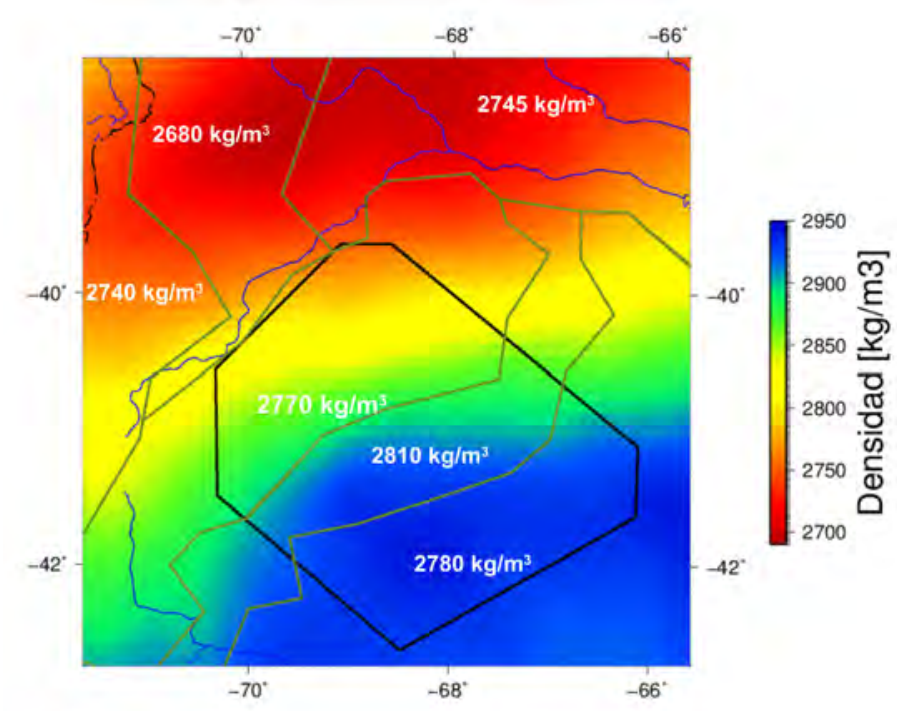

(b)

Figura 5.7. División de cuerpos de la corteza del modelo refinado que se utilizó como entrada del modelado térmico litosférico. a) Anomalías residuales del modelo gravimétrico y la división de cuerpos siguiendo la isolinea de $0 \mathrm{mGal}$ b) Densidad de cada uno de los cuerpos de la corteza en el modelo y su relación con la variación de densidad a los $25 \mathrm{~km}$ de profundidad según el modelo de tomografías sismológicas SL2013sv (Schaeffer y Lebedev, 2013) 
litosférico y un modelo de referencia, de la forma:

$$
\sum_{i} \rho_{i} h_{i}=\sum_{j} \rho_{j} h_{j}
$$

siendo $\rho_{i}$ y $h_{i}$ las densidades y los espesores de los cuerpos del modelo respectivamente (en cada punto) y $\rho_{j}$ y $h_{j}$ los del modelo de referencia. En el caso de esta tesis el modelo de referencia fue elegido en el punto de profundidad de Moho conocido (determinado por métodos sismológicos; Assumpção et al. 2013) en el cual hay menos residuo de gravedad. La topografía, la densidad de la corteza y del manto, así como también el espesor y densidad de los sedimentos, fueron extraídos del modelo gravimétrico tridimensional. La densidad del manto utilizada es el promedio de la grilla de densidades en el punto elegido. Con estos datos y utilizando la ecuación 5.17 se obtuvo como resultado la densidad media de la corteza en cada punto del modelo que puede observarse en la figura 5.8.

Se obtuvieron valores muy bajos de densidad (figura 5.8), en especial en el extremo noroeste de la zona de estudio. Esto hace que la densidad encontrada no sea realista, lo que puede deberse a una mala elección del modelo de referencia (el cual puede no ser representativo de la zona de estudio) o a que la hipótesis no sea correcta, es decir, que la zona no esté en balance isostático o no lo esté en su totalidad. Sin embargo, el cálculo de densidades sirve para tener un punto de comparación con la división de cuerpos establecida, ya que permite observar la variación relativa entre áreas con distintas densidades dentro de la zona de estudio. Siguiendo este fin, en la figura 5.8 se puede ver la buena relación entre la densidad media isostática y la división de cuerpos de distintas densidades.

Cabe destacar que, si bien la comparación con otra técnica para derivar la densidad media cortical del área es relevante para la validación de la división en cuerpos de distintas densidades, esta es robusta de antemano al ajustar al mismo tiempo la gravedad y la distribución de densidades a los $25 \mathrm{~km}$ obtenida de tomografías sismológicas que son un dato independiente.

El programa de modelado (GMS) requiere que se utilicen grillas iguales para todas las capas del modelo. En este caso se decidió grillar con un espaciamiento de $50 \mathrm{~km} x 50 \mathrm{~km}$ cada una de las discontinuidades del modelo ya que este es el espaciamiento que tiene el modelo de tomografías elegido como parte del modelo inicial (UU-P07 Amaru 2007).

Propiedades térmicas. Una vez que fue elegido el modelo estructural a utilizar como parámetro de entrada, es necesario otorgarle a cada uno de los cuerpos propiedades térmicas. Para el caso de la corteza, siguiendo la bibliografía, se eligieron propiedades acordes con la composición de los cuerpos principales: Chilenia y Patagonia y, a partir de ello, se realizaron 


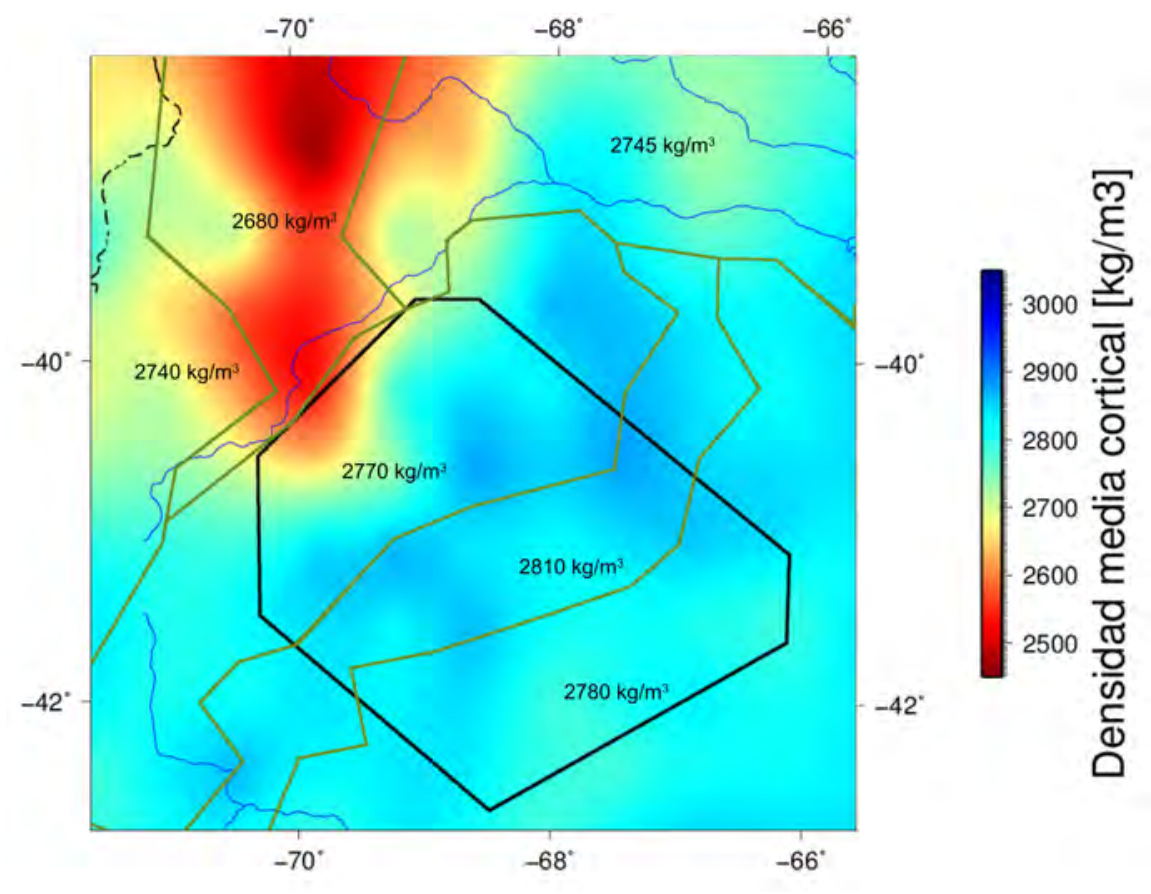

Figura 5.8. Densidad media cortical calculada bajo la hipótesis de balance isostático

modificaciones a esos valores de acuerdo a la variación de densidad entre cada cuerpo y la asignada al terreno paleozoico. Para Patagonia los valores elegidos para la conductividad térmica $(\kappa)$ y la producción de calor radiogénico $(S)$ fueron el promedio del valor encontrado para un terreno principalmente metamórfico (composición aflorante) y para las granulitas (composición encontrada en los xenolitos de la corteza inferior). En el caso de la conductividad térmica, los valores fueron extraídos de Cermak y Rybach (1982) y para la producción de calor radiogénico de Vila et al. (2010). Para el caso de Chilenia, al no disponer de xenolitos en esa área, se supuso que la composición de la corteza inferior sería parecida y por lo tanto, se realizó el promedio entre una composición principalmente plutónica (composición elegida para el modelado gravimétrico para Chilenia) y las granulitas para obtener un valor. Los valores fueron extraídos de las mismas fuentes bibliográficas. Para el manto, los valores también fueron obtenidos para una composición ultramáfica de Cermak y Rybach (1982) para $\kappa$ y de Vila et al. (2010) para $S$. En el caso de los sedimentos, para la producción de calor radiogénico se utilizó el valor dado en Vila et al. (2010) y para la conductividad térmica se tuvo en cuenta la porosidad y se calculó el valor utilizando:

$$
\kappa_{b}=\kappa_{w}^{\phi} \cdot \kappa_{s}^{(1-\phi)}
$$

siendo $\kappa_{b}$ la conductividad termal bulk, que es la que se utiliza en el cálculo de las temperatu- 
Tabla 5.4. Propiedades térmicas de los cuerpos del modelo litosférico. Referencias en el texto

\begin{tabular}{|l|l|l|}
\hline Cuerpo & $\kappa\left[W /\left(\mathrm{m}^{\circ} \mathrm{K}\right)\right]$ & $S\left[\mu \mathrm{W} / \mathrm{m}^{3}\right]$ \\
\hline Sedimentos & 1.81 & 1.1 \\
\hline Corteza 1 & 2.73 & 1.7 \\
\hline Corteza 2 & 2.95 & 1.75 \\
\hline Corteza 3 & 2.75 & 1.6 \\
\hline Corteza 4 & 2.89 & 1.5 \\
\hline Corteza 5 & 2.83 & 1.29 \\
\hline Corteza 6 & 2.87 & 1.43 \\
\hline Manto & 4.2 & 0.01 \\
\hline
\end{tabular}

ras, $\kappa_{w}$ la conductividad termal del agua asumida igual a $0.6 \mathrm{~W} /\left(\mathrm{m}^{\circ} \mathrm{K}\right), \kappa_{s}$ la conductividad térmica de la matriz, que fue calculada como el promedio de los valores encontrados en Midttomme y Roaldstet (1999) para las arenas, arcillas y limolitas y $\phi$ la porosidad. La porosidad fue calculada sabiendo que:

$$
\rho_{b}=\rho_{w} \phi+\rho_{s}(1-\phi),
$$

utilizando valores típicos para la densidad del la matriz $\left(\rho_{s}\right)$ y la densidad del agua $\left(\rho_{w}\right)$ extraídos de la bibliografía y el valor asignado a los sedimentos en el modelado gravimétrico para la densidad bulk $\left(\rho_{b}\right)$.

Para obtener otro resultado independiente sobre la producción de calor radiogénico en la corteza, se utilizaron los datos de análisis químicos de los xenolitos de la corteza inferior (Ponce, 2016; Mundl et al., 2015) y de rocas aflorantes también en el terreno Patagonia descriptas en el trabajo de Pankhurst et al. (2006), quienes realizaron geoquímica de roca total. Esos datos se utilizaron para definir los valores de $C_{U}, C_{T h}$ y $C_{K}$ que luego se utilizaron, según la ecuación 5.3, junto con valores de la producción de calor radiogénico de cada elemento extraídos de Turcotte y Schubert (1982). Los valores para la propiedad térmica $S$ para la corteza patagónica fueron coincidentes mediante ambas técnicas.

Los valores finales de las propiedades térmicas de cada cuerpo del modelo se detallan en la tabla 5.4.

Condiciones de borde. Con el fin de definir condiciones de borde que permitan resolver la ecuación diferencial de conducción de calor estacionaria, se eligió fijar las temperaturas de 


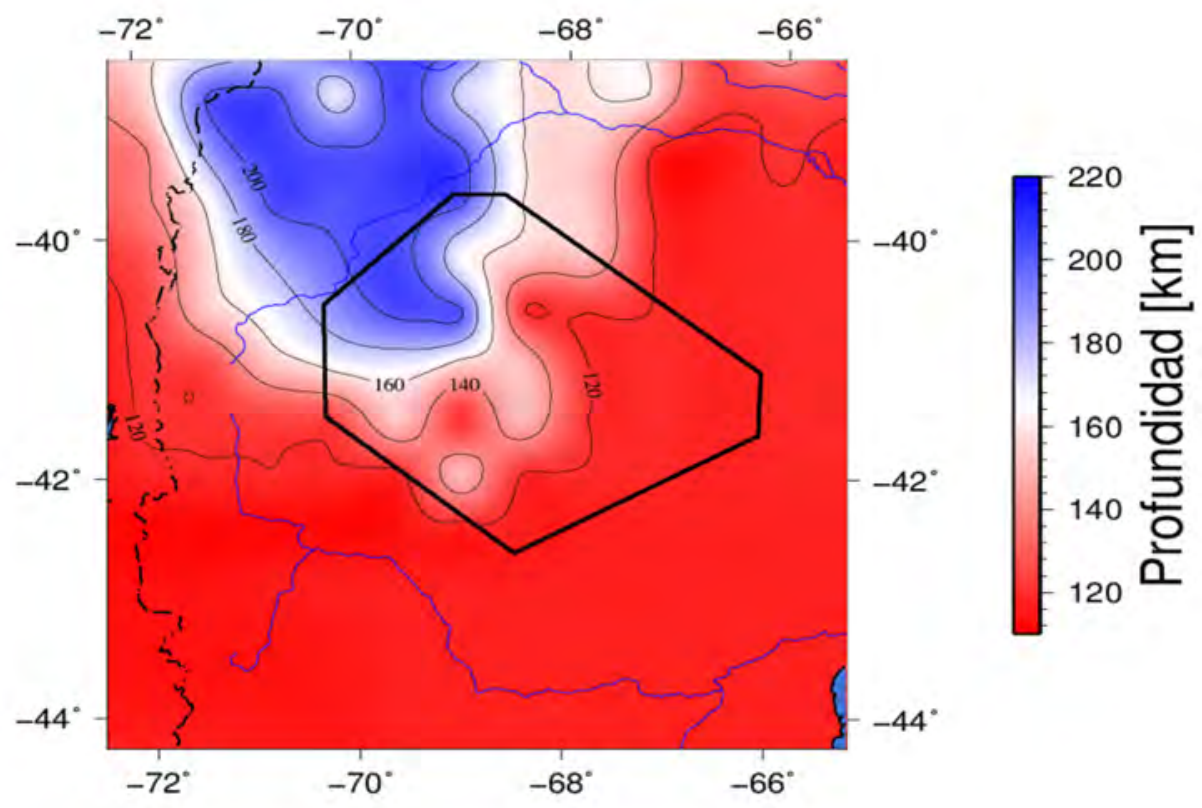

Figura 5.9. Profundidad de la isoterma de $1300^{\circ} \mathrm{C}$

los límites del modelo (condiciones de borde de Dirichlet), es decir, en la superficie y en la base de la litósfera. Para la superficie se utilizaron datos de temperaturas medias anuales en la zona de estudio y, tal cómo en el caso anterior, se optó por el valor de $9.5^{\circ} \mathrm{C}$ (Del Barrio y Martin, 2013). En el caso de la condición de borde inferior, se consideró igual a la ubicación de la isoterma de $1300{ }^{\circ} \mathrm{C}$, donde se considera que se encuentra la base de la litósfera, ya que a esa temperatura aproximadamente el comportamiento mecánico de los materiales del manto cambia (Turcotte y Schubert, 1982). Dicha isoterma fue hallada a partir de los datos del modelo de tomografías UU-P07 (Amaru, 2007) y mediante la conversión de sus velocidades de ondas $\mathrm{P}$ a temperaturas utilizando el programa velt, explicado en capítulos previos. Se utilizaron sólo los datos de este modelo de tomografías ya que fue el que demostró mayor coincidencia en su conversión a densidades con los datos calculados a partir de xenolitos. La profundidad de la isoterma de $1300{ }^{\circ} \mathrm{C}$ puede observarse en la figura 5.9 y varía entre $110 \mathrm{y}$ $210 \mathrm{~km}$, siendo mayor hacia el borde noroeste del modelo.

\subsubsection{Resultados}

La figura 5.10 muestra cortes a 10, 45 y $100 \mathrm{~km}$ de profundidad del modelo de temperatura calculado. A los $10 \mathrm{~km}$ de profundidad el modelo indica que la temperatura en el área de la altiplanicie del MNP es aproximadamente $10^{\circ} \mathrm{C}$ más fría que hacia el norte y el oeste, mientras que muestra temperaturas similares al sur y más frías al este (Figura 5.10(a)). 
La diferencia de temperaturas entre zonas dentro de la altiplanicie y fuera de ella llega a superar $\operatorname{los} 20^{\circ} \mathrm{C}$ para algunos puntos a esta profundidad. Esta configuración de temperaturas está relacionada con la ausencia de sedimentos, que actúen como aislantes, en la zona de la altiplanicie, ocasionando que el calor fluya hacia el exterior. En cambio, en áreas donde hay mayor espesor sedimentario (como en la cuenca Neuquina dentro de la zona de estudio) el calor se conduce más lentamente hacia el exterior. A una profundidad de $45 \mathrm{~km}$ (Figura 5.10(b)) se puede observar una mayor temperatura en la altiplanicie del MNP que en sus alrededores. Esta diferencia ronda $\operatorname{los} 50^{\circ} \mathrm{C}$ habiendo zonas dentro de la altiplanicie que difieren hasta en $100^{\circ} \mathrm{C}$ con respecto a zonas de los alrededores de la misma. Hacia el nornoroeste el gradiente de temperaturas es el mayor, ya que en esta zona se encuentran las menores temperaturas a esta profundidad. Hacia el oeste se pueden observar temperaturas elevadas también, aunque menores que en la altiplanicie (Figura 5.10(b)). La configuración de temperaturas a esta profundidad está relacionada con el mayor espesor de corteza cristalina encontrado en la altiplanicie del MNP, ya que en la corteza se genera una mayor cantidad de calor por producción de calor radiogénico, con respecto al que se genera en el manto. Por lo tanto, en la altiplanicie, el gran espesor de corteza y la gran profundidad del Moho hacen que se genere más calor y por consiguiente, haya mayores temperaturas a estas profundidades. A los $100 \mathrm{~km}$ las temperaturas siguen la configuración de la isoterma de $1300{ }^{\circ} \mathrm{C}$ incrementando de noroeste a sudeste.

Utilizando los resultados de temperatura, se calculó el flujo térmico superficial que genera el modelo, el cual puede ser observado en la figura 5.11. El modelo predice un valor mayor en el área de la altiplanicie, aunque este no es uniforme y presenta variaciones de alta frecuencia. Los valores en general se encuentran por encima de la media mencionada para áreas continentales.

Validación del modelo. Con el objetivo de validar el modelo realizado, se lo comparó con datos de temperaturas de pozos. En esta nueva área de estudio (más limitada) sólo tenemos cinco datos de temperatura de pozos, tres de ellos están ubicados al norte de la altiplanicie del MNP y los dos restantes al sur de la misma (figura 5.5). Todos ellos son temperaturas de fondo de pozo, lo que es importante ya que la circulación de fluidos durante la perforación afecta la medición. Para contrarrestar el efecto se puede proceder de dos maneras, o bien se mide en el fondo del pozo mientras se va perforando, ya que se considera que el fluido de perforación no tiene tiempo de afectar la temperatura en este punto; o de lo contrario se puede medir un tiempo después de terminada la perforación (Turcotte y Schubert, 1982). 


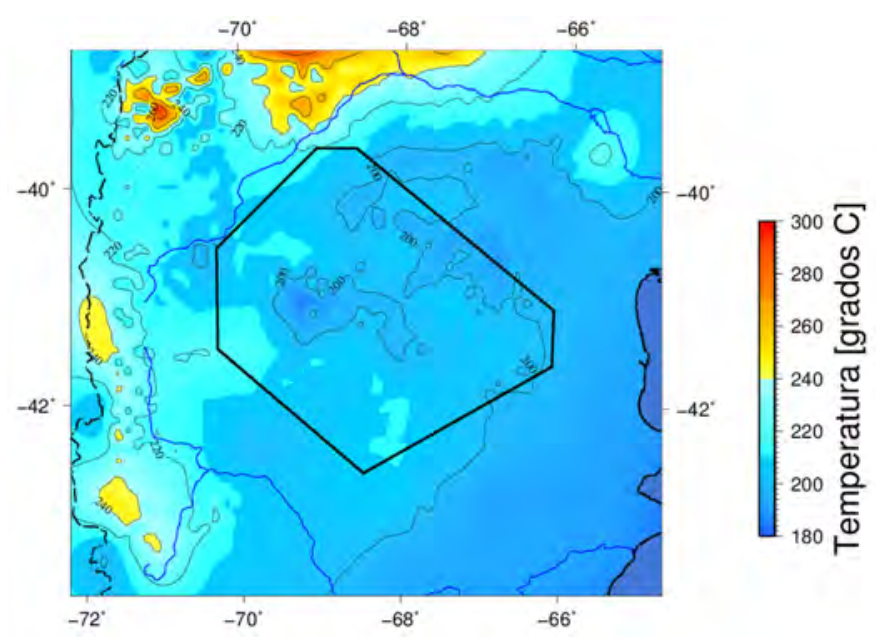

(a)

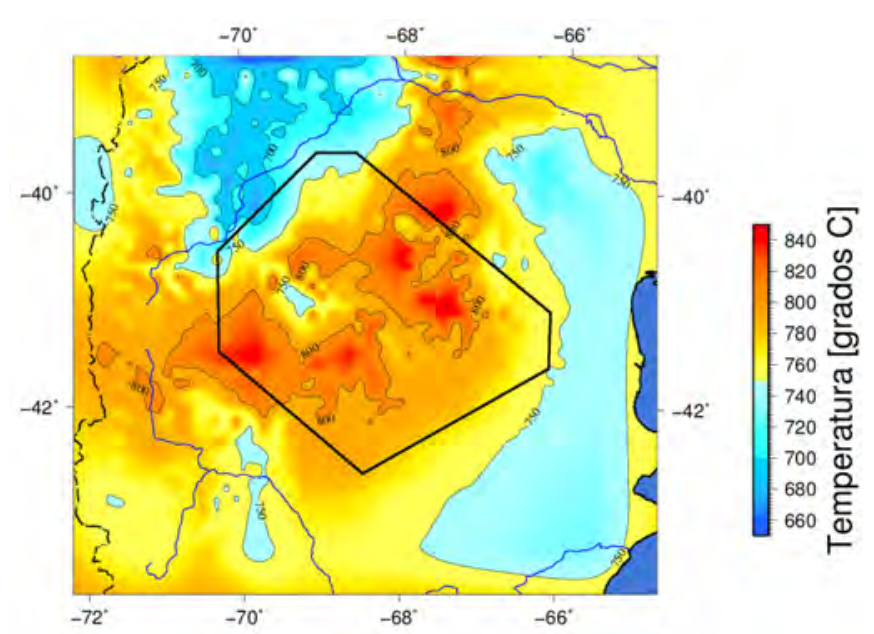

(b)

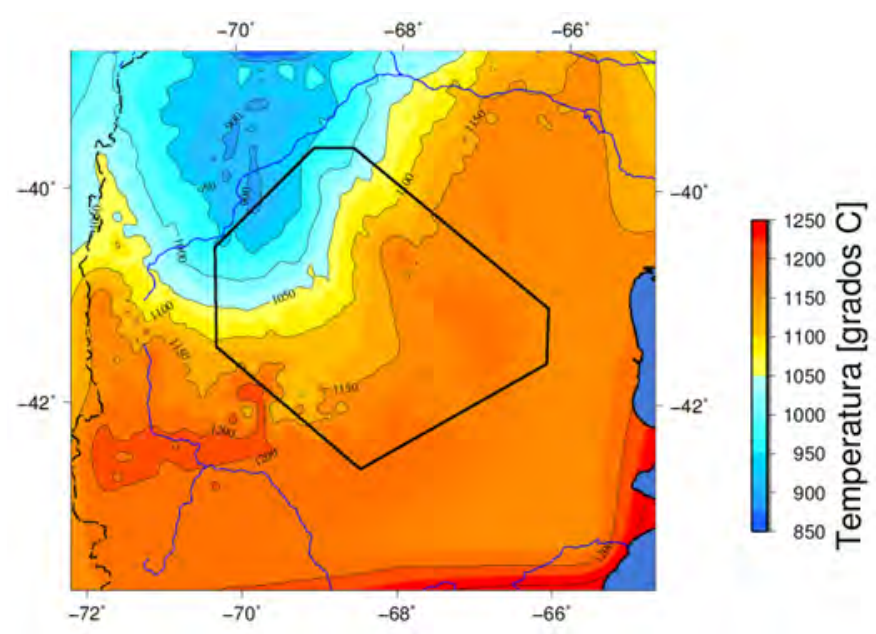

(c)

Figura 5.10. Cortes a distintas profundidades del modelo litosférico de temperaturas. a) Corte a $10 \mathrm{~km}$ de profundidad b) Corte a $45 \mathrm{~km}$ de profundidad c) Corte a $100 \mathrm{~km}$ de profundidad. 


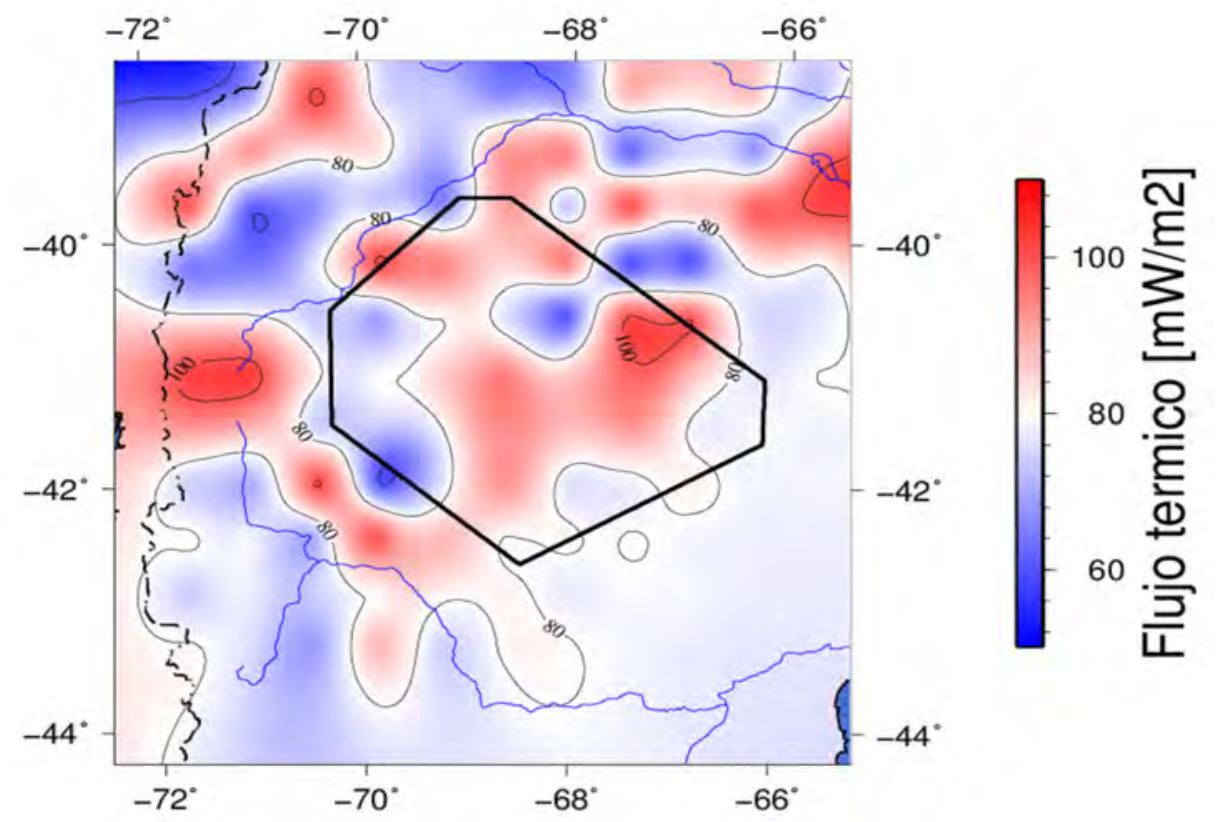

Figura 5.11. Flujo térmico superficial predicho por el modelo litosférico de temperatura.

También se pueden realizar correcciones sobre los valores medidos que intentan devolver el valor a la temperatura real, sin la variación impuesta por la circulación de fluidos.

La diferencia de temperatura entre los datos medidos en pozos y los calculados por el modelo puede ser observada en la tabla 5.5. Se puede ver que las diferencias con los pozos del norte son negativas, con lo cual el modelo tiene mayor temperatura que los datos reales, en cambio, lo contrario ocurre en los pozos del sur, lo que nos dice que el modelo en esa área es más frío que los datos. Esta tendencia puede estar confirmando la diferencia en composición e historia de los dos terrenos paleozoicos que forman el área de estudio, ya que, para ajustar a los datos de temperaturas medidos habría que disminuir la temperatura del modelo al norte y aumentarla al sur. El modelo es más parecido a los datos en los pozos del norte (especialmente en el N1 y el N2) que a los del sur. Es probable que los pozos del sur también requieran una corrección. Esto disminuiría su valor y ajustaría mejor al modelo.

También se realizó una comparación entre el flujo térmico del modelo y los datos del mapa de flujo térmico de Davies (2013). En este caso, sólo se comparó con este mapa ya que los datos incluidos en Hamza y Muñoz (1996) están concentrados en los Andes y en zonas de aguas termales, con lo cual suelen ser localmente altos. Las diferencias entre el flujo térmico calculado a partir del modelo y el de Davies (2013) tienen un promedio de $15.1 \mathrm{~mW} / \mathrm{m}^{2}$ y un desvío estándar de $8.62 \mathrm{~mW} / \mathrm{m}^{2}$. Las diferencias tienen alta frecuencia, ya que el mapa de flujo térmico de Davies (2013) es relativamente uniforme y con menor resolución que el modelo. 
Tabla 5.5. Validación del modelo térmico litosférico con temperaturas medidas en pozos. Cuadro que contiene las diferencias entre los datos de temperatura medidos y los del modelo realizado. La ubicación de los pozos pueden observarse en la figura 5.5. Los valores están expresados en ${ }^{\circ} \mathrm{C}$.

\begin{tabular}{|l|l|}
\hline Pozo N1 - Modelo & -2.42 \\
\hline Pozo N2 - Modelo & -2.75 \\
\hline Pozo N3 - Modelo & -13.55 \\
\hline Pozo S1 - Modelo & 14.76 \\
\hline Pozo S2 - Modelo & 10.43 \\
\hline
\end{tabular}

Además son, en su mayoría, positivas lo cual indica que el flujo térmico del modelo es mayor que el del mapa de Davies (2013). Esto se puede deber a que el mapa de Davies (2013) tiene pocos datos de flujo térmico en el área modelada o a que el modelo esté generando un flujo más elevado que el real. La última opción es poco probable, ya que de la comparación con las temperaturas medidas se deriva que al sur habría que aumentar la temperatura del modelo, obteniendo así un flujo térmico mayor y una mayor diferencia. Se cree que la diferencia se debe a la metodología que emplea el modelo de Davies (2013), en el que se asume que el flujo térmico se correlaciona con la geología superficial del área (en zonas de falta de datos como es el caso de la altiplanicie) y, por lo tanto, le asigna a la altiplanicie del MNP valores más bajos de flujo térmico debido al tipo de roca aflorante. Como consecuencia, las causas que generan alto flujo térmico en la zona, las cuales se encuentran en profundidad, no son tenidas en cuenta por el modelo de Davies (2013).

Los resultados de este modelo y su combinación con los resultados del modelo de densidades, serán discutidos en el capítulo 7 


\section{Capítulo 6}

\section{Modelado reológico y espesor}

\section{elástico}

En este capítulo se muestra y explica la realización de un modelo reológico para el área de estudio, junto con sus fundamentos teóricos y sus resultados. El objetivo del modelo es la obtención de la distribución de resistencia en la litósfera, la que en conjunto con las de densidades y temperaturas nos permite obtener conclusiones sobre la zona de trabajo. A partir de la reología del área, se obtuvo el espesor elástico equivalente, el cuál es comparado con el espesor elástico efectivo derivado de la gravedad.

\subsection{Modelado reológico}

La reología es la ciencia de la deformación y el flujo de los materiales sólidos sometidos a presión. La forma en la que un sólido reacciona a la presión depende de la intensidad de la misma y del tiempo durante el que es aplicada (Lowrie, 2007). A presiones y temperaturas ambiente muchas de las rocas son frágiles, es decir, se comportan casi elásticamente hasta que se fracturan. Sin embargo, también existen muchas circunstancias en las cuales las rocas se comportan de manera dúctil, en general, a profundidades mayores y temperaturas más altas (Turcotte y Schubert, 1982).

La resistencia se puede definir como el límite de la tensión diferencial requerida para iniciar una ruptura o comenzar a fluir con una cierta tasa de deformación (Tesauro et al., 2015). Es decir, es la tensión máxima que las rocas pueden resistir en forma elástica sin deformarse permanentemente (Tassara y Yáñez, 2003). Si la tensión es menor que la resistencia entonces la roca sufre deformación elástica en cortos intervalos de tiempo. Es decir, la deformación 
causada por la tensión es completamente recuperable cuando la tensión es removida. En cambio, si la tensión es mayor que la resistencia, la deformación puede ser frágil, es decir que sufre ruptura sin otra distorsión, o dúctil, el sólido se deforma lenta y permanentemente. La deformación frágil es un proceso abrupto que libera energía elástica en forma de ondas sísmicas, mientras que en el caso de la deformación dúctil el proceso es lento, es decir, el sólido debe ser sometido a tensión durante un tiempo prolongado (Lowrie, 2007).

La capacidad de un sólido de fluir se denomina ductilidad. La ductilidad de un sólido sometido a presiones superiores a la resistencia depende de la temperatura y la presión a la cual se encuentra (Lowrie, 2007). A temperaturas que son una fracción significativa de la temperatura de fusión, los átomos y dislocaciones en los sólidos cristalinos se vuelven suficientemente móviles para resultar en Reptación (o creep) si el sólido está sujeto a tensiones deviatóricas. Este tipo de comportamiento puede encontrarse, por ejemplo, en el manto cuando convecta o en la litósfera inferior donde se relajan las tensiones elásticas (Turcotte y Schubert, 1982).

La resistencia de una roca a cierta profundidad está determinada por el mecanismo de deformación que, ante esas condiciones, requiere la menor cantidad de tensión (Tesauro et al., 2015). Hay zonas donde ocurre una transición entre el comportamiento frágil y el dúctil. Esta se da cuando la resistencia frágil y la dúctil son iguales para esa roca bajo esa presión, temperatura y velocidad de deformación. La transición entre tipos de deformación frágil y dúctil ocurre a diferente profundidad en océanos y continentes y depende de varios factores: composición de las rocas, gradiente geotérmico local, espesor de corteza y velocidad de deformación, es decir que depende de la estructura estratificada vertical de la litosfera (Lowrie, 2007).

\subsubsection{Metodología}

\section{Fundamentos}

Para modelar el comportamiento reológico en las rocas de la corteza y del manto es apropiado usar idealizaciones. El comportamiento de cierta roca con la profundidad se puede modelar con una ley reológica que combina elasticidad lineal y viscosidad lineal y no lineal. Este tipo de materiales, que se comportan elástica y viscosamente, se conocen como viscoelásticos (Turcotte y Schubert, 1982).

Se pueden utilizar modelos de materiales ideales para luego combinarlos y representar la realidad. Un material elástico es aquel que se deforma de manera proporcional a la tensión aplicada y que una vez retirada la tensión vuelve a su estado inicial inmediatamente. En los 
materiales viscosos la variación de deformación es proporcional a la tensión y la constante de proporcionalidad se denomina viscosidad. Los materiales plásticos no se deforman hasta llegar a un cierto nivel de tensión, pero cuando se llega al límite el sólido puede deformarse continuamente sin incremento en la tensión.

Denominamos Leyes constitutivas a las relaciones entre la tensión $(\tau)$ y la tasa de deformación $(\dot{e})$. En el caso de los materiales ideales mencionados estas leyes son:

$$
\begin{gathered}
\dot{e}_{i j}^{\text {elástico }}=\frac{1}{2 G} \frac{d \tau_{i j}}{d t}, \\
\dot{e}_{i j}^{\text {viscoso }}=\frac{1}{2 \mu} \tau_{i j}, \\
\dot{e}_{i j}^{\text {plástico }}=\frac{\dot{\gamma}}{\tau_{l l}} \tau_{i j},
\end{gathered}
$$

siendo, G el módulo de corte, $\mu$ la viscosidad, $\dot{\gamma}$ la deformación plástica y $\tau_{l l}=\sqrt{\tau_{i j} \tau_{i j}}$, el segundo invariante del tensor de tensiones desviador.

La tasa de deformación final se construye con la superposición de leyes constitutivas. Se suman todas ellas para que cada una se minimice o sea prioritaria según corresponda a las variables del lugar y momento. Entonces la tasa de deformación final queda:

$$
\dot{e}_{i j}=\dot{e}_{i j}^{\text {elástico }}+\dot{e}_{i j}^{\text {viscoso }}+\dot{e}_{i j}^{\text {plástico }}
$$

con lo cual se tiene:

$$
\dot{e}_{i j}=\frac{1}{2 G} \frac{d \tau_{i j}}{d t}+\left(\frac{1}{2 \mu}+\frac{\dot{\gamma}}{\tau_{l l}}\right) \tau_{i j} .
$$

Al paréntesis de la ecuación 6.5 lo podemos describir como la viscosidad de un sólido viscoplástico (viscosidad efectiva, $\mu_{e f f}$ ) y será una función de la presión, la temperatura y el segundo invariante del tensor de tensiones desviador quedando:

$$
\dot{e}_{i j}=\frac{1}{2 G} \frac{d \tau_{i j}}{d t}+\frac{1}{2 \mu_{e f f}\left(P, T, \tau_{l l}\right)} \tau_{i j} .
$$

Para poder describir el comportamiento de un material en distintas condiciones, debemos encontrar la función viscosidad efectiva. Para esto, se estudia como fluyen las rocas.

En el caso de comportamiento frágil, lo que suele darse a bajas presiones y temperaturas, las rocas puede deformarse por los siguientes mecanismos: 
- Cataclasis: Se genera una pequeña fractura y hay un movimiento a lo largo de esas fracturas. Se da bajo presiones de confinamiento pequeñas.

- Frictional grain-boundary sliding: Desplazamiento de granos unos relativos a otros.

Ambos casos pueden modelarse utilizando la ley de Byerlee:

$$
\tau_{l l}=C+u P,
$$

donde $\tau_{l l}$ (cantidad que nos da el correspondiente largo o norma del tensor desviador de tensiones) está descripto por un parámetro $C$ denominado cohesión del material, que es la tensión mínima que necesita aplicarse a ese material antes de que se fracture si está a presión ambiente y por $u$ que es el coeficiente de fricción que también es una característica de cada material. Es decir, la tensión necesaria para deformar el material permanentemente, en el caso frágil, tiene una relación lineal con la presión.

En el caso de comportamiento dúctil, lo que suele darse a altas presiones y temperaturas, las rocas pueden fluir mediante los siguientes mecanismos:

- Reptación (o Creep) por difusión: Genera el transporte de roca de un lugar a otro dentro de un mismo cuerpo de roca. El movimiento se puede describir como el de un fluido Newtoniano y, por lo tanto, su tasa de deformación puede escribirse como:

$$
\dot{e}_{L}=B_{L} \tau_{l l} e^{-\frac{H_{L}}{R T}},
$$

siendo, $B_{L}$ una contante que depende del material denominada factor pre-exponencial, $H_{L}$ la entalpia de activación descripta por $H_{L}=A_{L}+V_{L} P$ donde $A_{L}$ es la energía de activación, $V_{L}$ el volumen de activación y $P$ es la presión, $R$ es la constante universal de los gases y T la temperatura. El subíndice $L$ indica que son las cantidades referidas a la reptación por difusión.

- Reptación (o Creep) por dislocación: Se da mediante procesos internos de los granos o cristales de la roca. En todas las redes cristalinas hay defectos, que pueden migrar cuando es sometida a tensión. Estos movimientos permiten a la red cristalina deformarse o cambiar de forma sin romperse. Este movimiento puede ser descripto por:

$$
\dot{e}_{N}=B_{N} \tau_{l l}^{n} e^{-\frac{H_{N}}{R T}},
$$


donde el subíndice $\mathrm{N}$ denota que las cantidades son referidas a la reptación por dislocación $\left(H_{N}\right.$ tiene la misma definición que $H_{L}$ pero en función de $A_{N}$ y $V_{N}$ ). En este caso, el segundo invariante del tensor desviador está elevado a la $n$, es decir que la dependencia no es lineal entre tensión y tasa de deformación. La potencia $n$ también varía según el tipo de roca. Este mecanismo se produce a presiones relativamente bajas, con lo que en la corteza la presión tiende a 0 y $H_{N}$ es parecido a $A$. En el manto, esta aproximación ya no puede ser utilizada.

- Reptación (o Creep) de Peierls: Modela el comportamiento del material bajo mucha tensión diferencial.

$$
\dot{e}_{P}=B_{P} e^{-\frac{H_{P}}{R T}\left(1-\frac{\tau_{l l}}{\tau_{P}}\right)},
$$

donde $\tau_{P}$ es la tensión de Peierls y $H_{P}$ está en función de $A_{P}$ y $V_{P}$ (energía y volumen de activación para este caso).

Ahora, teniendo en cuenta la relación entre tensión y tasa de deformación (ecuación 6.6) se puede despejar la viscosidad efectiva en función de la presión y la temperatura como sigue:

$$
\mu_{e f f}=\frac{1}{2} \tau_{l l}\left(\dot{e}_{L}+\dot{e}_{N}+\dot{e}_{P}\right)^{-1}
$$

De este modo, se modelan los tres mecanismos de reptación a la vez y actúan según la presión y temperatura a la que este sometida la roca. En la figura 6.1 se muestran los distintos tipos de reptación de acuerdo a las condiciones de presión y temperatura.

Por último, también se puede tener deformación plástica. En este caso, la viscosidad efectiva considera también la deformación plástica $(\dot{\gamma})$ como si fuera una reptación más, resultando:

$$
\mu_{e f f}=\frac{1}{2} \tau_{l l}\left(\dot{e}_{L}+\dot{e}_{N}+\dot{e}_{P}+\dot{\gamma}\right)^{-1} .
$$

Goetze y Evans (1979) definieron la Yield Strength Envelope (YSE o Envolvente de resistencia a la deformación permanente) para la litósfera, que es un perfil vertical que predice la tensión diferencial máxima soportada por una roca como función de la profundidad (Figura 6.2). La YSE es representada por curvas de dos tipos diferentes: a profundidades pequeñas, la línea recta corresponde a la fractura frágil, mostrando un incremento de la resistencia con la profundidad. A profundidades mayores la línea curva que describe la deformación dúctil muestra que la resistencia decrece con la profundidad exponencialmente debido al incremento 


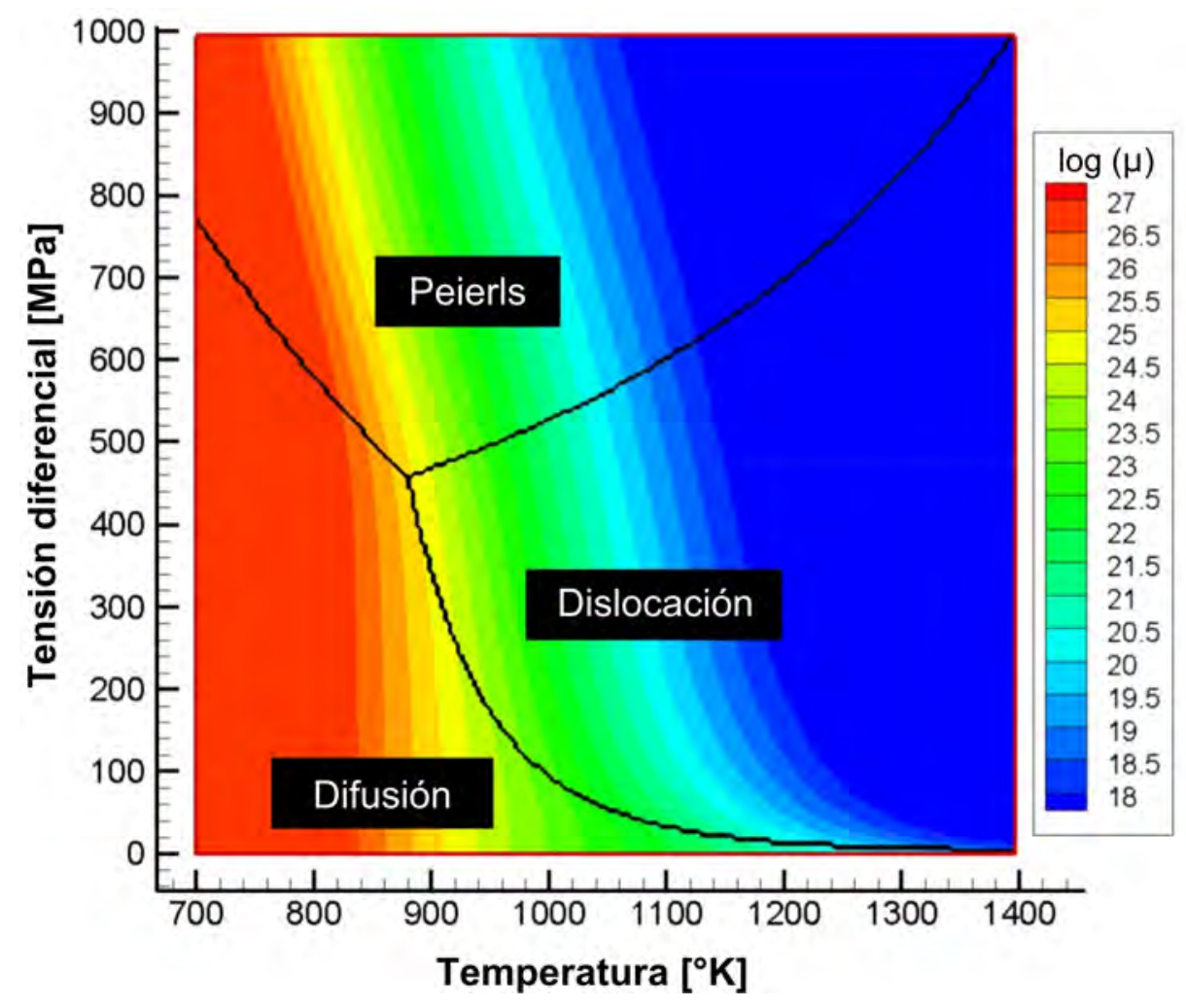

Figura 6.1. Distintos tipos de reptación según la presión y la temperatura. Imagen modificada de Quinteros (2013) 


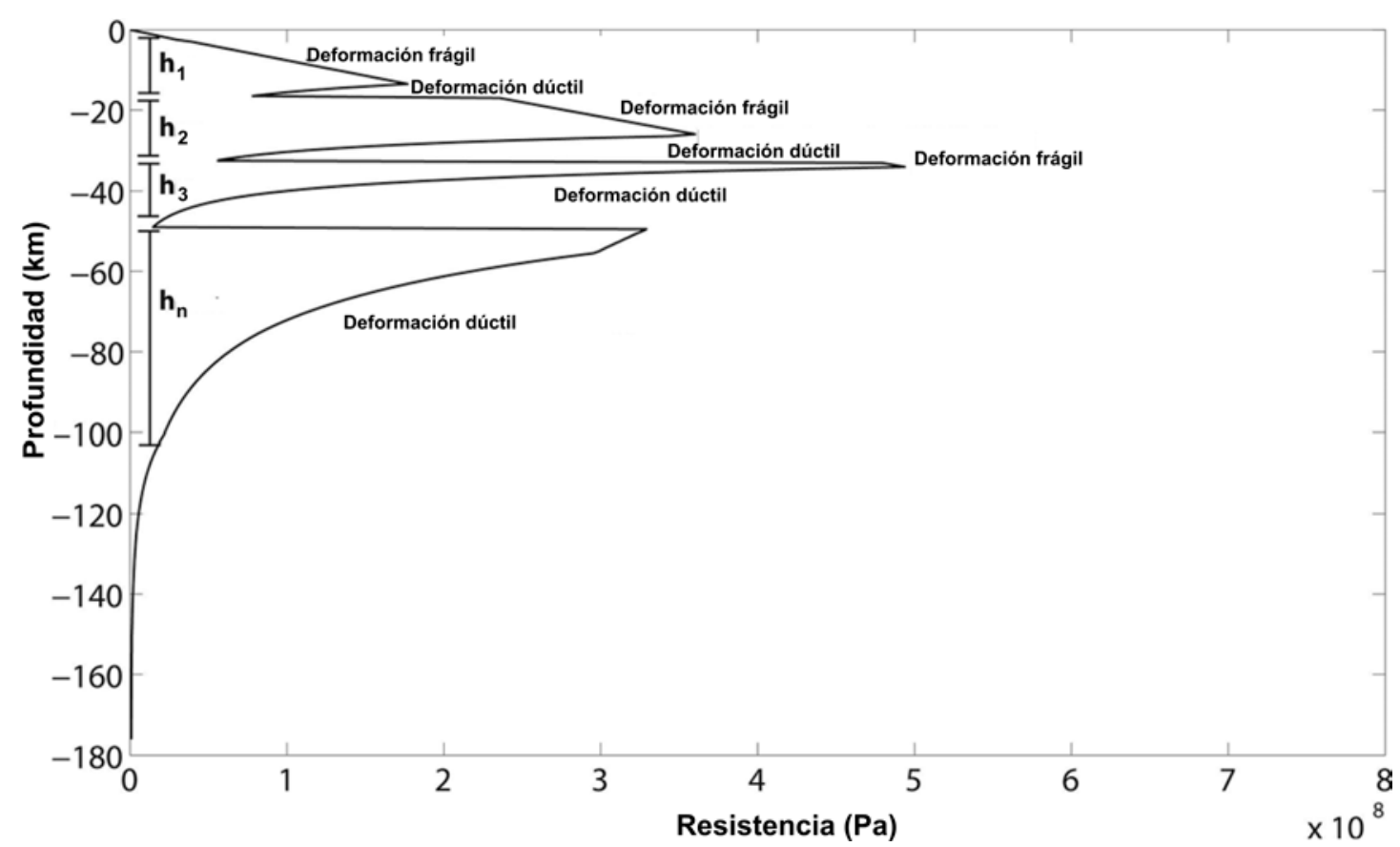

Figura 6.2. Ejemplo de Envolvente de resistencia a la deformación permanente (YSE). Imagen modificada de Tesauro et al. (2015)

de la temperatura y el correspondiente descenso de la viscosidad (Figura 6.2). La profundidad en la cual las resistencias frágil y dúctil son iguales denota la transición frágil-dúctil (BDT) que puede encontrarse en la corteza o en el manto superior (Tesauro et al., 2015). La curva se genera graficando todos los comportamientos posibles (elástico, plástico y viscoso) y, para cada profundidad, se grafica el comportamiento que ocurre a menor tensión, ya que es el que se puede observar en la realidad.

La resistencia integrada de la litósfera $\left(\sigma_{L}\right)$ bajo compresión se puede definir a través de la integración de la YSE como:

$$
\sigma_{L}=\int_{0}^{h}\left(\sigma_{1}(z)-\sigma_{3}(z)\right) d z,
$$

donde $h$ es el espesor de la litosfera, $z$ es la profundidad y $\sigma_{1}-\sigma_{3}$ la diferencia de esfuerzos principales (Tesauro et al., 2015). El parámetro $\sigma_{1}-\sigma_{3}$, es el empleado como medición de la longitud de las tensiones desviadoras en lugar de $\tau_{l l}$, siendo entonces la resistencia, es decir la máxima tensión diferencial que soporta una roca bajo ciertas condiciones de presión y temperatura, antes de experimentar deformación permanente (Sippel et al., 2016). La resistencia integrada puede ser estimada utilizando la reología y los modelos termales. Con esta integral también se puede calcular la resistencia integrada de la corteza, haciendo que $h$ sea el espesor 
de la corteza.

Hay dos modelos de distribución de esfuerzos en la litósfera. Un modelo se denomina "Jelly sandwich" y se caracteriza por concentrar la resistencia en la corteza superior y en el manto. El otro es llamado "Crème brûlée" ya que el manto es débil y la resistencia está limitada a la corteza (Burov y Watts, 2006). El modelo clásico de "Jelly sandwich" se refiere a una reología con una corteza superior y un manto superior "fuertes" separados por una corteza inferior dúctil que no permite que las tensiones flexurales se transmitan entre las capas. Esta definición puede ser extendida a otras variaciones del modelo clásico tales como, cortezas en las cuales hay una capa dúctil que no es la corteza inferior o cuando la corteza entera y el manto superior son fuertes. Con lo cual, la mayor diferencia con el modelo Crème brûlée es la presencia de un manto superior frágil y no dúctil (Tesauro et al., 2015). La pertenencia de una región a uno u otro modelo puede observarse tanto en la YSE como en la resistencia integrada.

A partir de la YSE es posible definir el espesor $\left(h_{i}\right)$ de la parte mecánicamente fuerte de las capas litosféricas que se extiende desde el tope de la capa hasta una profundidad en la cual el YSE es menor a un valor determinado (asociada con una geoterma específica, Tesauro et al. 2015, Figura 6.2). Una capa es considerada desacoplada si en algún punto de la misma la resistencia decrece por debajo del límite impuesto. En caso contrario, se considera acoplada. El espesor elástico equivalente $\left(T_{e E}\right)$ es calculado como la suma de los espesores de las capas mecánicamente fuertes $\left(h_{i}\right.$, Figura 6.2). Esta suma depende de si el comportamiento es acoplado o desacoplado. Se asume que si la corteza y el manto litosférico están acopladas, toda la litósfera se deforma como si fueran una sola capa, en este caso, si tuviéramos $n$ capas competentes el espesor elástico sería:

$$
T_{e E}=\sum_{i=1}^{n} h_{i}
$$

En muchos casos, la corteza y el manto litosférico están desacoplados. El desacople genera una reducción de la resistencia de la litósfera y del espesor elástico. El espesor elástico de una placa consistente en $n$ capas desacopladas puede calcularse como:

$$
T_{e E}=\left(\sum_{i=1}^{n} h_{i}^{3}\right)^{1 / 3}
$$

El espesor elástico de la litósfera es el espesor de una capa elástica homogénea que está caracterizada por la misma rigidez flexural que la litósfera (Tesauro et al., 2015). Es decir, 
es el espesor que tendría una capa elástica y homogénea si generara la misma deflexión que la litósfera genera. Este parámetro depende principalmente de los efectos combinados de las heterogeneidades térmicas y reológicas y refleja la historia a largo plazo de las placas continentales. En particular, las temperaturas controlan el acople o desacople de las capas litosféricas (Tesauro et al., 2015).

\section{Aplicación}

Para predecir las variaciones de la resistencia de la litósfera en el área de estudio, se utilizó el código desarrollado por Cacace y Scheck-Wenderoth (2016). En dicho código, el modelo reológico incorpora la temperatura y la dependencia de la tensión de cada composición basada en mediciones de laboratorio. La dependencia de la tensión es incluida siguiendo el concepto de YSE para un módulo de Young variable como se describe en Tesauro et al. (2015). La resistencia dependiente de la profundidad es determinada combinando el concepto de fricción con el de reptación en cuerpos sólidos (Cacace y Scheck-Wenderoth, 2016). En este caso, el parámetro de tensión diferencial, $\triangle \sigma=\sigma_{1}-\sigma_{3}$, es el empleado como medición de la longitud de las tensiones desviadoras cómo se mencionó previamente. El comportamiento frágil de las rocas en función de la presión es modelado en el código utilizando la ley de Byerlee, que fue descripta en la ecuación 6.7 pero en este caso es utilizada de este modo para obtener la tensión diferencial frágil $\left(\triangle \sigma_{b}\right)$ :

$$
\triangle \sigma_{b}=u \rho_{b u l k} g z\left(1-f_{p}\right)
$$

habiendo reemplazado la presión litostática por su correspondiente valor en función de la profundidad $(z)$, la aceleración de la gravedad $(g)$ y la densidad bulk $\left(\rho_{\text {bulk }}\right)$ y utilizando el parámetro $f_{p}$ denominado factor de presión de fluido intersticial hidrostático medio que es definido como el cociente entre la presión poral del fluido y la presión de soterramiento. El comportamiento dúctil es implementado como una combinación de las leyes que describen la reptación por dislocación para tensiones diferenciales menores que $200 \mathrm{MPa}$ y la reptación de Peierls para las tensiones diferenciales que superan este valor (ecuaciones 6.9 y 6.10). Esto se eligió de esa manera porque el mecanismo de reptación dominante en la corteza y el manto superior es el de dislocación, pero en el caso de que la presión sea muy elevada, es más representativo el de Peierls para la deformación del manto. Las ecuaciones utilizadas para modelar la tensión diferencial dúctil $\left(\triangle \sigma_{d}\right)$ son: 


$$
\begin{gathered}
\triangle \sigma_{d,<200 M P a}=\left(\frac{\dot{e}}{B_{N}}\right)^{1 / n} e^{\frac{H_{N}}{n R T}}, \\
\triangle \sigma_{d,>200 M P a}=\tau_{P}\left(1-\left[-\frac{R T}{A_{P}} \ln \frac{\dot{e}}{B_{P}}\right]^{1 / 2}\right) .
\end{gathered}
$$

La ecuación 6.18 se denomina Ley de Dorn (Sippel et al., 2016). Así, la resistencia de la placa resulta de la contribución relativa del comportamiento frágil y de la deformación por reptación que es activada por la temperatura pero con una tasa de deformación invariable (Cacace y Scheck-Wenderoth, 2016).

Los parámetros que fueron fijados para las ecuaciones 6.16, 6.17 y 6.18 en el modelo tienen los siguientes valores: aceleración de la gravedad $g=9.81 \mathrm{~m} / \mathrm{s}^{2}$, factor de porosidad medio del fluido $f_{P}=0.36$, coeficiente de fricción $\mu=0.75$ para la extensión o 3 para el caso de compresión (Tesauro et al., 2015), tasa de deformación $\dot{e}=10^{-15} \mathrm{~s}^{-1}$ (Sonder y England, 1986), constante universal de los gases $R=8.314 \mathrm{JK}^{-1} \mathrm{~mol}^{-1}$. En el caso de los parámetros de la ley de Dorne (ecuación 6.18) fueron utilizados los correspondientes a la olivina (Tesauro et al., 2015). En cambio, las temperaturas que se utilizaron para modelar la reología fueron las resultantes de los modelos de temperatura calculados y la potencia, el factor pre-exponencial y la energía de activación ( $n, B$ y $A$, respectivamente) fueron fijados para cada composición, como puede observarse en la tabla 6.1. Los parámetros reológicos asignados para cada unidad del modelo son consistentes con la densidad y las litologías supuestas en el modelo geológico (extraídos del modelo gravimétrico y térmico) siguiendo la bibliografía citada en la tabla 6.1.

En la figura 6.3 se resume el flujo de trabajo seguido para la confección del modelo reológico.

La variación de la resistencia con la profundidad para una cierta posición es expresada por la YSE que se construye como:

$$
Y S E(z)=\min \left(\triangle \sigma_{b}(z), \triangle \sigma_{d}(z)\right)
$$

Utilizando las curvas de resistencia obtenidas, se calculó la resistencia integrada en profundidad para la litósfera y para la corteza por medio de la utilización de la ecuación 6.13. También se calculó el espesor elástico que predice el modelo en toda el área de estudio. El mismo fue calculado utilizando las ecuaciones 6.14 y 6.15 y el criterio de corte utilizado por Tesauro et al. (2015) de $10 \mathrm{MPa}$ para encontrar la isoterma que define las capas mecánicamente resistentes. 
Tabla 6.1. Propiedades reológicas de los cuerpos del modelo litosférico.

\begin{tabular}{|l|l|l|l|l|}
\hline Cuerpo & $A[\mathrm{~J} / \mathrm{mol}]$ & $n$ & $B\left[\mathrm{~Pa}^{-n} / \mathrm{s}\right]$ & Referencias \\
\hline Sedimentos & $172.6 \cdot 10^{3}$ & 1.9 & $1.26 \cdot 10^{-13}$ & $\begin{array}{l}\text { Tesauro } \text { et al. } \\
(2015)\end{array}$ \\
\hline Corteza 1 & $186 \cdot 10^{3}$ & 3.3 & $3.16 \cdot 10^{-26}$ & $\begin{array}{l}\text { Tesauro et al. } \\
(2015)\end{array}$ \\
\hline Corteza 2 & $186 \cdot 10^{3}$ & 3.3 & $3.16 \cdot 10^{-26}$ & $\begin{array}{l}\text { Tesauro et al. } \\
(2015)\end{array}$ \\
\hline Corteza 3 & $186 \cdot 10^{3}$ & 3.3 & $3.16 \cdot 10^{-26}$ & $\begin{array}{l}\text { Tesauro et al. } \\
(2015)\end{array}$ \\
\hline Corteza 4 & $243 \cdot 10^{3}$ & 3.1 & $7.987 \cdot 10^{-23}$ & Burov (2011) \\
\hline Corteza 5 & $243 \cdot 10^{3}$ & 3.1 & $7.987 \cdot 10^{-23}$ & Burov (2011) \\
\hline Corteza 6 & $243 \cdot 10^{3}$ & 3.1 & $7.987 \cdot 10^{-23}$ & Burov (2011) \\
\hline Manto & $510 \cdot 10^{3}$ & 3 & $7 \cdot 10^{-14}$ & $\begin{array}{l}\text { Goetze y } \\
\text { Evans (1979) }\end{array}$ \\
\hline
\end{tabular}

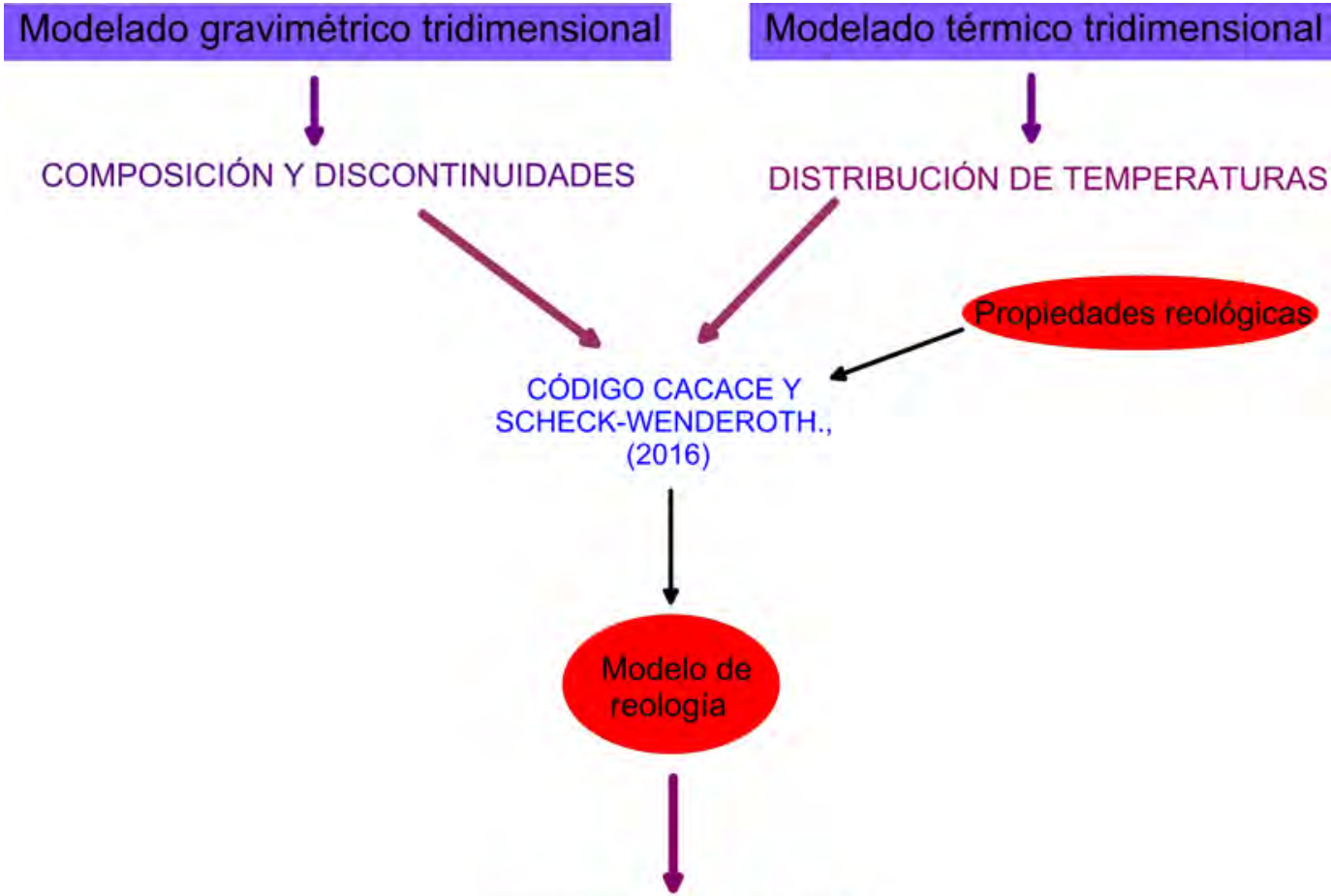

RESISTENCIA Y RIGIDEZ

Figura 6.3. Diagrama de flujo del modelo reológico 


\subsubsection{Resultados}

El área de estudio actualmente se encuentra sometida a compresión por la presencia de la placa de Nazca subductando por debajo de la placa Sudamericana. Por esta razón se eligió un régimen compresivo para calcular los resultados de la resistencia integrada. Se calculó este parámetro para cada punto de la grilla, tanto a nivel litosférico como cortical, para conocer donde se concentra más la resistencia. Estos resultados se muestran en la figura 6.4. Se puede observar que, a escala litosférica, hay más resistencia integrada en la cuenca Neuquina que en el MNP (figuras 6.4(a)). Las zonas con menor resistencia integrada están concentradas en las esquinas noreste y noroeste del modelo (figura 6.4(a). Con respecto a la resistencia integrada de la corteza, se puede observar que se distinguen bien los terrenos paleozoicos, habiendo mucha más resistencia en Patagonia que en Chilenia (figuras 6.4(b)). Comparando la resistencia integrada de la litósfera con la de la corteza, es posible observar que la mayor parte de la resistencia en Patagonia está concentrada en la corteza a diferencia de lo que ocurre en Chilenia (figura 6.4(b)). En las figura 6.4(c) podemos observar la relación porcentual entre la resistencia integrada de la corteza y la de la litósfera. Esto nos indica el porcentaje de resistencia que se concentra en la corteza, sobre el total de la resistencia litosférica. En esta figura se puede ver claramente que en el área del MNP la resistencia se concentra casi en su totalidad en la corteza, mientras que a sus alrededores el porcentaje no es tan alto. En particular, en el área de la cuenca Neuquina la resistencia está más concentrada en el manto que en la corteza, generando un contraste importante con lo que ocurre en el MNP. Esto muestra que la diferencia de temperatura observada en las figuras 5.10, influye principalmente en la resistencia del manto litosférico. En resumen, la resistencia integrada, distingue claramente al área del MNP como una zona que concentra la mayor parte de la resistencia en la corteza.

Se realizaron gráficos de la YSE en varios puntos del área de estudio utilizando el modelo reológico (Figura 6.5). La ubicación de los puntos puede observarse en el mapa de la figura 6.5(a) y los gráficos de las YSE en las figuras 6.5(b) a 6.5(j). Es notable la diferencia entre los YSE ubicados en la altiplanicie del MNP y los que se encuentran fuera de ella. Aquellos YSE ubicados en la altiplanicie (figuras 6.5(d) a 6.5(g)) no tienen casi resistencia en el manto. Esto se debe principalmente a las altas temperaturas alcanzadas al nivel del Moho (a causa de su gran profundidad) y la menor profundidad de la isoterma de $1300^{\circ} \mathrm{C}$ en esa zona, ya que según Tesauro et al. (2015), en regiones donde la temperatura en las partes someras del manto superior está cerca del punto de fusión, la resistencia estará concentrada en la corteza. 


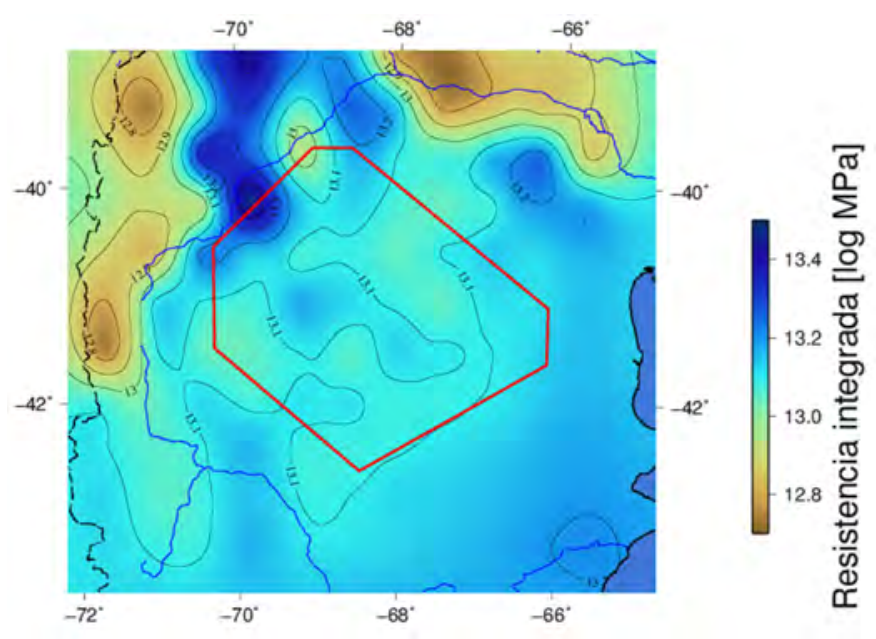

(a)

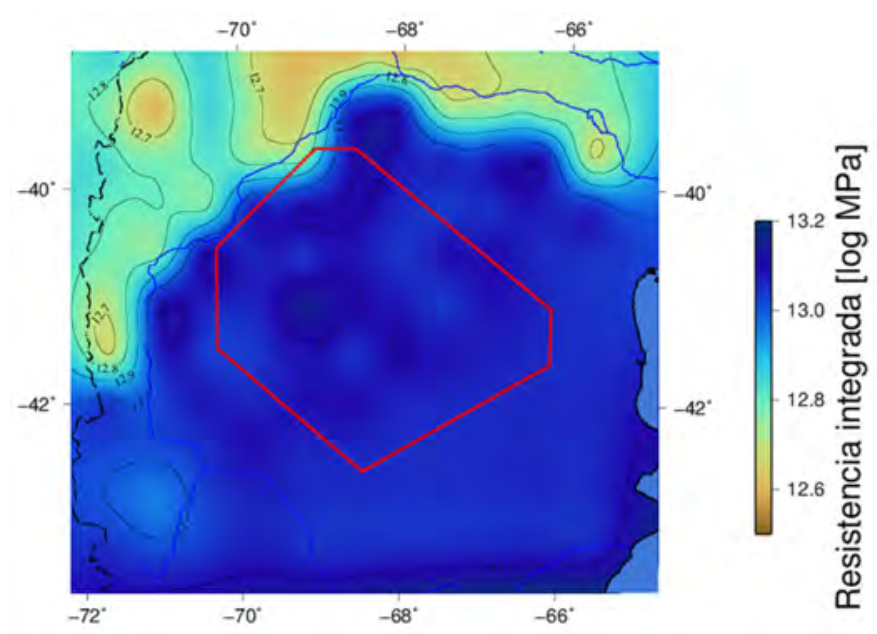

(b)

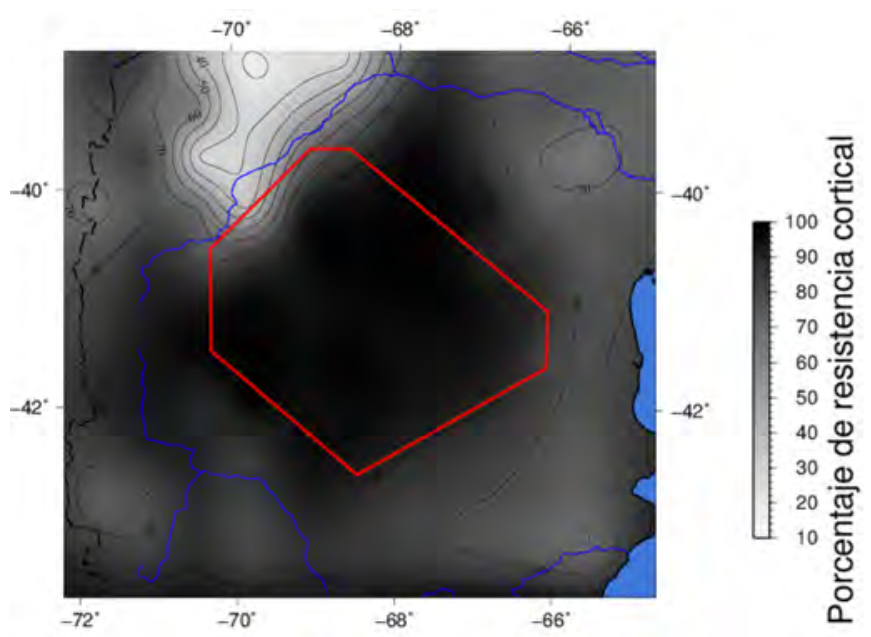

(c)

Figura 6.4. Resistencia integrada de la litósfera y la corteza (expresada en $\log 10 \mathrm{~Pa}$ m). a) Resistencia integrada de la litósfera. b) Resistencia integrada de la corteza. c) Porcentaje de resistencia concentrada en la corteza del total de resistencia en la litósfera 
Por el contrario, los YSE que están afuera de la altiplanicie si tienen, en mayor o menor medida, resistencia en el manto. La ubicación que cuenta con una mayor resistencia en el manto es el punto ubicado en la cuenca Neuquina. En todos los puntos analizados, se puede observar desacople entre las capas litosféricas, ya que se observa que a profundidades medias de la corteza la resistencia se reduce hasta valores cercanos a cero. La diferencia principal entre las curvas ubicadas dentro y fuera de la altiplanicie se ve en la resistencia en el manto litosférico que tiene valores muy bajos en el área del MNP. En esta región, caracterizada por corteza gruesa y alto régimen térmico, se puede aplicar el modelo "Crème brûlée" en el cual el manto es débil y la resistencia está localizada en la parte más somera de la corteza. En este modelo, el manto litosférico es casi indistinguible de la astenósfera, lo que indicaría una muy baja viscosidad y una alta capacidad de fluir (Burov y Watts, 2006).

En la figura 6.6 se muestra el mapa de espesor elástico calculado. En él puede apreciarse la disminución de este parámetro en el área de la altiplanicie del MNP. Esto ocurre a causa de la menor resistencia calculada para el área, lo cual implicaría una litósfera en general más blanda donde las cargas afecten en forma local tal como se explicará en el capítulo 6.2.

\subsection{Cálculo del espesor elástico efectivo}

En los modelos de isostasia regional o flexural, las masas topográficas son compensadas regionalmente por la rigidez de la litósfera (Wienecke, 2005). En otras palabras, el comportamiento mecánico de la litósfera influye en el modo de compensación isostática de una región y, por lo tanto, podemos extraer información sobre este comportamiento estudiando el balance isostático de una región.

Se puede estudiar la rigidez de la litósfera modelándola como una placa elástica fina, homogénea e isótropa que se somete a cargas y es sostenida por un sustrato más denso, que se comporta como fluido. Luego se estudia la deflexión que sufre esta placa ante la carga para conocer la rigidez de la misma. De esta manera podremos cuantificar la resistencia de la litósfera considerando el espesor de la placa elástica que ante una misma carga, exhibe la misma deflexión que la litósfera real. Esta cantidad es denominada Espesor elástico (Wienecke, 2005; Fernández, 2016). 


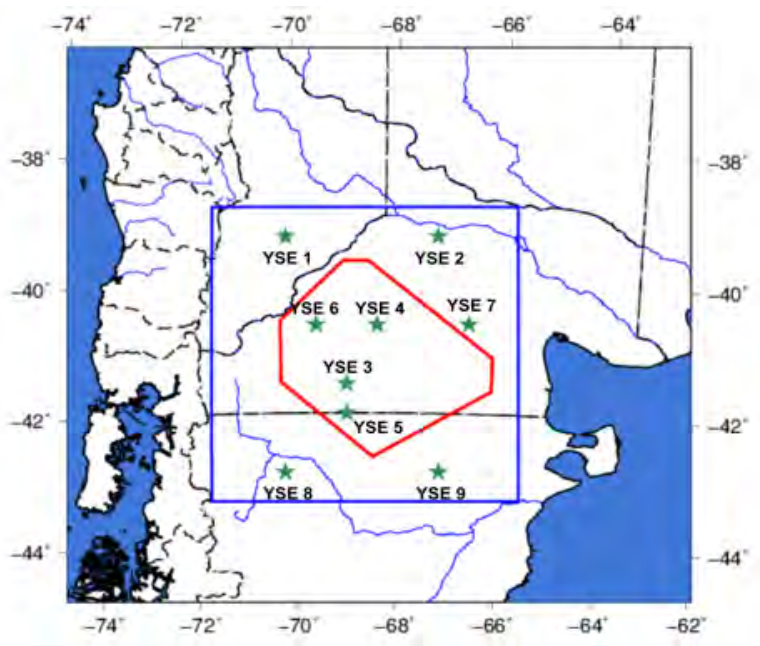

(a)

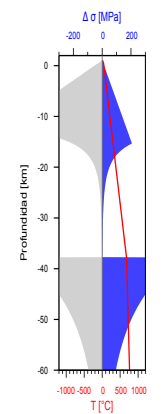

(b) YSE 1

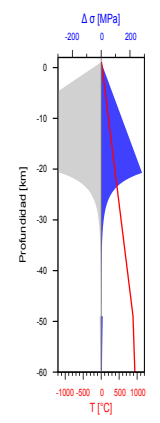

(e) YSE 4

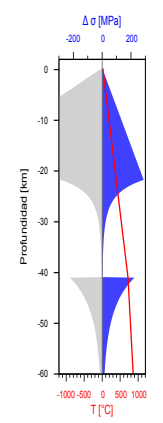

(h) YSE 7

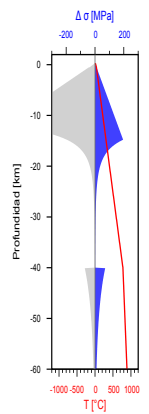

(c) YSE 2

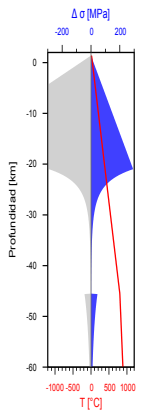

(f) YSE 5

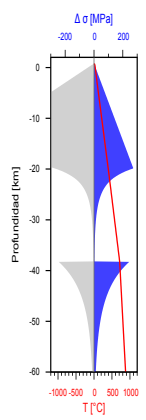

(i) YSE 8

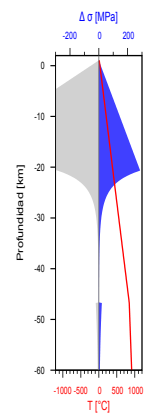

(d) YSE 3

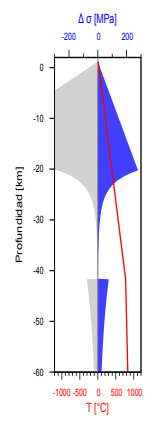

(g) YSE 6

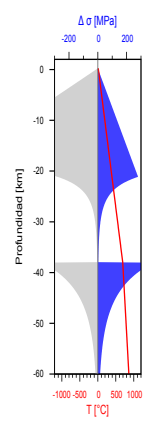

(j) YSE 9

Figura 6.5. YSEs predichas por el modelo en distintos puntos del area de estudio 


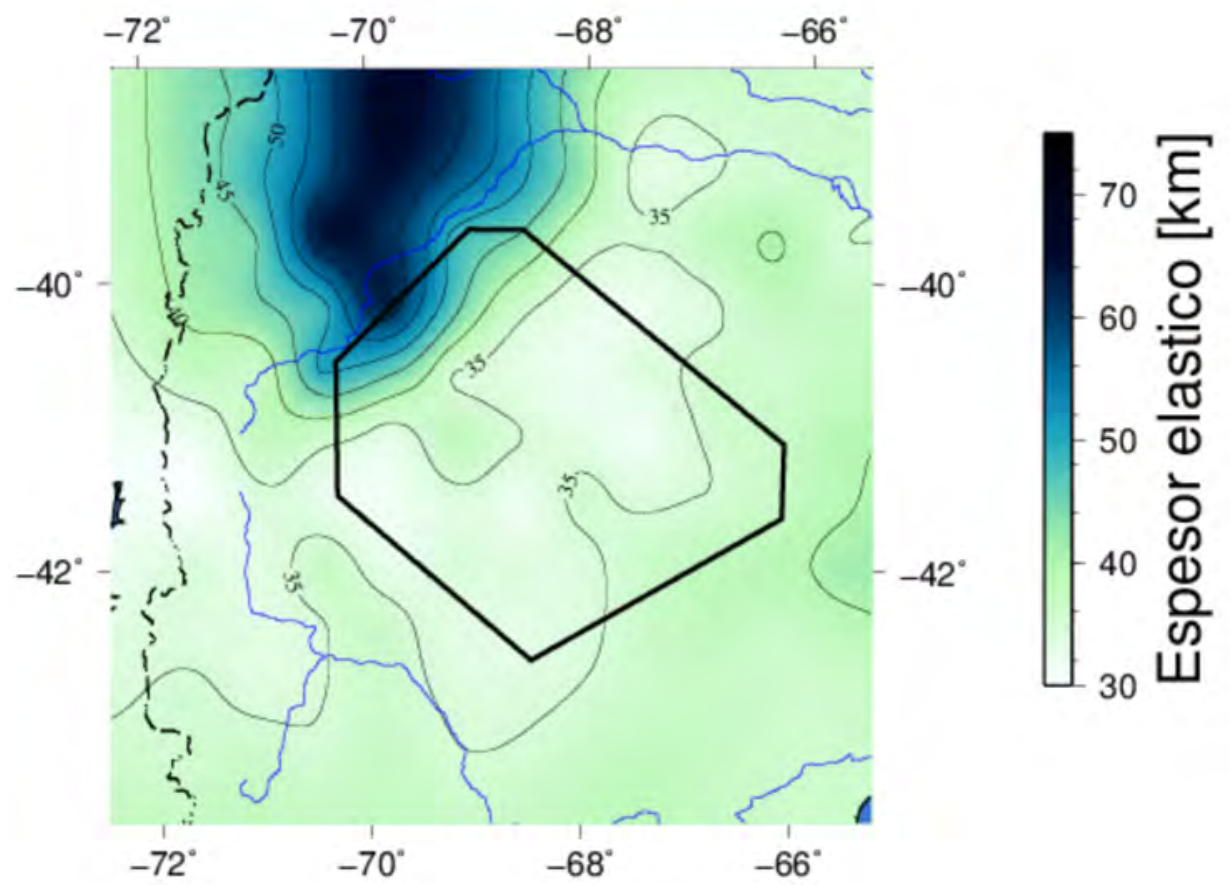

Figura 6.6. Distribución de espesor elástico equivalente obtenido a partir del modelo reológico.

\section{Isostasia regional y espesor elástico}

La isostasia regional de acuerdo a la teoría de Vening-Meinesz está basada en el modelo de Airy (Figura 2.1). Se asume que la topografía es una carga sobre la superficie de la tierra que hace que esta se deflecte generando una raíz de baja densidad similar a la predicha por Airy. La diferencia es que esta raíz será más amplia (no estará solamente por debajo de las cargas aplicadas) ya que la carga será soportada, al menos en parte, por la resistencia de la litósfera (Wienecke, 2005). El parámetro que caracteriza la aparente resistencia de la litósfera se denomina rigidez flexural y se denota $D$.

La rigidez flexural es usualmente expresada a través del espesor elástico $T_{e}$ y la relación entre ambos viene dada por:

$$
D=\frac{E T_{e}^{3}}{12\left(1-\nu^{2}\right)},
$$

en donde $E$ es el módulo de Young y $\nu$ es el coeficiente de Poisson.

En la ecuación anterior (6.20) puede verse que la relación entre el espesor elástico y la rigidez flexural tiene en cuenta implícitamente un modelo reológico, ya que se debe dar un valor a las constantes reológicas $E$ y $\nu$. En consecuencia, la deflexión de la placa dependerá 
de las propiedades de la misma, es decir, de cuán resistente a la deformación sea su material. El modelo de Airy de compensación local corresponde a un modelo flexural donde la placa no tiene resistencia y por lo tanto, el espesor elástico es cero (Wienecke, 2005).

Para cuantificar el problema de isostasia regional consideraremos una placa fina, es decir, una en la cual su largo y ancho sean mucho más grandes que su espesor. Esta aproximación funciona muy bien para representar la litósfera y también la corteza, para la cual según Wienecke (2005) se espera un error máximo de entre el 5 y el $10 \%$. A la deformación que sufre esta placa al ser sometida a cargas la caracterizaremos con una función $\omega(x, y)$ a la que denominaremos deflexión, siendo $x$ e $y$ las direcciones horizontales. $\omega$ es medida con respecto a la profundidad a la que se encontraba la sección media de la placa antes de ser deformada, la cual coincide con el plano $x-y$ y es positiva por debajo del nivel del mar.

Según los estudios de Kirchoff en el siglo XIX, la deflexión de una placa elástica sometida a cargas transversales al plano que determina, al considerarse pequeñas deformaciones, puede ser descripta por la siguiente ecuación diferencial:

$$
D \nabla^{2} \nabla^{2} \omega(x, y)=P(x, y)
$$

siendo, $D$ la rigidez flexural, $\nabla^{2}$ el operador laplaciano y $P(x, y)$ la fuerza por unidad de área a la que es sometida la placa. En esta ecuación el efecto de la temperatura, así como también las fuerzas horizontales a las cuales puede ser sometida la placa fueron despreciadas (Wienecke, 2005). Esta última hipótesis, se estima correcta ya que la litósfera ante las cargas mínimas necesarias para producir plegamiento, se fallará antes de deflectarse, salvo que la capa elástica sea de espesor muy bajo (Fernández, 2016).

\section{Aplicación de la deflexión de placas a la Geofísica}

Hasta este punto se habló de la litósfera como la capa rígida que flota sobre el material denso y con comportamiento de fluido, sin embargo podemos considerar que esta capa es la corteza moviéndose sobre el manto. En la teoría de Airy la corteza es la capa considerada y el concepto de isostasia flexural está basado en este modelo. Además, Wienecke (2005) concluye que la elección de la corteza o la litósfera está determinada por la profundidad en la cual ocurre un cambio importante en el módulo de Young. Si en el modelo se impone un contraste grande de este parámetro en la profundidad del Moho, entonces el comportamiento mecánico (la deflexión generada por una carga) será distinto entre la corteza y el manto y se puede utilizar la corteza como la capa rígida. En el caso en que los módulos de Young de la corteza 
y el manto sean distintos, calcular el espesor elástico de una capa de características medias no es representativo de la deflexión de la litósfera. En cambio, si no hay un contraste marcado ambas capas se deflectarán solidariamente y se comportarán como una sola capa mecánica (Wienecke, 2005). Es decir, la superficie de deflexión a modelar se puede desplazar al Moho y así ser válido para la corteza también. Considerando lo anteriormente dicho, se adaptará la ecuación de deflexión de una placa elástica a la situación de la flexión de la corteza.

Si asumimos que la corteza, representada por una placa elástica, está flotando sobre un manto que se comporta como fluido, entonces cuando ésta es sometida a una carga se deflecta y el abombamiento desplaza material del manto. En este caso, el manto ejercerá un empuje igual al peso del fluido desalojado (Principio de Arquímedes), el cual puede escribirse de la siguiente manera:

$$
E(x, y)=\left(\rho_{m}-\rho_{c}\right) g \omega(x, y)
$$

siendo $\rho_{m}$ la densidad del manto, $\rho_{c}$ la de la corteza y $g$ la aceleración de la gravedad. Entonces, el empuje es proporcional a la deflexión y a la constante de proporcionalidad la podemos renombrar como $k=\left(\rho_{m}-\rho_{c}\right) g$. Por otro lado, si la densidad de la topografía es $\rho$ y la altura de la misma $h(x, y)$ entonces la carga topográfica generará una presión (fuerza por unidad de area) en cada punto $(T(x, y))$ igual a:

$$
T(x, y)=\rho g h(x, y)
$$

En consecuencia, la carga neta vertical será:

$$
P(x, y)=T(x, y)-E(x, y)
$$

es decir,

$$
P(x, y)=\rho g h(x, y)-\left(\rho_{m}-\rho_{c}\right) g \omega(x, y)
$$

Teniendo esto en cuenta, la ecuación de deflexión de placas (ecuación 6.21) aplicada a la geofísica nos queda:

$$
D \nabla^{2} \nabla^{2} \omega(x, y)=\rho g h(x, y)-\left(\rho_{m}-\rho_{c}\right) g \omega(x, y) .
$$

Esta es la ecuación que resolveremos para encontrar la rigidez flexural y luego, a partir de ella, el espesor elástico. 
A modo de comentario podemos observar que, según el análisis espectral, la relación entre las cargas topográficas y la deflexión que las mismas generan en la litósfera puede ser expresada como:

$$
W\left(k_{x}, k_{y}\right)=\frac{1}{\frac{\rho_{m}}{\rho_{c}}-1+\frac{D}{g \rho_{c}}\left|\left(k_{x}, k_{y}\right)\right|^{4}} H\left(k_{x}, k_{y}\right),
$$

siendo $H$ y $W$ la transformada de Fourier de la topografía y de la deflexión de la placa respectivamente y $k_{x} k_{y}$ el número de onda en $x$ y en $y$. De esta ecuación se desprende que si no hay cargas actuando, entonces la placa permanece plana y que si la rigidez flexural tiende a 0, entonces la ecuación 6.27 tiende a la de Airy. Matemáticamente es la misma descripción por el hecho de que las placas sin resistencia se comportan siguiendo los principios de la isostasia local (Wienecke, 2005).

\section{Resolución de la ecuación de deflexión de placas para la Geofísica}

Para encontrar la distribución de espesor elástico en el área del Macizo Norpatagónico, se utilizó la resolución de Wienecke (2005) a la ecuación diferencial de cuarto orden (ecuación 6.29), implementada mediante el software Lithoflex (Braitenberg et al., 2007). La solución de Wienecke (2005) es analítica y fue derivada para ser aplicada a la Geofísica. La misma fue obtenida en base a las tres ecuaciones llamadas fórmulas de Hertz (1884) desarrolladas para una carga puntual sobre una placa elástica en tres dimensiones. Wienecke (2005) las adaptó al problema en cuestión y las unificó encontrando así la solución analítica a la deflexión de una litósfera elástica ante una carga topográfica (ASEP).

En primer lugar se mostrarán las soluciones de Hertz (1884), ya que son importantes para comprender la solución analítica de Wienecke (2005) que fue la utilizada en este trabajo de tesis. Si consideramos una placa elástica extendida infinitamente que flota en un líquido también extendido infinitamente y suponemos sólo pequeñas deflexiones, entonces podemos decir que los efectos pueden ser superpuestos linealmente, es decir, podemos considerar sólo el efecto de una carga puntual y luego sumar los efectos de las cargas puntuales de los alrededores que son significativos para ese punto. Por lo tanto, supondremos una carga $P$ situada en el origen de coordenadas, con lo cual tendremos:

$$
T(x, y)= \begin{cases}P & \text { si }(x, y)=(0,0) \\ 0 & \text { si }(x, y) \neq(0,0)\end{cases}
$$


Teniendo en cuenta esto vemos que la ecuación 6.26, fuera del origen puede escribirse como:

$$
\nabla^{2} \nabla^{2} \omega(x, y)+\frac{1}{\beta^{4}} \omega(x, y)=0
$$

siendo $\beta=\frac{D}{\left(\rho_{m}-\rho_{c}\right) g}$. Al buscar una solución que se anule para grandes distancias a la carga y tenga un valor finito en el origen, Hertz (1884) encuentra la siguiente solución:

$$
w(R)=\frac{P}{4 \pi \beta^{2}\left(\rho_{m}-\rho_{c}\right)} \int_{1}^{\infty} \frac{e^{-R \sqrt{1 / 2 \xi}} \sin R \sqrt{1 / 2 \xi}}{\sqrt{\xi^{2}-1}} d \xi,
$$

siendo $R$ la distancia radial al origen y $\xi$ la variable de integración. Para el origen, Hertz (1884) llegó a:

$$
w(0,0)=\frac{P}{8\left(\rho_{m}-\rho_{c}\right) g \beta^{2}},
$$

siendo este último el valor máximo de deflexión de la placa. ya que es el que se encuentra exactamente por debajo de la carga puntual $P$ (Fernández, 2016).

La ecuación 6.30 fue expandida en serie de dos maneras distintas, una para regiones cercanas al origen y otra para regiones lejanas. Para valores pequeños de $R$ la expresión queda:

$$
\begin{aligned}
& \omega(R)=\frac{P}{2 \pi \beta^{2}\left(\rho_{m}-\rho_{c}\right) g}\left\{\frac{R^{2}}{2^{2}} \ln (R)-\frac{R^{6}}{2^{2} 4^{2} 6^{2}}\left(\ln (R)-\frac{5}{6}\right)+\ldots+\right. \\
& \left.\frac{\pi}{4}\left(1-\frac{R^{4}}{2^{2} 4^{2}}+\frac{R^{8}}{2^{2} 4^{2} 6^{2} 8^{2}}-\ldots\right)+\ldots-1.1159\left(\frac{R^{2}}{2^{2}}-\frac{R^{6}}{2^{2} 4^{2} 6^{2}}+\ldots\right)\right\}
\end{aligned}
$$

esta expansión es denominada función logarítmica. Para valores grandes de $R$ se realiza otra expansión y se llega a:

$\omega(R)=\frac{P}{2 \pi \beta^{2}\left(\rho_{m}-\rho_{c}\right) g} \sqrt{\frac{\pi}{2}} \frac{e-R \sqrt{1 / 2}}{\sqrt{R}}\left\{\sin \left(R \sqrt{1 / 2}+\frac{\pi}{8}\right)-\frac{1}{8 R} \sin \left(R \sqrt{1 / 2}+\frac{3 \pi}{8}\right)+\ldots\right\}$

esta expresión se denomina función seno.

Wienecke (2005) modificó las tres ecuaciones de Hertz (1884) que originalmente eran para una placa de hielo flotando sobre agua para el caso geofísico de la corteza y el manto (ecuaciones $6.31,6.32$ y 6.33). Estas modificaciones han sido introducidas en los párrafos anteriores junto con la presentación de las ecuaciones de Hertz (1884). Luego, Wienecke (2005) unificó las tres ecuaciones $(6.31,6.32$ y 6.33) para encontrar una única solución analítica para calcular la rigidez flexural. Como las ecuaciones de Hertz (1884) fueron obtenidas para una carga puntual en el origen de coordenadas, entonces la solución analítica es la respuesta impulsiva 
de la corteza entendida como un sistema lineal invariante (Fernández, 2016). Wienecke (2005) realizó una investigación sobre las funciones de Hertz (1884) que la llevó a determinar que la solución analítica considere la ecuación para el origen (ecuación 6.31) en $R=0$, la función logarítmica (ecuación 6.32) hasta $R=2 \beta$ y la función seno (ecuación 6.33) para valores de $R$ a partir de $2 \beta$. Para $R=2 \beta$ la función logarítmica y la función seno valen lo mismo y a partir de ese punto la primera se descarta y se toma la segunda.

Utilizando la solución analítica podemos obtener la deflexión de la corteza $\omega(x, y)$ en cada punto debido a la carga topográfica. Esto se realiza convolucionando la respuesta impulsiva obtenida con la función analítica con la topografía. Esta deflexión generada en la corteza a causa de la topografía nos indica la profundidad del Moho en cada punto. Al Moho obtenido por este método se lo llamará Moho flexural. A partir de la deflexión calculada (Moho flexural) podemos obtener la rigidez flexural o el espesor elástico. Esto se realiza mediante la comparación entre un Moho externo (dato independiente que puede haber sido obtenido mediante gravimetría o sísmica en general) y varios Mohos flexurales obtenidos con distintos valores de rigidez flexural. Entonces, se calculan una serie de respuestas impulsivas (una para cada valor de $D$ ) que van a derivar en una serie de Mohos flexurales y estos se comparan con los datos de Moho externos para elegir el que mejor ajusta y en consecuencia el valor de rigidez flexural representativo.

Como el cálculo implica una convolución entre la respuesta impulsiva de la corteza y la topografía, entonces es necesario fijar un radio de convolución. Este radio es un parámetro importante ya que implica la necesidad de extender la región de cálculo con respecto a la región de estudio (área donde se quiere obtener $D$ o $T_{e}$ ). Los factores más importantes que influyen en el valor del radio de convolución son el módulo de Young, el espesor elástico y el contraste de densidad. En el trabajo de Wienecke (2005) se especifican valores de radio de convolución razonables ante la variación de los parámetros determinantes.

Los métodos desarrollados con anterioridad a la formulación de la solución analítica de Wienecke (2005) se basan principalmente en técnicas espectrales, siendo los más conocidos los métodos de admitancia y coherencia. Estos presentan varios inconvenientes, algunos propios de las técnicas espectrales y otros particulares del método. Para evitar efectos de borde, los datos de entrada tanto de cargas topográficas como de anomalías de gravedad deben ser extendidos significativamente. Además, si el área no es suficientemente grande se pierde mucha resolución a la hora de obtener una distribución de espesor elástico o rigidez flexural. En el caso del método convolucional, sólo se requiere la ampliación de los datos de topografía y este 
requerimiento es mucho menos restrictivo a causa de la disponibilidad de datos topográficos, por ejemplo a través de modelos digitales de elevación (DEM).

\subsubsection{Aplicación}

El método convolucional aplicando la solución analítica (tal como fue explicado con anterioridad) se aplicó mediante el software Lithoflex (Braitenberg et al., 2007). Este programa consta de varios módulos con diversas funciones entre los cuales se encuentra el $T_{e}$ inversión, que fue el utilizado en este caso para obtener la distribución de espesor elástico en el área del Macizo Norpatagónico.

El programa solicita que se le ingrese un valor máximo, mínimo y un paso para los espesores elásticos, con lo cual genera una serie de valores de $T_{e}$ probables. Además, se solicita la elección de la densidad de la corteza y del manto ( $\rho_{c}$ y $\rho_{m}$ respectivamente), un valor para la aceleración de la gravedad $(g)$, una profundidad de referencia y un valor del módulo de Young. Con estos datos el software calcula una respuesta impulsiva de la corteza para cada valor de espesor elástico de la serie.

Luego, realiza la convolución de cada una de las respuestas impulsivas obtenidas con un modelo de cargas topográficas que también debe ser ingresado por el usuario a través de una grilla de alturas. Como resultado de esta convolución se obtiene un Moho flexural para cada valor de espesor elástico ingresado. Para el cálculo de la convolución, es requerido que el usuario especifique un valor de radio de convolución y así la operación se realiza en el área de estudio ampliada en una distancia igual al radio de convolución. La grilla de alturas deberá estar definida igualmente en el área mencionada previamente pero el resultado de la convolución será dado solamente en el área de estudio.

Para calcular la distribución de espesores elásticos el programa ajusta cada una de las porciones de la grilla con un Moho externo, cuya grilla también debe ser ingresada por el usuario. Se solicita la elección de tamaños de ventanas en $x$ y en $y$ en las cuales se divide el área de estudio y en cada una de ellas se realiza la comparación entre el Moho externo y todos los Mohos flexurales. Esta comparación se realiza, en cada una de las ventanas, calculando el valor medio cuadrático de la diferencia entre el Moho externo y cada uno de los Mohos flexurales. De este modo, el valor de espesor elástico que se le asignará a cada subregión será el del Moho flexural cuyo valor medio cuadrático sea el menor. Por último estos valores son interpolados para obtener como salida una grilla de espesores elásticos en la región de estudio (del mismo intervalo de muestreo que las grillas ingresadas). 


\section{Datos utilizados y elección de parámetros}

Con el fin de realizar el cálculo de distribución de espesor elástico en la zona de estudio de esta tesis, se utilizaron datos de topografía del modelo digital de elevaciones ETOPO1 (Amante y Eakins, 2009). Este modelo fue creado por el NOAA (National Oceanic and Atmospheric Administration) y es un modelo global de relieve con una resolución de 1 minuto de arco. Fue generado a partir de diversos sets de datos tanto globales como regionales que fueron corridos a datums verticales y horizontales comunes y evaluados y editados (Amante y Eakins, 2009).

El rango de espesores elásticos ingresado fue de entre 5 hasta 60 con un paso de $5 \mathrm{~km}$. Se eligió de este modo ya que esta serie incluye todos los valores obtenidos para el área en cuestión en trabajos previos tales como Tassara y Yáñez (2003), Wienecke (2005) y PérezGussinyé et al. (2007), entre otros.

El Moho externo utilizado fue el extraído del modelo gravimétrico tridimensional explicado y desarrollado en el capítulo 4, siendo este la mejor aproximación encontrada teniendo en cuenta los datos disponibles. Utilizando el promedio de la misma grilla de datos que contiene la profundidad del Moho según el modelo gravimétrico, se calculó el valor de la profundidad de referencia y se fijó en $40 \mathrm{~km}$.

El módulo de Young y la aceleración de la gravedad se dejaron fijos en el valor que viene por default en el programa, siendo estos de $10^{11} \mathrm{~Pa}$ y de $9.81 \mathrm{~m} / \mathrm{s}^{2}$. En cuanto a la densidad de la corteza y del manto fueron obtenidas a partir de un promedio de las densidades del modelo tridimensional de gravedad y de este modo se obtuvieron valores de: $2750 \mathrm{~kg} / \mathrm{m}^{3}$ para la corteza y $3300 \mathrm{~kg} / \mathrm{m}^{3}$ para el manto.

Para el radio de convolución se consultaron los valores sugeridos por Wienecke (2005) en su trabajo y se concluyó que para el rango de espesores elásticos elegidos y la variación de densidad entre corteza y manto el valor de radio de convolución se fijaría en $600 \mathrm{~km}$.

\subsubsection{Resultados}

En la figura 6.7 se puede observar la distribución de espesor elástico cortical efectivo producto de la inversión utilizando el programa Lithoflex (que resuelve mediante la solución analítica de Wienecke) con los datos y parámetros de entrada especificados previamente.

Al observar la figura 6.7 se puede ver que hay menor espesor elástico en el área del Macizo Norpatagónico en comparación con sus alrededores. Esto puede observarse en la mayoría de sus límites, viéndose una variación muy marcada hacia el oeste, hacia el noreste y hacia el 


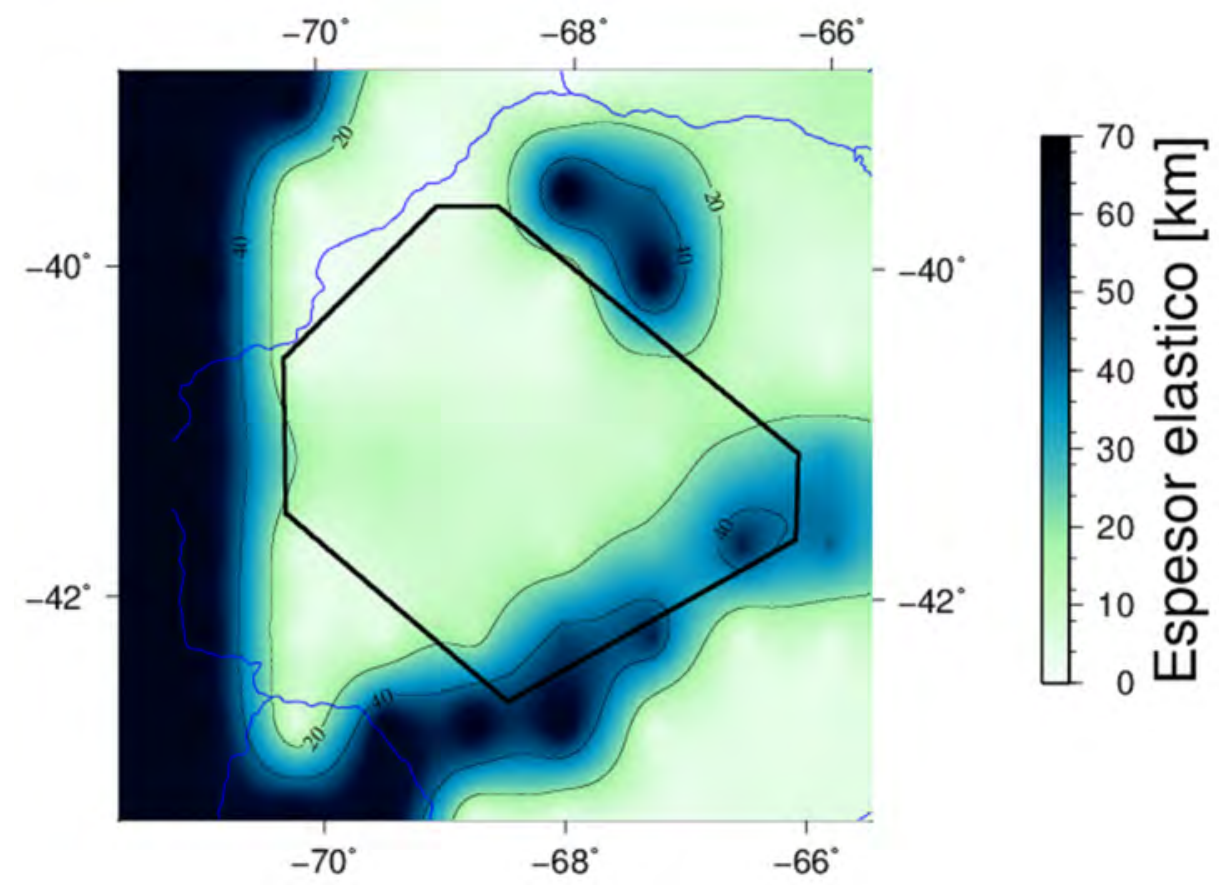

Figura 6.7. Distribución de espesor elástico cortical efectivo calculado mediante el software Lithoflex (Braitenberg et al., 2007) que utiliza la solución analítica de Wienecke (2005)

sudeste. Estas dos últimas variaciones se encuentran ubicadas siguiendo los lineamientos El Gualicho y Los Chacays. No se ve una diferencia importante hacia el noroeste, es decir, que según este modelo no es posible observar una diferencia marcada entre el MNP y la cuenca Neuquina.

El hecho de que se observe menor espesor elástico cortical en la zona de estudio estaría indicando una corteza con menor rigidez, es decir más débil o más propensa a deformación. Resultados similares pueden encontrarse en trabajos previos tales como Tassara y Yáñez (2003), Wienecke (2005) y Pérez-Gussinyé et al. (2007).

Además del resultado mostrado en la figura 6.7, se realizaron varias pruebas con distintos contrastes de densidad entre la corteza y el manto y profundidades de referencia. Al no cambiar el resultado principal del cálculo, es decir, el menor espesor elástico del MNP en comparación con sus alrededores, se decidió mostrar sólo el resultado de la figura que corresponde a valores extraídos del modelo gravimétrico tridimensional explicado previamente.

$\mathrm{Al}$ analizar el procedimiento realizado para obtener una estimación de la rigidez del área de estudio, surge la pregunta de porque no se intentó calcular el espesor elástico litosférico en lugar del cortical como fue realizado. Al querer calcular el espesor elástico litosférico nos encontramos con varios inconvenientes, como por ejemplo la determinación del contraste de 
densidad entre la litósfera y la astenósfera, el cual implica a su vez caracterizar con un único valor la densidad (y por lo tanto, cada una de las propiedades físicas) de toda la litósfera para un área tan extensa. Otro inconveniente es la determinación de la discontinuidad entre litósfera y astenósfera, la cual puede ser calculada mediante los modelos de tomografía, pero no es tan precisa como el Moho que fue producto del modelado de densidades con varios datos independientes de restricción. Además del error que puede ser introducido mediante la determinación de los parámetros, es posible que haya un desacople entre la corteza y el manto (cómo lo indica el modelo reológico) y, en ese caso, ambos pueden tener distinta rigidez y un comportamiento distinto. Si esto es lo que ocurre y calculamos el espesor elástico de la litósfera, al considerarla como un sólo cuerpo no estaríamos representando el comportamiento de la litósfera en conjunto, ni tampoco un promedio de ambos (corteza y manto litosférico).

\subsubsection{Comparación con el espesor elástico equivalente}

Es difícil comparar el espesor elástico efectivo cortical, obtenido mediante la inversión de la topografía y el Moho con el equivalente calculado mediante el modelado reológico expuesto en este capítulo (espesor elástico equivalente litosférico, ecuación 6.15). La diferencia esencial es que el primero se obtuvo para la corteza, siendo difícil emplearlo para la litósfera y el otro a la inversa. Además, el espesor elástico obtenido mediante Lithoflex supone una corteza homogénea mientras que el equivalente fue realizado utilizando un modelo de corteza heterogénea dividida en diversos cuerpos de distintas características. Sin embargo, es posible destacar que en ambos modelos totalmente independientes, se evidencia un menor espesor elástico en el área del MNP con respecto a sus alrededores (Figuras 6.7 y 6.6). Es importante volver a destacar que, tal como se evidencia en la figura 6.4(c), el área del MNP es una zona que tiene la gran mayoría de la resistencia concentrada en la corteza, con lo cual en esta zona, el espesor elástico cortical y litosférico deberían parecerse. La zona dentro del área de estudio que presenta mayor diferencia entre un modelo y el otro es la cuenca Neuquina (Figuras 6.7 y 6.6) lo cual también es esperable al ser el lugar con menor porcentaje de resistencia en la corteza según la figura 6.4(c). Estas diferencias conducen a que el contraste de espesor elástico entre el MNP y la cuenca Neuquina sea distinto en un planteo y en el otro. El hecho de que la corteza y el manto estén desacoplados, como indica la figura 6.5 (la resistencia disminuye a valores menores que el límite impuesto, explicado en la sección de metodología de este capítulo), confirma la elección de calcular sólo el espesor elástico efectivo utilizando el método convolucional. Otra diferencia importante entre ambas maneras 
de obtener la distribución de espesor elástico reside en el detalle del modelo de entrada, ya que en el caso del método convolucional, sólo se especifica un contraste de densidad y su superficie de discontinuidad, en cambio en el modelado reológico se incluye mucho más detalle, ya que se parte de un modelo estructural obtenido mediante el modelado de gravedad y también se incluyen las temperaturas y las características reológicas de cada composición. Por otro lado, el modelo convolucional asume que el área se encuentra compensada isostáticamente, lo cuál no está suficientemente comprobado. Todo esto trae aparejado diferencias lógicas, sobre todo en la corteza, lo cual justifica las desigualdades encontradas entre ambos modelos. Esto mismo hace que sea más confiable y robusto el resultado obtenido del modelado reológico en el cual observamos que a nivel cortical, el área del MNP tiene más resistencia que los alrededores, ocurriendo lo contrario a nivel litosférico (y hablando así de un manto muy dúctil en esta zona). El espesor elástico efectivo sólo fue calculado a modo de comparación, ya que es un método extendido en la literatura.

En resumen, según el modelado reológico el área de la altiplanicie del MNP tiene mayor rigidez en los primeros kilómetros de la corteza que sus alrededores. Esta situación se invierte para las mayores profundidades, es decir, la corteza profunda y el manto litosférico tienen menor rigidez en el área de la altiplanicie que en los alrededores. Además puede observarse un desacople entre la corteza y el manto en toda el área de estudio. En la zona de la altiplanicie, la gran mayoría de la resistencia de la litósfera (más del 80\%) está concentrada en los primeros kilómetros de corteza. Es decir, a pesar de que el espesor elástico sea menor en el área de la altiplanicie que en los alrededores (tanto a escala cortical como litosférica, lo que hace que el tipo de compensación isostática sea de tipo local), a bajas profundidades el MNP tiene mayor rigidez que su entorno. Estos resultados del modelo reológico y del espesor elástico serán discutidos en el capítulo 7. También se hará un análisis de las implicancias de todos los modelos en conjunto en el mismo capítulo. 


\section{Capítulo 7}

\section{Discusión}

En este capítulo se discutirán los resultados obtenidos en las distintas etapas de modelado. Se comenzará con el análisis de los resultados obtenidos sobre las densidades, luego sobre las temperaturas y reología y por último se discutirá una hipótesis geodinámica sobre el levantamiento de la región en el Paleógeno y sobre su estado actual.

\subsection{Análisis del modelo de densidades}

Se discutirán los resultados del modelo de densidades tridimensional a escala litosférica, que fue el modelo gravimétrico más completo y bien restringido. Se analizará primero la robustez del mismo y luego se discutirán las implicancias que puede tener en relación con otros resultados del área.

\subsubsection{Robustez}

El establecimiento del modelo inicial, para la realización del modelo de gravedad, involucra muchas asunciones. Una de ellas es la elección de la densidad de los sedimentos, en la que se consideró intrínsecamente una cierta porosidad de la litología. Si esta asunción es cambiada entre los extremos posibles, es decir entre sedimentos totalmente compactados (sin porosidad) y sedimentos no consolidados (por ejemplo con $70 \%$ de porosidad), la media de los residuos (Tabla 4.3) permanece casi igual pero el desvío estándar aumenta levemente (en el primer caso $2 \mathrm{mGal}$ y en el segundo $7 \mathrm{mGal}$ ). Además, en la mayor parte del área de estudio el patrón de los residuos se preserva a pesar de los cambios en la densidad sedimentaria. Por lo tanto, el valor de densidad elegido para los sedimentos no afecta significativamente los resultados principales del modelo (el espesor cortical). 


\section{Discusión}

Otra característica importante que fue predefinida en el modelo inicial, es la configuración de densidad en el manto. Si cambiamos dicha configuración en el modelo final, los residuos aumentan significativamente, tal como puede observarse en la tabla 7.1. Esta tabla muestra la estadística de las anomalías residuales si se reemplaza la configuración final de densidades del manto por la configuración A, B o por una densidad constante. Todos los parámetros estadísticos de los residuos (desvío estándar, máximo, mínimo) aumentan sustancialmente para cualquier otra configuración de densidades del manto (tabla 7.1) en comparación con la configuración final utilizada en el modelo (tabla 4.3). En los puntos donde el Moho es restringido por datos sísmicos también ocurre lo mismo (tablas 4.3 y 7.1). Por lo tanto, la selección de la configuración de densidades para el manto es muy importante en el proceso de modelado, ya que tiene gran impacto en sus resultados. La configuración elegida para el modelo final está basada en la comparación de cada una de las opciones encontradas con determinaciones de densidad independiente provenientes de datos de xenolitos mantélicos extraídos del área de estudio. Este procedimiento asegura la confiabilidad de la opción tomada, ya que ha sido basada en datos independientes para validar la conversión de velocidad a densidad. La configuración elegida proviene de la velocidad de ondas P y la razón por la cual arroja el mejor resultado puede deberse a diversas causas. Una de las razones puede ser el tipo de onda, ya que las ondas $\mathrm{P}$ son menos dependientes de la anisotropía; también puede tener que ver con la conversión empleada, ya que se realizaron dos conversiones con velocidad de ondas $\mathrm{S}$ que generaron resultados muy distintos $\mathrm{y}$, probablemente, ninguna de ellas sea apropiada para el caso. Otra razón, puede ser la resolución, ya que el modelo de velocidad de onda S no resuelve la subducción de la placa de Nazca a la latitud del modelo y, por lo tanto, quizás la resolución de este modelo no sea la suficiente en el área (Gómez Dacal et al., 2017).

\subsubsection{Análisis e implicancias}

Hay una diferencia importante entre el Moho modelado (Figura 4.9(a)) y el Moho inicial (Assumpção et al. 2013; Figura 4.5(d)) en las áreas donde no hay restricciones para esta superficie. La diferencia más marcada entre ambas se puede observar en el área de la altiplanicie, ya que el Moho modelado presenta en esta zona una profundidad mayor que los alrededores. De acuerdo al modelo, el Moho debajo de la altiplanicie del MNP tiene una profundidad media de $45.6 \mathrm{~km}$, un desvío estándar de $2.7 \mathrm{~km}$ (Figura 4.9(a)) y una diferencia importante de profundidad de entre 2 y $7 \mathrm{~km}$ con respecto a sus alrededores, que permite distinguir a 
Tabla 7.1. Estadísticas de los residuos (anomalía calculada - anomalía medida) de modelos con distinta configuración de densidad en el manto. Los valores están expresados en mGal.

\begin{tabular}{|l|l|l|l|}
\hline Residuos & $\begin{array}{l}\text { Con configu- } \\
\text { ración A }\end{array}$ & $\begin{array}{l}\text { Con configu- } \\
\text { ración B }\end{array}$ & $\begin{array}{l}\text { den- } \\
\text { sidad de } \\
\text { manto cons- } \\
\text { tante }\end{array}$ \\
\hline Promedio & $1.82 \cdot 10^{-7}$ & $6.36 \cdot 10^{-8}$ & $3.54 \cdot 10^{-7}$ \\
\hline Desvío estándar & 54.17 & 55.16 & 52.46 \\
\hline Valor máximo & 119.72 & 119.27 & 134.35 \\
\hline Valor mínimo & -99.95 & -102.38 & -86.17 \\
\hline $\begin{array}{l}\text { Promedio de los va- } \\
\text { lores en puntos de } \\
\text { Moho restringido }\end{array}$ & 33.55 & 45.99 & 37.81 \\
\hline $\begin{array}{l}\text { Máximo de los va- } \\
\text { lores en puntos de } \\
\text { Moho restringido }\end{array}$ & 51.66 & 64.19 & 56.48 \\
\hline
\end{tabular}




\section{Discusión}

la altiplanicie del MNP en el mapa de Moho (Figura 4.9(a)). Existe una correlación evidente entre el Moho descripto y la topografía, que también distingue al área de la altiplanicie (Figura 1.1). Como la isostasia asume pesos iguales a una cierta profundidad de compensación, la relación entre el Moho profundo y la alta topografía en el área, puede indicar que el área se encuentre en balance isostático a escala cortical. Es decir, la gran profundidad del Moho está compensada por una topografía alta para igualar las cargas a escala cortical. Esto pudo haber influido en la elevación actual de la altiplanicie y puede indicar que las fuerzas isostáticas pueden haber cumplido algún rol durante el levantamiento del Paleógeno.

Para definir las densidades corticales del modelo, se utilizó la distribución de velocidades a los $25 \mathrm{~km}$ de profundidad obtenida a partir del modelo de velocidades de onda S (Schaeffer y Lebedev, 2013) en la cual se observa una tendencia creciente desde el noroeste hacia el sudeste (Figura 4.5(e)). Buscando información geológica que pueda explicar esa diferencia en velocidad, se encontró que dicha tendencia se correlaciona con las suturas entre terrenos paleozoicos propuestos por Ramos (1988). Se convirtieron las velocidades en densidades para esta profundidad y se las comparó con la gravedad para validar las densidades encontradas. Como resultado, se modelaron dos dominios de distinta densidad con un contraste importante de densidad entre ellos (110 $\frac{\mathrm{kg}}{\mathrm{m}^{3}}$; Chilenia tiene menor densidad cortical media que Patagonia; Figura 4.5(a)). En la correlación entre la tendencia de velocidad y los distintos terrenos, es posible observar que la configuración cortical actual se relaciona con los tiempos Paleozoicos. Se puede inferir a partir del modelo, que los terrenos mencionados son muy distintos en composición, lo que refuerza la hipótesis de los distintos orígenes (Ramos, 1988; González et al., 2010, 2011b,a). En conclusión, la diferencia en la densidad media entre ambos terrenos puede estar relacionada con sus distintos orígenes y composición.

La expresión superficial del límite entre terrenos está ubicada al norte del límite integrado en profundidad, detectado a partir de la velocidad de ondas S (Figura 4.8); esto puede indicar que el mencionado límite inclina hacia el sur coincidiendo tanto con la hipótesis de Ramos (1988), que habla de una subducción buzante hacia el sudoeste por debajo del MNP, como con la de González et al. (2010, 2011b,a) que sugiere transporte lateral implicando fallas de rumbo que no son verticales e inclinan en una dirección coincidente con la que se observa en el modelo. Estos posibles escenarios tectónicos podrían estar relacionados también con la forma del Moho en el área del MNP, ya que la corteza está engrosada en dirección sudoeste-noreste siguiendo la dirección de la sutura entre terrenos. El engrosamiento en esta dirección puede tener alguna relación con el movimiento relativo entre ambos terrenos. Hay residuos en el 


\section{Discusión}

área entre la expresión superficial de la sutura entre terrenos y la misma sutura inferida en profundidad a través de la velocidad de ondas S (Figura 4.9(b)). Estas diferencias pueden estar causadas por la diferencia entre el límite modelado y la continuación del límite real en profundidad, que es desconocido.

Luego del modelado, todavía quedan anomalías residuales (Figura 4.9(b)) que, debido a su longitud de onda (entre 100 y $200 \mathrm{~km}$ ), parecen ser causadas por variaciones de densidad dentro de la corteza. Además, en algunos puntos dentro del área de la altiplanicie del MNP existe una correlación espacial entre estos residuos y plateaus basálticos, por ejemplo, el mayor residuo (en valor absoluto) coincide con uno de los plateaus basálticos ubicado al noroeste de la altiplanicie ( Figura 4.9(b)). Este plateau está ubicado cerca de la localidad III ( Comallo; Figura 4.9(b)) donde se encontraron los xenolitos extraídos más recientemente y, en consecuencia, el residuo negativo puede estar causado por un decrecimiento de la densidad relacionado con eventos magmáticos (efectos térmicos que generan el decrecimiento de densidad). En este contexto, se puede asumir que el magmatismo presente en el área pudo haber diferenciado la corteza generando heterogeneidades corticales que se reflejan en las anomalías residuales.

\section{Relación entre las densidades del manto y las discontinuidades en la corteza}

Con el fin de analizar las discontinuidades que se infieren de los residuos del modelo final de densidades, se realizó una nueva comparación entre resultados de xenolitos y de los modelos de tomografía (Figura 7.1) con el propósito de observar si existe alguna relación. En esta oportunidad, se relacionó la presión y temperatura de equilibrio calculadas con los datos de los xenolitos (Ponce 2016; Mundl et al. 2015, utilizando la composición química de los piroxenos como geotermómetros y geobarómetros y en todos los casos el método de Brey y Köhler 1990 para mantener la consistencia y comparabilidad de los datos) que indican estas condiciones en el momento del emplazamiento de los mismos, con las mismas propiedades extraídas de la conversión realizada sobre la tomografía sismológica de onda P (Amaru, 2007), que representa la presión y temperatura en la actualidad. Se eligió la tomografía de ondas P porque fue la seleccionada para el modelo de densidades por ser la que mostraba coincidencia con los resultados que se derivan de los datos de xenolitos. La conversión de velocidades a temperaturas fue obtenida utilizando el programa velt (An y Shi, 2007), tal como se describe en el capítulo 4. De la distribución de temperaturas tridimensional obtenida como resultado, se utilizaron las que corresponden en latitud y longitud a la ubicación de las localidades donde 


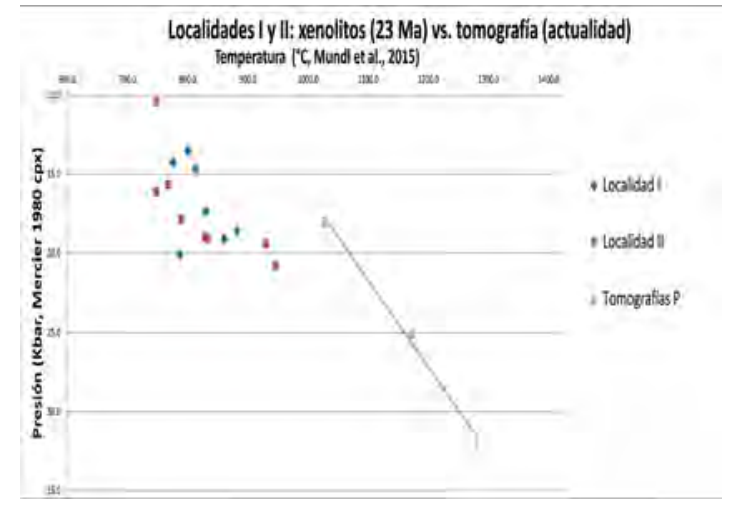

(a)

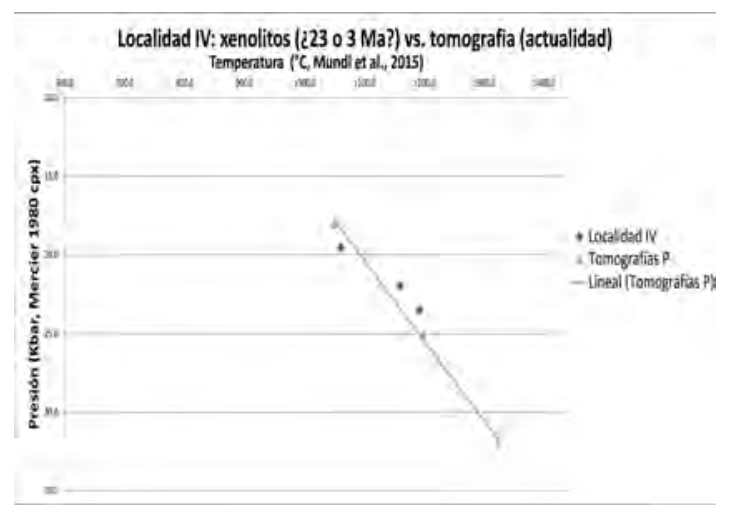

(c)

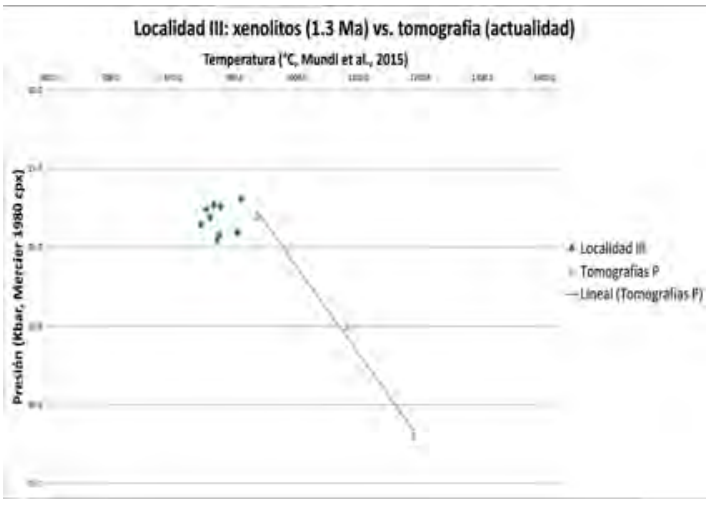

(b)

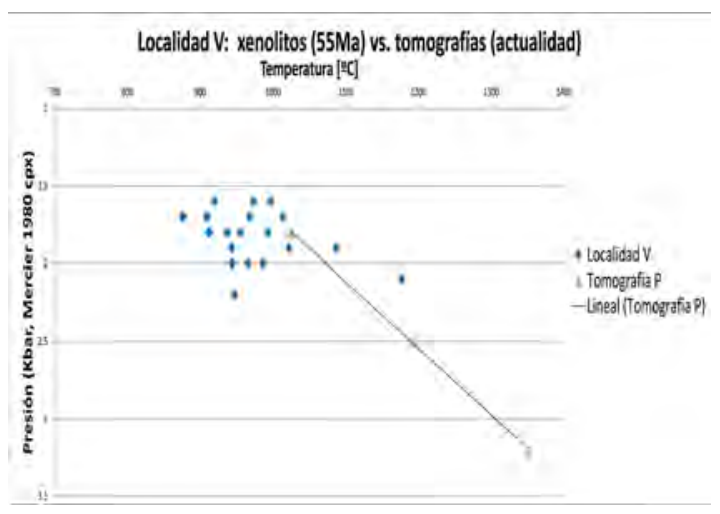

(d)

Figura 7.1. Comparación de presiones y temperaturas determinadas mediante xenolitos y tomografías. a) Comparación en las localidades I y II. b) Comparación en la localidad III.

c) Comparación en la localidad IV. d) Comparación en la localidad V.

se encontraron xenolitos. Se obtuvo un perfil de temperaturas dependientes de la presión para cada uno de estos puntos (Figura 7.1). Los valores de presión fueron obtenidos mediante la transformación de las profundidades del modelo tridimensional suponiendo presión litostática según el modelo ak135 (Kennett et al., 1995). La resolución en profundidad del modelo de tomografía es de $25 \mathrm{~km}$, con lo cual al utilizarse un valor por celda se genera un salto en las temperaturas, que igualmente permite obtener un gradiente. Los gráficos de las comparaciones pueden observarse en la figura 7.1.

En la figura 7.1(a) se puede observar la comparación realizada para las localidades I y II, las cuales se graficaron en conjunto a causa de su cercanía geográfica y cronológica. Es posible ver que las condiciones evaluadas mediante xenolitos no coinciden con el gradiente calculado con tomografías sismológicas. La falta de coincidencia podría deberse a la falta de concordancia temporal de los dos sets de datos. Según el gráfico, hoy en día habría mayor 


\section{Discusión}

temperatura en estas localidades que hace $23 M a$ cuando se extrajeron los xenolitos. En cambio, en el caso de la localidad III (Figura 7.1(b)) y la localidad IV (Figura 7.1(c)) las condiciones de presión y temperatura obtenidas por ambos métodos son mucho más cercanas entre si. En el primer caso, los resultados de los xenolitos están formando una nube de puntos, con poca distancia entre si y son casi coincidentes con la prolongación del gradiente (obtenido de las tomografías) hacia presiones menores (Figura 7.1(b)). En el caso de la localidad IV (Figura 7.1(c)) todos los valores se encuentran alrededor de la línea del gradiente. Estos casos en los cuales los resultados son coincidentes corresponden, justamente, a xenolitos extraídos más recientemente, permitiendo así pensar que las temperaturas actuales son muy parecidas a las del momento de la extracción. Esta última hipótesis está basada en las dataciones de xenolitos en Prahuaniyeu de Bertotto, W. (comunicación personal) ya que en el trabajo de Mundl et al. (2015), se habla de que los xenolitos de esta localidad (Prahuaniyeu, localidad IV) están emplazados en basaltos de 23 Ma. En el caso de la localidad V (Figura 7.1(d)), se observa que los resultados extraídos de los xenolitos tienen una dispersión muy amplia (tal como se puede ver en los histogramas de densidad de la figura 3.14(b)), es decir, para presiones similares se obtienen datos de temperatura diversos, esto se puede deber a que haya habido re-equilibrio en esa zona. Esta última aseveración está basada en evidencias de estructura simplectitica observadas en los xenolitos de esa localidad y documentados en el trabajo de Castro et al. (2011). Estas estructuras son consecuencia de descompresión rápida durante el ascenso y cambios químicos durante ese proceso. Como el cálculo de presión y temperatura está basado en la composición química encontrada en los piroxenos de las muestras y esta fue modificada por el ascenso y descompresión, en este caso, las muestras afectadas adoptarían las condiciones posteriores al emplazamiento y no las originales. Por lo tanto, la determinación podría ser errónea debido a los mencionados cambios de re-equilibrio químico con lo cual los datos de esta localidad no serían útiles para la comparación que se intenta realizar.

Mediante este análisis es posible observar que existen variaciones actuales en el manto del área de estudio (como se asevera en el capítulo 3) y que estas podrían influir en la composición de la corteza también, ya que habrían sido generadas por eventos magmáticos que aportarían a la diferenciación de la corteza. Las localidades con xenolitos extraídos más antiguamente (localidades I y II; figura 7.1(a)) son justamente, las que tienen histogramas con dos modas con una brecha muy grande en sus densidades (Figura 3.14(a)), lo que podría indicar la existencia de relictos de un empobrecimiento por fusión parcial en la época del emplazamiento (evidencia de Manto empobrecido en el norte de la altiplanicie siendo estas densidades altas restíticas 


\section{Discusión}

de la fusión parcial). Si comparamos los gradientes de temperatura, podremos observar que el de la actualidad (obtenido mediante tomografías) es menor que hace $23 \mathrm{Ma}$ (derivado a partir de los resultados de xenolitos). Las localidades III y IV, que tienen xenolitos extraídos más recientemente, tienen una sola moda que es la de bajas densidades en sus histogramas (figura 3.14(c)). Estas bajas densidades podrían estar generadas por las altas temperaturas, lo que coincide con los indicios de magmatismo reciente. La localidad III se encuentra en un residuo de anomalía de gravedad negativo (Figura 4.9(b)) que también puede provenir de las bajas densidades generadas por altas temperaturas. Las altas temperaturas observadas y el vulcanismo reciente, pueden estar indicando un proceso en el manto más reciente que la última anomalía térmica documentada en el Paleógeno por Aragón et al. (2011a, 2015); Kay et al. (1993, 2007); Muñoz et al. (2000); De Ignacio et al. (2001). La coincidencia de temperaturas en la localidad IV avalaría las dataciones de Bertotto W. (comunicación personal) que indican que hubo eventos más recientes en la zona. Por otro lado, las densidades en esta localidad son las más bajas obtenidas en todo el área de estudio lo que podría relacionarse, también, con las altas temperaturas predichas por el modelo en la zona.

En la localidad V, la única fuera de la altiplanicie, las condiciones del manto cambian generando una alta dispersión de datos de densidad y de condiciones de presión y temperatura, lo cual no permite realizar la comparación con los resultados de tomografías, pero sí inferir que existió o existe una condición que genere tal diferencia entre el manto dentro y fuera de la altiplanicie.

No se observan grandes diferencias entre los valores de densidad obtenidos en las distintas localidades como resultado del análisis de xenolitos. Sin embargo, esto es coincidente con la poca variación observada en la configuración de densidades obtenida con la tomografía de ondas P. Por otro lado, sí se observan variaciones grandes en el norte mediante este último método. Desafortunadamente, no se tienen datos de xenolitos esa zona particular, con lo cual, no es posible validar las densidades modeladas.

\subsection{Análisis de los modelos de temperatura, reología y espe- sor elástico}

\subsubsection{Robustez}

En el modelado térmico, la corteza fue dividida en seis cuerpos de distintas composiciones. Con el fin de analizar el impacto de esta división y la sensibilidad de los modelos de 


\section{Discusión}

temperatura y reología, se realizaron modelos con una corteza homogénea. Se conservaron las características de todos los cuerpos (sedimentos y manto) exceptuando a la corteza. La corteza se unificó en un sólo cuerpo con características térmicas (conductividad térmica: $\kappa$ y producción de calor radiogénico: $S$ ) iguales al promedio de los valores de los seis cuerpos del modelo anterior, con lo cual, $\kappa$ en la corteza es igual a $2.84 \mathrm{~W} /\left(m^{\circ} K\right)$ y $S$ es igual a $1.545 \mu \mathrm{W} / \mathrm{m}^{3}$. La figura 7.2 muestra los resultados del modelo homogéneo, en los cuales se puede observar una gran similitud con el modelo de corteza dividida (Figura 5.10) dejando de lado la diferencia trivial en los primeros kilómetros del modelo causada por la influencia de la configuración composicional de la corteza. En este sentido el modelo de corteza homogénea indica, a los $10 \mathrm{~km}$, que hacia el sudoeste y al norte hay mayor temperatura que en la altiplanicie mientras que hacia el noroeste y al este hay menor temperatura (Figura 7.2(a)). Igualmente, hay rasgos similares en los dos modelos: el sector sur de la altiplanicie tiene mayor temperatura que el norte, al este de la altiplanicie hay temperaturas menores y al norte mayores. Por otra parte el modelo de corteza dividida presenta mayor amplitud de temperaturas aunque los valores son similares. A profundidades mayores el modelo homogéneo se asemeja mucho al de corteza dividida. Además el valor de las temperaturas también es muy parecido entre ambos modelos. A los $45 \mathrm{~km}$ de profundidad la mayor diferencia se puede observar hacia el sur de la altiplanicie, donde el modelo de corteza dividida (Figura 5.10(b)) da como resultado temperaturas más bajas que el de corteza homogénea (Figura 7.2(b)). Los valores de temperatura son similares teniendo mayor amplitud el modelo de corteza homogénea. A los $100 \mathrm{~km}$, la semejanza entre ambos modelos es notable teniendo el modelo de corteza homogénea una variación más suave (Figuras 5.10(c) y 7.2(c)). En resumen, ambos modelos son muy parecidos tanto en la distribución como en los valores, haciendo que la configuración cortical no influya considerablemente en los resultados obtenidos y en las conclusiones que se extraen del modelado.

Además se realizó la comparación entre las temperaturas medidas en los pozos y las del modelo con corteza homogénea, la cual puede observarse en la tabla 7.2. A pesar de haber cambiado la configuración cortical, no se observa una diferencia notable en el ajuste del modelo con las temperaturas medidas. Las diferencias siguen siendo negativas en Patagonia y positivas en Chilenia y con valores que están en el mismo orden. Se cree que estas comparaciones hablan de la diferencia entre terrenos paleozoicos. Sería interesante asignarles características más distintivas a ambos terrenos y probar si ajustan mejor a las temperaturas de pozos. 


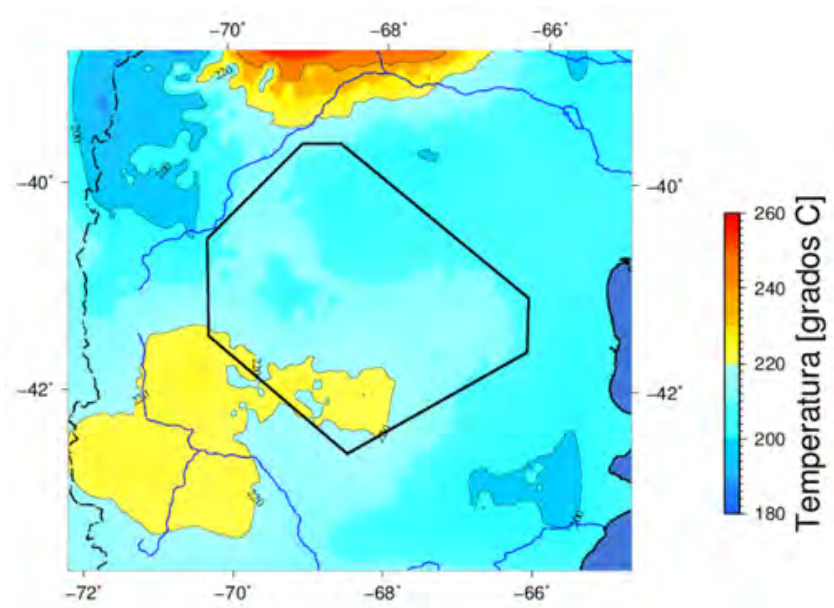

(a)

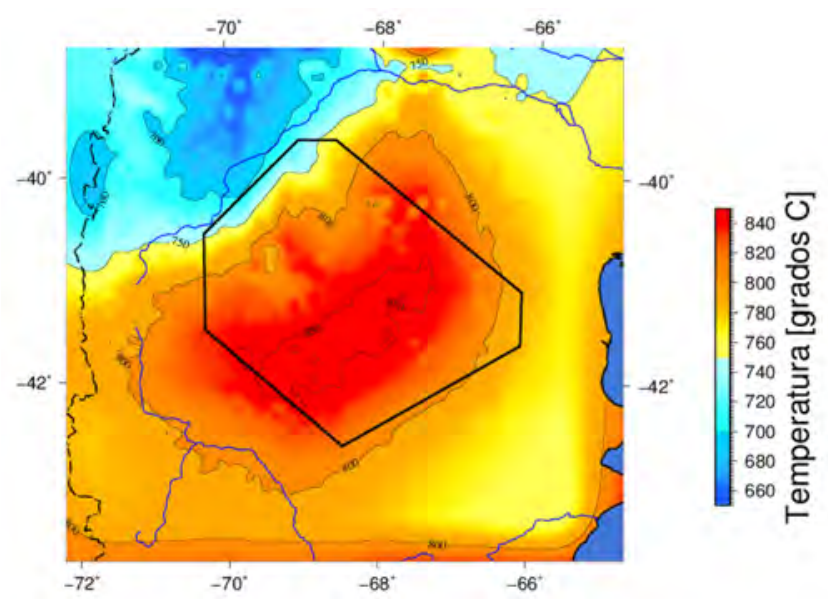

(b)

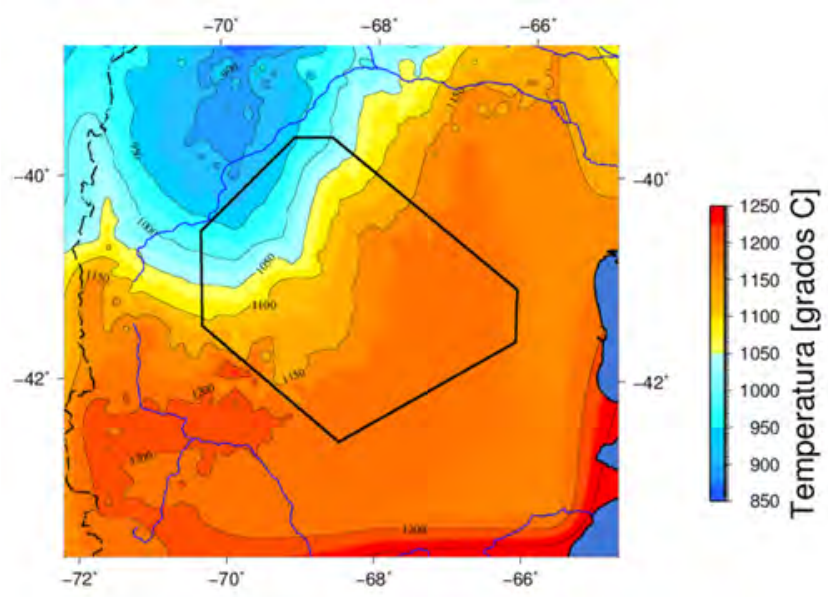

(c)

Figura 7.2. Cortes a distintas profundidades del modelo de temperatura homogéneo. a) Corte a $10 \mathrm{~km}$ de profundidad b) Corte a $45 \mathrm{~km}$ de profundidad c) Corte a $100 \mathrm{~km}$ de profundidad. 
Tabla 7.2. Comparación del modelo térmico de corteza homogénea con temperaturas medidas en pozos. Cuadro que contiene las diferencias entre los datos de temperatura medidos y el modelo realizado. Los nombres de los pozos pueden observarse en la figura 5.5. Los valores están expresados en ${ }^{\circ} \mathrm{C}$.

\begin{tabular}{|l|l|}
\hline Pozo N1 - Modelo & 2.64 \\
\hline Pozo N2 - Modelo & -3.9 \\
\hline Pozo N3 - Modelo & -14.1 \\
\hline Pozo S1 - Modelo & 12.65 \\
\hline Pozo S2 - Modelo & 8.64 \\
\hline
\end{tabular}

También se confeccionó un modelado reológico para el modelo de corteza homogénea. En este caso, los parámetros de los sedimentos y del manto se mantuvieron iguales a los del modelo de corteza dividida (Tabla 6.1). En cambio, los parámetros de la corteza se fijaron promediando los valores elegidos para todos los cuerpos del modelo de corteza dividida, obteniendo así $A=214.5 \cdot 10^{3} \mathrm{~J} / \mathrm{mol}, \mathrm{n}=3.2$ y $B=3.99 \cdot 10^{-23} \mathrm{~Pa}^{-n} / \mathrm{s}$. En la figura 7.3 se muestran los resultados de la resistencia integrada. En el caso de la resistencia litosférica (Figura 7.3(a)), los resultados son muy similares a los del modelo de corteza dividida (Figura 6.4(a)), observándose más resistencia en la zona de la cuenca Neuquina que en la altiplanicie. Sin embargo, se observa mayor diferencia entre ambas regiones en el modelo de corteza homogénea (Figura 7.3(a)). Analizando la resistencia integrada en la corteza (Figura 7.3(b)), puede observarse que no hay distinción notable entre terrenos, sin embargo existe un valor más elevado de este parámetro en la altiplanicie que en los terrenos que la limitan al norte (figura 7.3(b)). El rasgo interesante, es que sin importar la configuración cortical utilizada, el cociente entre la resistencia integrada de la corteza y de la litósfera, distingue claramente al área de la altiplanicie del MNP como una zona que concentra casi la totalidad de la resistencia en la corteza. Esta característica generaría que, igual que en el modelo de corteza dividida, las curvas de YSE dentro del macizo tuvieran sólo resistencia en la corteza, a diferencia de los alrededores y que el espesor elástico sea menor en la altiplanicie que en el área que la circunda. Es decir, la conclusión principal del modelado reológico se mantiene a pesar del cambio en la configuración de la corteza. 


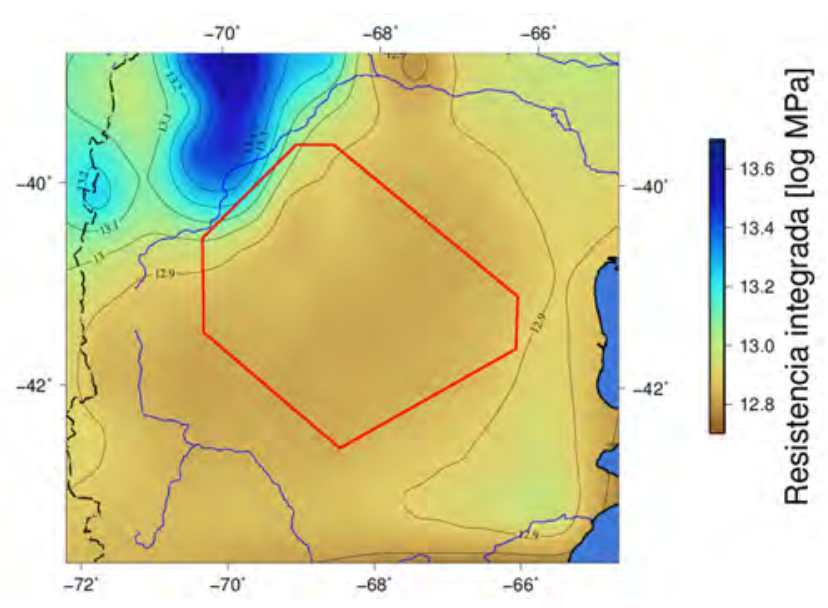

(a)

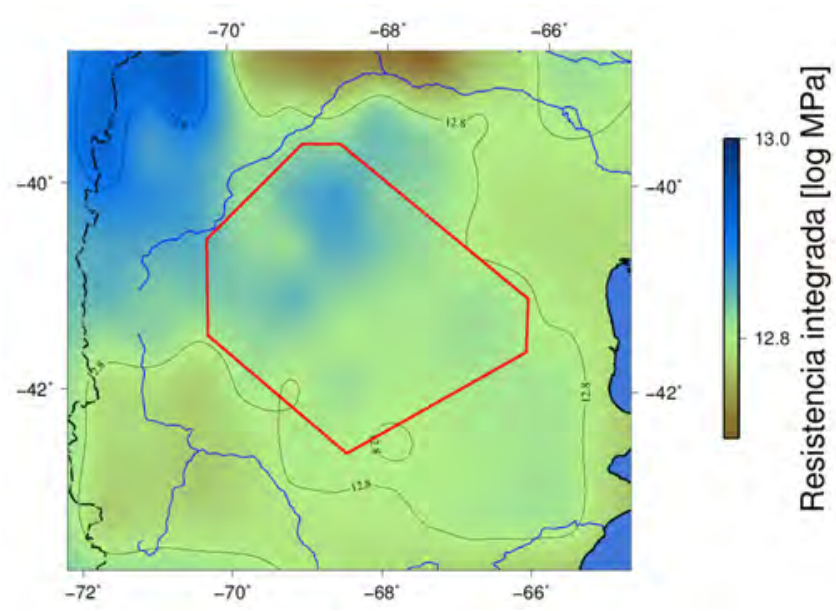

(b)

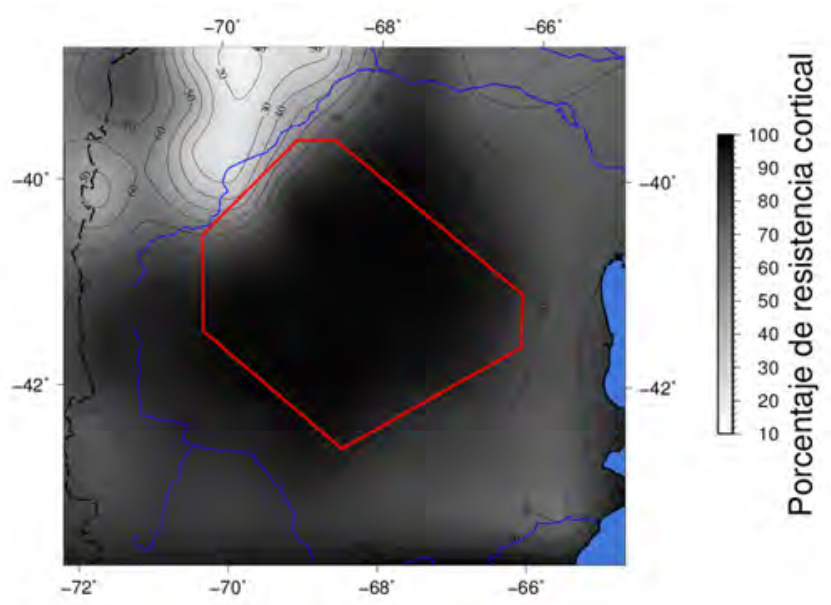

(c)

Figura 7.3. Resistencia integrada para el modelo de corteza homogénea en la litósfera y en la corteza (expresada en $\log 10 \mathrm{~Pa} \mathrm{~m})$. a) Resistencia integrada en la litósfera. b) Resistencia integrada en la corteza. c) Porcentaje de resistencia acumulado en la corteza del total de resistencia en la litósfera 


\subsubsection{Análisis e implicancias}

Según los resultados del modelado térmico y reológico, a poca profundidad la temperatura en la altiplanicie del MNP es menor que en los alrededores y la resistencia de la litósfera está mucho más concentrada en la corteza que en el caso de sus áreas circundantes (Figuras 6.4(c) y 7.3(c)). Esto habla de una corteza somera fría y rígida, tal y como se describe en Aragón et al. (2011a), lo cual puede conducir a la concentración de la deformación en los bordes de la altiplanicie, como se observa en las cuencas circundantes (Giacosa, comunicación personal).

Sin embargo, en el trabajo de Aragón et al. (2011a) las características descriptas son para toda la corteza y en el caso de nuestro estudio, las condiciones cambian en profundidad, obteniendo una corteza profunda y un manto litosférico con mayor temperatura y menor rigidez que los alrededores (Figuras 5.10 y 6.4). El hecho de que haya una mayor temperatura a mayor profundidad podría estar relacionado con la inestabilidad térmica del manto ocurrida en el Oligoceno tardío y estudiada en varios trabajos (Aragón et al., 2011a, 2015; Kay et al., 1993, 2007; Muñoz et al., 2000; De Ignacio et al., 2001). A pesar de las diferencias que se pueden encontrar en los mencionados trabajos, principalmente en la causa de la anomalía, todos ellos consideran su existencia en el Paleógeno y su relación con la reorganización de placas ocurrida en esta época. En estos trabajos no se menciona si la anomalía podría tener consecuencias (temperaturas elevadas) en la actualidad. Las temperaturas que se obtienen como resultado del modelado y su consecuente reología podrían ser un remanente de la anomalía térmica mencionada, ya que la difusión del calor se realiza por conducción en la litósfera y este es un proceso lento. Por otro lado, si se considera la hipótesis de Aragón et al. (2011a), en la cual se habla de ventana astenosférica por un cese de subducción temporal, entonces desde que la subducción reinició se podría haber generado un corner flow en el borde de la placa. Este borde actualmente se encuentra por debajo del MNP (según datos de tomografías sismológicas; Aragón et al. 2011a) y podría generar aporte de calor por convección. Un modelo de lo que podría estar ocurriendo puede ser observado en la figura 7.4. En coincidencia con la temperatura elevada derivada de los modelos térmicos, puede observarse que el flujo térmico es más elevado en la zona de la altiplanicie (figura 5.11) lo que nos indica como esa cantidad de calor se "escapa" a través de la superficie.

La zona de temperatura elevada (altiplanicie del MNP) coincide también con la de rigidez cercana a cero en el manto litosférico (Figura 7.4). Por otro lado, en las localidades dentro de la altiplanicie donde fueron encontrados xenolitos del manto litosférico, estos son redondeados lo podría estar indicando que fueron deformados dúctilmente y esto se correlacionaría 


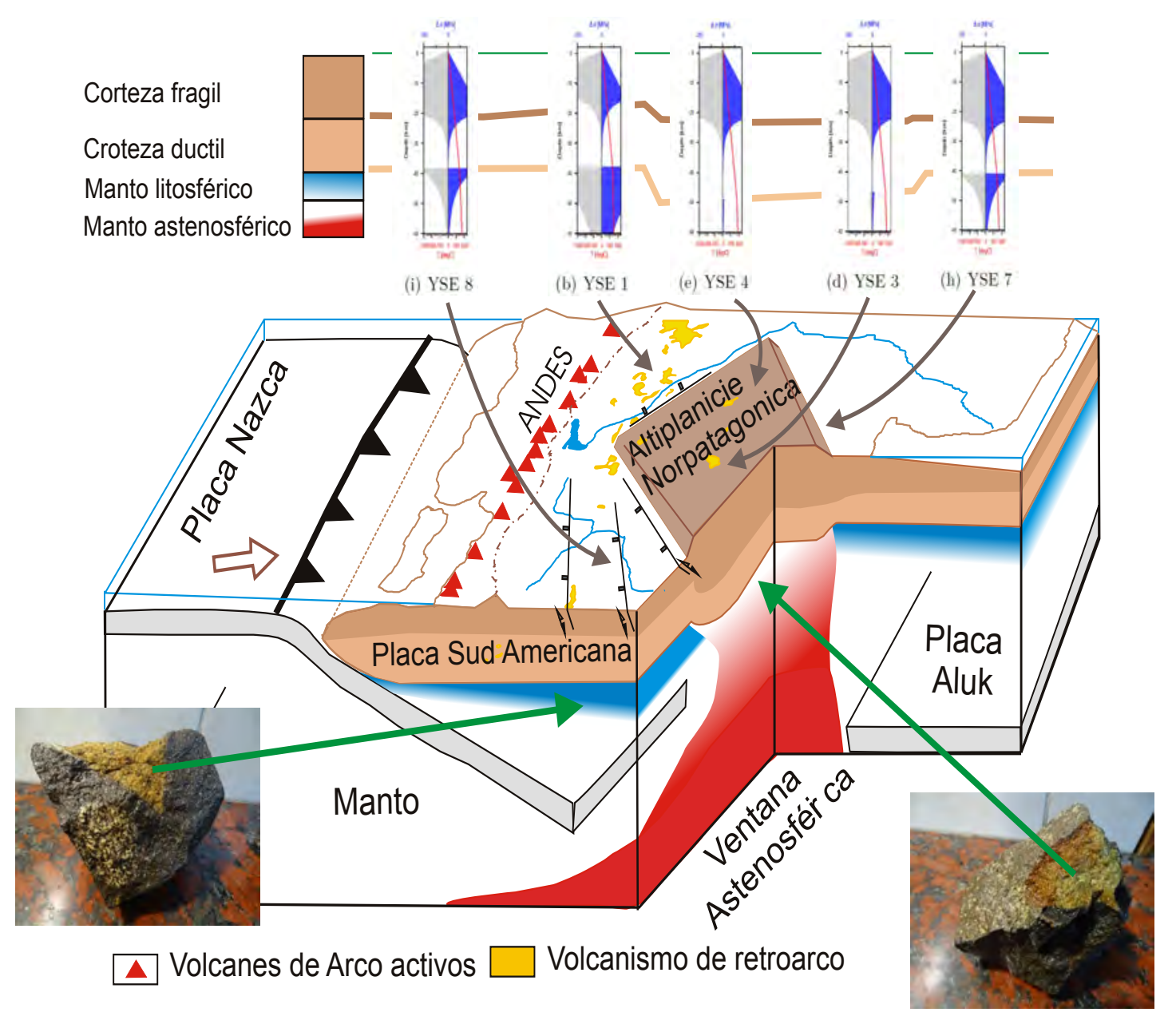

Figura 7.4. Situación geodinámica actual propuesta a partir de la unión de resultados predichos por los modelos e información adicional

con reología que resulta del modelo en el área. En cambio, en los alrededores, por ejemplo en Paso de Indios (localidad V) las curvas de YSE muestran que hay rigidez en el manto litosférico, lo que puede ser correlacionado con los xenolitos angulosos encontrados en la localidad para estas profundidades (Figura 7.4). En la misma localidad se encontraron xenolitos redondeados pertenecientes a corteza inferior, lo que coincide con las curvas de YSE de la localidad que muestran una reología dúctil para esas profundidades. La coincidencia entre la reología predicha por el modelo y las muestras de xenolitos refuerza y valida los resultados obtenidos. Todo lo anteriormente mencionado puede observarse en la figura 7.4 donde se unen los resultados de los modelos realizados y otra información independiente.

La poca rigidez a escasa profundidad en el área de la altiplanicie (evidenciada en los mapas de resistencia integrada y en los de espesor elástico de las figuras 6.4, 6.6 y 6.7 y también en las muestras de xenolitos que son redondeados para esta área cómo indica la figura 7.4) 


\section{Discusión}

podría estar amortiguando los esfuerzos a los que está sometida la zona a causa de la compresión del borde de subducción. Debido a que la corteza profunda y el manto litosférico se comportarían mecánicamente como la astenósfera, éstas se deformarían dúctilmente ante los esfuerzos compresivos y actuarían como un amortiguador aportando así a la falta de deformación observada en superficie. El hecho de que la parte somera de la corteza esté desacoplada de la litósfera más profunda, lo que se evidencia en la figura 6.5, nos indica comportamientos mecánicos independientes, lo que podría explicar la acumulación de esfuerzos en los bordes del MNP observados en superficie ante una corteza somera rígida y el flujo del resto de la litósfera en respuesta a los mismos esfuerzos.

Por otro lado, la baja rigidez observada en el área de la altiplanicie del MNP nos habla de una compensación de tipo local, donde la deflexión en cada punto es causada por las cargas también ubicadas en ese punto. Esta compensación local puede observarse comparando los mapas de topografía (Figura 1.1) y de Moho (Figura 4.9(a) resultante del modelo gravimétrico tridimensional realizado) en los cuales puede observarse una correlación entre las zonas de mayor altura (mayor carga) y las de mayor profundidad de Moho (mayor deflexión).

Esta zona corresponde a un modelo de "Crème brûlée" en el cual la resistencia está localizada en la parte somera de la corteza y el manto es débil. Según Tesauro et al. (2015), en estas áreas la ausencia de una capa mecánicamente resistente en el manto puede causar inestabilidad de las características tectónicas antiguas y observarse, en consecuencia, zonas deformadas o reactivadas por algún episodio. En este caso, la ausencia de una capa resistente en el manto puede ser la huella del levantamiento a causa de la anomalía térmica en el Oligoceno.

Es importante destacar que las conclusiones principales que pueden ser extraídas, tanto de la distribución de temperaturas como de la de resistencia son muy similares si se cambia la composición de la corteza por una homogénea. Esto indica que, a pesar de los errores que pudieron haber sido introducidos en la elección de la composición cortical, las características principales observadas se mantendrían cambiando la configuración cortical.

El Plateau del Colorado, EE.UU., es descripto como un problema de investigación similar al de la altiplanicie del MNP en varios trabajos, entre los que podemos mencionar a Levander et al. (2011). En el trabajo de Tesauro et al. (2015), por ejemplo, los resultados del modelado realizado indican que el manto superior debajo del Plateau del Colorado tiene temperatura elevada como consecuencia de un probable calentamiento durante los ultimos 30 a $40 \mathrm{Ma}$. También se enuncia en ese trabajo que dicho plateau tiene una litósfera débil con la resistencia 


\section{Discusión}

principalmente concentrada en la corteza y que las capas litosféricas están desacopladas. Estas características pueden observarse en los mapas y perfiles de resistencia integrada y en los gráficos de YSE del área (Tesauro et al., 2015). Es interesante y alentador que la comparación entre el Plateau del Colorado y la altiplanicie del MNP, que tienen una historia de formación y características similares, arrojen resultados parecidos a pesar de los procesos de modelado y datos disponibles tan distintos e independientes entre sí.

\subsection{Hipótesis geodinámica}

La corteza gruesa de la altiplanicie del MNP tiene un origen difícil de rastrear. Esta región de Gondwana fue sometida a movimientos transcurrentes de terrenos en el Paleozoico temprano según González et al. (2010, 2011b,a). En el Paleozoico tardío hubo emplazamiento de plutones en la región (Aragón et al., 2010) que fueron exhumados y erosionados desde el Triásico hasta el Cretácico, para llegar a una superficie de planación (Aragón et al., 2010), preservada en la altiplanicie del MNP hasta el presente. En el Jurásico medio, la región fue afectada por la apertura de Gondwana a causa de una gran anomalía térmica, que generó el Océano Atlántico. Se sugiere que el Moho de la región en el momento del levantamiento (Paleógeno) había sido modelado por los mecanismos descriptos previamente: las fuerzas involucradas en la amalgamación de los terrenos, la posible orogenia que generó los emplazamientos graníticos y la anomalía térmica responsable de la ruptura de Gondwana.

Durante el Paleógeno hubo un reacomodamiento de placas tectónicas que generó una discontinuidad térmica debajo del MNP. Varios trabajos se refieren a esta anomalía pero sugiriendo distintas hipótesis como causa de la misma (Aragón et al., 2011a, 2015; Kay et al., 1993, 2007; Muñoz et al., 2000; De Ignacio et al., 2001). Las altas temperaturas observadas en la actualidad en el área de la altiplanicie del MNP podrían ser un remanente de la anomalía térmica descripta. En el período durante el cual el área fue sometida un régimen extensional, el calentamiento del manto pudo haber conducido a una disminución en la densidad, que en conjunto con la corteza engrosada de la altiplanicie del MNP habrían llevado a un desequilibrio isostático y su consecuente levantamiento. Este levantamiento regional de la altiplanicie fue controlado por cuatro lineamientos mayores heredados, que en la época de extensión Paleocena permitieron desplazamiento normal.

Hoy en día, las razones de que el MNP conserve su gran elevación pueden ser el aparente balance isostático, como puede ser deducido de los resultados del modelo gravimétrico. Este 


\section{Discusión}

balance isostático sería local, según el espesor elástico predicho y como consecuencia, las zonas más altas estarían relacionadas localmente con las de Moho más profundo. Las fuerzas de flotación provenientes del balance isostático actuarían en conjunto con la posible baja densidad y/o fusión parcial del manto, como puede ser supuesto a partir de las altas temperaturas del modelo térmico y la baja rigidez de la parte profunda de la corteza y el manto litosférico. Se propone la posible existencia de una fuente de calor actual, relacionada con un corner flow ocasionado por el frente de avance de la placa que subduce. Esto estaría manteniendo el área con altas temperaturas y con densidades bajas. La compresión producto de la subducción en el margen oeste de Sudamérica (actuando desde el Mioceno) también puede estar contribuyendo a preservar la elevación del área. Esta fuerza genera una leve inclinación SO en el área (el sudoeste es la zona más elevada) y un engrosamiento en ese borde (límite SO), producto de la inversión tectónica que genera apilamiento de corteza somera en dicho margen respecto de la corteza somera más rígida de la altiplanicie. 


\section{Capítulo 8}

\section{Conclusiones}

El presente trabajo de tesis tuvo como objetivo principal la caracterización de las propiedades físicas en el área del Macizo Norpatagónico con vistas a aportar al conocimiento de las causas por las cuales la altiplanicie fue generada. Para esto, se utilizaron técnicas de modelado directo geofísico y se integró la información disponible tanto geofísica como geológica.

Para el armado del modelo inicial se analizaron los datos disponibles y se realizaron trabajos preliminares a partir de los cuales se extrajeron resultados sobre la discontinuidad corteza-manto (Moho) y sobre las densidades en el manto. Mediante la inversión de datos de gravedad para la obtención del Moho y la comparación con otros modelos de esta discontinuidad, se estimó que el Moho en la altiplanicie es más profundo que en sus alrededores. Por otra parte, se realizó un cálculo de la densidad de muestras de xenolitos del manto utilizando datos petrofísicos de los mismos. Se encontró que hay heterogeneidad en las densidades del manto y una correlación entre la densidad y la edad de la extracción. Esto nos permite pensar que la corteza en el área está diferenciada por los eventos magmáticos, es decir, que la temperatura afectó y está afectando a la densidad.

El modelado gravimétrico tridimensional a escala litosférica fue desarrollado con el objetivo de obtener la configuración cortical de densidades del Macizo Norpatagónico, como una herramienta para entender su estado isostático actual (al no tener definidas, previamente, la geometría y densidades del área no fue posible, en esta instancia, calcular anomalías isostáticas para tal fin). Como no hay información sismológica de la corteza dentro de la altiplanicie, fue necesario estimar la contribución de la densidad del manto al campo de gravedad observado para restringir el modelo. Esto fue realizado combinando datos sismológicos y de xenolitos. El resultado principal de este modelado es una profundidad del Moho consistente con datos multidisciplinarios. 
El Moho modelado tiene una profundidad de $46 \pm 3 \mathrm{~km}$ en el área de la altiplanicie del MNP y presenta una diferencia de entre 2 y $7 \mathrm{~km}$ con respecto a los alrededores. La gran profundidad del Moho se correlaciona con la alta topografía de la altiplanicie lo que podría estar indicando equilibrio isostático a escala cortical. El equilibrio isostático puede estar contribuyendo a la altura topográfica actual de la altiplanicie del MNP y, en conjunto con la alta temperatura observada en las tomografías y la tectónica activa en el margen occidental de Sudamérica podrían estar manteniendo el área de estudio elevada. Además, la corteza engrosada de la altiplanicie y su compensación isostática actual podrían indicar que la isostasia pudo haber tenido alguna influencia en el levantamiento ocurrido en el Paleógeno, actuando ante el desequilibrio isostático generado por la anomalía térmica referida por varios autores (Aragón et al., 2011a, 2015; Kay et al., 1993, 2007; Muñoz et al., 2000; De Ignacio et al., 2001). En la forma del Moho se puede distinguir una dirección preferencial de gran espesor cortical dentro del MNP. Esta dirección se correlaciona con la sutura propuesta entre terrenos corticales Paleozoicos (Chernicoff y Zappettini, 2004) y por lo tanto, la profundidad del Moho actual podría tener alguna relación con la amalgamación de Gondwana.

El modelado gravimétrico 3D integra un contraste de densidad dentro de la corteza que ha sido derivado de la conversión de las velocidades de onda S (Schaeffer y Lebedev, 2013) y que se correlaciona bien con la sutura de los terrenos Patagonia y Chilenia (Chernicoff y Zappettini, 2004; Ramos, 1988). En el residuo del modelo final, pueden inferirse más discontinuidades de densidad dentro de la corteza. Varias de esas discontinuidades coinciden con áreas volcánicas donde se encontraron xenolitos, sobretodo en aquellas con edades de extracción jóvenes como la localidad III (Comallo). Estos residuos, por lo tanto, están indicando la variación de densidades en la corteza que podría tener relación con la variación de la temperatura dada por eventos magmáticos. Es necesario contar con más datos para analizar estas discontinuidades de corta longitud de onda con más detalle.

El modelado térmico tridimensional realizado tiene el objetivo de obtener la distribución de temperaturas de la litósfera en el área para comprender mejor su geodinámica y a la vez ser utilizado como punto de partida para calcular, a posteriori, su reología. Sus resultados indican que en la parte somera de la corteza la temperatura en la altiplanicie es hasta $20^{\circ} \mathrm{C}$ menor que en los alrededores. Sin embargo, esto se revierte para profundidades mayores, en donde la temperatura debajo de la altiplanicie es más de $50^{\circ} \mathrm{C}$ mayor que en los alrededores. La mayor temperatura observada en las zonas profundas de la litósfera podría estar relacionada con una anomalía térmica ocurrida en el manto en el Oligoceno tardío (podría ser un remanente 


\section{Conclusiones}

de la temperatura de esa época). Por otra parte, se plantea la posibilidad de que exista una fuente de calor actual que podría ser originada por un corner flow. Esta condición podría generarse, según Aragón et al. (2011a) debido a una ventana astenosférica producto de un cese de subducción temporal. En este caso, cuando la subducción se reinició puede haber generado un corner flow en el borde de la placa subductante que actualmente se encontraría por debajo de la altiplanicie.

El modelado reológico se generó con el objetivo de conocer el comportamiento mecánico de las distintas zonas de la litósfera, analizar su efecto en la configuración actual de la altiplanicie e inferir si pudo haber tenido algún efecto en la geodinámica del Paleógeno. El modelo de temperaturas tridimensional fue utilizado como entrada para el cálculo de la reología, con lo cual los resultados son consecuentes con el mismo. Estos indican que la resistencia de la litósfera en la altiplanicie del MNP está concentrada en la parte somera de la corteza casi en su totalidad, por lo que, en esta zona el manto casi no tiene rigidez. El hecho de que haya mayor rigidez en los primeros kilómetros de la corteza se puede relacionar con trabajos que hablan sobre deformación en los alrededores de la altiplanicie, la cual no se observa dentro de la misma.

Los resultados del modelado geofísico realizado incluyendo la información previa disponible del área, permitió la formulación de hipótesis tanto sobre el comportamiento actual de la altiplanicie como sobre las causas de su levantamiento en el Paleógeno. En la actualidad tanto el posible equilibrio isostático como la temperatura elevada y la compresión generada por la tectónica activa podrían estar contribuyendo a mantener el área de estudio elevada. En el Paleógeno, estando el área bajo un régimen extensional, la anomalía térmica del manto podría haber generado un decrecimiento en las densidades que, junto con el gran espesor cortical del área, habrían producido un desequilibrio isostático e impulsado la elevación de la altiplanicie del Macizo Norpatagónico.

Los resultados obtenidos en la presente tesis contribuyen a la mejora del conocimiento en un área donde no hay muchos estudios o mediciones realizados y aportan a la construcción de una posible explicación al problema geodinámico de la generación de la altiplanicie. 


\section{Bibliografía}

Airy, G. B. (1855). On the computation of the effect of the attraction of mountain-masses, as disturbing the apparent astronomical latitude of stations of geodetic surveys. Phil. Trans. R. Soc, 145:101-104.

Alvarado, P., Beck, S., y Zandt, G. (2007). Crustal structure of the South-Central andes cordillera and backarc region from regional waveform modelling. Geophysics Journal International, 170:858-875. http://dx.doi.org/10.1111/j.1365-246X.2007.03452.x.

Alvers, M. R., Götze, H. J., Barrio-Alvers, L., Schmidt, S., Lahmeyer, B., y Plonka, C. (2014). A novel warped-space concept for interactive 3d-geometry-inversion to improve seismic imaging. First Break, 32 (4).

Amante, C. y Eakins, B. W. (2009). ETOPO1 1 arc-minute global relief model: procedures, data sources and analysis. US Department of Commerce, National Oceanic and Atmospheric Administration, National Environmental Satellite, Data, and Information Service, National Geophysical Data Center, Marine Geology and Geophysics Division Colorado.

Amaru, M. (2007). Global travel time tomography with 3-D reference models. Tesis doctoral, Faculty of Geosciences Utrecht University.

An, M. y Shi, Y. (2007). Three-dimensional thermal structure of the Chinese continental crust and upper mantle. Science in China Series D: Earth Sciences, 50:1441-1451.

Aragón, E., Aguilera, Y., Cavarozzi, C. E., y Ribot, A. (2010). The North Patagonian Altiplano and the Somún Curá basaltic plateau. Geociencias, 29:527-532.

Aragón, E., Brunelli, D., Castro, A., Rivalenti, G., Varela, R., Rabbia, O., Spackman, W., Cavarozzi, C. E., Aguilera, Y., Ribot, A., Mazzucchelli, M., D‘Eramo, F., y Demartis., M. L. (2011a). Tectono-magmatic response to major convergence changes in the North 
Patagonian suprasubduction system: The paleogene subduction-transcurrent plate margin transition. Tectonophysics., 509:218-237. http://dx.doi.org/10.1016/j.tecto.2011.06.012.

Aragón, E., D’ Eramo, F., Pinotti, L., Aguilera, Y., Cavarozzi, C., Demartis, M., Gómez Dacal, M. L., Hernando, I., y Fuentes, T. (2015). Un rift pasivo durante el Paleógeno en Patagonia septentrional: Evolución y cambios de estilo extensional. XIV congreso geológico chileno. En XIV Congreso Geológico Chileno.

Aragón, E., Tassara, A., Tocho, C., Mendoza, L. P. M., Spackman, W., Rabbia, O., Perdomo, R., y Bertotto., W. G. (2011b). Upper mantle geodynamic constrains beneath the north patagonian massif, argentina. En $18^{\circ}$ Congreso Geológico Argentino, pp. 350-351.

Assumpção, M., Feng, M., Tassara, A., y Julià, J. (2013). Models of crustal thickness for south america from seismic refraction, receiver functions and surface wave tomography. Tectonophysics, 609:82-96. http://dx.doi.org/10.1016/j.tecto.2012.11.014.

Barrio, L. (1993). Modelado bi y tridimensional de campos potenciales: metodología y aplicación. Tesis doctoral, Facultad de Ciencias Astronómicas y Geofísicas, Universidad Nacional de La Plata.

Barthelmes, F. (2009). Definition of functionals of the geopotential and theit calculation from spherical harmonic models. Scientific technical report STR09/02.

Barzaghi, R., Reguzzoni, M., Borghi, A., De Gaetani, C., Sampietro, D., y Marotta, A. M. (2014). Global to local Moho estimate based on GOCE geopotential model and local gravity data. Proceedings of the VIII Hotine-Marussi Symposium - IAG Symposia, Springer.

Bassin, C., Laske, G., y Masters, G. (2000). The current limits of resolution for surface wave tomography in North America. En EOS Trans AGU, volumen 81, p. F897.

Bayer, U., Scheck-Wenderoth, M., y Koehler, M. (1997). Modelling of the 3D thermal field in the northeast German Basin. International Journal Earth Sciences (Geol. Rundsch.), $86: 241-251$.

Birch, F. (1961). The velocity of compressional waves in rocks at 10 kilobars, part 2. Journal of Geophysical Research, 66 (7):2199-2224.

Braitenberg, C., Wienecke, S., Ebbing, J., Born, W., y Redfield, T. (2007). Joint gravity and isostatic analysis for basement studies- a novel tool. Extended abstracts. En EGM 2007 
International Workshop, Innovation in EM, Grav and Mag Methods: a new Perspective for Exploration, Villa Orlandi, Capri - Italy.

Brey, G. P. y Köhler, T. (1990). Geothermobarometry in fourphase lherzolites II. New thermobarometers and practical assessment of existing thermobarometers. Journal of Petrology, 31:1353-1378.

Burov, E. B. (2011). Rheology and strength of the lithosphere. Marine and petroleum geology, 28:1402-1443.

Burov, E. B. y Watts, A. B. (2006). The long-term strength of continental lithosphere: "jelly sandwich" or "crème brûlée" ? GSA today, 16(1):4.

Cacace, M. y Scheck-Wenderoth, M. (2016). Why intracontinental basins subside longer: 3-D feedback effects of lithospheric cooling and sedimentation on the flexural strength of the lithosphere. Journal of Geophysical Research: Solid Earth.

Caminos, R. (1999). Geología Argentina. Subsecretaría de Minería de la Nación, Servicio Geológico Minero Argentino, Instituto de Geología y Recursos Minerales, Anales №29.

Cammarano, F., Goes, S., Vacher, P., y Giardini, D. (2003). Inferring upper-mantle temperatures from seismic velocities. Physics of the Earth and Planetary Interiors, 138:197-222.

Canale, N., Ponce, J. J., Carmona, N. B., Drittanti, D. I., Olivera, D. E., Martinez, M. A., y Bournod, C. N. (2015). Sedimentología e icnología de deltas fluvio-dominados afectados por descargas hiperpícnicas de la formación Lajas (Jurásico medio), Cuenca Neuquina, Argentina. Andean Geology, 42(1):114-138.

Castro, A., Aragón, E., Díaz-Alvarado, J., Blanco, I., García-Casco, A., Vogt, K., y Liuf, D.-Y. (2011). Age and composition of granulite xenoliths from Paso de indios, Chubut province, Argentina. Journal of South American Earth Sciences. http://dx.doi.org/10.1016/j.jsames.2011.06.001.

Cermak, V. y Rybach, L. (1982). Thermal conductivity and specific heat of minerals and rocks, in physical properties of rocks - Zahlenwerte und Funktionen aus Naturwissenschaften und Technik - Landolt-Börnstein. Edited by G. Angenheister, Springer, New York., pp. 305-343. 
Chernicoff, C. J. y Zappettini, E. O. (2004). Geophysical evidence for terrane boundaries in South-Central Argentina. Gondwana Research, 7(4).

Dalla Salda, L., Cingolani, C., y Varela, R. (1990). El basamento de la región occidental del Macizo Nordpatagónico, Argentina. 11º Congreso Geológico Argentino, Actas, 1:11-14.

Davies, J. H. (2013). Global map of solid earth surface heat flow. Geochemistry, Geophysics, Geosystems., 14 (10):4608-4622. http://dx.doi.org/10.1002/ggge.20271.

De Ignacio, C., López, I., Oyarzún, R., y Marquez, A. (2001). The northern Patagonia Somuncura plateau basalts: a product of slabinduced, shallow asthenospheric upwelling? Terra Nova, 13:117-121.

Del Barrio, R. A. y Martin, D. M. (2013). Análisis de las limitantes climáticas sobre las potencialidades de desarrollo de la meseta sur de la provincia de rio negro: el viento y su interacción con las disponibilidades térmicas e hídricas.

Feng, M., Van der Lee, S., y Assumpçao, M. (2007). Upper mantle structure of South America from joint inversion of waveforms and fundamental mode group velocities of Rayleigh waves. Journal of Geophysical Research, 112. http://dx.doi.org/10.1029/2006JB004449.

Fernández, A. D. (2016). Distribución de espesor elástico para un sector de los Andes Centrales y del Sur. Tesis de grado. Facultad de Ciencias Astronómicas y Geofísicas, Universidad Nacional de La Plata.

Fowler, C. M. R. (1990). The solid Earth. An introduction to global Geophysics. Cambridge University Press.

Gómez Dacal, M. L. (2012). Modelado gravimétrico tridimensional del Macizo Norpatagónico. Tesis de grado. Facultad de Ciencias Astronómicas y Geofísicas, Universidad Nacional de La Plata. http://hdl.handle.net/10915/59867.

Gómez Dacal, M. L., Tocho, C., y Aragón, E. (2016). Mohorovicic discontinuity depth analysis beneath North Patagonian Massif. IAG 150 Years: Proceedings of the IAG Scientific Assembly in Postdam, Germany, 2013.

Gómez Dacal, M. L., Tocho, C., y Aragón, E. (2013). Adaptación de un modelo gravimétrico tridimensional al área del Macizo Norpatagónico. Geoacta, 38:153-167. 
Gómez Dacal, M. L., Tocho, C., Aragón, E., Sippel, J., Scheck-Wenderoth, M., y Ponce, A. (2017). Lithospheric 3D gravity modelling using upper-mantle density constraints: Towards a characterization of the crustal configuration in the North Patagonian Massif area, Argentina. Tectonophysics, 700:150-161. http://dx.doi.org/10.1016/j.tecto.2017.02.011.

Goes, S., Govers, R., y Vacher, P. (2000). Shallow mantle temperatures under Europe from P and S wave tomography. Journal of Geophysical Research, 105:153-169.

Goetze, C. y Evans, B. (1979). Stress and temperature in the bending lithosphere as constrained by experimental rock mechanics. Geophysical Journal International, 59(3):463-478.

González, P. D., Sato, A. M., Naipauer, M., Varela, R., Llambias, E., Basei, E., Sato, K., y Sproesser, W. (2011a). Does patagonia represent a missing piece detached from the Ross Orogen? East meet West: Abstracts, Rio de Janeiro, Brasil, 1 .

González, P. D., Sato, A. M., Naipauer, M., Varela, R., Llambias, E., Greco, G., Gonzalez, S., y Garcia, V. (2011b). Conexión Macizo Norpatagónico-Antártida oriental: Fósiles arqueociátidos, comparación geológica y circones detríticos. $18^{\circ}$ Congreso Geológico Argentino. Neuquén, pp. 87-88.

González, P. D., Varela, R., Sato, A. M., Greco, G., Naipauer, M., y Llambias, E. (2010). Evidencias geológicas y paleontológicas en la formación El Jagüelito para la conexión Patagonia-Antártida durante el Paleozoico inferior. 10ํㅡㄹ Congreso Argentino de Paleontología y Bioestratigrafía y $7^{\circ}$ Congreso Latinoamericano de Palelontología. La Plata, Buenos Aires, p. 48.

Gregori, D. A., Kostadinoff, J., Strazzere, L., y Raniolo, A. (2008). Tectonic significance and consequences of the Gondwanide orogeny in northern Patagonia, Argentina. Gondwana Reasearch. http://dx.doi.org/10.1016/j.gr.2008.04.005.

Götze, H. J. (1978). Ein numerisches Verfahren zur Berechnung der gravimetrischen Feldgröben dreidimensionaler Modellköper. TU Clausthal, pp. 195-215.

Götze, H. J. (1984). Über den Einsatz interaktiver Computergrafik in Rahmen 3 dimensionaler Interpretationstechniken in Gravimetrie und Magnetik Habiltationsschrift. Arch. Met. Geoph. Biokl., Ser. A, p. 236.

Götze, H. J. y Lahmeyer, B. (1988). Application of three-dimensional interactive modeling in gravity and magnetics. Geophysics, 53:1096-1108. http://dx.doi.org/10.1190/1.1442546. 
Götze, H. J. y Schmidt, S. (2010). Igmas+: a new 3D gravity, FTG and magnetic modeling software tool. Expanded abstracts from the ASEG-PESA Airborne Gravity 2010 Workshop, pp. 91-96.

Hacker, B. R. y Abers, G. A. (2004). Subduction factory 3: An excel worksheet and macro for calculating the densities, seismic wave speeds, and $\mathrm{H} 2 \mathrm{O}$ contents of minerals and rocks at pressure and temperature. Geochemistry, Geophysics, Geosystems, 5 (1). http://dx.doi.org/10.1029/2003GC000614.

Hamza, V. M. y Muñoz, M. (1996). Heat flow map of South America. Geothermics, 25 (6):599-646.

Heine, C. (2007). Formation and Evolution of intracontinental basins. Tesis doctoral, School of Geosciences, The University of Sydney, Australia.

Hertz, H. (1884). Über das Gleichgewicht schwimmender elastischer Platten. Annalen der Physik, 258(7):449-455.

Ishii, M. y Tromp, J. (2001). Even-degree lateral variations in the Earth's mantle constrained by free oscillations and the free-air gravity anomaly. Geophys. J. Int., 145:77-96.

Johannsen, A. (1931). Descriptive Petrography of the Igeous Rocks. University of Chicago Press.

Julià, J. y Mejía, J. (2004). Thickness and Vp/Vs ratio variation in the Iberian crust. Geophysics Journal International, 156:59-72. http://dx.doi.org/0.1111/j.1365-246X.2004.02127.x.

Karato, S. y Karki, B. (2001). Origin of lateral variation of seismic wave velocities and density in the deep mantle. Geophys. J. Int., 106 NO.B10:21771-21783.

Kay, S. M., Ardolino, A. A., Franchi, M., y Ramos, V. A. (1993). Origen de la meseta de Somún Curá: distribución y geoquímica de sus rocas volcánicas máficas. XII Congreso Geológico Argentino, 4:236-248.

Kay, S. M., Ardolino, A. A., Gorring, M. L., y Ramos, V. A. (2007). The Somuncura Large Igneous Province in Patagonia: Interaction of a transient mantle thermal anomaly with a subducting slab. Journal of Petrology, 48:43-77. http://dx.doi.org/10.1093/petrology/egl053.

Kennett, B. L. N., Engdahl, E. R., y Bulland, R. (1995). Constraints on seismic velocities in the Earth from traveltimes. Geophys. J. Int., 122 (1):108-124. 
Klitzke, P., Sippel, J., Faleide, J. I., y Scheck-Wenderoth, M. (2016). A 3D gravity and thermal model for the Barents Sea and Kara Sea. Tectonophysics, 684:131-147. https://doi.org/10.1016/j.tecto.2016.04.033.

Kostadinoff, J. y Gelós, E. M. (1994). Análisis de las mediciones gravimagnetométricas realizadas entre El Fuerte y Arroyo Verde, provincia de Río Negro. Rev. Asoc. Geol. Arg., 49:19-25.

Kostadinoff, J., Gregori, D., y Raniolo, A. (2005). Configuración geofísica-geológica del sector norte de la provincia de Río Negro. Revista de la Asociación Geológica Argentina, 60 (2):368-376.

Kostadinoff, J. y Schillizi, R. (1996). Características geofísicas del litoral atlántico entre el rio Chubut y Puerto Camarones. Rev. Asoc. Geol. Arg., 51:387-392.

Laske, G., Masters, G., Ma, Z., y Pasyanos, M. (2013). Update on CRUST1.0 - a 1-degree global model of Earth's crust. En Geophys. Res. Abstracts, volumen 15, p. 20132658abstrEGU.

Levander, A., Schmandt, B., Miller, M., Liu, K., Karlstrom, K., Crow, R., Lee, C.-T., y Humphreys, E. (2011). Continuing Colorado plateau uplift by delamination-style convective lithospheric downwelling. Nature, 472(7344):461-465.

Lillie, R. J. (1999). Whole Earth Geophysics. Prentice Hall, Inc.

Lince Klinger, F. (2010). Estudio gravi-magnetométrico en el Macizo Norpatagónico. Tesis doctoral, Universidad Nacional de San Juan.

Lowrie, W. (2007). Fundamentals of Geophysics. Cambridge University Press. http://dx.doi.org/10.1017/CBO9780511807107.

Mercier, J. C. C. (1980). Single-pyroxene thermobarometry. Tectonophysics, 70:1-37.

Midttomme, K. y Roaldstet, E. (1999). Thermal conductivity of sedimentary rocks: uncertainties in measurement and modelling. Geological Society of London. Special publication, 158 (1):45-60. http://dx.doi.org/10.1144/GSL.SP.1999.158.01.04.

Mira, A., Gómez Dacal, M. L., Tocho, C., y Vives, L. (2013). 3D gravity modeling of the Corrientes province (NE argentina) and its importance to the Guarani Aquifer System. Tectonophysics, 608:212-221. http://dx.doi.org/10.1016/j.tecto.2013.09.034. 
Mundl, A., Ntaflos, T., Ackerman, L., Bizimis, M., Bjerg, B. A., Wegner, W., y Hauzenberger, C. A. (2015). Geochemical and Os-Hf-Nd-Sr isotopic characterization of North Patagonian mantle xenoliths: Implications for extensive melt extraction and percolation processes. Journal of Petrology, pp. 1-31. http://dx.doi.org/10.1093/petrology/egv048.

Muñoz, J., Troncoso, R., Duhart, P., Crignola, P., Farmer, L., y Stern, C. R. (2000). The relation of the mid-Tertiary coastal magmatic belt in South-Central Chile to the late Oligocene increase in plate convergence rate. Revista Geológica de Chile, 27:177-203.

Nakajima, J., Matsuzawa, T., Hasegawa, A., y Zhao, D. (2001). Three-dimensional structure of $\mathrm{Vs}, \mathrm{Vp}$ and $\mathrm{Vp} / \mathrm{Vs}$ beneath northeastern japan: Implications for arc magmatism and fluids. Journal of Geophysical Research, 106:843-857.

Pankhurst, R. J., Rapela, C. W., Fanning, C. M., y Marquez, M. (2006). Gondwanide continental collision and the origin of Patagonia. Herat Science Reviews, 76:235-257.

Pavlis, N. K., Holmes, S. A., Kenyon, S. C., y Factor, J. K. (2012). The development and evaluation of the Earth Gravitational Model 2008 (EGM2008). J. Geophys. Res., 117. http://dx.doi.org/10.1029/2011JB008916.

Pérez-Gussinyé, M., Lowry, A. R., y Watts, A. B. (2007). Effective elastic thickness of South America and its implications for intracontinental deformation. Geochemistry, Geophysics, Geosystems, 8(5).

Ponce, A. D. (2016). Petrología de los xenolitos del manto alojados en rocas basálticas del Paleoceno-Eoceno en la zona de Paso de Indios, provincia del Chubut. Tesis doctoral, Facultad de Ciencias Naturales y Museo, Universidad Nacional de La Plata.

Ponce, A. D., Bertotto, G. W., Zanetti, A., Brunelli, D., Giovanardi, T., Aragón, E., Bernardi, M. I., Hémond, C., y Mazzucchelli, M. (2015). Short-scale variability of the SCLM beneath the extra-Andean back-arc (Paso de indios, Argentina): Evidence from spinel-facies mantle xenoliths. Open Geosciences. De Gruyter open, 7:362-385.

Pratt, J. H. (1859). On the deflection of the plumb-line in India, caused by the attraction of the Himalaya mountains and of the elevated regions beyond; and its modification by the compensating effect of a deficiency of matter below the mountain mass . Phil. Trans. R. Soc, 149:745-796.

Quinteros, J. (2013). Introducción al modelado termomecánico. 
Ramos, V. A. (1986). Paleozoic terranes of the central Argentine-Chilean Andes. Tectonics, $5(6): 855-880$.

Ramos, V. A. (1988). Tectonics of the late Proterozoic-early Paleozoic: a collisional history of southern South America. Episodes, 11(3):168-174.

Ramos, V. A. (1994). Terranes of southern Gondwanaland and their control in the Andean structure (30-33 S latitude). En Tectonics of the Southern Central Andes, pp. 249-261. Springer.

Rapela, C. W., Pankhurst, R. J., Fanning, C. M., y Herve, F. (2005). Pacific subduction coeval with the Karoo mantle plume: the early Jurassic subcordilleran belt of northwestern Patagonia. Terrane Processes at the Margins of Gondwana. Geological Society of London, Special Publications, , 246:217-239.

Reguzzoni, M., Sampietro, D., y Sanso, F. (2013). Global Moho from the combination of the CRUST2.0 model and GOCE data. Geophys. J. Int., 195:222-237. http://dx.doi.org/10.1093/gji/ggt247.

Resovsky, J. y Trampert, J. (2003). Using probabilistic seismic tomography to test mantle velocity-density relationships. Earth and Planetary Science Letters, 215:121-134. http://dx.doi.org/10.1016/S0012-821X(03)00436-9.

Sampietro, D. y Reguzzoni, M. (2011). Global Moho from the combination of the CRUST 2.0 model and GOCE data. GNGTS.

Schaeffer, A. J. y Lebedev, S. (2013). Global shear-speed structure of the upper mantle and transition zone. Geophys. J. Int., 194 (1):417-449. http://dx.doi.org/10.1093/gji/ggt095.

Schmidt, S. y Götze, H. J. (1998). Interactive visualization and modification of 3D models using GIS functions. Phys. Chem. Earth, 23 (3):289-295. http://dx.doi.org/10.1016/S00791946(98)00027-5.

Sigismondi, M. E. (2012). Estudio de la deformación litosférica de la cuenca Neuquina: estructura termal, datos de gravedad y sísmica de reflexión. Tesis doctoral, Facultad de ciencias exactas y naturales. Universidad de Buenos Aires.

Simmons, N. A., Forte, A. M., y Grand, S. P. (2009). Joint seismic, geodynamic and mineral physical constraints on three-dimensional mantle heterogeneity: Implications for the relati- 
ve importance of thermal versus compositional heterogeneity. Geophys. J. Int., 177:12841304. http://dx.doi.org/10.1111/j.1365-246X.2009.04133.x.

Sippel, J., Meeßen, C., Cacace, M., Mechie, J., Fishwick, S., Heine, C., Scheck-Wenderoth, M., y Strecker, M. R. (2016). The Kenya rift revisited: insights into lithospheric strength through data-driven 3D gravity and thermal modelling. Solid Earth Discussions.

Sonder, L. J. y England, P. (1986). Vertical averages of rheology of the continental lithosphere: relation to thin sheet parameters. Earth Planetary Science Letters, 7:81-90.

Tassara, A. y Echaurren, A. (2012). Anatomy of the chilean subduction zone: Threedimensional density model upgraded and compared against global-scale models. Geophysical Journal International. http://dx.doi.org/10.1111/j.1365-246X.2012.05397.x.

Tassara, A. y Yáñez, G. (2003). Relación entre el espesor elástico de la litosfera y la segmentación tectónica del margen andino (15-47ºs). Revista geológica de Chile, 30 (2):159-186. http://dx.doi.org/110.4067/S0716-02082003000200002.

Telford, W. M., Geldart, L. P., y Sheriff, R. E. (1990). Applied Geophysics. Second edition. Cambridge Universuty Press.

Tesauro, M., Kaban, M. K., y Mooney, W. D. (2015). Variations of the lithospheric strength and elastic thickness in North America. Geochemistry, Geophysics, Geosystems. AGU Publications, 16:2197-2220. http://dx.doi.org/10.1002/2015GC005937.

Turcotte, D. L. y Schubert, G. (1982). Geodynamics. Applications of continuum Physics to geological problems. John Wiley and Sons, Inc.

Vaughan, A. P. M. y Pankhurst, R. J. (2008). Tectonic overview of the West Gondwana margin. Gondwana Research, 13(2):150-162.

Vening Meinesz, F. A. (1931). Une nouvelle méthode pour la réduction isostatique régionale de l'intensité de la pesanteur. Bulletin geodesique, 29(1):33-51.

Vila, M., Fernandez, M., y Jimenez-Munt, I. (2010). Radiogenic heat production variability of some common lithological groups and its significance to lithospheric thermal modeling. Techtonophysics, 490(3-4):152-164. http://dx.doi.org/10.1016/j.tecto.2010.05.003.

Von Gosen, W. (2003). Thrust tectonics in the North Patagonian Massif (Argentina): Implications for a Patagonia plate. Tectonics, 22(1). 
Watts, A. B. (2001). Isostasy and flexure of the lithosphere. Cambridge University Press.

Wienecke, S. (2005). A new analytical solution for the calculation of flexural rigidity: significance and applications. Tesis doctoral, Freie Universität Berlin. 